\title{
A MULTIPLE CASE STUDY OF MUSIC COOPERATING TEACHER ROLES IN MENTORING
} DIALOGUES

by

ANGELA M. MUNROE

B.S., Western Michigan University, 2001

M.M.E., Northwestern University, 2005

\author{
A thesis submitted to the \\ Faculty of the Graduate School of the \\ University of Colorado in partial fulfillment \\ of the requirement for the degree of \\ Doctor of Philosophy \\ Department of Music Education \\ 2018
}


This thesis entitled:

A MULTIPLE CASE STUDY OF MUSIC COOPERATING TEACHER ROLES IN MENTORING DIALOGUES

written by Angela M. Munroe has been approved for the Department of Music Education

Margaret H. Berg, Ph.D., Chair

David A. Rickels, DMA

James A. Austin, Ph.D.

Austin Okigbo, Ph.D.

Daniel Liston, Ph.D.

The final copy of this thesis has been examined by the signatories, and we find that both the content and the form meet acceptable presentation standards of scholarly work in the above-mentioned discipline.

IRB Protocol \# 17-0070 
Munroe, Angela M.

A Multiple Case Study of Music Cooperating Teacher Roles in Mentoring Dialogues

Dissertation directed by Dr. Margaret H. Berg

\begin{abstract}
Mentoring dialogues are the discourse between the mentor, often referred to as the cooperating teacher, and the student teacher that may include feedback and reflection on practice (Hennissen, Crasborn, Brouwer, Korthagen, \& Bergen, 2008; Tsui, Lopez-Real, Law, Tang, \& Shum, 2001; Zeichner \& Liston, 1985). While some researchers have closely examined mentoring dialogues (Fernandez \& Erbilgin, 2009; Tsui et al., 2001; Zeichner \& Liston, 1985), the focus has been primarily on how the student teacher learns to teach through participation in mentoring dialogues. Given the pivotal role the mentor teacher plays in the development of student teachers, research is needed on how the mentoring role is enacted during these dialogues and if the role changes over the course of a student teaching placement. Therefore, the purpose of this multiple case study (Stake, 1995) was to examine the mentoring dialogues between cooperating teachers and student teachers. Research questions addressed the factors that impact the mentoring role adopted during mentoring dialogues, the mentoring style observed during mentoring dialogues, and the cooperating teacher response to video-based reflection.

Four music cooperating teacher/student teacher pairs were selected for participation in this study. All four cooperating teachers were experienced middle school or high school instrumental music teachers who hosted a student teacher during an eightweek placement. Each pair video-recorded weekly mentoring dialogues and stimulated recall interviews were conducted with the cooperating teachers using the video-footage, during which the researcher invited the participants to recall their thinking during the
\end{abstract}


conversation (Lyle, 2010). Additionally, two semi-structured interviews were conducted with each cooperating teacher and the student teacher.

Data were analyzed using the Mentor Roles in Dialogues Model (Hennison, et al., 2008). Cooperating teachers assumed an 'encourager' or 'imperator' role based on topics addressed, time factors, phases of the dialogue, and cooperating teacher style and input. Various factors impacted the mentoring role assumed during dialogues including aspects of the student teaching context, perceived role, personality of the cooperating teacher and the student teacher, and their relationship. Factors unique to the music ensemble class and student teaching placement timing were especially impactful on mentoring dialogues. Additionally, while challenging for some cooperating teachers, participation in video-based reflection resulted in self critique of their mentoring approach during dialogues. 


\section{ACKNOWLEDGEMENTS}

First, I would like to offer my sincerest gratitude to my advisor, Dr. Margaret Berg, for her continuous support, guidance, questions, and answers. You have challenged me to always strive to be a better researcher and teacher. I never would have made it this far if it weren't for all of the meetings, emails, text messages, phone calls, and video conferences across the miles. You have been giving of your time and exceedingly patient through all of the challenges, successes, and interruptions.

I also want to acknowledge my committee members: Dr. David Rickels, Dr. James Austin,

Dr. Dan Liston, and Dr. Austin Okigbo for your knowledge, feedback, and support throughout this process.

To my participants, Adam and Samantha, Isabelle and Tyler, Joanna and Ellen, and Bob and Charlie: thank you for spending time with me, allowing me into your classroom, and sharing your teaching and learning experiences with me!

Finally, my unending love and gratitude goes to my amazing family. You have never stopped supporting me, humoring me, loving me, and picking me up when I fall apart. Thank you to my husband Joe, you have never stopped supporting me and walking with me on this crazy journey! Thank you to my daughter Leyna and my son Daniel, for making me laugh, reminding me to play, and making sure I don't work too hard! 


\section{TABLE OF CONTENTS}

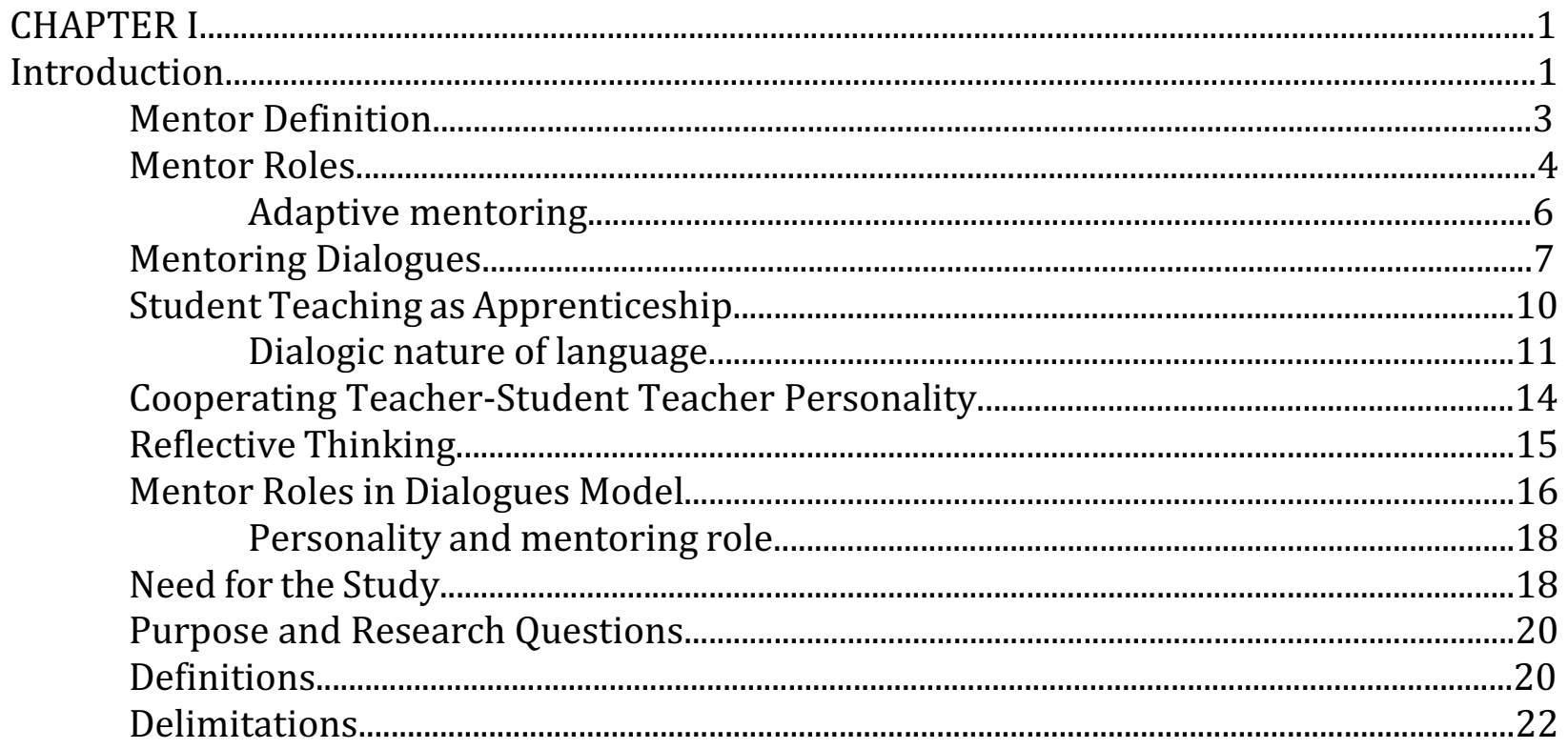

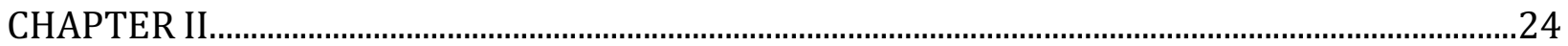

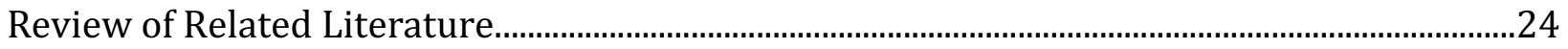

Perceived Role of the Mentor....................................................................................................26

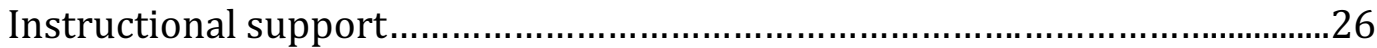

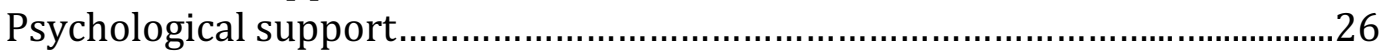

Cooperating teacher - student teacher relationship ..........................................28

Personality contributing to relationships ...........................................29

Negative influences...................................................................... 31

Establishing a collaborative relationship ..............................................32

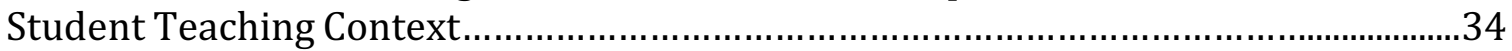

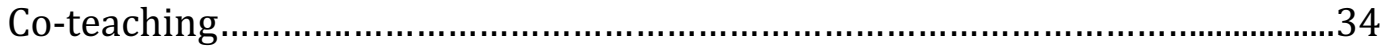

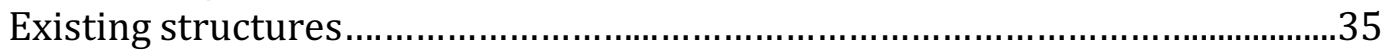

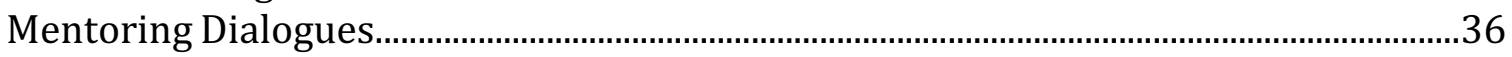

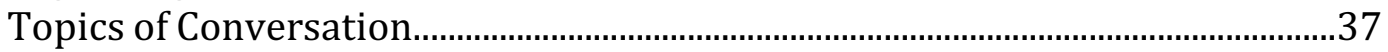

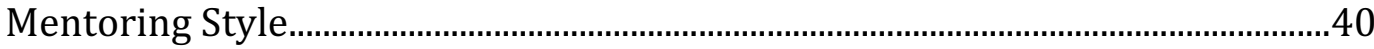

Direct vs. non-direct........................................................................ 41

Direct to facilitative continuum............................................................4

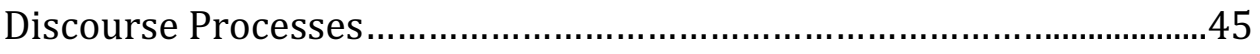

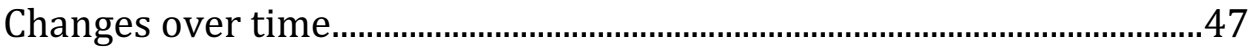

Adaptive mentoring ………………………………………………………...... 48

Mentor Teacher Input.................................................................................................4

Time Aspects...................................................................................................................52

Phases of the Dialogue...............................................................................................53

Stimulated Recall..........................................................................................................................

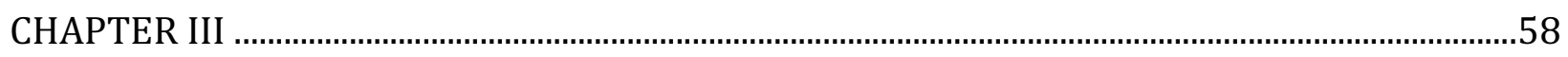

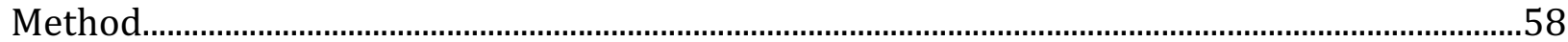

Multiple Case Study............................................................................................................. 
Participants and Teaching Contexts.......................................................................................60

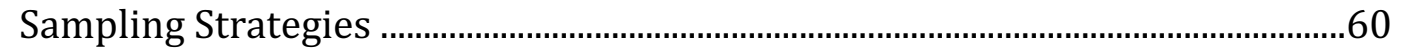

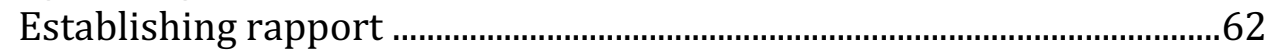

Cooperating teacher participants...................................................................63

Student teacher participants.........................................................................69

Student teaching placements and preparation.............................................71

Data Collection....................................................................................................................72

Stimulated recall technique.....................................................................................

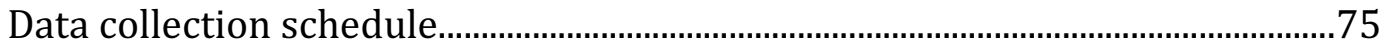

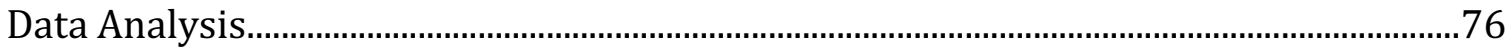

Data management.......................................................................................................

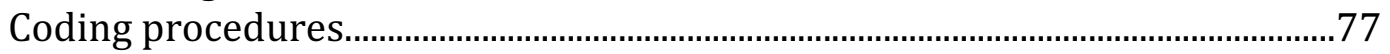

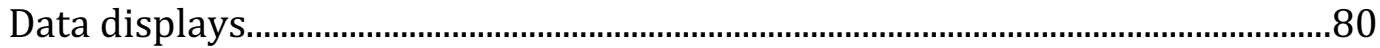

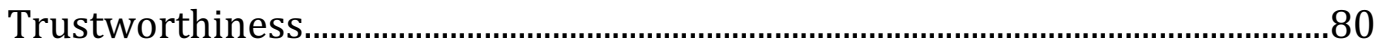

Researcher's Background, Role, and Assumptions..............................................................81

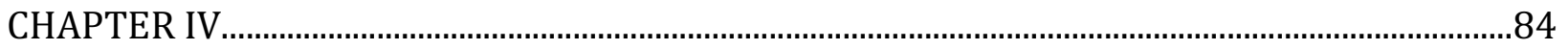

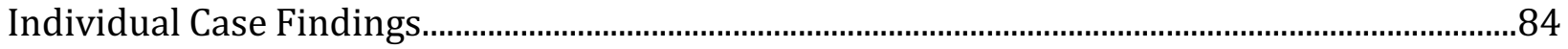

Conceptual Framework ………………………………………………………………....84

Adam and Samantha: Orion High School...............................................................................86

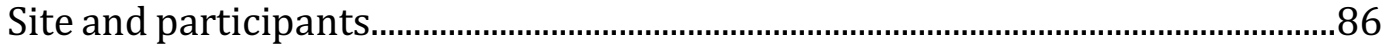

Conceptual framework: Adam and Samantha...........................................................8

Student teaching context.............................................................................................90

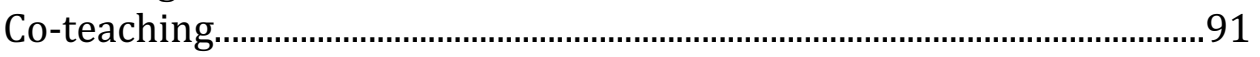

Performance preparation/pressure and placement timing.....................92

Perceived role as a cooperating teacher.....................................................................94

Psychological support....................................................................................95

"Friend, colleague, and mentor".................................................................96

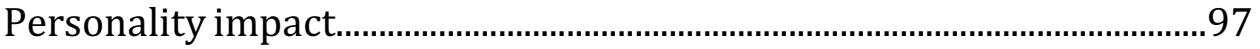

Instructional support...............................................................................99

Facets of the MERID model......................................................................................100

Topics of conversation ……………………………………………………10

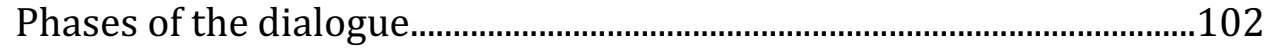

Conversation timing.....................................................................................104

Cooperating teacher input.............................................................................106

Student teacher response..............................................................108

Style and supervisory skills.....................................................................110

Mentor Roles in Dialogues (MERID) model...........................................................112

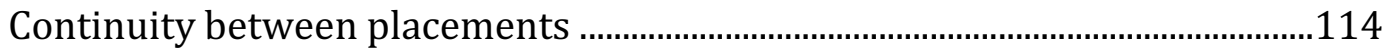

Isabelle and Tyler: Grapevine Middle School....................................................................115

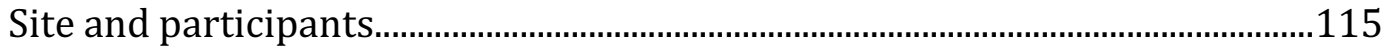

Conceptual framework: Isabelle and Tyler............................................................116

Student teaching context...........................................................................................118

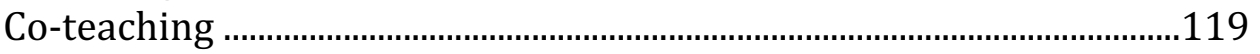

"Teacher figure".............................................................................119

Performance preparation/pressure and placement timing...................120 


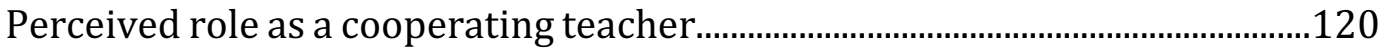

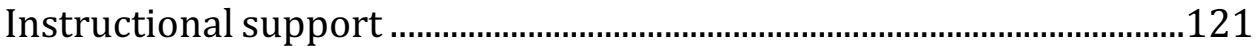

Adapting to the student..................................................................123

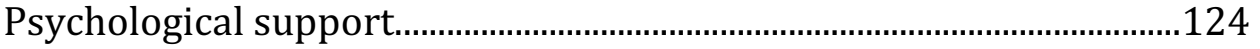

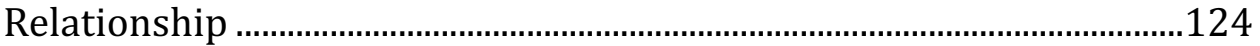

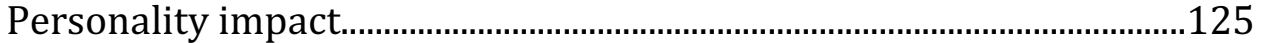

Facets of the MERID model..................................................................................127

Topics of conversation..............................................................................127

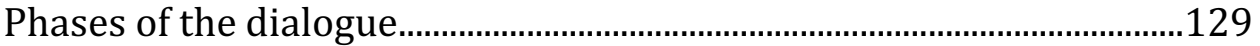

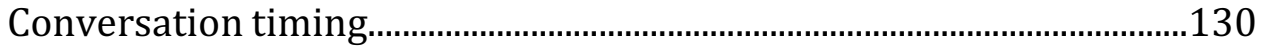

Cooperating teacher input...........................................................................132

Student teacher response..............................................................133

Style and supervisory skills......................................................................134

Mentor Roles in Dialogues (MERID) model...........................................................137

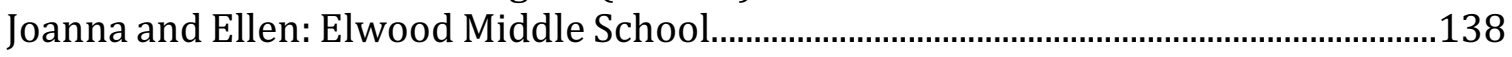

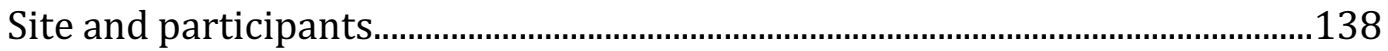

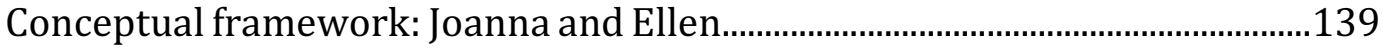

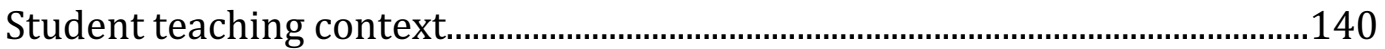

Co-teaching ………..................................................................................142

Performance preparation/pressure..........................................................142

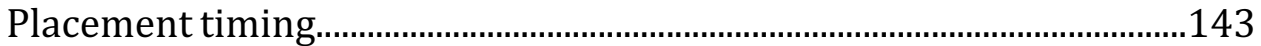

Perceived role of the cooperating teacher................................................................144

Psychological support.................................................................................144

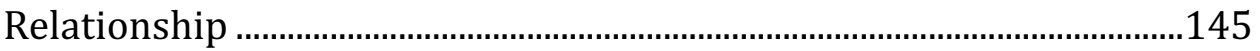

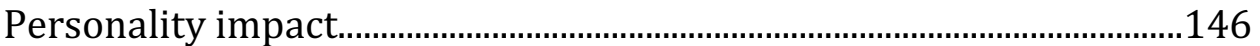

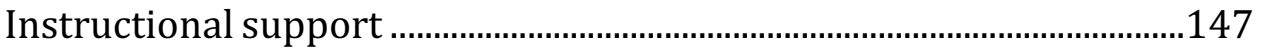

Facets of the MERID model....................................................................................148

Topics of conversation..................................................................................148

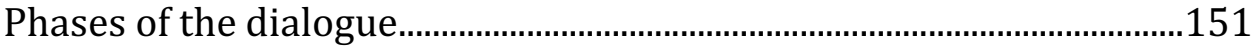

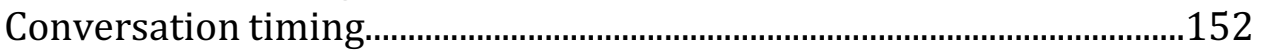

Cooperating teacher input.........................................................................154

Student teacher response.................................................................155

Style and supervisory skills........................................................................156

Mentor Roles in Dialogues (MERID) model........................................................159

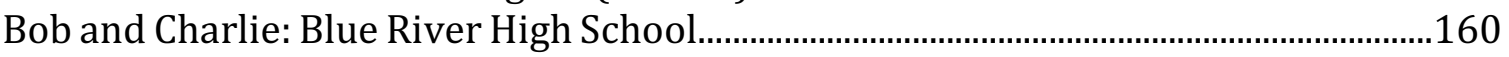

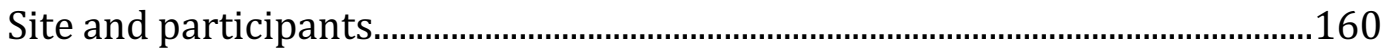

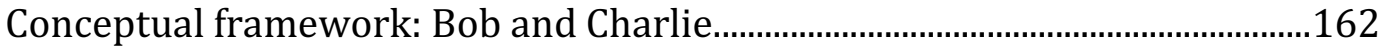

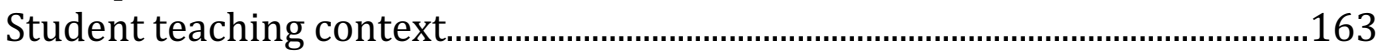

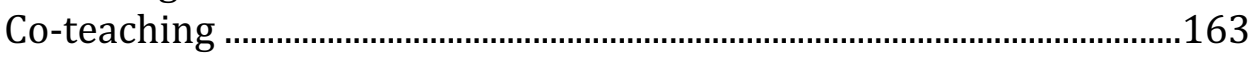

Performance preparation/pressure and placement timing...................165

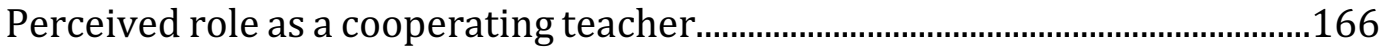

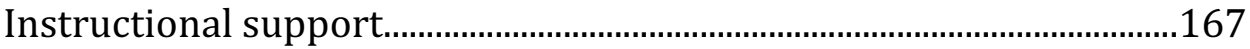

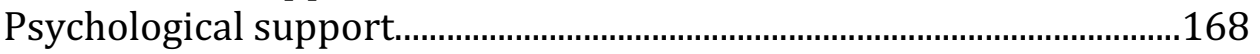

"I started out wanting it to feel equal".......................................................169

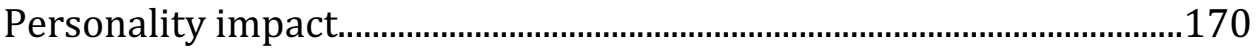

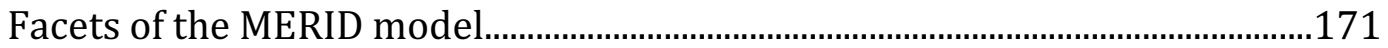




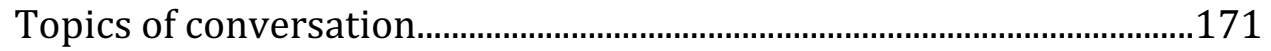

Phases of the dialogue.................................................................................173

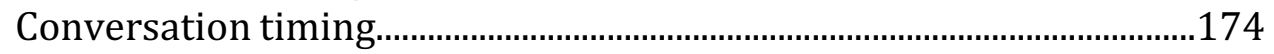

Cooperating teacher input............................................................................176

Student teacher response.............................................................177

Style and supervisory skills.....................................................................178

Mentor Roles in Dialogues (MERID) model...........................................................181

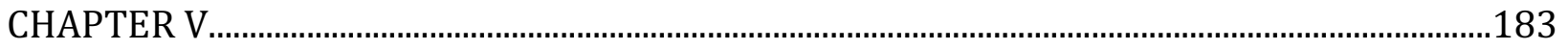

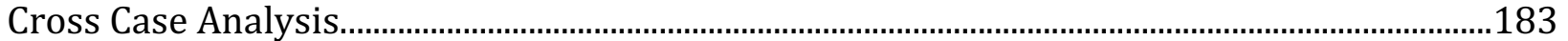

Mentor Roles in Dialogues (MERID) Model.......................................................................183

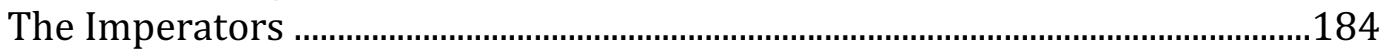

Impact of personality...................................................................................186

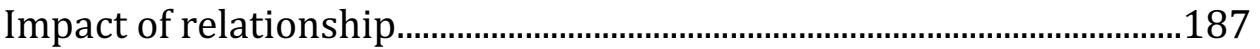

Impact of student teaching context...........................................................189

The Encouragers................................................................................................191

Impact of personality................................................................................192

Impact of relationship...............................................................................193

Impact of student teaching context..........................................................194

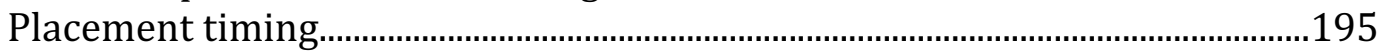

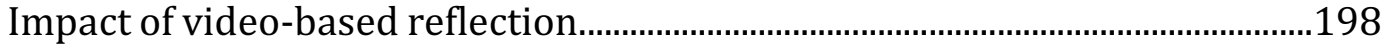

"I didn't realize I spoke that much"...........................................................198

"He lets me rant"..........................................................................................199

"A better way to ask" ......................................................................................20

"I just spoon fed him a whole lot"................................................................20

Formal conversations..................................................................................201

Comparison of the Models........................................................................................................203

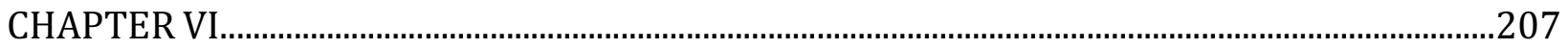

Summary and Conclusions...........................................................................................................207

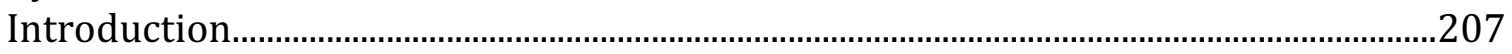

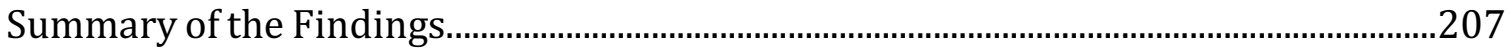

Factors contributing to mentoring roles during dialogues.................................207

Student teaching context..............................................................................207

Perceived role ………………………………………………………………...209

Mentoring role assumed during mentoring dialogues..........................................211

Impact of video-based reflection.........................................................................213

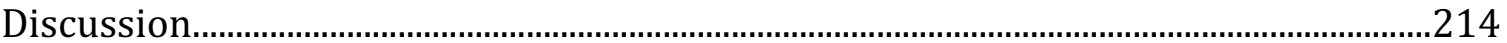

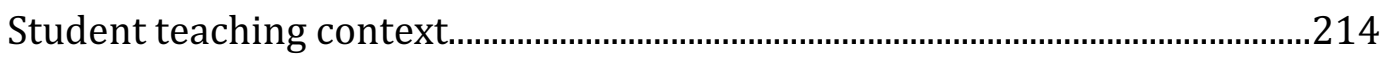

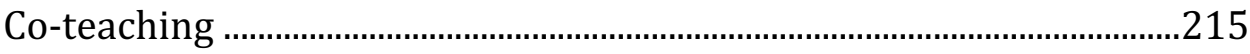

Placement timing/performance preparation/pressure..........................215

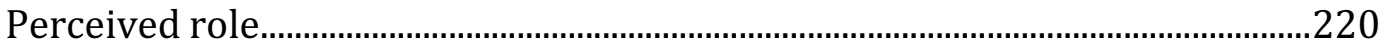

Mentoring Roles in Dialogues (MERID) model.......................................................226

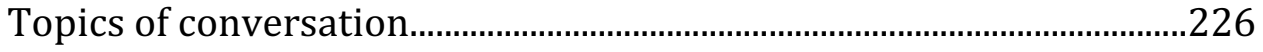

Phases of the dialogue...............................................................................228

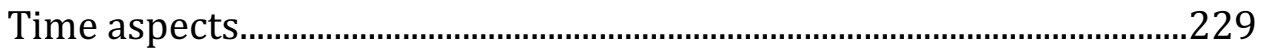


Mentoring style and input..........................................................................230

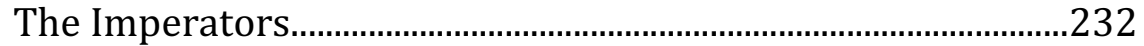

The Encouragers..............................................................................233

Student teacher response..............................................................233

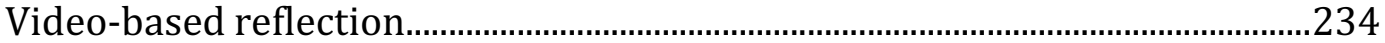

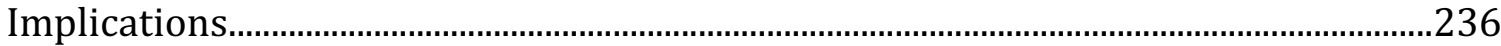

Cooperating teacher development.....................................................................236

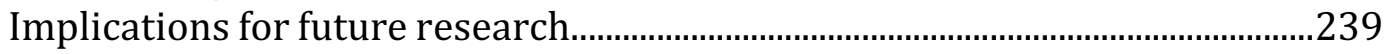

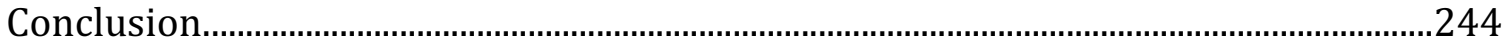

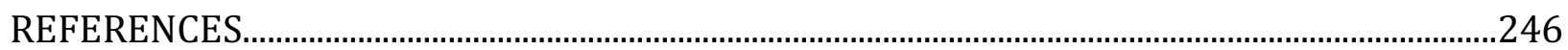

\section{APPENDICES}

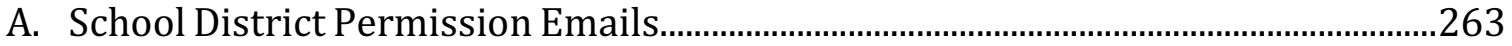

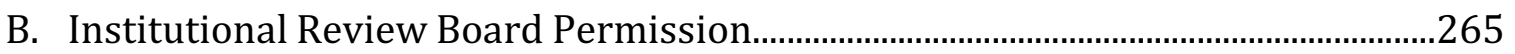

C. Informed Consent Forms..........................................................................................26

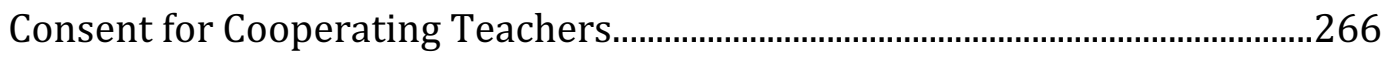

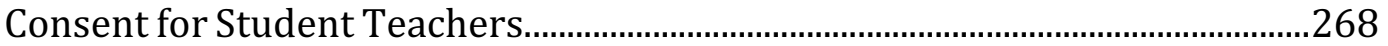

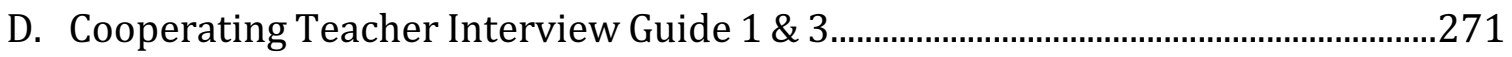

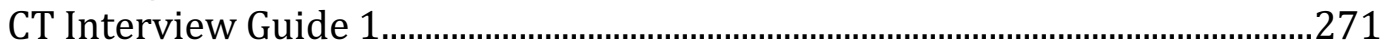

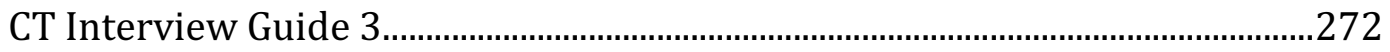

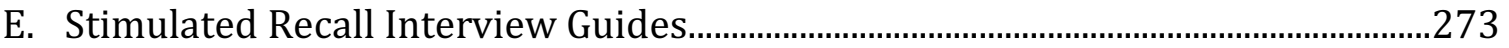

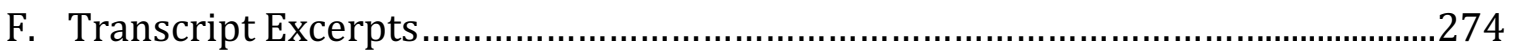

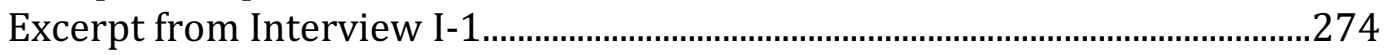

Excerpt from Interview A-2 .................................................................................2. 275

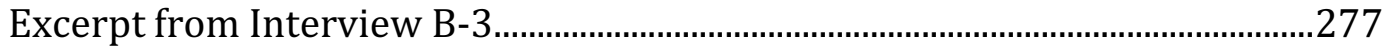

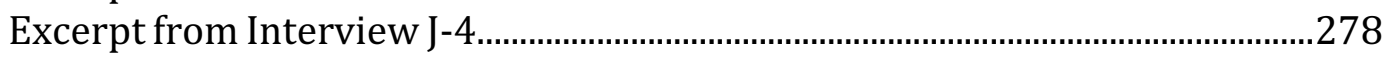

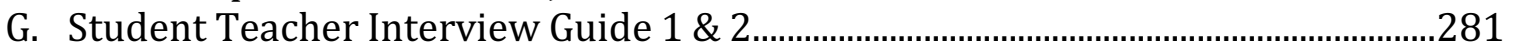

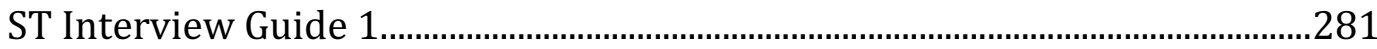

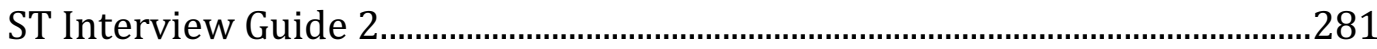

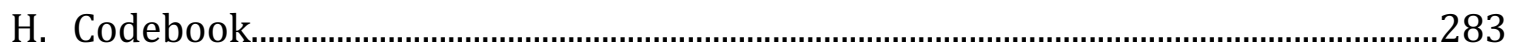




\section{LIST OF TABLES}

Table

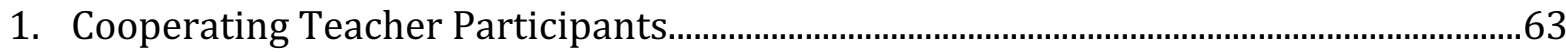

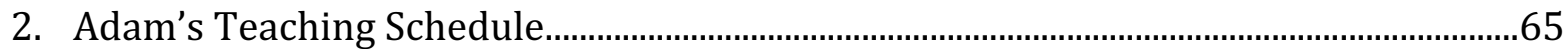

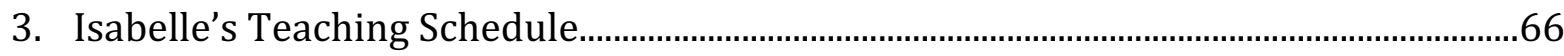

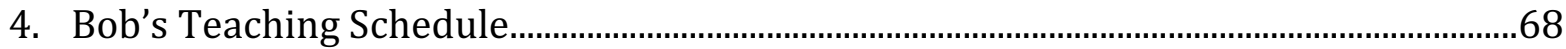

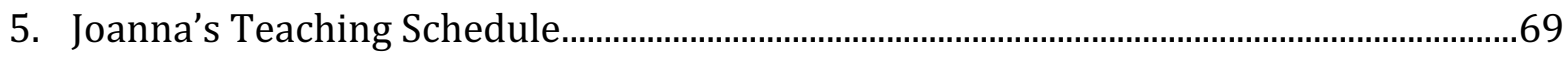

6. Student Teacher Participants................................................................................................ 70

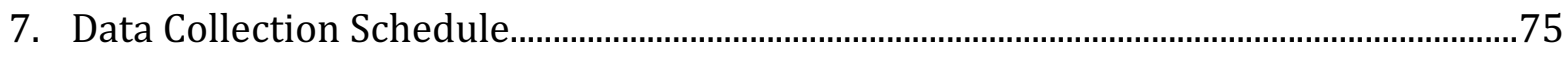

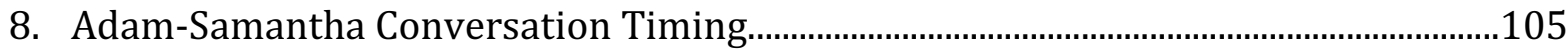

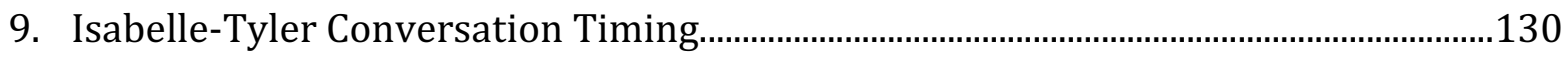

10. Joanna-Ellen Conversation Timing.........................................................................................154

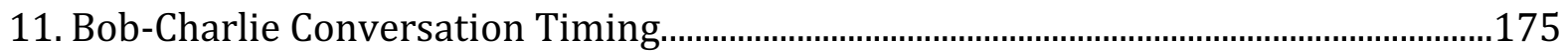




\section{FIGURES}

Figure

1. Mentor Roles in Dialogues (MERID) Model..................................................................17

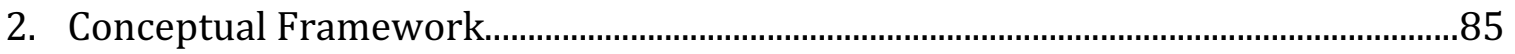

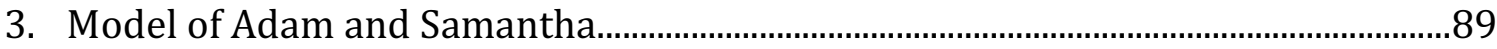

4. Mentor Roles in Dialogues (MERID) Model...............................................................112

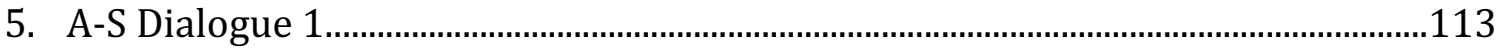

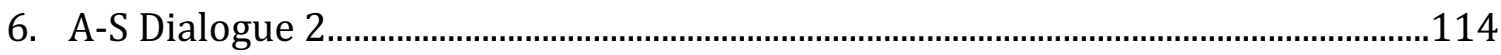

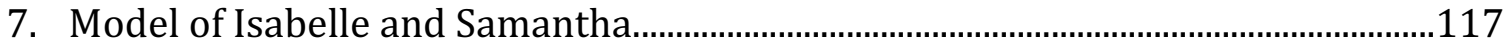

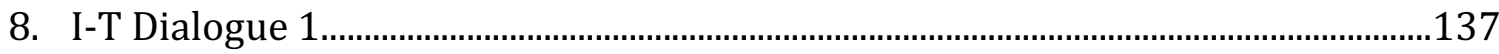

9. I-T Dialogue 2

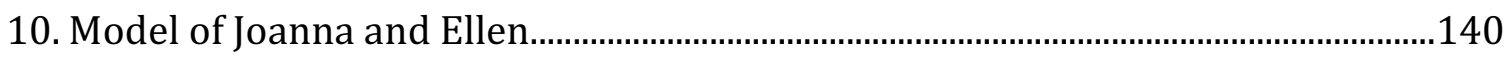

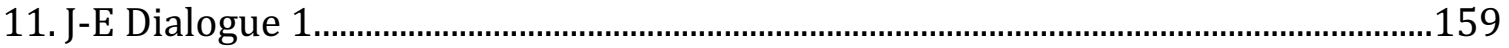

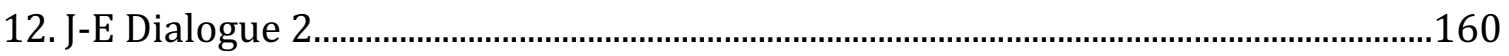

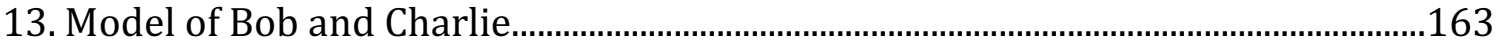

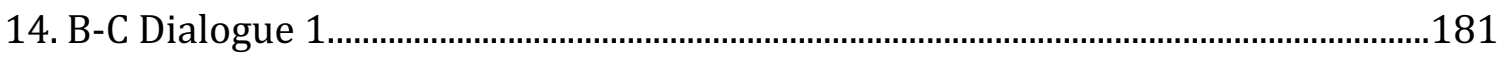

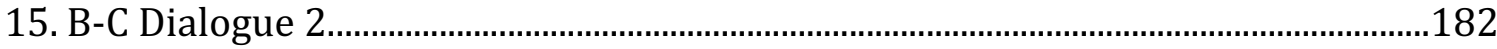

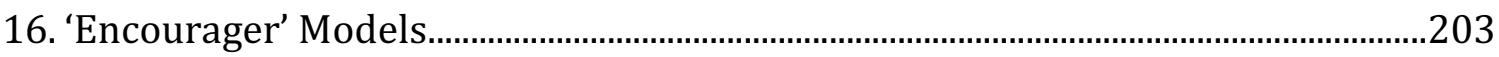

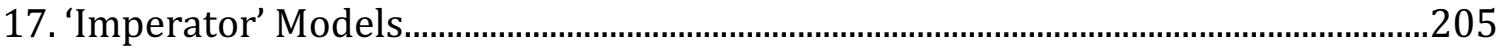




\section{CHAPTER I}

\section{Introduction}

When I first began the doctoral program at the University of Colorado one the of the responsibilities that I was the most excited about was mentoring student teachers. I recalled my own student teaching experience very fondly, as it was the semester where everything from my coursework came together and I began to feel like a real music teacher. When I was assigned to supervise a student teacher it felt like a great responsibility. I couldn't wait to meet both him and the cooperating teacher. Before I had a chance to visit the school I was contacted by the cooperating teacher, anxiously explaining concerns about David's progress in the first week and a half of his student teaching semester. I quickly scheduled my first visit to the school as well as extra follow-up observations. Each time I visited the school, I observed David teaching an elementary general music class and debriefed with him after the lesson. During our conversations I found myself adjusting my own approach, sometimes asking him to reflect, while also giving him tips and strategies especially as he continued to struggle to make improvements in his teaching. I also felt like I only had a limited impact, as I was only at the school for such a limited amount of time. I began to wonder what the conversations between David and his cooperating teacher were like, and if and how they changed as he gained more teaching experience.

The student teaching experience is often referred to as the capstone of the teacher education program. Student teachers apply content learned in a variety of music, methods, education, and general education coursework to daily guided practice (Conway, 2002; Feiman-Nemser, 2001a; Fernandez \& Erbilgin, 2009; Frykholm, 1998; Rideout \& Feldman, 2002; Roulston, Legette, \& Womack, 2005; Zeichner, 2002). Many teachers reflect on the 
student teaching experience as being the most valuable part of their teacher preparation program (Conway, 2002; Fredrickson \& Pembrook, 1999) where the greatest learning occurred (Grossman, Smagorinsky, \& Valencia, 1999; Tsui, Lopez-Real, Law, Tang, \& Shum, 2001). Fredrickson and Pembrook (1999) found that music student teachers were excited and overwhelmed at the prospect of teaching all day. Even though the student teacher may have had previous part-time practicum or field experiences in schools, student teaching is usually their first full-time teaching experience. Student teaching provides a chance to experiment with different instructional techniques, with the cooperating teacher serving as a 'safety net' should the student teacher require assistance (Rajuan, Beijaard, \& Verloop, 2007). Simultaneously, it is the culmination of the teacher education program, and success is required for graduation and teacher certification (Grossman, Smagorinsky, \& Valencia, 1999).

Like preservice teachers in other content areas, music student teachers are traditionally placed in the classroom of an experienced music teacher with a particular instructional focus - general, band, choir, or orchestra. The student shares the classroom with the full-time teacher, often beginning by observing, teaching sectionals and lesson segments, teaching one or two classes or grade levels, and eventually taking over the cooperating teacher's full teaching schedule by the end of the student teaching placement. Over the course of the student teaching term, the student teacher has the opportunity to learn from and collaborate with the cooperating teacher. The culmination of the student teaching experience typically results in graduation as well as teaching certification within the student's state. 
Traditionally, there is a triad of participants contributing to an effective student teaching experience: the preservice teacher, the school-based cooperating teacher, and the university supervisor (Rideout \& Feldman, 2002). The university supervisor may observe the student teacher periodically over the course of the student teaching experience, formally evaluate the student teacher, and provide opportunities for reflection. While the cooperating teacher assumes an evaluative role, they also guide the student teacher daily by reviewing their teaching, making suggestions for improvement, and assisting them with learning about the logistics and politics of working in the school setting (Tsui et al., 2001). Formal evaluation of the student teacher tends to occur near the end of a student teaching placement. For cooperating teachers, this means a shift from providing ongoing feedback, or formative assessment, to a more formal summative assessment (Clarke, Triggs, \& Nielsen, 2014). Little existing research has focused on the evaluative role of the cooperating teacher or how this may impact the mentoring relationship.

Given the extended amounts of time the student teacher and the cooperating teacher spend together in a student teaching situation, the cooperating teacher can have a great deal of influence on the development of the preservice teacher (Friebus, 1977; Krueger, 1985) as student teachers look to them for advice, guidance, and coaching (Friebus, 1977).

\section{Mentor Definition}

Based on craft apprenticeship models and dating back to Greek legends, the concept of mentoring is not new (Armstrong, Allinson, \& Hayes, 2002; Shea, 1995). Current definitions of mentors refer to an informal teacher/student relationship (Armstrong et al., 2002; Rajuan, Beijaard, \& Verloop, 2010). Shea (1995) defines the modern mentoring 
process as "a developmental, caring, sharing, helping relationship where one person invests time, know-how and effort in increasing another person's growth, knowledge, and skills" (p 3).

Over the years, the concept of the role of the cooperating teacher has changed. In the 1970s and 1980s the mentor took on the role of a supervisor, giving information about the school and advice regarding teaching strategies (Hennissen, et al., 2008). Over time, expectations shifted to include guiding the student teacher's professional development through encouragement of reflection (Feiman-Nemser, 2001b). For preservice teachers, a cooperating teacher during their student teaching experience serves as a mentor through guided practice and reflection. Though it is a formal relationship serving the purpose of teacher preparation, the cooperating teacher mentors the student teacher in a variety of formal and informal ways. Not only do cooperating teachers model effective practice, they serve as a mentors by helping student teachers develop as professionals through ongoing guidance, reflection, and coaching (Boreen, Johnson, Niday, \& Potts, 2000; Glenn, 2006). Within the context of student teaching, the preservice teacher functions as an apprentice to the cooperating teacher, learning within the context of the community of practice (Lave \& Wenger, 1991).

\section{Mentor Roles}

According to Zeichner (2002),

Being a good cooperating teacher is important, but not synonymous with being a good teacher. Being a good cooperating teacher is more than providing access to a classroom or modeling a particular version of good practice. It involves active mentoring (p. 59). 
This quote suggests that while there may be similarities between teaching and mentoring a student teacher, an effective mentor engages in unique actions that comprise the mentor role. Mentors serve a variety of functions including providing emotional support and building a trusting relationship while simultaneously providing instructional support and improving the mentee's teaching practice (Lieberman, Hanson, \& Gless, 2012). The various roles of the cooperating teacher emerge from these functions of mentoring.

Several researchers have focused on the psychological support provided by mentors through encouraging the student teacher, being empathetic, and providing personal and emotional support (Feiman-Nemser \& Parker, 1993; Jonson, 2002; Rajuan et al., 2007; Stanulis, 1994). Focusing on novice teacher development, Jonson (2002) thought that the role of the mentor was to develop independent qualities such as confidence, competence, self-direction, and professionalism. Others have focused on the instructional roles of the mentor such as guiding instructional decisions, sharing resources, giving feedback and formally evaluating the student teacher (Anderson, 2004; Borko \& Mayfield, 1995; Rajuan et al., 2007). Rajuan, Beijard, and Verloop (2007) found that cooperating teachers saw themselves as a model of instructional techniques and the organizer of the classroom environment. The perceived role of the cooperating teacher may impact the approach to mentoring as enacted during mentoring dialogues.

Feiman-Nemser (2001b) used the phrase educative mentoring to broaden the concept of the mentor role beyond providing support and offering advice. Educative mentoring was defined as an orientation in which the mentor fosters an inquiring stance from the mentee by simultaneously responding to the immediate needs of the student teacher while maintaining focus on the larger teacher development goals. Achinstein and 
Athanases (2006) also focused on educative mentoring and view mentors as learners and inquirers. Mentors are thinking, reflecting, inquiring, and engaging in dialogues with their student teachers. As a result, cooperating teachers influence their mentees to become more reflective, while reflecting upon their own teaching as well.

Adaptive mentoring. Mentors may adjust their approach over time or according to the needs and personality of the student teacher (Grabis-Bunker, 1995; van Ginkel, Oolbekkink, Meijer, \& Verloop, 2016). Stanulis (1994) chronicled one cooperating teacher's shift from giving direct instructional advice to guiding the student teacher through questioning and reflection. A mismatch between the mentoring approach and focus and the needs of the mentee could limit the growth and development of the preservice teacher (Crasborn, Hennissen, Brouwer, Korthagen, \& Bergen, 2011; Williams et al., 1998). There could be negative consequences if a mentor fails to provide support for the mentee's emotional and psychological well-being or if the content of conversations do not progress beyond practical issues such as management, organization, and subject matter (Hobson, Ashby, Malderez, \& Tomlinson, 2009). Mentors need to adapt their roles and strategies to the needs and concerns of their mentees. The mentor's role is evident in their intentions, content, and approach during dialogues and can have an impact on how student teachers learn (Crasborn et al., 2011; Helman, 2006).

Mentors who are attuned to the emotional state of the mentee may adapt their approach to fit their capacity for reflection and align with the mentee's expectations (Van Ginkel et al., 2016). The cooperating teacher may adjust their strategies according to the individual characteristics of the student teacher (Estabrooke \& Goldsberry, 1995). As the needs of the student teacher may shift over time, the cooperating teacher may adjust their 
approach accordingly. Though the change in the student teacher-cooperating teacher relationship has been studied in a music classroom (Grabis-Bunker, 1995), how this change is enacted through mentoring dialogues has not been the focus of previous research.

\section{Mentoring Dialogues}

While the literature on mentor roles provides some information on the variety of roles a mentor might assume, the enactment of these roles can be studied during mentoring dialogues. Conversations, a basic form of human interaction and communication, provide an opportunity for the mentor and student teacher to negotiate meanings in order to make sense of each other's thoughts and experiences (Rosen, 1985). A mentoring dialogue, central to the practice of mentoring, is one form of professional conversation (Orland-Barak \& Klein, 2005). Mentors can have a great deal of influence over student teachers through their dialogues (Feiman-Nemser, 2001b). During a dialogue the focus may be not only on the student teacher as a learner, but also on how precollegiate students are learning from the student teacher (Achinstein \& Athanases, 2006; Hennissen, Crasborn, Brouwer, Korthagen, \& Bergen, 2010).

Sometimes called mentoring conversations, post observation conferences, or supervisory conferences, mentoring dialogues refers to the discourse between the mentor and the student teacher that may include feedback and reflection on practice (Hennissen, Crasborn, Brouwer, Korthagen, \& Bergen, 2008; Orland-Barak \& Klein, 2005; Tsui et al., 2001; Zeichner \& Liston, 1985). These conversations are central to the practice of mentoring and to the development of the student teacher's professional practice (OrlandBarak \& Klein, 2005; Timperley, 2001). Mentoring dialogues are thoughtful and critical conversations intended to allow the student teacher and the mentor to reflect on practice 
and promote teacher learning (Feiman-Nemser, 2001b; Hennissen et al., 2008). Though many conversations occurring between a cooperating teacher and a student teacher may be brief and informal, a mentoring dialogue refers to a formal two-way conversation (Crasborn et al., 2011). A mentoring dialogue may occur in response to a teaching episode or they may be a regular conversation meant to check on progress and encourage reflection (Ben-Peretz \& Rumney, 1991; Crasborn et al., 2011; Hawkey, 1998a). They may also vary in length from 10-20 minutes (Ben-Peretz \& Rumney, 1991; Dunne \& Bennett, 1997) to an hour or more (Borko \& Mayfield, 1995; Hawkey, 1998a).

In the 1980s, Zeichner and Liston (1985) created a conceptual framework for the examination of supervisory conferences. Research prior to this had used pre-determined categories for the study of conferences based on classroom observation systems and did not focus on the cognitive processes evident within the discourse (McFaul \& Cooper, 1983; Weller, 1971). Zeichner and Liston (1985) studied the discourse between university supervisors and elementary student teachers and identified categories for discourse including factual (descriptive and information), prudential (suggestions or advice), justificatory (reasoning), and critical (value of reasoning). Tsui, Lopez-Real, Law, Tang, and Shum (2001) studied the discourse between the triad of student teacher, cooperating teacher, and university supervisor. They identified two major speech functions occurring in the discourse: eliciting and offering. These researchers also noticed instances where a participant would steer the direction of the conversation or take control. This was labeled as managing the conference. Fernandez and Erbilgin (2009) also studied the supervisory conferences of student teachers, university supervisors, and cooperating teachers in order to examine the role of these conferences in guiding the learning of preservice teachers. 
While the focus of these studies was on the student teacher - university supervisor dyad or the triad of the university supervisor, cooperating teacher, and student teacher, these frameworks can provide a foundation for the study of student teacher - cooperating teacher dialogues.

More recently, researchers have investigated the roles mentors assume during mentoring dialogues (Crasborn, Hennissen, Brouwer, Korthagen, \& Bergen, 2008, 2010; Crasborn et al., 2011; Hennissen et al., 2008, 2010; Hennissen, Crasborn, Brouwer, Korthagen, \& Bergen, 2011). Hennison, Crasborn, Korthagen, and Bergen (2008) identified five dimensions of mentoring dialogues that contribute to the role assumed by the mentor: topics of conversation, mentoring style, conversational input, time aspects, and phases of the dialogue. The topics of conversation focused primarily on instruction and organization, the students, and the subject matter (Ben-Peretz \& Rumney, 1991; Coulon, 1994; Dunne \& Bennett, 1997; Hawkey, 1998b). Much of the existing studies have identified a distinction between direct and indirect mentoring style (Ben-Peretz \& Rumney, 1991; Harrison, Lawson, \& Wortley, 2005; Hawkey, 1998b; Orland-Barak \& Klein, 2005; Williams et al., 1998), though some have identified a continuum as opposed to two distinct categories (Davis, 2006; Glickman, 2002). Much of the research on mentoring style has focused on the impact of mentor training on style (Ben-Peretz \& Rumney, 1991; Evertson \& Smithey, 2000; Harrison et al., 2005; Timperley, 2001; Williams et al., 1998), though some studies have focused on how the mentoring style may shift over time or in response to the needs of the mentee (Bullough, 2005; Crasborn et al., 2008; Grabis-Bunker, 1995; van Ginkel et al., 2016). Existing research has referred to the conversational input of the cooperating teacher as active or reactive (Crasborn, et al., 2010; Hennissen, et al., 2008). Most 
researchers that have focused on the conversational input found that an active mentor usually introduced the topics, while a reactive mentor may respond to the student teacher (Feiman-Nemser, Parker, \& Zeichner, 1992; Haggarty, 1995; Wang, Strong, \& Odell, 2004). A more active mentor may spend more time speaking (Dunne \& Bennett, 1997; Hawkey, 1998b). Researchers have also noticed a pattern in the phases of the mentoring dialogue where the mentor often begins with a compliment, summarizes the lesson, offers comments or questions, and finishes with suggestions for improvement (Feiman-Nemser et al., 1992b; Wang et al., 2004). While these dimensions of mentoring dialogues have been studied by general education researchers (Crasborn et al., 2011; Hennissen et al., 2008), mentoring dialogues have not been closely examined by music education researchers.

\section{Student Teaching as Apprenticeship}

Initially based on the study of tailors' apprentices, Lave and Wenger (1991) describe an apprenticeship as "situated learning" or learning by doing. Through observation and participation, the apprentice experiences a process of "legitimate peripheral practice" in which they become part of the culture of practice (p. 95). Apprenticeship has also been described as informal education as opposed to more formal schooling, in which formal schooling refers to instruction taken out of context and informal learning embedded in everyday activities (Lave, 1996). Through apprenticeship, the learner experiences many complex ideas simultaneously such as everyday tasks and the social identity of the career.

In studies of the masters of Islamic law, the experts serve as both the master and teachers of the apprentices (Lave, 1996). In the context of student teaching, the cooperating teacher serves as the expert on the school culture, a teacher to both their students and the student teacher at the same time. The cooperating teacher adopts a dual 
focus on both the students in their classroom and the apprentice, or student teacher (Achinstein \& Athanases, 2006).

Lave (1996) describes learning mechanisms as ways of becoming a participant and ways in which participants change. Within the apprenticeship experience of student teaching, discourse between the participants may be considered a learning mechanism, or process for reflection and change as the student teacher becomes a legitimate participant in the community (Lave \& Wenger, 1991). Learning through talk, or discourse, can be a very meaningful process for knowledge transmission and may be used as a basis for change of the apprentice's understanding and perspective (Lave \& Wenger, 1991; Rogoff, 1990). Through conversations with their mentor, the student teacher may reflect upon ways to change their practice, as well as learn how to 'talk' as a teacher does (Lave \& Wenger, 1991). Lave and Wenger (1991) make the distinction between talking about a practice and talking within a practice. While talking within a practice, the participants focus on the progress of ongoing activities, or the reflection on teaching practice. Talking about practice may involve a mentor sharing their own experience, ideas, or advice.

Dialogic nature of language. Within the sociocultural context of the mentoring dialogue, the cooperating teacher and student teacher communicate meanings based on their own experiences and in response to each other. Communication in itself is complex and affects interpersonal communications (Kim, 2011). According to Bakhtin (1986) all language is responsive to prior utterances and in anticipation of the response. The listener is not a passive participant, but simultaneously perceives meaning and takes an active, responsive attitude toward it (Bakhtin, 1986, p. 68). In a mentoring dialogue, while one party may be more active than the other, the listener is still active and responding 
somehow. In some cases the listener may not respond immediately. The student teacher may respond to a cooperating teacher by reflecting upon their own teaching.

A mentoring dialogue will never be monologic, but rather multi-voiced. In Bakhtin's writings, the concept of heteroglossia represents the multitude of voices representing different points of view (Holquist, 1990) that inform a conversation. In relation to heteroglossia, the listener may shape the content and the response in any given discourse (Shields, 2007). Therefore, the listener is always an active participant and the speaker is constantly aware of the listener's response and understanding (Bakhtin, 1981a). Early on in a mentoring relationship, the cooperating teacher may talk more, taking a direct approach. Over time, as the cooperating teacher speaks less and listens more, the student teacher may develop their voice (Shields, 2007). As this shift occurs, the relationship may move from a hierarchical one to a more equal power relationship. According to Bakhtinian theory, this power sharing ensures that the participants in the dialogue will value each other's contributions and both may learn from the dialogue (Fecho \& Botzakis, 2007). This may ensure that feedback and improvement becomes a mutual effort as opposed to punitive.

Multivoicedness may also be evident in the mentor's perceptions of their role based on their prior experience supervising student teachers and as a student teacher themselves. As each individual brings their own unique worldview to dialogic interactions (Bakhtin, 1981a), the cooperating teacher may draw upon their prior experiences when approaching mentoring dialogues. As some cooperating teachers have had little or no training for their role, they may mentor as they were mentored or they may draw comparisons between prior interns (Clarke, 2006). In addition, multivoicedness implies 
that not every utterance is taken into consideration or acknowledged based on one's individual world view (Kim, 2011). As a result, the student teacher may not act on all of the cooperating teacher's suggestions despite their position of authority within the dyad.

Despite a potential desire for collaboration or equal partnership (Awaya et al., 2003; Draves, 2008b), the student teacher may feel a tension between their role as a teacher and their role as a student. Within the relationship the cooperating teacher will naturally have greater power, which may manifest itself during discourse (Britzman, 1991). As the discourse between the cooperating teacher and the student teacher is heteroglossic, there may be a power struggle within this dialogic relationship (Bakhtin, 1981b; Britzman, 1991). Bakhtin (1981b) made a distinction between authoritative discourse, as formal discourse that must be followed, and internally persuasive discourse, reflecting less institutional authority and allowing for personal questions and reflection. Within the dialogue between a student and a teacher this may be reflected in the questions raised which extend one's thinking or views (Britzman, 1991).

The continuum of power-sharing within the cooperating teacher-student teacher relationship (Draves, 2008a) may manifest itself in the mentoring dialogues. The type of discourse may shift according the role adopted by the cooperating teacher during these dialogues. Drawing from Bakhtinian theory, Britzman (1991) encourages a broader perspective including the multitude of factors impacting discourse. Likewise there may be a multitude of factors impacting the role of the cooperating teacher during mentoring dialogues. A mentor's style, intentions, and topics may manifest themselves during dialogues and may be reflected in the Mentor Roles in Dialogues Model (Hennissen et al., 2008). 


\section{Cooperating Teacher-Student Teacher Personality}

The personality of a teacher may have a major impact on the classroom environment and student learning (Teachout, 2001). Personality types are commonly referred to as introverted or extroverted (The Myers \& Briggs Foundation, 2018). The Myers-Briggs Type Indicator (MBTI), based on Jungian theory, established four preferences including favorite world, information, decisions, and structure. Favorite world refers to one's preference for the outer world or one's own inner world, commonly known as extraversion or introversion. Information is related to the interpretation of meaning and whether one focuses on basic information or the interpretation of meaning. The decision making process refers to a distinction between focusing on logic and consistency or on people and special circumstances. Finally, structure refers to dealing with the outside world through decision making or by remaining open to new information and options (Myers, 2016). Based on one's score in each category, individuals may be classified according to each index measuring extraversion-introversion (EI), sensing-intuition (SN), thinking-feeling (TF), and judgement-perception (JP) (McCrae \& Costa, 1989).

Additional researchers who have focused on personality traits have identified five major factors of personality (Goldberg, 1990; McCrae \& Costa, 1989). The five dimensions of neuroticism, extraversion, openness to experience, agreeableness, and conscientiousness include a variety of discrete traits within each dimension (McCrae \& Costa, 1989). Two of the five personality traits, extraversion and agreeableness or friendliness are related to social interaction and therefore may influence the social context of a classroom (De Jong et al., 2014; Goldberg, 1990; Kokkinos, 2007). Those who are considered more agreeable may tend to maintain more positive relationships (De Jong et al., 2014). 
While some educational researchers have examined the personality traits of teachers and preservice teachers (Cage, Bob, \& Price, 1980; Lawley, 2012), this concept has often been discussed in connection with the cooperating teacher-student teacher relationship or pedagogical orientation (Hagen, 2011; Young, 1995). Cage, Bob, and Price (1980) examined student teacher attitudes toward teaching as rated by their cooperating teachers and found that a personality match was not impactful to the relationship. Hagen's (2011) cooperating teacher-student teacher participants identified a personality match as being important, but not implying that they had to be the same. Sudzina and Coolican (1994) found that personality conflicts may negatively impact the relationship. While certain personality traits may influence the relationship between the cooperating teacher and the student teacher (Hagen, 2011; Sudzina \& Coolican, 1994; Young, 1995) few have examined the influence of personality on the role of the cooperating teacher.

\section{Reflective Thinking}

Reflective thinking is a process in which we draw upon our prior experience, or "funded experience" to interpret our immediate experience (Dewey, 1933). Through the process of reflection, one pauses decision making in order to assess the situation and determine possible solutions. Dewey (1938) identified a five-stage model of reflective thinking in which one identifies the problem, refines the problem to create a fuller understanding, hypothesizes about the problem and potential solutions, further scrutinizes the hypothesis, and finally tests out the hypothesis in action. This process may be facilitated for cooperating teachers through reflection on mentoring dialogues. Previous researchers have used video-based reflection in order to stimulate reflective thinking, but their focus was on performing musicians or preservice teachers (Berg, Woody, \& Bauer, 
2002; Whitaker, 1996). Using video segments of music classroom teaching, Berg, Woody, and Bauer (2002) found that preservice teachers focused most frequently on the teacher. Reflection pertained to aspects of teaching and learning, explanations for observations, and recognition of problems.

Schön (1983) labeled reflection-on-action as thinking about teaching after it has occurred. Reflection on one's practice has been established as necessary for teacher development (Schön, 1983; Stegman, 2007). Dialogue with an experienced music teacher may facilitate reflection for preservice music teachers (Stegman, 2007). Butke (2006) identified three modes of reflection including thinking, writing, and conversing. During the conversing mode the teacher intentionally participates on a dialogue focused on teaching practice. Through mentoring dialogues, both the student teacher and the cooperating teacher may be engaged in reflection on action through discussion of teaching practice. Though Stegman (2007) studied the reflective conversations between music cooperating teachers and student teachers, the focus was on the student teacher. Additional research is needed related to the reflective practice of music cooperating teachers.

\section{Mentor Roles in Dialogues Model}

Hennison, Crasborn, Brouwer, Korthagen, and Bergen (2008) established the Mentor Roles in Dialogues (MERID) model to explore the roles assumed by mentors during mentor dialogues. Described in this section, this model will serve as a framework for analysis in this study. The model includes four quadrants related to the actions of the mentor on a continuum from non-directive to directive and reactive vs. active. The directiveness axis refers to the style of mentoring and the input axis refers to who initiates 
topics of conversation. By combining these two components, mentors assume one of four roles. Figure 1 shows the MERID model.

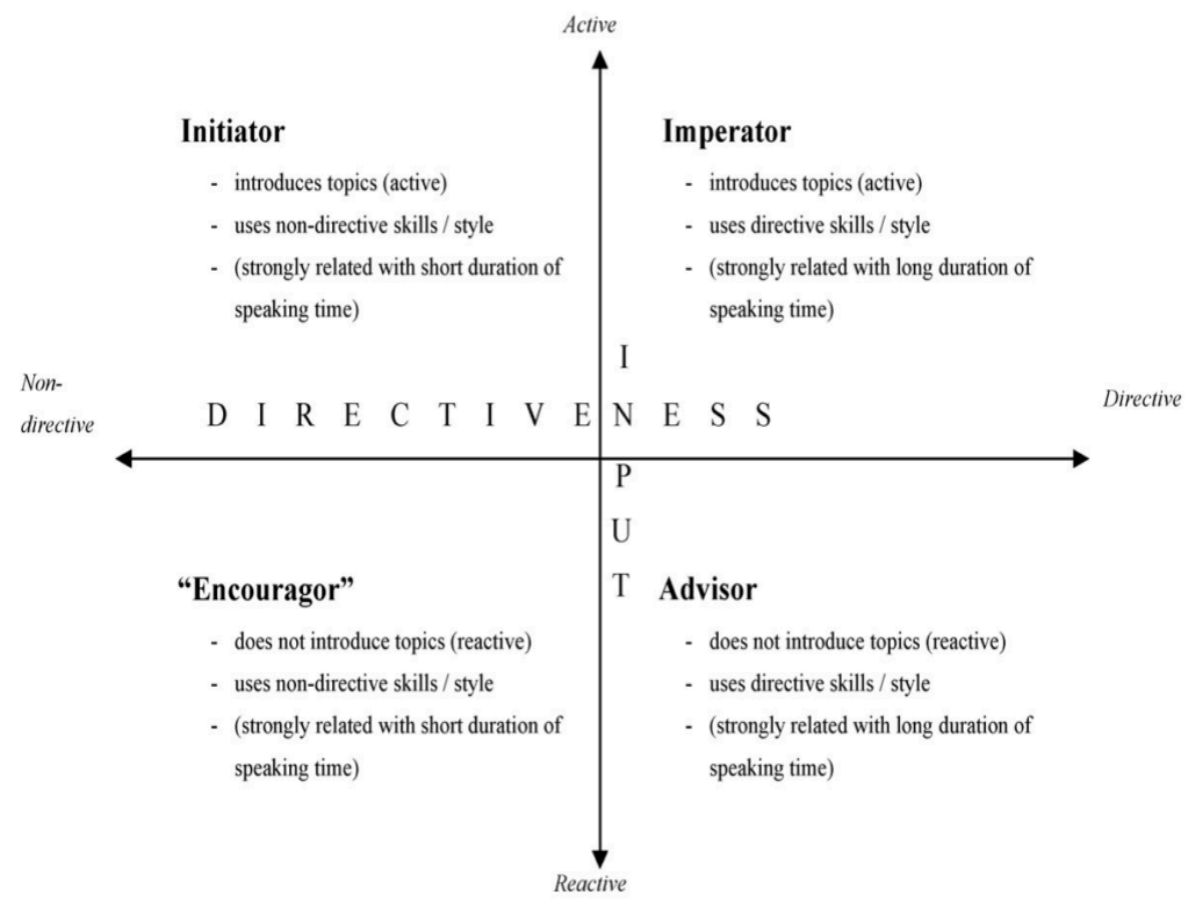

Figure 1: MERID model (Hennissen et al., 2008)

Using an active, non-directive approach, the initiator will introduce topics to the student teacher while which using non-directive skills such as asking open questions, listening, and guiding toward reflection. The imperator mentor will take a more direct approach by frequently sharing opinions and advice. Taking a more reactive, direct approach, the advisor will react to topics that the student teacher introduces and give direct advice. Finally, the encourager will react to student teacher introduced topics and use non-directive supervisory skills (Crasborn et al., 2011).

In an empirical study of the MERID model involving 20 mentor teachers, Crasborn, Hennissen, Brouwer, Korthagen, and Bergen (2011) found that most mentors were active, introducing topics to the student teacher. Direct vs. non-directive approach was much 
more evenly split with $49 \%$ of conversational turns being directive and $51 \%$ being indirect. This resulted in most mentors being aligned with the imperator role.

For this study I have used the MERID model as a framework for analysis of the mentoring dialogues between music cooperating teachers and student teachers in order to determine if this model applies to selected music mentor-student teacher dialogues. The model will also help to track the changes, if any, in the mentoring role over the course of the eight-week student teaching experience.

Personality and mentoring role. Cooperating teacher personality may also serve as a foundation for the MERID model axes. While not explicitly examined in prior research (Hennissen, et al., 2008), the personality traits related to extraversion may be connected to a mentor's tendency to be more direct/indirect or active/reactive. A cooperating teacher who tends to be more talkative may dominate the conversation by adopting a more direct and active role during mentoring dialogues. Additionally, the personality traits of the student teacher may influence the relationship and the role adopted by the cooperating teacher. Their tendency toward extraversion or introversion may impact the dialogues as well as their level of agreeableness (Goldberg, 1990). A friendly and agreeable student teacher may tend to defer to the cooperating teacher's opinion in the classroom.

\section{Need for the Study}

While other music education researchers have examined the interactions and the relationship between the cooperating teacher and the student teacher, they did not explicitly study the role assumed by the mentor during mentoring dialogues (Draves, 2008a; Krueger, 1985; Stegman, 2007). Draves (2008b) and Krueger (1985) examined the relationship between the music cooperating teacher and their student teachers, but not the 
mentoring style. Stegman (2007) studied the reflective conversations between music cooperating teachers and student teachers, but the focus of analysis was on student teacher rather than the cooperating teacher during conversations. A close examination of mentoring dialogues may lead to a deeper understanding of a music teacher's approach to mentoring in different music classroom contexts over the course of a student teaching placement.

General education researchers have examined mentoring dialogues, but these have involved various classroom contexts in different subject areas and countries (Bertone, Chaliès, Clarke, \& Méard, 2006; Crasborn et al., 2010; Hawkey, 1998b; Hennissen et al., 2008; Orland-Barak \& Klein, 2005; Timperley, 2001). Music classrooms may be different than these contexts. In most music classrooms performance tends to be a major focus and this may impact the relationship and the mentoring style of the music cooperating teacher (Draves, 2008b). This may be especially true in ensemble-based classrooms. Music teachers, like other teachers, are under continuous pressure for student growth and achievement (West, 2012). This may impact the mentoring style of the cooperating teacher as their focus is on both the development of the student teacher and the growth and achievement of their students (Achinstein \& Athanases, 2006). While cooperating teachers in other content areas also consider the development of the student teacher and achievement of their students, a need exists for research on the unique impacts of music program expectations on the mentoring role assumed by the cooperating teacher.

While several researchers have closely examined post-lesson or supervisory conferences (Fernandez \& Erbilgin, 2009; Tsui et al., 2001; Zeichner \& Liston, 1985), the focus has been primarily on how the student teacher learns to teach through the process of 
participation in mentoring dialogues. Given the pivotal role the mentor teacher plays in the development of student teachers, research is needed on how the mentoring role is enacted during these dialogues and how and why the cooperating teacher might shift their approach over the course of the student teaching placement. In addition, research that also includes mentor review of mentoring dialogues via video and interviews on the mentor's perceived role will help the profession better understand mentors' perceptions of this role (Koerner, 1992; Kruse, 2011) through reflection on their practice (Koerner, 1992;

Pellegrino, 2015).

\section{Purpose and Research Questions}

The purpose of this multiple case study (Stake, 1995) was to examine the roles assumed by cooperating teachers during mentoring dialogues with student teachers. The following research questions were addressed:

1. What factors impacted the mentoring roles assumed during mentoring dialogues?

2. What mentoring role did the cooperating teachers assume during mentoring dialogues?

3. How did the cooperating teachers respond to video-based reflection on mentoring dialogues?

\section{Definitions}

- Student teaching: Traditionally the final term of a teacher preparation program, following completion of coursework prior to graduation (Rideout \& Feldman, 2002). 
- Student teacher: The preservice teacher assigned to work with a cooperating teacher in a K-12 school for their student teaching placement (Rideout \& Feldman, 2002). The student teacher is sometimes referred to as the teacher candidate.

- Cooperating teacher: The school-based mentor tasked with sharing their classroom and guiding the student teacher. The cooperating teacher has also been referred to as a mentor teacher, school-based mentor (Borko \& Mayfield, 1995; Hennissen et al., 2008; Orland-Barak \& Klein, 2005; Timperley, 2001).

- University supervisor: The representative of the university assigned to observe and evaluate the student teacher.

- Mentor: An expert paired with a novice. The mentor is the expert, or cooperating teacher engaged in an apprenticeship relationship focused on socialization and professional development (Achinstein \& Athanases, 2006).

- Mentee: The novice, or student teacher, engaged in the apprenticeship relationship (Achinstein \& Athanases, 2006).

- Mentoring role: the expected behavior within a social position (Hennissen et al., 2008). They may serve as a model and guide of instructional practice or they may provide psychological support through coaching and guiding (Lieberman et al., 2012). For the purpose of this study, role indicates the labels of initiator, imperator, encourager, or advisor created by Hennisen, Crasborn, Brouwer, Korthagen, and Bergen (2008) for use in the MERID model.

- Mentoring dialogues: A formal, two-way conversation between a mentor and a mentee. In prior research this has also been referred to as a supervisory conference 
or post-lesson conference (Crasborn et al., 2011; Hennissen et al., 2008; Zeichner \& Liston, 1985).

- Mentoring style: Also known as an approach or stance to mentoring. May be direct or non-directive (Hennissen et al., 2008).

○ Direct: a mentoring style that is instructive, explicit, prescriptive, and informative (Glickman, 2002; Hennissen et al., 2008).

○ Non-directive: a mentoring style that is elicitive, indirect, collaborative, or facilitative (Helman, 2006; Hennissen et al., 2008).

- Adaptive mentoring: A shift in mentoring style based on the individual needs of the mentee (van Ginkel et al., 2016).

\section{Delimitations}

One limit of case study research is the small number of cases to be studied. This limits the generalizability of the findings. Though multiple cases can increase generalizability, one should still be cautious as the findings are limited by the boundaries of these four cases (Stake, 1995). However, through thick description of the cases, findings may be transferrable to similar cases (Onwuegbuzie \& Leech, 2010).

Additionally, due to school district research restrictions, the primary data for this study were limited to interviews and recordings of teaching and mentoring dialogues. No researcher observations of cooperating teacher - student teacher informal interactions at the schools were conducted. While this may limit the findings, the primary focus of the study was on the mentoring dialogues that were recorded and reviewed by the researcher and the cooperating teachers through stimulated recall interviews. 
The window for data collection was eight weeks, as this is the length of the student teaching placements of the participants. As a result of this time limitation, the relationship between the cooperating teacher and the student teacher may be impacted. Additionally, potential changes in the mentoring approach may be limited by the length of the placement. 


\section{CHAPTER II}

\section{Review of Related Literature}

Student teaching is often considered to be the most important phase of the teacher preparation program because of the opportunity to apply concepts studied during coursework to a real classroom setting (Conway, 2002; Friebus, 1977; Grossman et al., 1999). As the cooperating teacher has the most daily contact with the student teacher, they have a great influence on the socialization of the student teacher (Friebus, 1977). A variety of factors may affect the approach of the cooperating teacher, including the needs of the students (Achinstein \& Athanases, 2006), the student teacher, and the cooperating teacher's perspective on the mentor role. The mentor's approach may shift over time and may be evident in the formal mentoring dialogues with their student teacher.

In chapter I, I provided an overview of mentoring roles and mentoring dialogues and described sociocultural aspects of communication including speech acts and the dialogic nature of language that relate to the purpose of this study. This chapter is divided into three sections: (1) perceived role of the cooperating teacher including the cooperating teacher - student teacher relationship; (2) student teaching context; and (3) mentoring dialogues including the topic of conversation, mentoring style, mentor teacher input, time aspects, and phases of the conversations.

\section{Perceived Role of the Mentor}

In the next section, literature on the perceived role of the cooperating teacher will be reviewed. As stated in chapter 1 , the role of the mentor may be broadly categorized as providing psychological support (Feiman-Nemser \& Parker, 1993; Jonson, 2002; Rajuan, Beijaard, \& Verloop, 2007; Stanulis, 1994) and instructional support through modeling, 
sharing resources, and providing feedback (Anderson, 2004; Borko \& Mayfield, 1995;

Rajuan et al., 2007). Some cooperating teachers have seen themselves as a guide, helper, or coach (Feiman-Nemser \& Parker, 1993; Rajuan, Beijaard, \& Verloop, 2007; Stanulis, 1994). Others gave direct advice in order to share their experience and guide preservice teachers in learning how to teach (Borko \& Mayfield, 1995). Additionally, the perceived role of the cooperating teacher may be enacted through the relationship developed with the student teacher.

In a case study of a student teacher and their cooperating teacher and university supervisor, Weaver and Stanulis (1996) described a collaborative student teaching triad. Through open communication between all three parties, they created a shared understanding of the mentoring role. The mentor served as a guide who asked questions as opposed to evaluating. Weekly conferences between the student teacher, cooperating teacher, and university supervisor encouraged collaboration and the student teacher's sense of freedom. The researchers found that the cooperating teacher and the university supervisor had to examine their own bias and beliefs in order to adapt to the student teacher's needs and goals.

In an examination of two school-university partnerships, Kruse (2011) found that the cooperating teachers viewed their role as a service to the profession through mentoring young teachers. Their own teaching was also impacted through reminders of the importance of clear conducting and enthusiasm. The cooperating teachers found themselves "stealing rehearsal tricks" from the university students. They also noticed the benefit to their students, as they had the opportunity to "teach" the university students. 
Instructional support. Gathering interview and observation data from four student teachers and their cooperating teachers and university supervisors, Borko and Mayfield (1995) studied the role of the cooperating teacher and the university supervisor in the student teaching experience. By observing conferences between student teachers and their cooperating teachers, they found some variety between the different teachers. Some cooperating teachers offered brief suggestions while others reflected and guided through lengthy discussions. The variance was impacted by the cooperating teachers' beliefs regarding learning to teach and their roles as cooperating teachers. All agreed that one learns to teach through experience. Some felt that they should take a very active role in the student teacher's development, while others believed that the student teacher should figure things out for themselves through time and experience.

In addition to learning to teach through experience, cooperating teachers carry the task of evaluating and providing feedback for the student teacher (Borko \& Mayfield, 1995). The cooperating teacher may be aware of their power within the relationship that comes with the responsibility of evaluating the student teacher. In a mixed methods study including interviews with 12 student teacher-cooperating teacher pairs, Anderson (2004) found that some cooperating teachers questioned the authenticity of the student teacher's change of teaching strategy as it could be an effort to gain a passing grade. Personality conflicts between the cooperating teacher and the student teachers may result in a lower summative evaluation of the student teacher (Sudzina \& Coolican, 1994).

Psychological support. Feiman-Nemser and Parker (1993) conducted a comparative study of two new teacher induction programs in different parts of the United States. One was an alternative certification program through a large school district and the 
other was a graduate intern program in cooperation with a university-based Master's program. Through program analysis and interviews with mentors, researchers focused on the way in which teachers defined and enacted their mentoring role. Based on the findings they identified three perspectives on the mentoring role. The mentor who tried to smooth the passage into teaching by sharing policies, curriculum, and solving problems was referred to as the "local guide." Mentors described as "educational companions" took on more of an educational role by helping them cope with problems while also addressing professional goals such as student learning. "Agents of change" were the mentors who attempted to break down the traditional isolation through collaboration and shared inquiry. While this study was focused on a new teacher induction process, similar mentoring roles may apply in a student teaching situation.

In a study of forty cooperating teachers in Israel, Rajuan, Beijard, and Verloop (2007) led focus group discussions with both cooperating teachers and student teachers in order to elicit their opinions about the role of a cooperating teacher. The cooperating teachers predominantly valued a technical role as a model of classroom techniques and organizer of the classroom environment. They also valued the practical role of sharing information about students and discussion of problems. In this case the cooperating teacher was viewed as a guide or a helper. Areas related to academics and curriculum, the idea of teaching as mission, and the personal role of being a friend or "mother" were rated lower by the cooperating teachers. Conversely, the student teachers placed higher value on the personal role of the cooperating teacher, along with the practical role of being a guide with information about students. Their value of the personal nature of the relationship was 
related to the cooperating teacher being a "safety net," being available, and supporting their efforts.

Using a case study approach, Stanulis (1994) documented one cooperating teacher's process of reflecting upon their own practices as a mentor. Stimulated recall interviews were used to gather the cooperating teacher's thoughts about their approach and intentions during mentoring dialogues. Through reflection on these conversations, the cooperating teacher noticed herself shift from giving direct advice and answers to using more questioning to encourage the student teacher to reflect and make their own decisions. She saw her role as a coach and worked to spend less time talking and telling her mentee what to do.

Cooperating teachers have various perceptions of their roles, from model, to guide, to coach, to evaluator (Borko \& Mayfield, 1995; Rajuan et al., 2007; Stanulis, 1994). Perceptions of the role may be impacted by personal views of learning to teach (Borko \& Mayfield, 1995) and may shift according to the needs of the student teacher (Weaver \& Stanulis, 1996). Various factors may impact their assumed role including the need to evaluate the student teacher and instructional concerns. This study will explore how cooperating teachers' perceptions of the mentor role are evident in mentoring dialogues with student teachers.

Cooperating teacher-student teacher relationship. A variety of factors may influence the relationship between a cooperating teacher and student teacher including individual personalities, comfort level with the students, and openness or transparency of the communication (Hagen, 2011; Stanulis \& Russell, 2000). There may also be unique factors in a music classroom such as performances or length of the student teaching 
placement that may impact the relationship (Draves, 2008a; Draves, 2008b; Hagen, 2011).

Additionally, the relationship may also change or develop over time (Awaya et al., 2003). This section will review research on factors that contribute to the cooperating teacher/student teacher relationship, negative influences on the relationship, and processes identified for establishing a collaborative relationship.

Personality contributing to relationships. As personality traits of the cooperating teacher and the student teacher may influence the relationship between the cooperating teacher and the student teacher, some researchers have drawn a connection between the two ideas (De Jong, et al., 2014; Hagen, 2011; Lawley, 2012). Despite this seemingly natural connection, prior research has found little significant influence of personality on the collaborative relationship (De Jong, et al., 2014; Lawley, 2012) though some have found that the cooperating teachers or the student teachers value a personality match (Hagen, 2011; Rajuan, et al., 2007). Powell (2018) found that cooperating teachers felt the need to understand their student teacher's personality in order to develop a collaborative relationship.

Palmer (2018) examined music cooperating teachers' perceptions of their role during the student teaching experience. Cooperating teachers were found to value their position as giving back to the profession as a "teacher of teachers." They also saw benefits to their own teaching as they gained strategies from the student teachers, shared responsibility in the classroom, and refined their practice as a teacher and a mentor through reflection. The relationship between the cooperating teacher and the student teacher was also found to be an important factor and dependent upon the student teachers' 
preparation, musicianship, personality, and work ethic. If any one of these areas is lacking, the relationship becomes more challenging to nurture and maintain.

Hagen (2011) examined three music cooperating teacher/student teacher pairs involved in collaborative research projects during the student teaching semester in order to determine how active collaboration would impact the mentoring relationship. The collaborative research project topics were chosen by the cooperating teachers and student teachers as issues of interest and importance to them including the changing male voice, guided listening in band, and music vocabulary. In reflecting on the mentor/mentee relationship, cooperating teachers all valued a feeling of comfort and openness in the relationship where they felt like they could talk to their student teacher and "be themselves." The cooperating teachers also valued a personality match with the student teacher, recognizing that this contributed to a sense of being compatible. Cooperating teachers also looked for a 'teacher presence' in their student teachers where the student teacher exhibited confidence when teaching groups of students.

Similar to Hagen (2011), De Jong, Mainhard, Tartwijk, Veldman, Verloop, and Wubbels (2014) studied personality as a concept related to relationships, though their focus was on the relationship between preservice teachers and students. In a study involving 120 preservice teachers from three different graduate schools in the Netherlands, researchers sought to identify predictors of a positive teacher-student relationship including personality traits, self-efficacy, and discipline strategies. They identified two personality traits, extraversion and friendliness, as having the potential to impact the social context of the classroom. By measuring the students' perception of the teacher-student 
relationship, they found no association between extraversion or friendliness but suggested that the personality traits may play a different role in the social context of a classroom.

Lawley (2012) examined personality traits of cooperating teachers and student teachers and their opinions of their collaborative relationship. Using sixty-six participants, cooperating teachers and student teachers were paired either randomly or purposefully based on their dominant personality traits. Findings indicated that there was no relationship between the personality trait and their self-reported opinions of collaboration. Participants were able to collaborate and value each other's contributions even if they did not agree.

Negative influences. In a critical grounded theory study focused on the relationship between cooperating teachers and preservice teachers in a methods course field experience, Abrahams (2009) found that the preservice music teachers thought the cooperating teachers' routines were incompatible with what they had learned in their courses. They compared themselves to the cooperating teachers and were critical at times of how the cooperating teacher handled certain classroom situations. Though some of the themes were focused on the relationship between the preservice teacher and the cooperating teacher, the data collected was entirely from the perspective of the preservice teachers.

Sudzina and Coolican (1994) examined the relationships between cooperating teachers and student teachers in order to determine what features may impact the success of the relationship. Responses to questions for student teachers and cooperating teachers as well as three vignettes depicting three failed mentor/mentee relationships suggest that both personality conflicts and pedagogical disagreements can cause a breakdown in the 
relationship. In one case the two had differing expectations for student teaching and pedagogical disagreements. The second case involved a clash between philosophies, pedagogical approaches and behavior management. The third included a student teacher who was resistant to mentoring. Different views of the role of the mentor may also impact this relationship as some cooperating teachers saw mentoring as being in charge of the relationship, while others viewed it as a shared relationship.

Establishing a collaborative relationship. Draves (2008b) examined the relationship between the cooperating teacher and the music student teacher from the perspective of the cooperating teacher. Data was collected by interviewing three music cooperating teachers across three different teaching areas and levels. Relationships existed on a continuum from a student-teacher relationship to a team-teaching relationship to a collaborative partnership. These relationships were characterized by the degree of power sharing with the cooperating teacher. Power sharing was defined as the amount of responsibility taken on by the student teacher. The power was shared more equally between the mentor and the mentee in a collaborative relationship. The cooperating teachers tended to value the collaborative relationships the most where the student teacher was motivated to accept the role as teacher and took initiative rather than waiting to be told what to do.

Awaya, McEwan, Heyler, Linsky, Lum, and Wakukawa (2003) focused on the developing relationship between a cooperating teacher from a professional development school and a student teacher enrolled in a two-year Master's degree program resulting in teacher certification. In the first year the students were in the school part-time, followed by a full-time paid teaching experience in the second year. Through author/participant 
reflections, student reflections, and interviews with mentors, comparisons were made between the two-year program and prior experience with student teachers. Instead of a hierarchical relationship between mentor and mentee, their program valued an equal partnership developed gradually over time. As opposed to mentoring as "something that is done" to the mentee, the program leaders view the mentor and the student as equal partners. Inspired by Homer's Odyssey, the authors described the relationship as a journey, with the mentor providing knowledge and moral support, while allowing the mentee space to show what they can do. At times, this required the mentor to show restraint and allow the mentee time to develop their skills.

In a qualitative study with two cooperating teachers and their student teachers from a Master's degree program including licensure, Stanulis and Russell (2000) found that trust and communication were essential for a productive mentor/mentee relationship. The program utilized a collaborative model that included mentor training, a coordinator for communication between the university and the schools, and monthly meetings between university supervisors, mentor teachers, and student teachers. They also elicited feedback from the mentors about the program. The student teachers progressed from part-time to full time teaching over the course of a full year. Data collection involved observations, small-group and large-group reflection, and journals over the course of six months. The cooperating teachers indicated that they had to feel like they could trust the student teacher to take over their class. Once trust was felt by both parties, then the student teachers were encouraged to "jump right in" and teach. All parties agreed that open communication through reflective, joint conversation was important for effective mentoring. 
Researchers have found that trust and communication are important for establishing a productive relationship and that cooperating teachers value collaboration with their student teachers (Draves, 2008a; Hagen, 2011; Stanulis \& Russell, 2000). Although personality and pedagogical disagreements may negatively impact the cooperating teacher/student teacher relationship, a personality match and power sharing between the two may enhance the collaboration (Abrahams, 2009; Draves, 2008; Sudzina \& Coolican, 1994). The interactions between the mentor and the mentee may impact this relationship (Sudzina \& Coolican, 1994), though few have examined how the relationship is manifested during conversations between the cooperating teacher and the student teacher.

\section{Student Teaching Context}

Co-teaching. Within the context of a student teaching placement, the cooperating teacher and the student teacher may engage in certain co-teaching practices. Cook and Friend (1995) defined co-teaching as "two or more professionals delivering substantive instruction to a diverse, or blended, group of students in a single physical space." Though they were referring to multiple teachers in a special education setting, co-teaching strategies are also incorporated into student teaching arrangements (Diana, 2014). Cook and Friend (1995) described a variety of strategies for co-teaching including one teach/one observe, one teach/one assist, station teaching, parallel teaching, alternative teaching, or team teaching. In some cases one person is teaching while the other is observing or assisting. In station and parallel teaching both are teaching at the same time. Alternative teaching involves each teacher taking turns teaching using alternate strategies. In a team teaching arrangement, both teachers are responsible for instruction and may take turns delivering instruction and interacting with students. In this co-teaching model, teachers 
share instruction and freely offer instruction. Team teaching requires the most trust and collaboration. In a student teaching context the cooperating teacher may be the primary teacher with the student teacher assisting, or they may divide instruction, plan together, or team teach.

Hildenbrand (2009) explained that the model of co-teaching applied in a given situation may vary in intensity and quality. Through an examination of student teachers in a co-teaching arrangement, the researcher found that the participants valued co-teaching as benefitting both the teachers and the learners, but that it was difficult to maintain effectively. Benefits for the teachers included employing multiple teaching methods and the flexibility in co-teaching models. Additional benefits for the students included increased attention from multiple teachers. Open communication between both teachers was necessary as well as time to co-plan. A positive and respectful environment in which the teachers felt comfortable working together was necessary for success. In some cases, as the relationship between the teachers developed over time, the co-teaching relationship improved.

Existing structures. Powell (2017) studied the experiences of three novice music teachers, beginning during their student teaching experience and following them into their first music teaching job. Stepping into large, rigid, and competitive band programs, the participants felt like they struggled to fit into the existing structure. They lacked the "agency" to make their own decisions. They felt like assistants to the cooperating teacher as opposed to students, student teachers, or colleagues. Despite their lack of agency, they understood the structure that they were stepping into. Their goal was to learn everything 
that they could from their successful cooperating teachers. They respected their mentor's opinion and the structure and organization of the band program.

Krueger (1985) referred to certain factors of the student teaching context as "structural norms." These include class size, teaching schedule, differentiation, and concert cycle. Krueger studied the influence of these structural norms on the student teaching experience of two choral/general music student teaches and found that the student teachers had to learn how to navigate the contextual factors of each placement in order to be successful. Contextual factors such as these may impact the teaching experience of the student teacher and the mentoring approach of the cooperating teacher.

As performances can have an impact on teaching and learning in a music ensemble setting, performance anxiety may influence the cooperating teacher and their interactions with their student teacher. Osborne and McPherson (2018) used the Precompetitive Appraisal Measure to measure performance anxiety in musicians at the beginning of the semester and prior to the final recital. Using primary appraisals of the importance of an upcoming performance, and secondary appraisals of one's skills related to the performance, they sought to determine a musician's ability to cope with performance anxiety. Those who perceived the performance as a challenge as opposed to the threat had lower levels of anxiety. While contextual factors related to the student teaching experience has been the focus of previous research, their impact on the mentoring dialogues between the cooperating teacher and the student teacher has not been studied.

\section{Mentoring Dialogues}

Hennison, Crasborn, Brouwer, Korthagen, and Berger (2008) identified five primary aspects of mentoring dialogues based on prior literature: content, mentoring style, mentor 
teacher input, time aspects of the dialogue and the phases of the dialogues. This section will review the existing literature related to each of these aspects of mentoring dialogues (Hennissen et al., 2008). While some educational researchers have examined mentoring dialogues (Crasborn et al., 2010, 2011; Hawkey, 1998b; Hennissen et al., 2008; Sempowicz \& Hudson, 2011; Timperley, 2001), there is no existing research in music education that has specifically examined the mentoring dialogues between cooperating teachers and student teachers.

As illustrated in the literature, the cooperating teacher functions as a mentor in the classroom (Draves, 2008a, 2008b; Feiman-Nemser \& Parker, 1993; Timperley, 2001). The interactions between the student teacher and the cooperating teacher, or mentor take on a variety of functions in the development of the student teacher (Feiman-Nemser, 2001b). Through their conversations, the mentor attempts to pass on their knowledge to the novice teacher while simultaneously encouraging their autonomy through reflection on their practice. The mentor may adjust their style depending on the needs of the mentee or the purpose of the conversation (Helman, 2006).

Topics of conversation. In a comprehensive examination of literature regarding mentoring dialogues, Hennison, Crasborn, Brouwer, Korthagen, and Bergen (2008) found there to be three main categories of the content of mentoring dialogues: instruction and organization, students and the class, and the subject matter. Instruction and organization tend to be the most commonly discussed topics with students and content being less prevalent (Coulon, 1994; Edwards \& Protheroe, 2013). Additionally, some dialogue was devoted to miscellaneous topics such as professional development or school requirements (Hennissen et al., 2008). Zeichner and Liston (1985) called this "critical discourse" as 
related to the values and assumptions of curriculum and instruction, or the hidden curriculum of teaching.

Topics of conversation may also center around the relevant concerns of the student teacher. Fuller and Bown (1975) outlined a three-stage progression of concerns commonly experienced by preservice and novice teachers. The first stage is related to survival concerns such as classroom management. Task concerns have to do with teaching behaviors such as planning and assessment and the third stage are concerns related to students such as achievement and well-being. Fuller and Bown suggested that pre-service teachers progress through these stages in a linear fashion with student concerns occurring later in their preparation program. Berg and Miksza (2010) and Powell (2014) reported findings that confirmed this linear progression in pre-service instrumental music education students. Mentoring dialogues between cooperating teachers and student teachers may reflect these stages according to the concerns of the student teacher.

As classroom management tends to be a common concern for preservice and beginning teachers, Sempowicz and Hudson (2011) examined mentoring dialogues between classroom cooperating teachers and preservice teachers for the development of classroom management skills. The researchers examined one preservice teacher and mentor teacher pair using formal and informal mentoring dialogues, recorded teaching episodes, lesson plans, reflections, evaluations, written observations, and interviews. When the lesson taught was longer and the content was new, the dialogue was focused on content and pedagogy. Dialogues in response to shorter lessons tended to be more focused on classroom management. The mentor guided the preservice teacher to make links 
between pedagogical knowledge and classroom management through advice and reflective questioning.

In a case study of twelve student teachers from across England, Edwards, and Protheroe (2013) sought to discover more about the impact of mentoring on student teacher knowledge. As each student teacher worked with two cooperating teachers, interviews from each placement were analyzed. Most topics of conversation focused on student responses and classroom organization. The focus on organization increased in the second placement. In general, the mentors were concerned with the pace of curriculum coverage and management, though assessment of students was not a major concern.

Hawkey (1998a) focused on the mentoring dialogues between a secondary English student teacher and her cooperating teacher. The cooperating teacher was an experienced teacher, but an inexperienced mentor. Weekly conversations were audiotaped and transcribed by the researcher/university supervisor. Each meeting was approximately one hour and served as a weekly progress meeting as opposed to a post-lesson feedback conference. Each instance of talk in which a participant uttered a thought focused on a single idea was analyzed and categorized. The categories of talk for the cooperating teacher included prompting student thinking, demonstrating, offering tips or advice, offering support, and summarizing or reflecting. Most instances of cooperating teacher talk focused on prompting student thinking or offering tips and general advice.

Coulon (1994) used a case study approach to observe the influence of cooperating teachers' task statements on their physical education student teachers' teaching behaviors. Two cooperating teachers who had received supervisory effectiveness training volunteered to take part. The training had focused on discussing collected data, identifying strength 
and weakness areas, and the mentor and mentee working together. Classes were observed and teaching conferences were recorded and coded for teaching task statements provided by the cooperating teachers. Most of the comments provided by the cooperating teachers were related to lesson content, classroom organization and management, and feedback.

Mentoring style. The term 'mentoring style' is used in the literature on mentoring to describe the overall approach of the mentor and may be observed in the stance (FeimanNemser, 2001b; Helman, 2006) adopted during mentoring dialogues. Some conceptualize mentoring style as being direct or non-direct (John \& Gilchrist, 1999; Orland-Barak \& Klein, 2005). Others have described mentoring style along a continuum from direct, to collaborative, to facilitative (Draves, 2008b; Glickman, 2002; John \& Gilchrist, 1999). In the literature, various terms are used to describe a direct approach including instructive, explicit, prescriptive and informative (Achinstein \& Athanases, 2006; Glickman, 2002; Helman, 2006; Hennissen et al., 2008; Williams et al., 1998). When using a direct approach, a mentor or cooperating teacher may define, give suggestions, offer solutions, and provide information for the preservice teacher (Helman, 2006). They are more likely to tell a mentee what to do and to control the conversation (Hennissen et al., 2008).

The non-direct style has been referred to as elicitive, indirect, collaborative, or facilitative (Hawkey, 1998b; Helman, 2006; Hennissen et al., 2008; Williams et al., 1998). Using a collaborative approach, the mentor may ask clarifying questions, guide the mentee toward possible solutions, paraphrase and make connections, and help the mentee to reflect upon their teaching (Helman, 2006). In these conversations, the mentor spends less time talking and the mentee may introduce topics more often (Hennissen et al., 2008). 
Using a facilitative approach, the mentee has taken control of information and reflection and the mentor facilitates through listening, paraphrasing, and clarifying (Davis, 2006).

Direct vs. non-direct. Focusing on the mentors contributions to the dialogues between two mentor/mentee pairs, Williams, Butt, Gray, Leach, Marr, and Soares (1998) found that both mentors used either directive approaches and elicitive, or non-directive approaches, but in different ways. One gave many directions about student tasks, classroom management, and lesson timing while the other used few directives except to set the agenda for the meeting. Both mentors used questioning, but one asked open-ended questions in order to encourage reflection while the other used more closed question meant to elicit information.

Hawkey (1998b) also analyzed the mentoring dialogues of two cooperating teachers and found two contrasting styles. One was very directive, giving the student teacher answers, ideas, and advice. Questions were asked, but were mostly rhetorical in nature. The contrasting case showed a mentor acting as a facilitator and asking the student teacher for input. The student teachers confirmed this view through interviews with the researcher. They each learned different things in different ways depending on the approach. One was challenged by the direct approach, but this encouraged understanding of their own values. The mentee of the non-directive mentor felt like she was part of a more collaborative relationship, yet they had difficulty expressing how they learned from it.

In a study of fourteen physical education student teachers, Byra (1994) compared a direct approach during post-lesson conferences with a collaborative approach. Based on self-reflections and brief interviews, the researcher analyzed the focus and level of the 
participants' reflections. Using quantitative analyses, it was determined that the collaborative approach was more effective for stimulating the preservice teachers to reflect on their teaching.

Strong and Baron (2004) examined 64 conversations between 16 veteran teachers and their novice teacher mentees. Transcripts were read for teacher suggestions and coded for direct or indirect suggestions as well as the novice teacher response. An indirect suggestion could be anything from a subtle, gentle suggestion for improvement to a question prodding the novice teacher to respond in a certain way. The vast majority $(196 / 206)$ of the suggestions in this study were coded as indirect. The researchers were surprised that the mentors seemed to go out of their way to avoid making a direct suggestion and conjectured that this could be a result of the mentor-training program. The mentors in this program had been encouraged to promote thinking and elicit ideas from the mentees.

Using 22 transcripts of mentoring dialogues between cooperating teachers and student teachers, Timperly (2001) examined how these dialogues changed after participation in mentor training. Before training the dialogue was directive, focused on giving advice related to student teacher concerns. Following the training, the mentors disclosed concerns to the student teacher, asked the student teacher for input about the reasoning, and developed joint solutions to concerns. The dialogues became more collaborative.

The style of the mentor may be enacted in the stance adopted during mentoring dialogues. In an examination of four case studies of new teachers and their mentors, Helman (2006) found that there tended to be three different mentoring stances emerging 
during conversations. Mentors taking an indirect approach probed to extend the new teacher's thinking. Those using a direct approach explicitly taught or made suggestions, or focused the new teacher on school or state standards. The stance that the mentor took in any given situation depended on their relationship with the new teacher, the new teacher's emotional state, the knowledge base of the mentor, the purpose of the conversation, and the external expectations related to standards and student achievement. Mentors also speculated that the direct approach may have been used more in their content area of expertise.

Direct to facilitative continuum. While most of the literature used the direct/nondirect framework to describe mentoring style, a few studies characterize style along a continuum. Glickman (2002) described a continuum of the mentor's power in the relationship from a directive-control interpersonal approach, to a directive-informational interpersonal approach, to a collaborative interpersonal approach, and finally to a nondirective interpersonal approach. These approaches manifest themselves through a variety of behaviors including listening, asking clarifying questions, encouraging, reflecting, presenting their ideas, problem solving, negotiating solutions, directing, standardizing through expected criteria, and positive and negative reinforcement. Some of these behaviors place more responsibility on the mentor, others on the mentee. When the mentor directs or standardizes the expected results, they are adopting a directive-control interpersonal approach. When the mentor directs, but allows for mentee choice, their approach is directive-informational. When the mentor shares their ideas and listens to the mentee's perspective and problem solves through negotiation, their approach is more collaborative. Finally, their approach is non-directive when the mentor listens to the 
mentee and clarifies and encourages them to speak more and reflect on their practice. Davis (2006) also identified a continuum of mentoring approaches in a study of mentoring beginning teachers. Adapted from Glickman (2002), Davis begins with an instructive approach where the mentor controls the dialogue and offers suggestions or solutions. The approach moves to a collaborative effort where the mentor guides without controlling, and finally to a facilitative approach where the new teacher controls and directs the interactions.

John and Gilchrist (1999) used the case study approach to study a series of postlesson discussions between a cooperating teacher and a student teacher. Recordings of the conversations were chosen as the least intrusive way of collecting data. In addition to classifying the mentor's approach on a continuum of suggesting, questioning, supporting, directing, and silence, the researchers classified the student teacher's response as justification, being assured, silence, rationalizing, and anxious. They were most likely to be anxious after what they deemed a bad lesson. The mentor was responsive to the needs of the student teacher by using a lower level of questioning when the student teacher was particularly uncertain. There is a great deal of shared conversation with neither side dominating the dialogue.

In one research study, the mentoring style was described as therapeutic, modeling, or reflective. Mentors may be more therapeutic where the mentor takes on a counseling role, an apprenticeship where the mentor serves as a model, or reflective where there is a more reciprocal relationship (Orland-Barak \& Klein, 2005). Taking a psychological stance, the counseling role is adopted in an effort to reach common understanding and improve personal growth. In an apprenticeship or instructional approach, the mentor functions as a 
model of desired behaviors. In a reflective relationship, the expert and novice roles are acknowledged while encouraging reflection through questioning. In a study of twelve mentor teachers, Orland-Barack and Klein (2005) compared the "expressed" vision of mentoring through visual images with the "realized" mentoring practice through dialogues. Participants expressed value in a reflective, collaborative approach to mentoring, but their expressed approach in their dialogues was more prescriptive or instructional. Researchers suggested that the conversations were guided and influenced by local and regional standards and agendas.

Some researchers have described the mentoring style as a continuum from directive to collaborative to facilitative (Davis, 2006; Glickman, 2002; Orland-Barak \& Klein, 2005), while others have studied distinct direct and non-direct categories (Crasborn et al., 2010, 2011; John \& Gilchrist, 1999; Orland-Barak \& Klein, 2005; Williams et al., 1998). In both cases, the mentor may take a very direct or prescriptive approach or a more flexible, collaborative approach where the mentee takes more initiative in the relationship (Glickman, 2002). This role may shift over time or may change depending on the needs of the mentee (Grabis-Bunker, 1995; van Ginkel et al., 2016).

Discourse processes. Researchers have also examined the supervisory conferences between the student teacher and the university supervisor or the triad including the cooperating teacher in order to closely study the mentoring style, supervisory roles, approaches, and expectations (Fernandez \& Erbilgin, 2009; Tsui et al., 2001; Zeichner \& Liston, 1985). Zeichner and Liston (1985) studied the conferences of university supervisor with fourteen elementary student teachers in order to examine the discourses between them. They identified four different categories of discourse: factual discourse related to 
what occurred in a teaching episode, prudential discourse involving suggestions and evaluation, justificatory discourse calling on reasons behind decisions, and critical discourse addressing the adequacy of justification and the values and assumptions behind the curriculum. Findings indicated that most of the discourse fell within the factual discourse category indicating that the discourse was oriented toward describing an observation, giving information, creating meaning, and identifying causal relationships such as why an event occurred. In an examination of the conceptual levels of complexity, self-responsibility, and independence (Hunt, 1977), the researchers determined that the student teacher may have a stronger influence over determining the level of discourse than the supervisor.

Tsui, Lopez-Real, Law, Tang, and Shum (2001) collected data from six supervisory conferences between student teachers, cooperating teachers, and university supervisors in Hong Kong. The speech functions of the conversations fit into three primary categories: (a) eliciting reflections or evaluations; (b) offering observations, evaluations, or suggestions; and (c) managing the conversation by acknowledging a contribution, agreeing, or giving confirmation. Similarly, Fernandez and Erbilgin (2009) found that the supervisors elicited through questioning and offered suggestions and assessments. Within the broad categories of eliciting and offering, the supervisor may reflect, analyze, or evaluate the teaching episode. Zeichner and Liston (1985) call this prudential discourse. When the participants describe the events of the lesson, Zeichner and Liston (1985) call this factual discourse, and when the supervisor elicits or offers explanation the authors categorize this as justificatory discourse. Prudential discourse would relate to the psychological aspects of mentoring including offering support. 
Changes over time. The mentoring style of the cooperating teacher may change from a directive style to a more non-directive style over the course of the semester (Bullough, 2005; Grabis-Bunker, 1995). This change may be in response to the individual learning needs of their student teacher (Bullough, 2005; van Ginkel et al., 2016). In a music classroom this change may also be influenced by performances or multiple student teaching placements (Draves, 2008a). Though these changes have been studied, researchers have not examined the changes evident in mentoring dialogues, especially within the context of a music classroom.

In a multiple case study of three pairs of elementary cooperating teachers and student teachers, Grabis-Bunker (1995) studied the changes in the relationships that took place over a twelve-week period. The researcher identified five stages occurring over the course of the student teaching semester. The pairs begin in the teacher-student stage where each assumes their assigned, familiar roles with the student teacher observing and helping. Soon, they progress to a supervising teacher and learner stage where the cooperating teacher assigns lesson plans and responsibilities and checks them to be sure that their students are receiving quality instruction. The cooperating teacher gives feedback, but this may vary according to the student teacher's response. The student teacher begins to take on more responsibility, reaching the junior teacher and senior teacher stage. At this point, the student teacher has taken over at least half of the teaching responsibilities and they are given more freedom. The cooperating teacher takes less of an evaluative role and treats the student teacher as a colleague. Feedback takes the form of helpful hints or alternative ideas. Efforts may change over time and move from more directive mentoring to a more responsive mode of assistance. The student teacher's 
conception of themselves as a teacher as well as their response to criticism will impact the relationship between the mentee/mentor relationship. At times, the mentor must make themselves vulnerable and change their approach in order to meet the needs of the mentee. When the student teacher takes control of the entire day, the cooperating teacher has moved to the off-duty teacher and visiting teacher stage. At this point there is little interaction between the two because the cooperating leaves the student teacher alone to take control of the classroom. The student teacher gains confidence and reflects on their teaching independently. During this time the cooperating teacher may also complete their student teacher's final evaluation. Finally, the cooperating teacher returns to the classroom to take over teaching responsibilities before the end of the student teaching semester. When they discuss the students, the student teacher now guides the cooperating teacher on what the students have learned. The changes in the stages of the relationship contribute to the changes in the cooperating teachers approach with the student teacher.

Adaptive mentoring. Van Ginkel, Oolbekkink, Meijer, \& Verloop (2016) examined the manner in which cooperating teachers adapt to the individual mentee. The authors make a distinction between a developmental mentoring conception in which mentors maintain a dual focus on mentee professional development and student considerations (Feiman-Nemser, 2001b) and an instrumental conception where the mentors are primarily concerned with effective teaching practice (Orland-Barak \& Klein, 2005). Interviews were conducted with 18 mentor teachers selected to represent each orientation. The interviews were conducted in response to an observed post-lesson conference in order to gather the mentor's intention behind specific actions during the conference. The mentors identified four activities that involved adapting to the mentee's needs and how novice teachers learn. 
They were attuned to the emotional state of the mentee, adapted to the novice teacher's capacity for reflection, built tasks from simple to complex according to the mentee's competence level, and aligned mentoring to meet the mentee's expectations. Highly adaptive mentors were attuned to the emotional or cognitive needs of their mentees and encouraged the novice teachers to reflect on their own practice.

In a qualitative study of the relationship between the supervisor of the internship program for a Master's in teaching certification program, Estabrook and Goldsberry (1995) chronicled the supervision practices and the relationship with the interns over the course of the year-long internship. The interns took over full teaching responsibility during the final six weeks. The authors found that the strategies for mentoring the interns varied according to the intern's characteristics, the lesson requirements, the class context, and the intern's response. They attempted to encourage a cooperative approach during conferences by allowing the intern to retell the teaching experience, questioning, and modeling effective teaching practices and self-assessment techniques.

The extent to which the cooperating teacher responds to and adapt to the changing needs may be evident in the conversations between the cooperating teacher and the student teacher. They may reconceptualize their approach to mentoring over time (Bullough, 2005; Crasborn et al., 2008). The cooperating teacher may also adjust their style according to the changing needs of the student teacher or the students in their classroom (Achinstein \& Athanases, 2006; Helman, 2006; van Ginkel et al., 2016).

Mentor teacher input. Some researchers have also examined who takes the initiative to introduce topics of conversation during mentoring dialogues (Hennissen et al., 2008). The mentor may be more active, introducing topics, or reactive, responding to the 
student teacher (Hennissen et al., 2008). In a content analysis of a school-based teacher education program, Haggarty (1995) found that in most cases the mentor is the initiator and in some cases the mentor dominated the conversation with their own ideas, experiences, or concerns. Similarly, in a comparison between mentor/novice teacher pairs in the U.S. and China, Wang, Strong, and Odell (2004) found that the mentor initiated the topics of conversation and the agenda for the conversation, especially in the cases of the Chinese mentors.

Feiman-Nemser, Parker, and Zeichner (1992) studied the influence of mentor training on their practice by examining three mentoring cases of secondary English teachers. Mentor training focused on giving them research-based knowledge about teaching and learning that could be passed on to mentees during face-to-face classroom conversations. The mentors were taught coaching skills such as active listening, feedback through eliciting feelings and specific praise, opening questions, and focusing or probing questions. The mentor was encouraged to manage the conference by setting the agenda, directing the conversation, and providing information. The mentors were encouraged to control the conversation and input most of the information and topics. The authors found it problematic that the program de-valued the mentor's ideas about teaching and learning and encouraged them to follow the procedures of the program.

Haggarty (1995) used content analysis to study a mathematics teacher education program in which the preservice teachers worked in a school in partnership with their university supervisor and cooperating teacher. Five different cooperating teachers from different secondary schools were studied. Five dimensions of mentoring dialogues were used for coding including the initiator of the conversation, the source of information, 
participation or contribution of ideas, criteria for evaluation, and judgments made by someone or about something. In most cases it was found that the cooperating teacher initiated the conversation and dominated the conversation, though this varied by teacher. For some, the conversation was focused on the cooperating teacher's experiences and ideas and some students allowed the mentor to dominate the conversation.

Wang, Strong, and Odell (2004) compared the mentor-novice teacher conversations of two cases from the United States and two cases from China. All four of the mentees were first year elementary teachers. All four of the mentors were experienced teachers and observed their mentees frequently. Though the exact requirement varied by teaching context, each mentor provided regular feedback for their mentees. In the U.S. context, the mentors came to the reflective conference with a focus and guiding questions in mind, but there was freedom for an open conversation. Most conversations followed a similar pattern of beginning with a question, describing the lesson, or offering a compliment. In the Chinese setting they also conducted post-lesson conferences in which the mentor would critique and make suggestions. In comparison, initiation of topics was evenly split between the mentor and the mentee in the U.S. pairs, while the Chinese mentors introduced topics $80 \%$ of the time, therefore dominating the conversations.

In addition to examining the speech functions during supervisory conferences, Tsui, Lopez-Real, Law, Tang, and Shum (2001) studied the dynamics of the conference discourse. The researchers identified four dimensions based on who talked the most, who elicited the most, who steered the direction of the conference by initiating conference change, and the juncture and manner in which participants made contributions. In most cases, the university supervisor controlled the conversation, talking and eliciting information most 
often. The university supervisor also steered the direction of the conferences, sometimes strategically to include the cooperating teacher. In a conference between a cooperating teacher and a student teacher a shift in who steers the direction of the conversation may indicate a shift in mentoring style.

Time aspects. Researchers have also focused on time aspects related to mentoring dialogues (Hennissen et al., 2008). The duration of the dialogues have been studied along with the amount of talking time attributed to each party (Ben-Peretz \& Rumney, 1991; Dunne \& Bennett, 1997; Hawkey, 1998a). Two of the studies reviewed focused on postlesson conferences and these tended to be shorter, while Hawkey (1998a) focused on longer weekly dialogues. In the shorter post-lesson conferences the cooperating teacher spent more time talking and directing the conversation (Ben-Peretz \& Rumney, 1991; Dunne \& Bennett, 1997). Hawkey (1998a) also observed direct mentors talking more during dialogues while more indirect mentors talked for approximately half of the dialogue.

Ben-Peretz \& Rumney (1991) observed 31 cooperating teacher/mentee conferences from six different teacher education programs with varying requirements regarding field experience. In addition to observing conferences, questionnaires were administered, lessons were observed, and interviews were conducted. The observed conferences tended to last approximately 10-20 minutes. The majority of the conferences observed involved an authoritative approach by the cooperating teacher, resulting in the student teacher being very passive and the cooperating teacher spending more time talking. In $93 \%$ of conferences they made evaluative statements regarding teaching strategies. In only $26 \%$ of the conferences did a student teacher offer any alternative ways of teaching. 
Dunne and Bennett (1997) examined four student teacher-cooperating teacheruniversity supervisor triads from four schools in Great Britain. The four student teachers all came from the same university which provided a model of mentoring centered around broad dimensions of teaching such as direct instruction and guided practice, management, monitoring progress, classroom ambience, planning and preparation, and written evaluation. The progress and development of the student teachers were guided by these dimensions. Dialogues, or conferences with the classroom teacher were held regularly, lasted approximately 10-20 minutes, and were based on teaching observations. During dialogues with the cooperating, or class teachers the majority of talk time was attributed to the class teacher. University supervisor conferences tended to be more balanced between the supervisor and the student teacher.

Phases of the dialogue. Though not always explicitly addressed as a separate issue, some researchers have mentioned phases of the dialogue, or the overall structure of the conversation (Hennissen et al., 2008). Mentors commonly begin the conversation with a compliment, followed by a summary of the lesson, some critical comments or questions, and finish with suggestions for improvement (Feiman-Nemser et al., 1992; Wang et al., 2004). Ben-Peretz and Rumney (1991) noticed more time was spent by the mentor giving direct feedback and directions for future lessons. Some mentors may spend more time reflecting upon the teaching episode while others may spend more time looking forward to future lessons (Hennissen et al., 2008).

Evertson and Smithey (2000) compared mentors of new teachers who had participated in a formal mentoring program with experienced teacher mentors who had never experienced formal training. Based on Feiman-Nemser, Zeichner, and Parker's 
(1992) idea that mentor teachers are teacher educators, the goal of the mentor training was to move from providing emotional support to helping new teachers reflect through dialogues. During training, the mentors studied the balance between telling the new teacher information and guiding them to reflect and construct their own knowledge. Mentors who had been trained spent more time guiding than evaluating and also asked more reflective questions of their mentees. They were able to assist their mentees in reconstructing lessons and make connections to prior dialogues.

Aiming to examine the impact of mentoring on reflective practice strategies, Harrison, Lawson, and Wortley (2005) worked with 30 mentors who were introduced to a variety of mentoring strategies through training workshops. The strategies included encouraging critical thinking, experiential learning through questioning of an event, action research through observation and reflection, description of a critical incident, and telling a story of an incident. All strategies were intended to encourage reflective practice. By using the reflective strategies, the mentors were able to help their mentees to analyze their teaching practice and think of new ways to improve their practice. As a result, the new teachers were better equipped to both deconstruct their teaching and construct new approaches.

Through their dialogues, cooperating teachers may encourage the student teacher to be reflective, while also focusing on larger teacher development goals (Feiman-Nemser, 2001b). The mentoring style may vary from a more directive stance to a non-directive, facilitative stance (Hawkey, 1998b; Hennissen et al., 2008; Timperley, 2001). The input and the balance of talking time between the participants of the dialogue may shift according to mentor style as some may spend more time directing or giving suggestions, 
while others may spend more time listening, questioning, and guiding (Evertson \& Smithey, 2000; Feiman-Nemser et al., 1992; Hennissen et al., 2008). While the focus of previous research related to mentoring dialogues has involved teachers in other content areas or participants in mentor training (Crasborn, et al., 2010; Harrison, et al., 2005), the mentoring role assumed by music cooperating teachers during mentoring dialogues has not been studied.

\section{Stimulated Recall}

Stimulated recall is a research procedure used to investigate cognitive processes by inviting participants to recall their thinking during an event when prompted by the video of the event (Lyle, 2010). By viewing a video of an event, the participant may more accurately recall their intentions than they would without the aid of a video recording (Ericsson \& Simon, 1999). The use of stimulated recall shows great potential for educational research for analyzing teacher behavior, learning strategies, and mentor behavior (Lyle, 2010). Various educational studies have used stimulated recall as a technique for gathering verbal data. Crasborn, Hennissen, Brouwer, Korthagen, and Bergen (2010) weighed the advantages and disadvantages of the stimulated recall technique to study mentoring dialogues. As opposed to free recall of an event, the use of the video as a stimulus can allow for a more accurate, complete and timely recollection as they are more likely to recall reflective moments throughout the dialogue. Alternatively, as the video is shown after the event, the collection of data occurs retrospectively instead of during the moment. Therefore, these authors used stimulated recall as well as a push button approach in which the participants pushed a button whenever they saw a reflective moment on the video. Using video stimulated recall with student teachers, Kelting, Jenkins, and Gaudreault 
(2014) found that watching the videos allowed the participants to notice more about themselves and the students than they otherwise would have. Bertone, Chaliès, Clarke, \& Méard (2006) used stimulated recall with physical education cooperating teachers and student teachers in order to analyze their mentoring dialogues. The researcher and the cooperating teacher viewed the videos together and paused it whenever an event occurred that seemed important. The researcher asked questions concerning their intentions, what was on their mind at the time, or what they wanted the student teacher to say. Mena, García, Clarke, and Barkatsas (2015) used stimulated recall as a tool for analyzing mentoring dialogues by allowing the student teachers to view a teaching episode and reflect on it with their mentors. They found the technique to be more precise than other approaches, as the students were allowed to pinpoint specific events during their teaching to reflect upon.

In music education, Powell (2011) used stimulated recall with preservice teachers in order to examine peer teaching and field teaching videos. Instead of asking specific questions, participants were asked to watch a video of their teaching and pause it whenever they wanted to reflect upon an event in the teaching episode. Miksza and Austin (2010) also used a stimulated recall technique in a study examining the reflections of high school students enrolled in a pre-collegiate recruitment program. Participants were asked to pause the video when they saw something that helped them recall the teaching experience. Follow-up questions were used to extend their responses and reflection. Berg, Woody, and Bauer (2002) also used a stimulated recall technique where preservice music teachers watched video-taped excerpts of music teaching episodes. Following each 45- 
second segment they were prompted to respond to a prompt about their thoughts during each video-clip. 


\section{CHAPTER III}

\section{Method}

Qualitative research takes a naturalistic approach to understanding the multifaceted nature of reality through the eyes of the participants (Miles \& Huberman, 1994). Through analysis of words and artifacts, the researcher takes a holistic view of the context and organizes the data into segments and themes. Stake (1995) has defined a case study as "the study of the particularity and complexity of a single case, coming to understand its activity within important circumstances" (p. xi). Case study research is prevalent in educational settings due to the unique and multifaceted nature of schools, teaching, and learning. With the researcher as the primary instrument of data collection, such studies tend to draw upon multiple data sources such as interview transcripts, field notes, and artifacts (Merriam, 2009).

Merriam (2009) has described the most defining feature of case study research as the delimitations, or boundaries of the case. By defining the boundaries of a case, we can limit, or "fence in" exactly what we are to study. A case may be a person or persons, place, or phenomenon and can be bounded by time, setting, or group. Miles and Huberman (1994) depict it as a circle drawn around the case so one studies only that which lies within the circle. This case was bounded by the setting (middle, or high school) and instructional focus (instrumental band and orchestra). This multiple case study was also bounded by time, as data was collected during the second half of the student teaching semester over a period of eight weeks.

Case studies "allow us to fill in more robust and integrated knowledge about areas of inquiry that need further explication and explanation, such as those aspects of music 
teaching and learning that are especially complex and intertwined" (Barrett, 2014, p. 130). As the mentoring dialogues between a music cooperating teacher and a student teacher can be complex and greatly impact the development of a preservice teacher, in this case study, I aim to contribute to the knowledge base on mentoring music student teachers by using a case study approach in which several data sources were used to describe the setting, subjects, and events in detail (Bogdan \& Biklen, 1998; Stake, 1995).

In this chapter I will provide a description of the multiple case study approach, a description of the participant sampling strategies used, a description of the participants and context, and an overview of data collection procedures. Also, data analysis strategies and efforts to establish the trustworthiness of the study will be provided, as well as a description of my background, role and assumptions as the researcher.

\section{Multiple Case Study}

Also referred to as collective case studies, cross-case, multicase, multi-site, or comparative case studies (Merriam, 2009), Bogdan and Biklen (1998) define a multiple case study as an examination of two or more subjects, settings, or depositories of data. Some have a single focus case, drawing on additional cases to increase generalizability, while others focus equally on multiple cases. By studying multiple cases in order to understand a particular issue, the researcher may maximize what they can learn, adding variation to the interpretation (Merriam, 2009). Multiple cases may increase generalizability, though caution should still be exercised with a small number of cases (Stake, 1995).

One common criticism of case study research is the issue of generalizability due to the small number of participants (Barrett, 2014; Flyvbjerg, 2011). Yin (2012) refers to the 
concept of analytical generalizability, which uses a theoretical framework to establish that one case may be generalizable to others. Generalizability in qualitative research may also be related to the concept of transferability, where generalizations can be made between similar cases (Onwuegbuzie \& Leech, 2010). This can be accomplished through thick description of the case and contexts so that the reader may relate the findings to similar cases (Barrett, 2014).

In multiple case study research, the individual case is of interest because of its connection to other cases sharing common characteristics (Stake, 2006). Therefore, analysis involves studying each individual case as well as making comparisons across the cases. In studying each individual case, the researcher develops "a well-grounded sense of local reality" based on the characteristics of the individual case (Miles, Huberman, \& Saldana, 2014, p. 101). Through cross-case analysis the researcher can increase transferability by ensuring that the findings are not confined to a single case. Additionally, cross-case analysis can deepen understanding and explanation (Miles et al., 2014). Negative case analysis may strengthen the findings by finding similarities and differences between the different cases.

\section{Participants and Teaching Contexts}

Sampling strategies. Stake (1995) recommends looking for cases that are interesting and accessible with characteristics that can be compared, although some variability is expected. This study will focus equally on four cooperating teachers who taught in different schools, although the instructional setting (Instrumental band or orchestra) was similar. Several sampling strategies were used to select the participants for this study. First, convenience sampling was used as all potential cooperating teachers were 
contracted to mentor a student teacher from the same university, which allowed for quicker access to potential cases given the researcher's affiliation with the university. Sampling then occurred in two phases. First, a stratified purposeful sampling strategy (Patton, 1990) was used to categorize 12 potential cases based on teaching level (middle and high school) and instructional focus. Secondary instrumental settings were chosen in order to focus on the role of the cooperating teacher within similar teaching contexts. Then, a criterion sampling strategy (Patton, 1990) was employed to select four cases for this study. The criterion used for selection was experience as an instrumental music teacher, school district permission availability, and willingness of the cooperating teacher and student teacher to participate in the study. Two area school districts granted permission to conduct research with teachers and student teachers, and so participation was limited to those districts. From the original pool of 12 potential cases, four cooperating teacher/student teacher pairs were selected representing secondary instrumental music teachers from the two available school districts.

The two school districts in which the cooperating teachers taught were near a medium-sized public university in the Rocky Mountain region. Mountain Valley School District, the district in which Adam and Isabelle taught, houses over 30 elementary schools, 19 middle schools, and 13 high schools, educating a diverse student body of over 30,000 students. Due to its close proximity to the university, teachers in this district are often called upon to host student teachers as well as mentor earlier field experiences in cooperation with music education faculty. Adam taught at Orion High School and Isabelle taught at Grapevine Middle School. River Valley School District, in which Bob and Joanna taught, is the seventh largest district in the state serving over 32,000 students in thirteen 
diverse communities. There are fifty-five schools including traditional elementary, middle, and high schools as well as K-8 schools, early learning center, alternative high school, online school, and charter schools. Bob taught at Blue River High School and Joanna taught at Elwood Middle School.

Permission to meet with and interview teachers outside of class time was requested via email and granted by two nearby school districts (see Appendix A). I submitted an Institutional Review Board (IRB) protocol, receiving approval on February 20, 2017 (see Appendix B).

Establishing rapport. Once school district and IRB permission was granted and four potential cooperating teacher participants were identified, initial contact was made via email. I then visited each teacher at their school or called them to explain the details of the study and to gain verbal consent to participate. Following the first interview each participant was asked to sign the informed consent document (see Appendix C). In order to protect all personally identifying information, pseudonyms have been used for all participants, schools, and school districts.

As I had never met any of the cooperating teachers prior to these visits, I had to establish rapport with each of them so that they might develop a sense of trust (Spradley, 1979). Rapport was established over time, with each of them seeming to grow more comfortable with each visit, as they were more willing to talk and share details about their experiences. I also established rapport by buying them lunch, coffee, or tea each time we met for an interview. Once the cooperating teachers agreed to participate in the study, contact was made with the student teachers and all agreed to participate. I already had some prior history with the student teachers, having been their course instructor during 
the previous semester. Since this course included a field teaching component at their student teaching sites, we were able to refer to previous discussions from the course during interviews for this research, which contributed to the conversational tone of the interviews (Seidman, 2006).

Cooperating teacher participants. The table below includes information on the school setting, instructional focus, years of teaching experience, and gender for each cooperating teacher.

Table 1: Cooperating Teacher Participants

\begin{tabular}{|l|l|l|l|l|}
\hline Pseudonym & School & $\begin{array}{l}\text { Instructional } \\
\text { Focus }\end{array}$ & $\begin{array}{l}\text { Teaching } \\
\text { Experience }\end{array}$ & Gender \\
\hline Adam & $\begin{array}{l}\text { Orion High } \\
\text { School }\end{array}$ & Band & 15 yrs. & Male \\
\hline Bob & $\begin{array}{l}\text { Blue River } \\
\text { High School }\end{array}$ & Band & 11 yrs. & Male \\
\hline Isabelle & $\begin{array}{l}\text { Grapevine } \\
\text { Middle School }\end{array}$ & Band & 10 yrs. & Female \\
\hline Joanna & $\begin{array}{l}\text { Elwood Middle } \\
\text { School }\end{array}$ & Orchestra & 20 yrs. & Female \\
\hline
\end{tabular}

Adam. Adam is a medium stature male with light brown hair. He is an experienced teacher at Orion High School in Mountain Valley School District. Adam has been teaching instrumental music at Orion for nine years and fifteen years overall. Adam attended Orion as a student before earning his bachelor's degree in music education from the university where his student teacher attends. Prior to teaching at Orion, he taught elementary general music as well as middle school and high school band, choir, and orchestra in three other school districts around the state before returning to his alma mater. In other positions he struggled with longer commutes and issues of work/life balance when his daughters were 
younger. Now that his daughters are older, they both attend Orion and the family lives minutes away from the school.

To this point, Adam had hosted at least 12-15 student teachers in addition to several practicum students completing field-based teaching experiences linked to methods courses. In the past two years he had hosted 3-4 student teachers in one academic year. All but one of his student teachers had been from the nearby university. Given his location and connection to the university, he felt a sense of duty to the profession of music education to provide preservice teachers with valuable teaching experience.

Located less than ten miles away from the university, Orion High School was a diverse suburban high school enrolling over 1,000 students in grades 9-12 and offering programs in engineering, International Baccalaureate (IB), and Advanced Placement. The building was a large brown building with few windows, located in a bustling suburban area. The main entrance was set back from the road near a large parking lot for students, staff, and visitors. Near the main entrance there was a small mural painted on the wall picturing mountains surrounded by international flags and the slogan "unity in diversity." The band program was well-known for its marching band, and drumline equipment could be seen stacked in the corner. In addition to marching band, Adam taught two concert bands, jazz band, IB music, and assisted with eighth grade band at Grapevine Middle School which was located across the street from Orion High School. 
Table 2: Adam's Teaching Schedule

\begin{tabular}{|l|l|}
\hline $1^{\text {st }}$ period & Jazz Band \\
\hline $2^{\text {nd }}$ period & Wind Symphony \\
\hline $3^{\text {rd }}$ period & Symphonic Band \\
\hline $4^{\text {th }}$ period & $8^{\text {th }}$ grade band @ Grapevine \\
\hline $5^{\text {th }}$ period & Lunch/Prep \\
\hline $6^{\text {th }}$ period & IB music \\
\hline
\end{tabular}

Isabelle. Isabelle was a petite female with long, straight brown hair. She served as the band director at Grapevine Middle School, located across the street from Orion. She had worked in cooperation with Adam, assisting with the percussion ensemble, and Adam assisted with the eighth-grade band at Grapevine. In addition to her $6^{\text {th }}, 7^{\text {th }}$, and $8^{\text {th }}$ grade bands at Grapevine and assisting with percussion ensemble at Orion, Isabelle taught fifth grade bands at five different area elementary schools.

Her primary school was Grapevine and she had been teaching there for six years. Before that she spent a year in the same district teaching elementary general music and fifth grade band. Prior to moving to the area, she taught for three years in a southwest state teaching middle school band and orchestra. In the past six years, she had hosted six student teachers in addition to several students completing field experiences linked to methods courses. Most student teachers who chose to student teach with either Isabelle or Adam had their second placement with the other teacher. As the two teachers work closely together, they preferred to share student teachers which they believed adds some 
consistency for the student teachers as well as their students over the course of the student teaching semester.

Located across the street from Orion High School, Grapevine Middle School served a culturally and economically diverse population of over 600 students in grade six through eight. The building was a large, red brick building with a green roof. The building was set back from the main road, with the main entrance near the back next to the long parking lot that runs the length of the school. Bike racks were loaded with bikes near the door and the hallways were often bustling with students during lunch or passing periods when I came to meet with Isabelle. The band room was located down the hall from the cafeteria between the choir room and the orchestra room. Isabelle's lunch and/or prep period varied by day depending on which elementary schools she visited in the afternoon.

Table 3: Isabelle's Teaching Schedule

\begin{tabular}{|l|l|}
\hline Before school & Assist at Orion High School \\
\hline Period 1 & $6^{\text {th }}$ grade band \\
\hline Period 2 & $8^{\text {th }}$ grade band \\
\hline Period 3 & $7^{\text {th }}$ grade band \\
\hline Lunch/Prep & Lunch/Prep \\
\hline Afternoon & $1-2$ elementary bands \\
\hline
\end{tabular}

Bob. Bob was in his third year as the director of bands at Blue River High School in River Valley School District. Bob was a tall, medium stature male with short dark hair. He has a very relaxed demeanor with his casual dress and welcoming attitude. He lived close to the school with his wife and four children, one of whom attended Elwood Middle School, which was a feeder middle school. Originally from the Northwest region of the country, 
Bob had student taught at the high school he attended in a smaller-sized town. His cooperating teacher had been very well-known in the state and had taught at the school for thirty-two years when Bob came to student teach with him. When he retired, Bob became his successor in the position. During the eight years he held that position, Bob taught a variety of instrumental and choral ensembles as well as the after-school theater program. During those years he also earned a Master's degree in music education from a hybrid online/summer program. He moved to the area when his wife decided to pursue a Master's degree. He was in his third year teaching at Blue River High School. While he is an experienced teacher, Charles was his first student teacher. He has had one university student as an observer previously, and he expected to host more student teachers in the future.

Blue River High School was located within a mile of Elwood Middle School. The immediate area surrounding the school appeared to be mostly rural farmland with a boarded-up farmhouse and barn across the street from the large modern high school. Next to the school parking lot was a development of newer townhouses. There were other newer housing developments in the area as well as the headquarters for a large technology company a couple miles away. The school enrolled approximately 1,200 students in grades 9-12. There was a very active performing arts department, including band, orchestra, choir, and theater. At Blue River, Bob taught five instrumental ensembles including concert and symphonic band, beginning and advanced jazz band, and a percussion ensemble. Additionally, he taught an elective course entitled The History of Rock. During the data collection period he was also serving as the music director for Blue River's musical production. 
Table 4: Bob's Teaching Schedule

\begin{tabular}{|l|l|}
\hline A Day & B Day \\
\hline Marching Band & Concert Band \\
\hline Prep & Prep \\
\hline History of Rock & Beginning Jazz Band \\
\hline Advanced Jazz Band & Percussion Class \\
\hline
\end{tabular}

Joanna. Joanna was a medium stature female with shoulder-length brown hair. She had three school-age children who attended nearby schools. She had been teaching middle school orchestra at Elwood Middle School for nine years. Prior to Elwood, she taught in two other area school districts, spending three years teaching elementary general music and two years teaching middle school orchestra. In her current district she taught middle school and high school orchestra before coming to Elwood Middle School. During that time she took two years off of teaching while she earned her Master's degree from the same university where her student teacher attends. Most of the eight or nine past student teachers she had hosted have attended the same university.

Elwood Middle School was a large suburban middle school in River Valley School District educating over 800 students in grades 6-8. The school was one of the middle schools that feeds into Blue River High School, where Bob taught. The building was a large two-story orange brick building located next door to an elementary school. The surrounding area was a sprawling suburban area where newer subdivisions were located near rural farmland. In the nine years that Joanna had been at the school she had seen the student population grow from 500 students to 800 students. Orchestra was one part of a 
flourishing performing arts department also including band and choral ensembles with full time directors for each as well as part-time assistants. Joanna directed six orchestra ensembles and a grade 6-8 combined pops orchestra. Her weekly teaching schedule appears in table 5.

Table 5: Joanna's Teaching Schedule

\begin{tabular}{|l|l|}
\hline A Day & B Day \\
\hline $7^{\text {th }}$ grade orchestra & $7^{\text {th }}$ grade orchestra \\
\hline $8^{\text {th }}$ grade orchestra & Prep \\
\hline Pops orchestra & Pops orchestra \\
\hline Lunch & Lunch \\
\hline $6^{\text {th }}$ grade orchestra & $6^{\text {th }}$ grade orchestra \\
\hline Prep & Prep \\
\hline
\end{tabular}

Student Teacher Participants. After obtaining verbal consent to participate from the four cooperating teachers, I contacted each student teacher to ask if they would be willing to participate in the study. An overview of the study was given and the time commitment required was explained. All four student teachers provided verbal consent to participate, followed by written informed consent (see Appendix C). Information pertaining to the student teacher participants appears in table 6 . 
Table 6: Student Teacher Participants

\begin{tabular}{|l|l|l|l|}
\hline Name & School & Instructional Focus & Gender \\
\hline Ellen & Elwood Middle School & Orchestra & Female \\
\hline Tyler & Grapevine Middle School & Band & Male \\
\hline Samantha & Orion High School & Band & Female \\
\hline Charles & Blue River High School & Band & Male \\
\hline
\end{tabular}

Ellen. Ellen was completing her middle school orchestra placement with Joanna at Elwood Middle School. She had shoulder length curly brown hair, shorter stature, and a reserved personality. Joanna described her as quiet, though she was more comfortable talking one on one. Primarily a viola player, Ellen completed her first student teaching placement in a high school orchestra program very close to the university in Mountain Valley School District. Not only did she compare and contrast the two different levels, but also the two different cooperating teachers. Her first cooperating teacher took a very different approach than Joanna, so Ellen became accustomed to being interrupted while teaching and trying to adapt her teaching to the cooperating teacher's methods of instruction.

Tyler. Tyler was completing his middle school band placement with Isabelle at Grapevine Middle School. Despite the fact that most of Isabelle's student teachers also student taught at Orion, Adam was only able to take on one student teacher this semester. Therefore, Tyler completed his high school band placement at another high school in a nearby school district. Tyler, whose primary instrument was trumpet, was tall and thin with a very reserved personality. His quiet, calm demeanor contrasted with Isabelle's more 
outgoing personality. Due to Isabelle accompanying the Orion band on a trip to Boston, Tyler was trusted with assuming the role of lead teacher for all of her classes two weeks into his placement.

Samantha. Samantha also completed her middle school placement with Isabelle during the first half of the semester. Samantha, blonde-haired and short in stature, was a very capable student teacher who seemed to step comfortably into the routine at Orion.

She had met Adam previously when his daughter participated in a middle school ensemble program sponsored by the university, but mentioned feeling "intimidated" by him until she got to know him better. As a flute player, Adam appreciated her expertise with the woodwind sections.

Charles. Charles completed his second student teaching placement at Blue River High School with Bob. Shorter in stature with shaggy blonde hair, Charles was an accomplished trumpet player with a quiet personality. He described himself as being very laid back, similar to Bob. In prior music education coursework, Charles had been a belowaverage to average student. Near the beginning of his student teaching semester, he had begun to realize that he had lost his motivation to teach music. Following repeated observations and interventions from the University Supervisor, it was determined that Charles would not complete his student teaching semester and therefore would not earn a K-12 music teaching license. This unique situation impacted the relationship and mentoring dialogues between Bob and Charles throughout the eight-week placement.

Student teaching placements and preparation. The students in this music education program are given some degree of choice in the selection of their cooperating teachers. Through a joint selection process, the students are tasked with approaching 
potential cooperating teachers, observing in their classroom, and asking them about the potential for them to serve as their cooperating teacher. Some students will return to classrooms where they have had prior field experiences, while others will consult their faculty advisor for advice on other potential student teaching sites. All student choices have to be approved by the music education faculty before the student teaching application is submitted to the School of Education. Since all students are required to work with elementary and secondary-aged students during the student teaching semester, most have two student teaching placements with each placement lasting eight weeks. All four of the student teacher participants had completed their first eight week placement in another instrumental setting. During this placement they completed a high stakes external assessment of teaching practice called the edTPA which included unit plans, teaching videos, assessments linked to the unit plans, and self-reflection (Stanford Center for Assessment Learning and Equity, 2016).

Prior to the student teaching semester, all music education students are enrolled in a class entitled Introduction to Student Teaching. In addition to topics related to professionalism, job search, classroom management, and edTPA preparation, there is a practicum component. Each student spends 25 hours at each of their student teaching sites working with their cooperating teacher and their students.

\section{Data Collection}

Various data collection strategies were used including interviews, video-recorded mentoring dialogues, and stimulated recall interviews with cooperating teachers based on the video recordings. The primary data source for this study was interviews with each of the cooperating teacher participants. Four semi-structured interviews were completed 
with each cooperating teacher. Each interview followed an interview guide that was similar for each teacher and lasted approximately 45 to 90 minutes (see Appendix D). The first interview focused on the cooperating teacher's background and experience mentoring preservice music teachers as well as their usual format for mentoring dialogues. The third interview focused on their perception of their role as a cooperating teacher.

Video-recordings of weekly mentoring dialogues between cooperating teachers and student teachers served as a secondary data source. As the researcher, I tried to leave the length of the scheduled mentoring dialogue flexible, recommending the conversation last between 10-30 minutes. Using a stimulated recall technique, during the $2^{\text {nd }}$ and $4^{\text {th }}$ interviews the teachers watched a video of a mentoring dialogue and commented on the conversation as they watched the video (see Appendix E) (Hennissen et al., 2010). Excerpts from one interview with each cooperating teacher participant can be seen in Appendix F.

The student teachers were each interviewed twice. The first interview with the student teacher was completed near the beginning of their student teaching placement and focused on their perception of the role of the cooperating teacher. The second student teacher interview took place near the end of the placement and focused on their relationship over the course of the eight-week placement. Interview guides for the two student teacher interviews can be found in Appendix G. The interviews with the student teachers lasted between 30-45 minutes.

Stimulated recall technique. An advantage of using stimulated recall is that viewing a video of an event can help the mentor teacher to recollect the reflective moments in the dialogue more clearly than direct questions about the event (Crasborn et al., 2010). 
Rowe (2009) also found that the technique gave some control to the participants by allowing them to identify salient moments in the video and raise their own ideas or concerns. Disadvantages of the technique are related to asking teachers to recall reflective moments afterwards instead of in the moment (Crasborn et al., 2010). Lyle (2010) also questioned whether the cooperating teacher may change or adjust their recollection of the moment as they view the video.

Therefore, the stimulated recall interview should be conducted relatively soon after the recorded episode. When the time between the recorded event and the stimulated recall interview is brief, the participant can access their short term memory in order to recall the events more accurately. They may be able to retrieve cognitive process from the long term memory of the event as a result of viewing the video (Ericsson \& Simon, 1999). Viewing the video may allow them to further reflect on the original event and allow them to elaborate on the reasoning behind their actions (Lyle, 2010).

In this study, cooperating teachers were asked to video record weekly mentoring dialogues throughout the eight-week student teaching experience. For each cooperating teacher-student teacher pair, two of the cooperating teacher-student teacher dialogue videos were transcribed verbatim and used for the stimulated recall interviews. The primary reason behind choosing a particular video was the timing of the scheduled interview. Every effort was made to hold the stimulated recall interview relatively soon after the recording was made. Stimulated recall interviews occurred at about the halfway point in the student teaching placement (week 3 or 4) and near the end of the placement (week 7 or 8). The timing of the stimulated recall interviews allowed the researcher to compare the interviews for changes in the mentoring role adopted during the dialogues. 
During the stimulated recall episodes, the participant and I watched the video of their mentoring dialogue on my laptop. An audio recorder was used to record both the audio from the video and our conversation. The cooperating teachers were asked to both explain the content of the recorded mentoring dialogue as well as provide an explanation of their thoughts, ideas, or motives. More specifically, either the participant or the researcher paused the video whenever something significant or interesting occurred. The researcher paused and asked questions such as "what were you thinking?" or "why did you say that?" or "how did you think the student teacher would respond?" (Margaret H Berg et al., 2002; Bertone et al., 2006). This required them to link their current thoughts to the earlier thoughts and processes during the mentoring dialogue as well as their opinions about their mentoring approach (Ericsson \& Simon, 1999).

Data collection schedule. Table 7 shows a schedule for data collection. Interviews with each cooperating teacher and student teacher were conducted individually and were scheduled based on participant availability either after school or during their lunch hour.

Table 7: Data Collection Schedule

\begin{tabular}{|l|l|}
\hline Interview & Week \\
\hline Student Teacher Interviews - 1 & Weeks 1-2 \\
\hline Cooperating Teacher Interviews - 1 & Weeks 1-2 \\
\hline Cooperating Teacher Interviews - 2 (SR) & Weeks 3-4 \\
\hline Cooperating Teacher Interviews - 3 & Weeks 5-6 \\
\hline Cooperating Teacher Interviews - 4 (SR) & Weeks 7-8 \\
\hline Student Teacher Interviews - 2 & Week 8 \\
\hline
\end{tabular}




\section{Data Analysis}

Throughout data collection, analysis occurred concurrently allowing for ongoing generation of mentoring strategy codes and possible themes (Miles et al., 2014). According to Miles, Huberman, and Saldana (2014), this allows the researcher to "cycle back and forth between thinking about the existing data and generating strategies for collecting new, often better, data" (p. 70). Following the data collection period, analysis continued with coding of all data. Data displays were generated which helped to draw connections across data sources and illustrate the findings.

Within case analysis was completed for each individual case as well as cross-case analysis in order to draw comparisons between the different cases. Ragin (1987) described a case-oriented approach in which each case is examined as a whole before making comparisons. Additionally, a variable-oriented approach using codes drawn from the literature was used to look for themes across the different cases. Miles, Huberman, and Saldana (2014) recommend a combination of strategies, or stacking comparable cases where each case is analyzed using similar strategies and then compared using a series of matrix-type data displays.

Data management. With a variety of data sources from multiple participants, an organized system of data management was essential. Electronic folders were utilized for each participant in which all transcripts, field notes, and artifacts were kept. Folders were stored on the researcher's password protected personal computer. A numerical code was created for each data source indicating the participant, type of data, and visit number. The code was used as a heading on each data source along with the date and time of data 
collection. Line numbers and consistent spacing and formatting was also used on all written data.

Each interview was audio recorded using a Sony handheld digital audio recorder. Mentoring dialogues were video recorded by the participants using a digital videorecorder. The cooperating teachers or student teachers were asked to share this with the researcher using a password protected Google drive or email message. Interviews and videos from mentoring dialogues were transcribed verbatim using Microsoft Word and Express Scribe software. Observer comments were added to each document allowing for ongoing analysis and reflection. Each data set included a contact summary sheet (Miles \& Huberman, 1994). In addition to tracking all contact with participants, these were used to analyze possible themes, generate additional questions, make connections, and record my own personal biases or reactions. Throughout the process a researcher diary and analytical memos were used to record researcher reactions and conjectures related to potential themes.

Coding procedures. Codes are labels for chunks of data used to assign meaning (Miles et al., 2014). These codes can be used to note patterns, categories, or themes. The initial codes can later be clustered in order to find connections and draw conclusions (Miles et al., 2014). Prior to coding, all written data were read and reread for overall content (Schensul \& LeCompte, 2013).

All transcripts and expanded field notes were coded using first and second cycle coding (Saldana, 2013). For the first cycle "descriptive" or "in vivo" codes were added to the margin of each document (Miles et al., 2014). Descriptive codes assign a summary label 
to a passage of text. An in vivo code uses a brief direct quote from the participant, and a process code uses gerunds to describe an action from the text (Miles et al., 2014).

According to Miles and Huberman (1994), pattern codes can be used to identify “an emergent theme, configuration, or explanation" ( $p$ 69). They can reduce or synthesize the data by grouping the first cycle codes into themes or constructs. The first cycle codes are compared and grouped together into similar constructs, resulting in fewer categories. Pattern codes often fall into one of four categories: categories or themes, causes and explanations, relationships among people, and theoretical constructs (Miles et al., 2014). Once first cycle coding was completed, pattern coding began by finding connections between the first cycle codes. Pattern codes as well as existing related literature were consulted in order to generate a final codebook, which was used to code all written data (LeCompte \& Schensul, 2013). Final coding was completed using Nvivo software, which enabled the researcher to easily count code occurrences and engage in cross-case analysis.

Additionally, conversation analysis and content analysis techniques were used to analyze the mentoring dialogues (Leech \& Onwuegbuzie, 2008). Content analysis was used to count occurrences of codes across each data source. These techniques were used to analyze the video-footage of the mentoring dialogues. This lead to a deeper understanding of the cooperating teacher's mentoring style. Conversation analysis was used to examine the interactions during mentoring dialogues. Taking the context into account, this technique allowed analysis of the behaviors and intentions during conversations. The focus of conversation analysis was on the turn taking during the dialogue, the reciprocal response of each participant, the situation and the context influencing conversational 
decisions, and summarizing responses of the other participant (Leech \& Onwuegbuzie, 2008).

Codes were generated from the data as well as from the MERID model (Hennissen et al., 2008). These categories included direct and non-direct mentoring style, use of questioning or statements, talking time of each participant, initiating topics, length of dialogue, and topics of conversation. Additional categories related to the discourse were drawn from Zeichner and Liston (1985) including factual discourse (what occurred or what will occur in the future), prudential discourse (suggestions for improvement and evaluation), justificatory discourse (reasons behind instructional decisions), and critical discourse (assessing the adequacy of the justification or the values and assumptions of the curriculum). Drawing from Tsui, Lopez-Real, Law, Tang, and Shum (2001) the conversational discourse can be categorized as eliciting reflections or observations, offering observations, evaluation, or suggestions, and managing interactions through acknowledging contributions, asking for confirmation, or agreements. The final codebook can be found in Appendix $\mathrm{H}$.

Additionally, the mentoring roles were determined by analyzing each mentoring dialogue. Codes related to the mentoring style and input were counted for each dialogue. Results of the code counting were used to create graphs mapping the mentoring role during each mentoring dialogue. Graphs for Adam and Samantha's dialogues can be seen in figures 5 and 6. Isabelle and Tyler's dialogues are shown in figures 8 and 9. Joanna and Ellen's dialogues are shown in figures 11 and 12 and Bob and Charlie's dialogues are shown in figures 14 and 15 (see Chapter 4). 
Data displays. Data displays are a visual representation of the data to aid the researcher in organizing the findings and drawing conclusions (Miles \& Huberman, 1994). As the written data is contained on many pages across multiple sources from multiple participants, analysis can feel overwhelming and confusing. The use of data displays can allow the researcher to make connections between ideas, concepts, and participants. In the final report, they can also be used to clarify the findings for the readers. In addition to the graphs used to display the mentoring role observed during each mentoring dialogue, tables were used to display the conversation times for each dialogue (see tables 8, 9, 10, and 11). Finally, case-level matrix-type displays were created for each case and then combined into a meta-matrix in order to make comparisons between each case (Miles \& Huberman, 1994). Five different drafts of a conceptual framework were created in order to clearly display one that may display the major features of each case. A final version of the conceptual framework can be found in chapter 4 (see figure 2).

Trustworthiness. Qualitative researchers use a variety of methods to establish that a study is believable, accurate, or transferrable. Lincoln and Guba (1985) created four categories for establishing the trustworthiness of qualitative research including credibility, transferability, dependability, and confirmability.

Credibility of the study was established through triangulation of sources and member checks. All sources including videos, interview transcripts, and stimulated recall transcripts were consulted in order to confirm the findings across at least two sources. Triangulation was also achieved by corroborating information between the cooperating teachers and the student teachers. Member checks were also utilized through sharing 
findings with the participants as well as through the stimulated recall interviews with the cooperating teachers.

Transferability refers to the extent to which the findings can be generalized beyond the setting of this study. Thick description has been provided for each site and participant to enable to reader to understand and potentially relate to the setting and the participants' stories. Through purposeful sampling, I also ensured that the participants are representative of different secondary music teaching levels. As this study is limited to only four cooperating teachers, the generalizability of the findings are limited.

Dependability refers to the transparency of the methodology. All aspects of data collection, analysis, and methods for ensuring the trustworthiness of the findings have been described in detail. This enables the reader to follow and understand the sequence of data collection and analysis.

Finally, confirmability has been achieved through careful reflection and awareness of the researcher's role in the process. Any potential bias has been examined and tracked through a field diary, observer comments, analytical memos. Peer review from colleagues and advisors has also been used to confirm and question analysis procedures and findings.

\section{Researcher's Background, Role, and Assumptions}

I was drawn to this topic due to my experience as a University Supervisor during my doctoral studies. I supervised four student teachers in prior semesters and supervised two more during data collection for this study who were not participants of this study. All of my supervising experience have been in general music placements. As a university supervisor, I have realized that I have a more limited impact on the development of the student teacher than the cooperating teacher due to the limited time in the classroom. 
Communication with the cooperating teacher becomes important not only to answer questions and provide assistance to the cooperating teacher, but also to meet the individual needs of the student teacher. The cooperating teacher can provide a more complete picture of the student teacher's successes and struggles due to their daily interactions with the student teacher.

During my post-lesson dialogues with the student teachers I supervised, I realized that I needed to adapt my approach to each individual student teacher. Some student teachers were ready and willing to reflect on their own teaching. As a supervisor, I can guide them through questioning to set goals to improve their teaching practice. Other student teachers had specific questions for me, hoping for additional tips and tricks to use in their teaching. Finally, some student teachers were feeling more uncomfortable with their teaching and needed more direct advice or instruction on specific instructional matters. This approach may change over the course of the semester depending on the needs of the student. As the cooperating teacher spends so much more time with the student teachers, I often wondered how they approached conversations with their student teacher and how this impacted the student teacher's development.

As an experienced music teacher and university supervisor, I have ideas about effective music teaching and mentoring of preservice music teachers. Though I was serving as a university supervisor during data collection, none of my assigned students were participants for this study. I do not have any prior experience as a cooperating teacher, though, so I was able to examine this side of the relationship without personal bias. As my area of expertise is in general music teaching, my limited experience with secondary instrumental ensembles may have resulted in less judgment of the cooperating teacher's 
instructional approach and program design. As a researcher, I tracked my opinions and any potential bias through the use of observer comments embedded in interview transcripts and analytical memos (Bogdan \& Biklen, 1998).

During data collection I was also the instructor for the Introduction to Student Teaching course and therefore had a working relationship with each of the student participants. I also taught a general music methods course two years prior in which all students were enrolled. As the supervisor for their practicum experience, I was in email contact with each of the cooperating teachers. These emails primarily served to answer questions about the practicum and student teaching requirements and ask for professionalism and teaching evaluations related to their student teacher. 


\section{CHAPTER IV}

\section{Individual Case Findings}

\section{Conceptual Framework}

Figure 2 shows a model of the conceptual framework which has been used for the analysis of each case. The outer layer shows the factors of the student teaching context such as co-teaching instructional approach, performance preparation/pressure, and placement timing. The next layer of the framework includes factors related to the mentor's perceived role as a cooperating teacher which is informed by instructional and psychological support provided by the cooperating teacher in addition to their relationship. The relationship is influenced by both the cooperating teacher and student teacher personality. At the center of the conceptual framework is the MERID model (Hennissen, et al, 2008). The facets of this model were used to analyze all of the formal mentoring dialogues between the cooperating teacher/student teacher pairs as well as the interviews with the cooperating teachers and student teachers. 


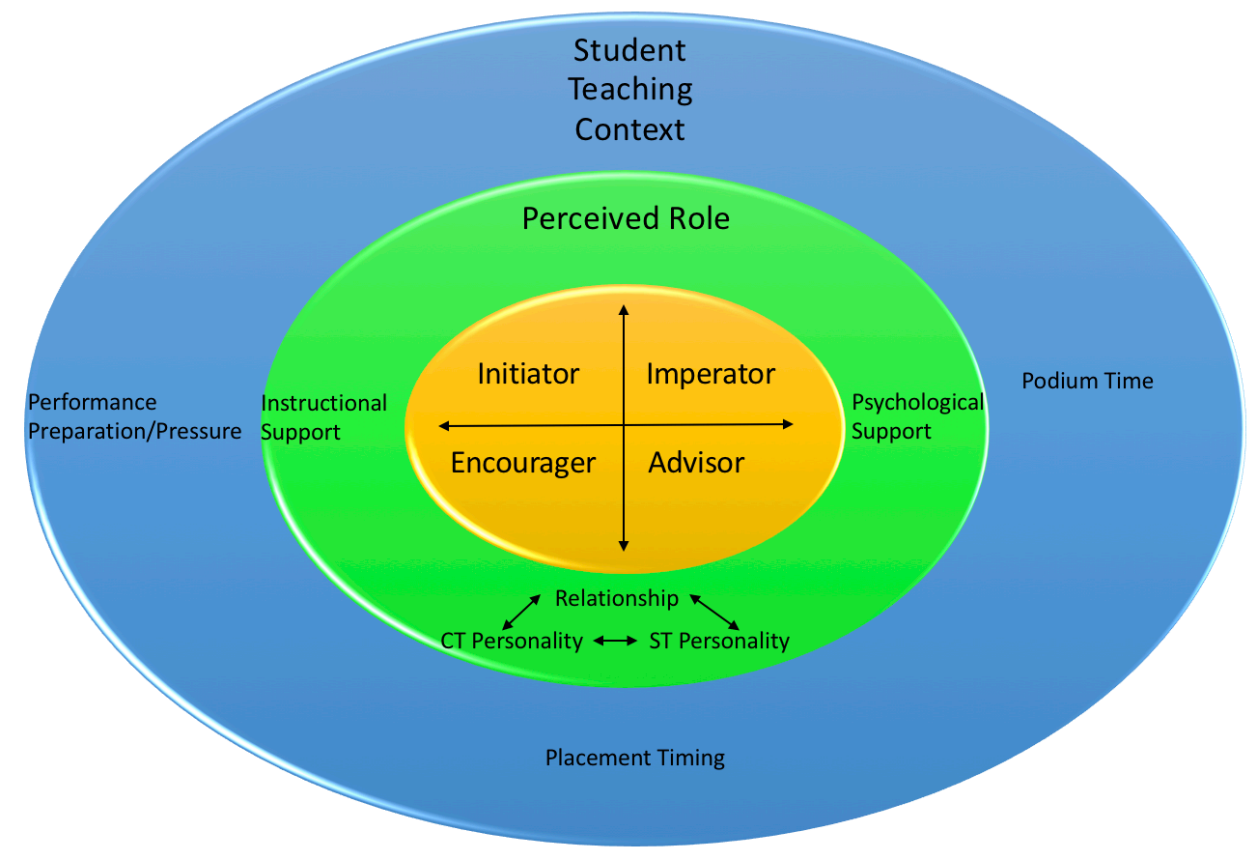

Figure 2: Conceptual Framework

For each case I will describe the findings in terms of the different layers of the framework beginning with the outer layers of the model including the student teaching context followed by the perceived role layer. Finally, the facets of the MERID model will be described including the topics of conversation, the phases of the dialogues, conversation timing, mentor teacher input, and supervisory style (Hennissen, et. al, 2008). For each individual case the most salient factors will be represented on the model with bold font and lines depicting connections. Additionally, data from the transcripts will be included to illustrate the findings. For clarity, excerpts from the recorded conversations between the cooperating teachers and the student teachers will be in italicized font. 


\section{Adam and Samantha: Orion High School}

Site and participants. I pulled into a very crowded parking lot on a blustery day in early spring. I found a parking spot near the back of the lot not too far from the main entrance as students were coming and going for lunch. I found my way to the main office to sign in, and remembered my way to the band room just down the hall. I had only met Adam twice so far: once at our initial meeting and once for our first interview. I knew Samantha a bit better as I had her as a student in a couple of classes. Adam was very easy to talk to, but I still felt like we were getting to know each other better and establishing rapport. This meeting was our second interview, the first stimulated recall interview where we talked about a recorded conversation between Adam and Samantha.

I walked into the band room and noticed a few students hanging out and playing some keyboards. The band room is a large, tiered classroom with most of the chairs stacked, a few stands still set up from rehearsals, and instruments pushed into the corners. I crossed the room to the band office to find Adam sitting at his desk and Samantha sitting nearby on the couch. The office feels like organized chaos with instruments and papers stacked up in corners, on top of the desk and piano and strewn across the comfortable couch where Samantha was sitting with her laptop. When I come in she moves some stacks of music to make space for me to sit down at the end of the couch closest to Adam's desk. All three of us greeted each other comfortably and I asked Samantha if she had received her scores from the edTPA yet. She excitedly told me that she passed and she's ready to start looking for jobs.

I turned to Adam as he finished a brief phone call and explained that we were going to watch a video this time from their most recent recorded conversation. I set up my 
computer, external speaker on a large speaker near Adam's desk, and balanced my handheld recorder on the arm of the couch. I was sitting near his desk, but the surface of the desk is too cluttered to put anything on it. Before we started the interview I asked him how the recording went, since this was their first conversation. He made a face...he didn't seem to like recording their conversations. He said it was okay, just weird to record themselves. It didn't really feel like what they normally do when they talk. He didn't volunteer any more information, so I made a note to follow up on this topic later.

Despite the fact that recording conversations with Samantha was a little awkward and difficult to find time for, he seemed very comfortable with our interview. He talked freely and openly. At times he leaned back in his chair comfortably and other times leaned forward, engaged in the conversation and the video we were watching. I told him to pause the video whenever he saw something that he noticed and wanted to talk about and he did, within the first minute of the video. He talked freely, reflecting primarily on himself and questions that he had asked of Samantha. During most of the interview, Samantha was still in the office working on her computer or sorting music. I told her it might feel awkward for her or Adam to have her there, but neither one of them seemed to mind and Adam told her that she could stay. He would even stop and ask her questions to follow up on something he had asked in the earlier recorded conversation. In the video, they had talked about her choice to put their single percussionist on tympani and he realized that he should have asked her why that was a good choice. Since she was sitting next to me, he paused the video and asked her then. 
A: out of curiosity <Samantha>, why was it a good switch to tympani?

S: because it's a more exposed and independent part, it will give him a more meaningful musical experience in play, than auxiliary percussion

A: right, I would agree with that

S: it's a more substantial part

A: what else is important with that tympani part?

S: we need it in the ensemble (A-2)

She was also present for a portion of another interview, and both of them seemed very comfortable talking with each other during the interviews or just having Samantha there listening to Adam talk about her. At another point he even apologized to her for talking so much and interrupting her.

Conceptual framework: Adam and Samantha. Figure 3 depicts the conceptual framework model adapted to show factors that were important in the case of Adam and Samantha. Encourager, psychological support, and placement timing have been shown in a box in bold font because these factors stood out in this case. Lines have been drawn to indicate a connection between certain factors. 


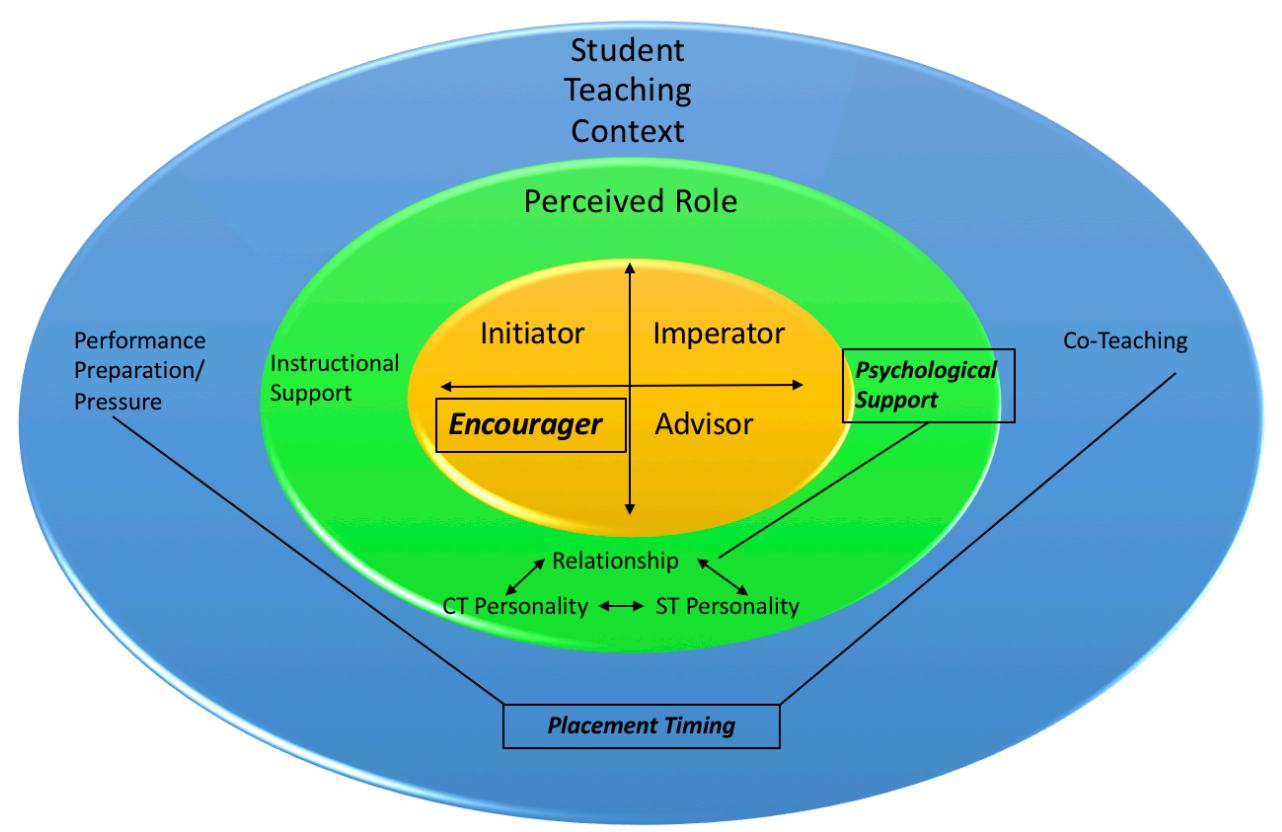

Figure 3: Model of Adam and Samantha

The following excerpt from the first recorded conversation shows a fairly typical conversation between Adam and Samantha. Adam asked reflective questions to guide Samantha's thinking about her experience sight reading a new piece with the ensemble. She reflected on her concerns for the one student playing percussion in the ensemble. He reacted to her concerns by reassuring her with positive feedback and suggestions for improvement. During the first recorded conversation especially, he was observed interjecting advice or ideas based in his own experience, such as when he encouraged her to give the percussionist more comments. When he did give her advice or ideas it was in response to something that she had mentioned.

A: other things?

S: I've been struggling with how to involve <name inaudible $>$ on percussion 
A: I thought your switch to tympani was good, because then that's more, I think when you have one percussionist and all the others are in a different period because of the nature of the schedule, um I think giving him the tympani was smart. And it's hard to incorporate some good comments to help him out when you feel like you're giving all the attention to just one but that kind of goes back to that pointalistic <inaudible>, when you're like how much time to I spend on it

S: right

A: but I would <inaudible>, I would want to make sure I give him some comments from time to time too, like, percussionists tend to get neglected

S: right

A: and so maybe, um as we kind of develop that score and the music from Jupiter you might anticipate some moment where you can give him some comments S: and I think it might be helpful just to go back and work with him for a couple of minutes, cause he does have these big exposed <inaudible> A: and maybe that's something where you and I can work together, while you're running full rehearsal I can be working with him and vice versa, that would be good $(A-2)$.

Student teaching context. A variety of classroom factors had an impact on Adam's approach enacted during their dialogues. Adam always tried to ensure that she would have adequate of teaching time with each class, which varied over the course of the placement. Given the timing of her placement at the end of the second semester, the concert cycle and pressure to perform had an impact on the amount of time she had with each ensemble as well as the time they had allowed for formal dialogues. Therefore, the timing of Samantha's 
placement is shown in bold and connected to their co-teaching arrangement and the pressure of preparing for performances (see Figure 3).

Co-teaching. Near the beginning of the semester, during her placement with Isabelle, Samantha chose one piece for each ensemble that would be her responsibility to rehearse and conduct for the concert, in addition to occasionally rehearsing some of Adam's assigned pieces. Samantha knew that "it's important to teach everyday, and both of my CT's have stressed that, that it's important to get up in front of a group every single day and have that teaching time" (S-1). On an average day the pair split the podium time approximately 50/50. They planned for her to have one solo week later in her placement. This plan shifted over the course of the placement, as Samantha reported having two solo weeks where she taught the entire class for both large ensembles (S-2).

Their relationship developed over time into a comfortable working relationship. During many rehearsals they took turns on the podium, each of them spending time rehearsing with the group. While one is teaching the other will play with the ensemble or help students individually. Samantha has been given the freedom to decide what to rehearse and how she will handle rehearsal. This freedom has instilled Samantha with a sense of trust and responsibility. "Yeah, so he's sort of just kind of let me loose and I just take care of what I need to take care of, which is nice to have that sort of trust" (S-2). Ultimately, he wants each of his student teachers to have a very authentic teaching experience, and respects her time on the podium as the teacher. "I don't believe that I should be calling out the student teacher in front of the kids because then all of a sudden the kids lose that respect that I hope would be built up in front of them, so she gets that authentic experience. We'll debrief later about it" (A-3). 
As he trusted her and valued her opinion, he also asked for her opinion about his time in front of the ensemble. He was open to hearing some of her feedback. "well, we talk about it sometimes when I'm in front, like, what did you see? What could I have done better, you know? And switch roles and have her...that might be the one area where she maybe is not comfortable telling me what she is thinking, because she doesn't necessarily always offer" (A-4). He understands that she may not feel comfortable giving her cooperating teacher feedback, but he wants her to have that experience of having a dialogue about teaching. This also overlaps with the open relationship that he is maintaining for her. "I want her to know that there's a community of teachers and that we support each other, like you're a colleague now, and that's how I see her in a lot of light, is we're equals" (A-4).

Performance preparation/pressure and placement timing. Due to the concert cycle and keeping pieces ready for performance, Adam reflects that he can't turn everything over to Samantha. "Well, just the timing of it with the performance and already having pieces in the folder that I've worked up with them, changing halfway through didn't seem like it was good for the kids" (A-3). Near the beginning of her placement there were a lot of performances for jazz band and even a week where Adam and most of the students were out of town for performances, therefore she wasn't able to have as much time with those students. Adam stated that was partially due to the timing of her placement in the second half of the semester.

If she was at the beginning of the year, and I've had enough student teachers where throughout the years I feel like there's different good times to student teach, and so if she came into the high school piece the first eight or nine weeks, she'd be on the 
front end of all the literature that went into their folder and so she'd be more responsible. I could put her in charge of more pieces. You know, where maybe she's more - closer to that $100 \%$ at some point than she would be the second half (A-3). Additionally, with her placement occurring during the last eight weeks of the spring semester, state standardized testing disrupted their normal class schedule, resulting in lost rehearsal time before their Spring concert. With Orion having an International Baccalaureate (IB) program, all students in IB courses were pulled out of their classes for tests as well. When asked if he had any regrets about Samantha's time at Orion, he said that he regretted not giving her enough rehearsal time to prepare her pieces. "because I think that would have felt differently, at least on Overture Jubiloso, to give her enough time to feel accomplished at the end...because really the Wind Symphony players play pretty well and I think she wanted to have a nice polished piece that's representative of her work" $(\mathrm{A}-4)$.

The busy performance schedule also tended to get in the way of being able to sit down together for a formal mentoring dialogue. At the beginning of her placement, Samantha mentioned that they hadn't had much time to sit down to have an extended conversation, but expected things to calm down after the band trip. "We're getting ready for the festival, we had two festivals and then a concert and then their trip, all in the last two weeks, so he's been a little harried" (S-1). When it came to the end of the semester, they had difficulty finding the time to sit down and record a conversation. Their teaching time was interrupted by testing and then they were preparing for the final concert. During this time they functioned more like colleagues trying to get everything done. "Yeah, we 
probably have less conversations about what's happening in the class as things get a little frantic" (A-3).

Perceived role as a cooperating teacher. Adam believed that it was important to host student teachers in order to provide his future colleagues with an opportunity to learn. He feels a sense of duty to the profession. "it's part of our duty I think, right?...I felt an obligation to give an opportunity" (A-1). He reflected on some of his colleagues in the district who were less willing to host student teachers "because they felt like they messed up their program...I'm like come on, you know, we're in the field of education, and how are we going to have teachers in the future if they don't get that opportunity?" (A-1).

Adam strives to give his student teachers an "authentic experience" by creating opportunities for them to experience the daily responsibilities of a high school band director. "...like $<$ Samantha $>$ got to conduct at the concert festival. I'm not sure I know of another student teacher that had that opportunity, so to get some of the exposure, that hopefully will make them more comfortable when they go and get their own gig" (A-1). He also ensures that they gain experience with the variety of non-instructional tasks that fall under his responsibility. "She did a bus request, she's talked to the office staff and made a connection there. She has made a few copies from time to time" (A-3). Over time, she took over responsibility for fundraising and was very instrumental in coordinating the task of moving the classroom before school renovation began at the end of the semester, even when it meant staying at Orion after graduation. "As far as administrative tasks go, we've been splitting up this moving project pretty evenly. I'll stay here and direct kids what to bring to the auditorium and he'll show them where they should put it when they get there. 
Sort of deciding how we should organize things in the process and when we get there has been sort of a team effort with lots of discussion" (S-2).

Psychological support. Central to their experience was providing psychological support through nurturing a trusting relationship and a collaborative environment. Therefore, psychological support has been shown in bold and connected to relationship on the model (see Figure 3). He wanted her to feel comfortable talking to him and for his students to view her as a teacher.

I think from the get-go I tell her that this is an experience I value for you and so I want you to get what you need out of this, and so um, any questions arise I just want you to ask, even if you think that it's not appropriate, just ask away, cause this is a safe environment. It should be, if I make it safe for those kids, it should be safe for you and so I want you to be able to ask whatever you feel will help you to be a better teacher $(\mathrm{A}-4)$.

Adam sought to establish a comfortable learning environment for Samantha so that she would gain what she needed from her time with him. "We had a really good relationship where we could talk to each other and share ideas and I feel good about that, because ultimately I want the student teachers to feel comfortable talking about whatever's on their mind and I felt like she could" (A-4). Simultaneously, he sets the tone for his students to view her as a teacher. By sharing both teaching and administrative duties, more responsibility falls on Samantha. "When we deal with the fundraising stuff, I'll be like 'go see $<$ Samantha $>$ and she'll handle it' I don't even involve myself. She'll just handle it and the kids now start going to her directly as opposed to coming to me, for certain things. We try to create an environment where she's seen as the same" (A-3). 
Adam also maintains open communication with Samantha by admitting that he makes mistakes and shows a willingness to learn from her. "I try to approach her from the 'we're always learning no matter where we are in our career'... I always tell them this is what works for me, and works is relative..." (A-3). He is open to Samantha experimenting with new ideas and will also ask for her input on his teaching when she has observed him on the podium: "let's tell it all, to each other and see if we can both improve" (A-4). He also enjoys gaining a fresh perspective from student teachers: “...I'm in the profession of learning too" (A-1). He will defer to her expertise at times, especially when it comes to flutes and other woodwinds, as that is her primary instrument while his is trumpet.

"Friend, colleague, and mentor." By the end of the semester, Samantha felt proud of the trust she has earned. "I feel that I've sort of proven that I can handle bigger tasks and more information being thrown at me and so I've been able to see more and more of his daily life and be a bigger part of it. Sort of just earning his trust and then him earning my trust..." (S-2). She reflected on a comfort level that has developed over time during her placement with Adam. "I definitely felt the pressure like I was being watched. That has sort of gone away. It didn't go away as much in my last placement but I feel like he's just been so supportive and answers any questions I might have" (S-2).

“I think that it's gotten more collegial instead of more as like a supervisor...He's turned into a really amazing friend, colleague, and mentor" (S-2). Their relationship has developed over time, yet was also impacted by the busy schedule over the course of the semester. Near the end of the semester, they were very busy coming out of the testing schedule when they lost rehearsal time then heading into performances. On top of a busy performance schedule, they were tasked with moving everything out of the band room for 
summer construction to begin before the end of the school year. In order to stay on top of all of their responsibilities they split up duties. At that point Samantha had already graduated and was technically finished student teaching, but had stayed for the concert and to help with the move. "There's probably a time in that time during the day that's probably fairly large where she's more of a colleague than she is a student-teacher/cooperatingteacher. I try to see her on the same level and give her a lot of, kind of divide and conquer. She's great. She'll ask questions when she's got questions. Yeah, a little bit more of that cooperating teacher, student teacher kind of goes away and it's more colleague based" (A$3)$.

Adam also noticed the difference in their relationship as they got to know each other better, becoming more comfortable working together. He noticed the difference in his mentoring approach as they grew more comfortable together. "I think as you get more comfortable, I can be more picky about what she's doing. You know, and how she's going to react to certain sorts of feedback (A-3). Ultimately, he thinks of his student teachers as colleagues, or future colleagues. "Like you're a colleague now, and that's how I see her in a lot of light, is we're equals" (A-4). He knows that their relationship doesn't end at graduation and he will continue to be a resource and a mentor for them in the future. "I think when they leave, I want them to feel like they have a colleague out there who is going to support them and they can call if they have any questions" (A-3).

Personality impact. Adam has indicated that Samantha's personality has enabled her to take over so much responsibility. Reflecting on his past experience as a cooperating teacher, Adam recalled that not all of them are so ready and willing. "I think it's the qualities of student teachers. There are some student teachers that are a little 
apprehensive to taking on that responsibility. Maybe they don't feel like they should do it. You know? I mean, they just don't know. 'That's not my program, I don't want to mess anything up.' Then you have folks like <Samantha $>$ who just jump in. They just do" (A-3).

As one might expect, it took time for Samantha to feel fully comfortable working with Adam. "Um, I think, well I'm kind of shy when I first meet someone, so it took a while to develop..."(S-1). Prior to working with Adam during her field experience she knew him years earlier when she was part of a teaching program for high school students to work with middle school students. Samantha was a junior in high school and Adam's daughter was in sixth grade. "It's taken a long time...he's kind of intimidating to begin with..." (S-1). Over the course of her field experience during the semester before student teaching and throughout the semester, Samantha became very comfortable with Adam and was able to ask him questions freely. Having a variety of prior field experiences connected with coursework, she felt more comfortable with Adam than she had with other teachers. “...he's just really positive, and it doesn't, it's a nice change because it doesn't feel like some of my practicum experiences I felt really pressured and uncomfortable when I had to teach in front of my cooperating teacher, and um, I don't feel that way with him, which is a really nice change" (S-1). Adam also noticed the development of their rapport and comfort level over time. "I think as we get more familiar with each other, I think it's a more safe environment for her to ask questions she wants to maybe really ask. Not that she lacks the - she's forthright with most everything...but I think she's more comfortable asking those questions that she originally was" (A-3).

As described previously, Adam has a very relaxed attitude. This informal, relaxed approach also impacts the daily mentoring dialogues between Adam and Samantha. They 
tend to have a lot of informal, naturally occurring conversations. "We do a lot of um, informal sort of conversations" (A-2). When recording conversations for the purpose of the study they began with a topic, such as a recent teaching episode, and Adam led the conversation through reflective questioning. He didn't have formal notes from a teaching observation and was open to allowing Samantha to ask questions or raise concerns. When reflecting on her two cooperating teachers, Samantha said " $<$ Adam $>$ is maybe a little more informal than my relationship with $<$ Isabelle>, just because I think our senses of humor are similar" (S-2).

Instructional support. Though not as obvious as the psychological support, Adam also perceived his role as a cooperating teacher to provide instructional resources so that they may be better prepared for their first job. From the beginning of their time together Adam began by offering assistance and being open to answering questions. "I definitely feel comfortable asking him any of my questions, and he's been super helpful in volunteering information and resources" (S-1). He allowed her to borrow materials and forms that she might find useful when she began teaching.

During their dialogues he provided feedback on her teaching and gave suggestions based on his own experience as a teacher. "I think you hit it on the head how we discuss that piece at the beginning and that first impression is important, and for sort of an immature group like that sometimes takes a piece that's slow and thinks it's boring" (A-4). He also draws on his own experience as a cooperating teacher in considering his feedback and approach with Samantha. "Most student teachers are, they want to, like, they want to like, they hear a mistake and they want to fix it right away..." (A-4). 
Another form of instructional support provided by mentors can be modeling instructional strategies. Samantha noticed how Adam was able to model his teaching style with the different ensembles that they taught at Orion:

It's been really interesting, he teaches two bands and jazz band and IB music so it's been cool to see how he changes his teaching style and that's like something I've never really seen anyone change their teaching style so much, so for his top band the Wind Symphony he moves really quickly and gives really targeted feedback and then for the lower band, the Symphonic Band, he goes a lot more slowly and like, I don't know, he kind of guides them through the process more, where it's more like teaching them how to practice the fundamentals and stuff, which is really interesting (S-1).

Facets of the MERID model. The mentoring dialogues between the cooperating teacher and the student teacher did not occur in isolation. Each interaction was informed by and influenced by the context of the student teaching placement and the perceived role of the cooperating teacher. These factors comprise the outer layers of the model (see Figure 2). Finally, the dialogues have been analyzed using the MERID model (Hennissen, Crasborn, et. al, 2008). The first three facets that are described include the topics of conversation, phases of the dialogues, and the timing of the conversation. Though not an explicit part of the model, they informed the style and the input of the mentor according to the MERID model (Hennissen, Crasborn, et. al, 2008).

Topics of conversation. Topics of conversation were coded as instruction and organization, musical, students and class, and miscellaneous. When Adam and Samantha talked about instruction and organization, they were primarily focused on Samantha's 
rehearsal pacing. Adam referred to this as a "micro" or "macro" approach and letting some mistakes go so that students might play through the whole piece more often. "We had this discussion before where she was spending so much time on like the first half of the piece, the second half wasn't nearly as comfortable as the first half" (A-4). In their first mentoring dialogue, Samantha reflected on musical issues in a piece that she was conducting. "I think breaking it down into smaller pieces in some parts, it was hard in that middle section, cause it's so like, pointalistic with the eighth notes" (A-2). In the final mentoring dialogue their musical reflections had more to do with students' connection with the music. "Jupiter is like programmatic music, but this is just music, and so we could have explored that a little bit more and giving them that perspective could have opened their minds up to that" (A-4).

Early in Samantha's placement Adam made a point of letting her in on administrative responsibilities such as planning trips and scheduling busses for field trips. Later in the semester she was involved in fundraising and moving furniture out of the classroom as well as planning ahead for her new job in a remote part of the country. “...I just want to make sure that you know, you're kind of going out by yourself and I don't want to make you anxious, I just want to make sure that you're thinking about what you're getting yourself into" (A-4).

The most common topic of conversation was the students. They were often discussed in relation to Samantha's instruction or their response to her instruction or the music they were rehearsing such as when Samantha brought up her concern for the single percussionist in Concert Band during the first recorded conversation. "S: I've been struggling with how to involve <name inaudible $>$ on percussion"(A-2). In the final recorded conversation Adam brought the topic back around to Samantha's struggles getting the 
students to connect to one particular piece that she was rehearsing which led Samantha to reflect on the music and what she could have done differently.

A: Let's talk about the Air for Band issues you had at the beginning, because they weren't accepting. Strategies that you tried to use that maybe didn't work, or did work in terms of getting their buy in on that piece?

S: Well, the buy in I think has to start from the very beginning when we introduce the piece, and I don't think we did enough of that, so just introducing it as an important piece of band literature and um that it's just a really beautiful melody and just try to frame it as a piece of music that you play for music's sake and not maybe to tell a story could have been an interesting thing to say to them, cause I don't think they play a lot of music that's like that. Thinking about what else they've played, like All Glory Told tells a story, it's like that graduation story and Jupiter is like programmatic music, but this is just music, and so we could have explored that a little bit more and giving them that perspective could have opened their minds up to that (A-4).

Phases of the dialogue. The phases of the dialogue refers to the overall pattern of the entire conversation including questioning, feedback, and advice. “...sometimes we'll just start like, 'Hey, how did it go? How did you feel?' you know?...it usually starts 'it went well...what went well?' We'll talk about that and what not. What didn't go so well? We start general and try to get more specific" (A-3). This overall phase of the conversation as described by Adam can be observed in the recorded conversations when he begins with a general question “...so sight-reading some Jupiter with Concert Band, why don't you tell me how that went for you, maybe, and how you felt it went for the ensemble" (A-2) and follow up with additional questions. In addition to revisiting the initial question to guide her towards 
thinking about the ensemble "other things that went well, or maybe not so well with the kids?" (A-2), some are details or clarifications. "Did you make notes prior to this?... what did you write down?... and then those too, were you correct in that anticipation, or?" (A-2).

As described previously, Adam tries to guide Samantha through reflecting on her own practice through questioning. If there is a "glaring concern" then he will bring it up during their informal conversations frequently. "If there is a growing trend, we could have that be more of a topic of conversation almost every time we talk" (A-3). Drawing on past experience with previous student teachers, he tends to offer more direct advice if something goes poorly and the student teacher doesn't know what to do. "It's usually some sort of classroom management or engagement sort of something that's going on. But I'll usually step in if they go, 'I don't know where it went wrong' and then we'll talk about where it went wrong" (A-3). With Samantha, he acknowledged that she had very few classroom management issues. During the recorded dialogues when Adam offered direct advice, it was usually in response to something that Samantha expressed concern about or reflected on.

S: so maybe just breaking it down, even into just like sections, so this section is gonna play their eighth notes alone, and so it will be out of context, but they would know exactly where to place them and at least they would have <inaudible> A: and from a pacing standpoint, one thing you have to mindful of is how much time you spend with a specific section, I think the pacing today, even though maybe you felt rushed, I thought it was good because everyone was engaged and when you broke it down, um, kids who weren't playing were attentive to what was happening, I felt that wa-, I don't know how you felt on the podium, but sitting in the ensemble (A-2) 
As illustrated in the previous excerpt, all of the feedback provided during the recorded conversations was positive. "I was sitting with the trumpets and I don't think there was a time when they were like uh, I haven't played yet, you know what I mean, I think they were pretty into what was happening and I know you wanted to get them involved, which is good, but I thought the pacing was great" (A-2). As opposed to directly telling Samantha to do something, Adam sometimes offered more gentle suggestions for improvement. "You know, maybe you just don't want to dwell on too much for one day, maybe just come back the next day and hit it a little bit the next day a little bit and try to work it up that way" (A-2). Most of the time Adam guided Samantha through reflection through questioning, as was confirmed by Samantha. "He asks a lot of questions...he asks me what I think went well and what I would like to do better and how I plan on doing that better" (S-1).

Conversation timing. In the first recorded conversation, Adam used reflective questions to find out Samantha's reaction to an experience sight reading with the ensemble. She responded by talking about strengths and weaknesses of her teaching. He reacted to her concerns by reassuring her with positive feedback and suggestions for improvement. He drew on his own experience to give her ideas or advice.

In the final recorded conversation, Adam used even more questioning seeking Samantha's thoughts and ideas. Therefore, she spent more time talking and reflecting on her own strengths and weaknesses. This is reflected in the talking time of each conversation split between each of them. 
Table 8: A-S Conversation Timing

\begin{tabular}{|l|l|l|}
\hline A-S Video 1 & A: $5: 58$ & $72.62 \%$ \\
\hline & S: $2: 15$ & $27.38 \%$ \\
\hline A-S Video 2 & A: $4: 30$ & $52.94 \%$ \\
\hline & S: $4: 00$ & $47.06 \%$ \\
\hline
\end{tabular}

By the final conversation the talking time was split almost evenly between them. There was more of a comfortable, back-and-forth exchange observed in the final dialogue. A change was observed in the coding as adopting a slightly more indirect approach through more reflective questioning.

A: Alright <Samantha>, so we finished up the concert had a chance to conduct a few pieces, um, what are some of your takeaways from that whole experience from working something from the beginning all the way to the end?

S: um <pause> I was really proud of the progress actually with the Symphonic Band, because they hated that piece at the beginning <loud beeping sound interrupting video, inaudible> especially, I feel like they kind connected with it a little more, or they tolerated it more at the end, and gave a pretty musical performance of Air for Band. Um, and then with Wind Symphony I was, I was pretty happy with it, I mean there's so many moving parts to that and we didn't get as much time as I would have liked to prepare, especially towards the end, because there was so much going on. But I think that technically they did a good job with it and balancing to the melody they did a pretty good job with it, there were some of those musical things that we could have done more with. And I forgot to tune. 
A: <smiling> you forgot to tune. That's okay, it happens. Um, if you had a chance to kind of go through the process again, um, what are some things that maybe you would like reconsider doing or change to either better prepare them, you mentioned you didn't have enough time (A-4)

Cooperating teacher input. When a cooperating teacher is more active, they introduce topics and steer the conversation as they see fit. A more reactive cooperating teacher will respond to the student teacher (Hennissen, Crasborn et al. 2008). Adam was observed as primarily reactive in both conversations, yet he was almost evenly split between active and reactive in the final recorded conversation. Just as he believed that it was important to mentor through guidance and indirect questioning, Adam also believed that the student teacher should take the lead in the conversations so that she might get the guidance that she needed. "Get her to lead the conversation the way she wants to lead it as opposed to the way I want to lead it, so that she can kind of get the responses she wants on things that she sees as important to her" (A-4). This is clear as he asks general, reflective questions and then responds to her reflections. If he gives advice, it is in response to something that she has said. "but, absolutely, don't feel rushed, take the time to make sure, it'll help the kids out later too to understand that relationship when time is a little more steady and they understand that" (A-2). He also reassures her when she struggles: "yeah, that's a tough on to sight-read, especially with a young group..." (A-2).

Adam was observed actively introducing topics through questioning during the recorded formal dialogues, and was also observed responding to her reflections with ideas, reassurance, and feedback. During the recorded conversations, if there was a topic that he thought she should reflect upon or improve, he would actively revisit the idea through 
statements or probing questions. In the first recorded conversation Adam was active in starting the conversations with a question about a particular topic, in order to steer the conversation in a certain direction. "Alright, so sight-reading some Jupiter with Concert Band, why don't you tell me how that went for you maybe, and then how you felt it went for the ensemble?" (A-2). After some reflection primarily focused on her, he returned the focus to the students. "And so how do you think it went ensemble wise for the kids? We talked a little bit about you, how did it go for the group?" (A-2). This was the main topic that he guided her in thinking about during the first recorded conversation. He was also very reactive, usually reassuring her if she expressed some frustration about how something had gone in rehearsal. "Absolutely, but because you feel rushed, like you want to get through things, but maybe it's the over-programmed nature of that piece, but absolutely, don't feel rushed, take the time to make sure..." (A-2). He described himself as a filter: "then she's reflecting on that process as coming up with the strategies, and I'm more of um, a filter of those strategies and saying, maybe I'll just chime in and help you out with this..." (A-2).

In the final recorded conversation, the coding indicated that he was more active than he was in the first recorded conversation. In general, he was more focused on asking reflective questions in order to get specific responses from Samantha. Adam began with a reflective question "... what are some of your takeaways from that whole experience from working something from the beginning all the way to the end?" (A-4). Though it seems like a fairly general question, he was really looking for a pretty specific response related to a macro vs. micro rehearsal approach. When she didn't reflect on this point right away, he followed up with a more specific question. "So what are some of the, you talked about the whole macro, micro, macro approach, um, in rehearsal set up, um describe for me some of the 
macro approaches that you like to tackle and then-“ $(A-4)$. He was looking for this specific response because it was an area that he felt she needed to work on before she went into her first job. "I was still trying to drive her towards the teacher instructional stuff that I felt like she needed to improve on. She doesn't have many areas that she needs to improve on, but I felt like the pace and the instructional style, for me, is the biggest issue" (A-4).

Student teacher response. As Adam leads the conversation through guided questioning, Samantha responds with reflection on what went well and also areas where she is working to improve. "yeah <smiling> I have a hard time, like taking that time..." (A2). In turn, Adam responds by reassuring or giving suggestions for improvement. A: but, absolutely, don't feel rushed, take the time to make sure, it'll help the kids out later too to understand that relationship, um $<$ cough $>$ when time is a little more steady and they understand that. Other take ways from it besides time?

S: um, I think breaking it down into smaller pieces in some parts, it was hard in that middle section, cause it's so like, pointalistic with the eighth notes

A: yeah, that's a tough one to sight read, especially with a young group like that, and that's what makes this piece maybe a little out of their reach is that independence is needed. If we think to like that section, what is it, 108?

S: yeah

A: You have the presentation of that melody and 8 bars later we have another group who has the same melody, that's easy, cause you can rehearse them at the same time on something like that, but when it's so independent, or dependent on each other to make it actually sound like it's supposed to sound, that makes it hard 
S: so maybe just breaking It down, even into just like sections, so this section is gonna play their eighth notes alone, and so it will be out of context, but they would know exactly where to place them and at least they would have <inaudible> (A-2).

As seen in the above excerpt, in addition to reflection, Samantha also adds to the conversation by making suggestions or stating her own ideas for moving ahead with the group. At other times, Samantha would seem to ask for advice by bringing up a topic that she is struggling with. "Yeah, I was trying to get them to not play them so connected, but then on both of the final run throughs they played them super connected, and I was looking at them, making eye contact, so I didn't really know what to do, because I feel like style and rhythm when sight-reading is important, and notes will come..." (A-2). Adam reacts to her statement by reassuring her through agreement which leads Samantha to add her own idea for meeting the needs of the students:

A: and the probably tend to look at the notes more than anything else S: right

A: right, they don't want to get a fingering wrong or if they do they want to go back and fix it and at that point rhythms have been messed up and they don't get the style S: right

A: I agree

S: so maybe we need to like make sure like the whole ensemble's on the same page with priorities or something (A-2).

During the second recorded conversation, Samantha could be seen reflecting on what she could have done better "... and I did have them try to come up with those stories early on in the process, but I think revisiting it when they were feeling a little warmer towards 
the piece might have been good" $(A-4)$. She also reflected on her own success both overcoming a challenge with students: "but I think we got there eventually, I think, I mean some of them told me they liked the piece by the end of it, so that's a win" and on the semester overall: "it's been an awesome semester, the kids are great, I had a lot of fun!" (A-4).

From Adam's description of their relationship and their off-camera conversations, it can be inferred that Samantha tended to ask a lot more questions than were observed in the recorded conversations. "She asks a lot of questions...she'll go 'hey, what about this, and then we'll talk about that" (A-4). Adam reflected that he preferred for their conversations to begin like that, and they tended to in their more informal daily interactions. "I usually like it when she starts it because that means that she's got questions that she wants to talk about and probably more specific things than what I might bring up that I feel like might have been issues or concerns or things that went well, whatever it might have been" (A-3).

Style and supervisory skills. When a cooperating teacher is observed giving direct advice, ideas, or objectives to the student teacher they described as adopting a direct style. Other times, the cooperating teacher might adopt a more indirect style through the use of reflective and guiding questions. In the observed dialogues, Adam consistently began with a reflective question. Following her response, he would follow up with ongoing questions, leading to whatever topic he felt was important to address during that conversation. $\mathrm{He}$ firmly believed that it was important for the student teacher to come to their own conclusions without being influenced by his evaluative reaction. "I usually try to keep my initial reactions to what happened out of it, so that what they're feeling is authentic, as opposed to tainted by what, whatever I might be like, well you should have done this or 
that and then all of a sudden they're like oh, yeah I should have and then all of a sudden their perspective changes on how it went. I usually try to let them say what they felt like" (A-1). During our stimulated recall interviews, if he observed himself giving her answers or talking too much he often reflected on what he should have done differently. "I would have probably let her answer the questions, I kind of jump in and I like, what about this, as opposed to letting her simmer on it a little bit and process" (A-2). In addition to reflective, guiding questions, he will follow up with more specific questions in order to guide her to think about whatever issue might be on his mind: "other takeaways besides time?...What else is important with that tympani part?" (A-2). He avoided giving direct advice, preferring to guide them to their own conclusions. If he had a concern that did not come up naturally during the course of their conversations, then he would guide through questions or gentle advice. "Then I'll guide them to the end result, especially if I feel like there's a glaring concern that they haven't brought up" (A-3).

Samantha confirmed his pattern of using questions to guide her through reflection. She appreciated his intention of guiding her to make connections on her own.

So we debrief after I teach, and he asks me what I think went well and what I would like to do better and how I plan on doing that better. He uses a lot of questioning, which is helpful...it makes me think critically, because sometimes, him framing that question will help me think about something in a different way, which is nice. And then I can learn to notice those things that I need to improve on my own, instead of just having someone just tell me what I need to fix (S-1).

The indirect approach was very important to Adam, as evidenced by his use of guiding questions and valuing the student teacher's voice in the relationship. 
Consequently, it was noticeable when he did use a direct approach. During the first recorded conversation he always led with questioning, but then would draw on his own experience and tell her what he would do. "Sometimes with these guys being as young as they are we sometimes have to be just blatantly like this is what we need to focus on...like I want you to listen to style, and sometimes I even have to say when I sing it to you I'm actually singing it in the style that I want you to play it..." (A-2). During the second dialogue he only gave direct advice when there was a point that he felt like he had to be sure that she understood and they were running out of time in the placement. "I think going to where you were talking about Overture Jubiloso, where they would turn the page and not know what's going on might be a macro mistake, in the sense that sometimes we have to overlook some mistakes we hear initially and get them through the piece and exposed to the piece in equal amounts, right?" (A-4). He explained that it usually occurs when there is an issue that has been happening over time and he feels that it must be addressed.

\section{Mentor Roles in Dialogues (MERID) model.}

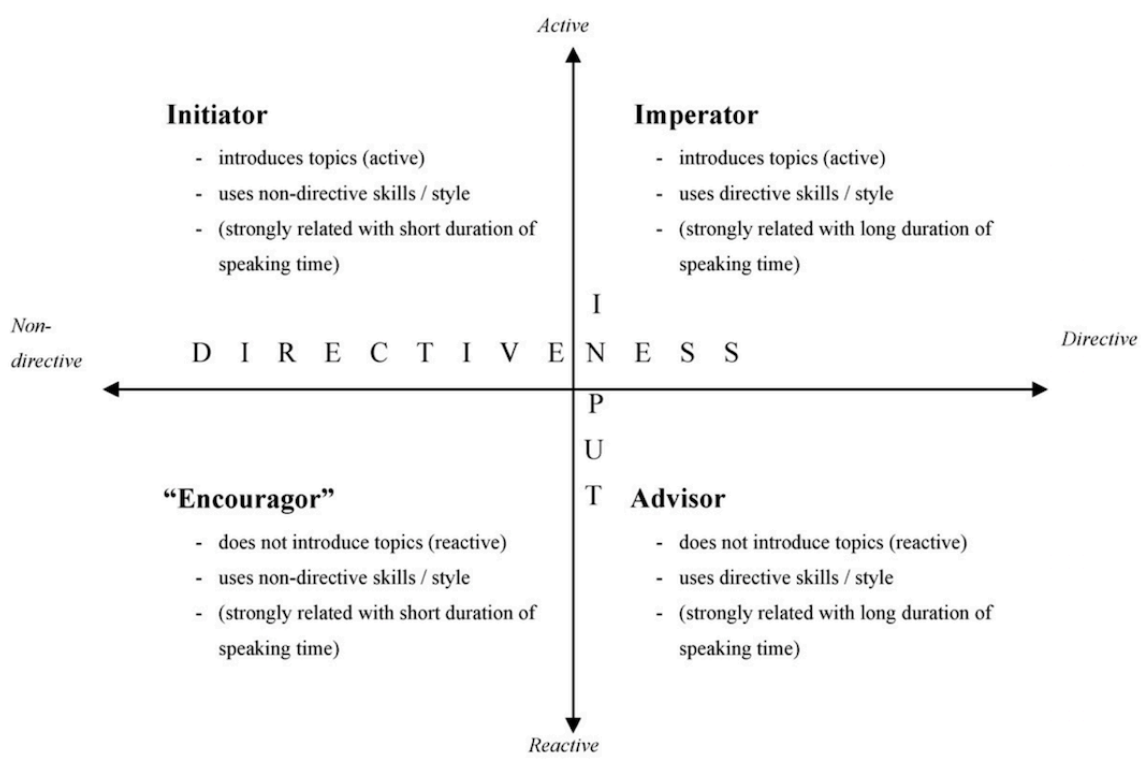

Figure 4: MERID Model (Hennissen, Crasborn, et. al, 2008) 
Examination of the recorded dialogues between Adam and Samantha indicate that his approach falls within the encourager quadrant (Hennissen, Crasborn et al. 2008). He was reactive to Samantha's reflections, yet he was also active at introducing topics of conversation through questioning. He adopted an indirect style as observed through his use of reflective questioning instead of direct advice. Figure 5 shows where Adam's approach during the first recorded conversation falls on the MERID model. His approach was coded as mostly reactive and indirect (direct: 15, indirect: 17; active: 12, reactive: 18). As shown in Figure 6, there is little change in the final recorded conversation (direct: 6, indirect: 9; active: 7, reactive: 8). His approach was slightly more indirect and slightly less reactive, but he still falls within the encourager quadrant.

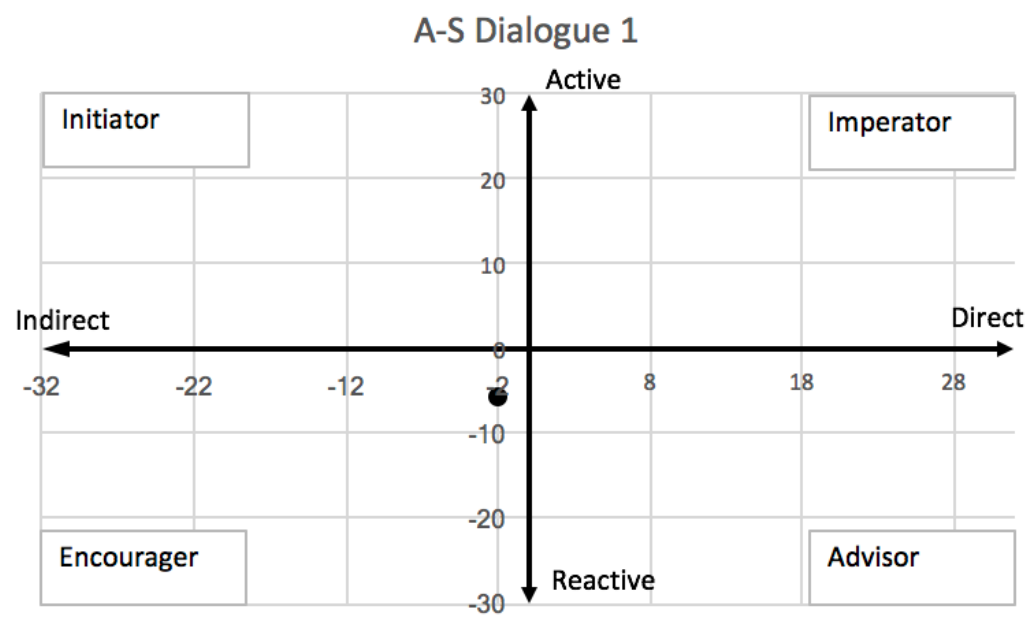

Figure 5: A-S Dialogue 1 


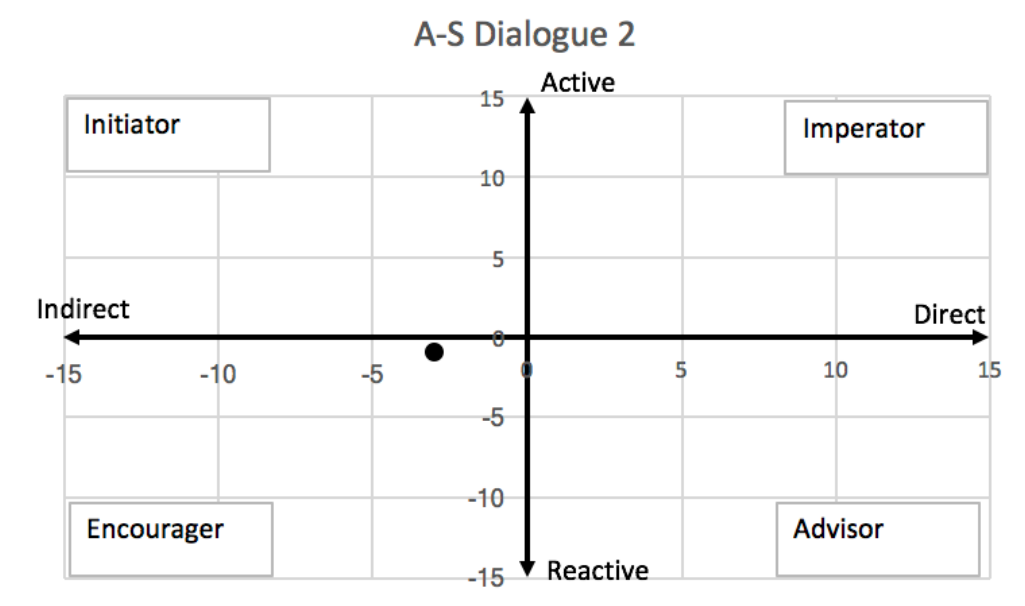

Figure 6: A-S Dialogue 2

Continuity between placements. Despite the fact that Samantha wasn't "on the front end of choosing literature" with Adam, he knew that she had been with Isabelle during her first eight weeks at Grapevine Middle School. Since Adam and Isabelle work closely together, they both prefer for their student teachers to have a shared placement and be placed with both of them. While Tyler did not work with Adam before going to Grapevine, Samantha did her first placement with Isabelle. Both cooperating teachers believe that this creates a more consistent student teaching experience overall "more like what you would if you were in a general education student teaching placement" (A-1). Adding to this continuity, Isabelle and Adam communicate about their students and "bounce off each other...I guess < Isabelle $>$ is more organized with her thoughts, and I feel like I offer some more depth perspective like the high school, sort of like the details of the music kind of thing, and <Isabelle > offers some really good instruction, for the instruction side of it" (A-4). 


\section{Isabelle and Tyler: Grapevine Middle School}

Site and participants. I pulled into the parking lot at Grapevine Middle School, right across the street from Orion High School. It was a beautiful sunny day, so there were quite a few bikes on the bike racks outside of the entrances to the school. Following our initial meeting and the first interview, this was my third visit to the school. By now I easily knew my way through the office and to the band room, down the main hallway past the cafeteria and the choir room. We had all of our interviews at the same time, on the one day during the week when Isabelle had a longer lunch period because she only had one elementary to go to in the afternoon. On this visit, just like the others, I found her in the front of the band room preparing for an upcoming class and chatting with Tyler. Student chairs and stands had been stacked and moved off to the side following the morning rehearsals. Since it was lunch time, I had brought lunch for Isabelle. We walked down the hall with Tyler to a small staff room with a table, vending machines, a microwave, and a refrigerator. We had all of our conversations in this room. Even though it appeared to be a common lunch hour, we were the only ones in the room. Isabelle and Tyler usually recorded their formal mentoring dialogues at this time as well, since they were often eating while they talked.

As we walked into the room and sat down, I set up my computer and handheld recorded while we chatted about school. I asked them how teaching was going and Isabelle asked about my progress on my dissertation and how the study was going. As she is married to a Ph.D. Candidate from the same program, she is familiar with the process and was curious about my research and what my expectations and goals were for the study. As 
I didn't want my expectations to influence her answers, I was careful to share only a general overview of the purpose.

As we began to interview, I explained that we were going to watch a video of their recorded conversation and that she should feel free to pause the video whenever she noticed something that she wanted to talk about. I explained that she might notice questions she asked or a time when she expected Tyler to ask a question. I also let Tyler know that he was welcome to stay if he didn't mind watching the video and listening to Isabelle talk about him. I didn't want to kick him out during his lunch, but I thought it might be awkward for him to sit there while we talked about him. I also wanted Isabelle to be able to talk freely. Tyler stayed for a couple of minutes, but then left to go back to the band room and prepare for upcoming classes.

Conceptual framework: Isabelle and Tyler. Figure 7 depicts the conceptual framework model adapted to show factors that were important in the case of Isabelle and Tyler. Imperator, instructional support and personality, and co-teaching are shown in a box in bold font because these factors had a great impact on the dialogues in this case. Lines have also been drawn to indicate a connection between certain factors. 


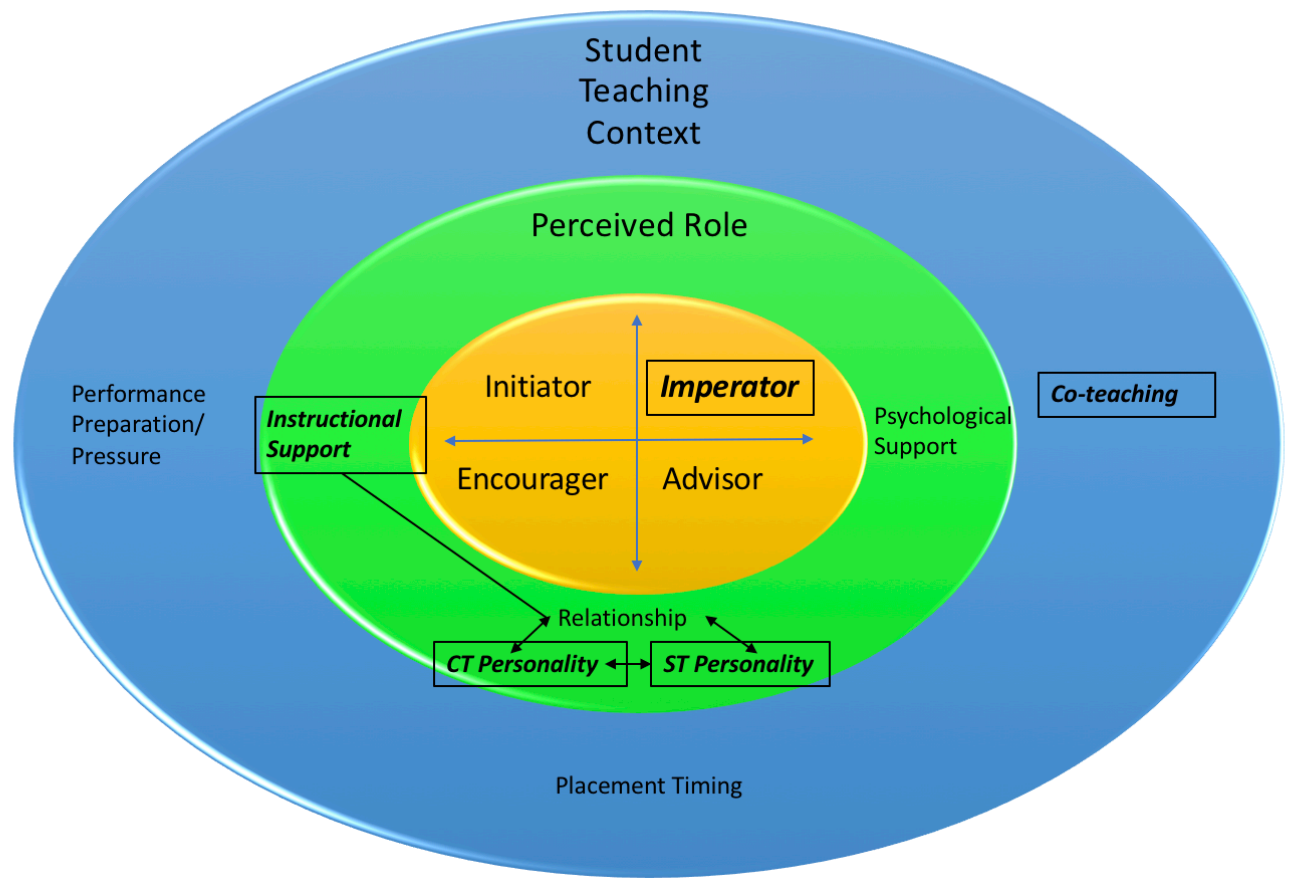

Figure 7: Model of Isabelle and Tyler

The following excerpt shows a fairly typical conversation between Isabelle and Tyler. Their conversations were often rather one-sided. Isabelle was very talkative, telling him what she noticed about his teaching, both positive feedback and areas for improvement. Tyler's typical response was "okay," while occasionally expanding with more thoughts or responses to her feedback.

I: So we sent about probably like 25 minutes on Vehicle, um and I pretty much just kept like a running commentary and I have like a couple big ideas

\section{T: okay}

I: that I saw happening. I thought the start to your rehearsal was really really good where you were having them sing it and then air it and then when you, when you didn't like the way you sang it, you just immediately sang what you wanted to hear, and that immediately changed the way they sang it back to you, so that was a really 
good piece of feedback for them, and it might not have felt like feedback to you, cause you weren't saying anything to them, you were singing T: yeah

I: Um, I did notice that you started the piece without telling them the plan for the solos. T: oh, yeah, yeah

I: even though you asked me about that. And you started the piece and I was like man they sound good, and I was like let's see what's gonna happen when they get to the solos. Let's find out.

T: I guess I was just kind of planning on stopping before the solos, so... I: yeah, that's fine...cool. Um, let's see, another moment that was really good, you stopped them and you said look at measure four, and then you spoke to the section, I think it was like the saxophones, and you talked about how they needed to articulate beat 2 , and let's try it again. And it was really, really clear what they need to do, and then you clarified the rhythm for them and the they had a chance to play it again and that was a really good example of a place where you had a good complete teaching cycle. You stopped them, called attention to it, have a clear instruction again of what needed to happen and then gave them another chance to try it. I thought that was really positive. And it sounded better after. Um, I thought you were doing a really good job of using your conducting to say what you wanted musically from them. Um, yeah.

T: <laugh> $(\mathrm{I}-4)$.

Student teaching context. It was very important to Isabelle that Tyler gain plenty of teaching experience. Therefore, the co-teaching arrangement within the classroom is 
shown in bold on the model and informed the dialogues between Isabelle and Tyler. Placement timing and preparing for performances had an impact on Isabelle's role during their conversations, but it was less obvious than the daily co-teaching arrangement in the classroom.

Co-teaching. Most days consisted of them taking turns teaching, rehearsing each of their pieces with the ensembles. Tyler had one piece for each middle school ensemble, but would sometimes spend some time rehearsing some of Isabelle's pieces with them as well. He was able to stay at Grapevine after graduation in order to conduct on the middle school concert. It was important to Isabelle to ensure that Tyler had plenty of teaching time and freedom to teach without constantly being observed while not handing everything over to him. "I also like to make sure that at some point they have at least one full day where they are teaching and the students are not aware that I'm present." (I-1). Tyler had four days on his own early in his placement since she went on the Orion High School band trip. Samantha had this time as well, since Adam was gone, but most of her students were also gone on the trip. Tyler had full classes to teach while Isabelle was gone. For the rest of the placement, Isabelle was always cognizant of Tyler having enough time. "I try to give him at least some time every single day where he's giving instruction to kids" (I-3).

"Teacher figure." In his first placement Tyler became more of the "main teacher figure" over time. His cooperating teacher would leave and Tyler would be in charge. "I still think that <Isabelle> allows me to be ... go out and do those, like be the teacher in the classroom and make my own decisions but I still, for <Grapevine>, the environment that's kind of set up there for me is kind of like she's still making those big decisions and she's still teaching the kids, too" (T-2). He described it as "balanced" instead of him taking more 
responsibility in a certain class. Balance was a goal for Isabelle, as she provided him with teaching experience and a balance between formal observations and solo time without her in the room.

Performance preparation/pressure and placement timing. During the middle school concert, Tyler conducted one piece with each ensemble and was also involved with the elementary concerts. As the concert grew closer, the time that he had in front of each ensemble might fluctuate according to the needs of the ensemble. Isabelle explained how Tyler's podium time changed over the course of the placement:

That sort of has to do with... That has to do with objectives of the lesson. My objectives for him and how close we are to the concert and our ensemble objectives. When I think about his whole student teaching placement with me, I try to make sure he gets a decent amount of podium time where he's by himself and I'm observing him and he's in charge of the class (I-3).

Though Tyler did have the responsibility and experience of preparing pieces and conducting them for the concert, their rehearsal pattern would change as the concert approached. As a result, Tyler had less podium time leading up to the concert, though this topic did not appear during mentoring dialogues.

In the second part of Tyler's placement they lost over a week of teaching time due to state standardized testing. Though the timing was a challenge as they were gearing up for concerts, Isabelle took it in stride: "testing...what can I do?" (I-3).

Perceived role as a cooperating teacher. Looking back on her own experience as a student teacher, Isabelle recalls feeling very supported by her cooperating teacher through modelling connections with students and personal support such as when she "took 
me out for margaritas when we had a bad day" (I-1). On the other hand, she recalls that her cooperating teacher wasn't always very good at clearly explaining how she did things instructionally. Isabelle believes that this is very important and strives to be able to support her student teachers in improving their delivery of instruction. One reason that she enjoys hosting student teachers is that they encourage her to reflect on her own practice: “so it's good for me because he's forcing me to articulate my strategies, but then it's good for him because it gives him another way to think about it as well" (I-4).

Instructional support. This was an area that Isabelle felt was very important and was something that was important for her to nurture in her student teachers. She prided herself on being able to help student teachers improve their instructional strategies and therefore, this is shown in bold on the model (see Figure 5). She approaches planning for her student teachers similar to how she plans for her students. She looks ahead at what their assessment is, their observations during their placement, and upcoming performances and uses that to guide her in structuring experience so that they can be successful by the end of the placement. "I ask my student teachers to identify what are some instructional skills that you personally are working on" (I-1).

When asked how she prepared to be a cooperating teacher Isabelle replied "I didn't" (I-1). She followed up by explaining that she viewed it as being very similar to her preparation for her students. "I feel like the qualities that make people good teachers are what make them good mentors" (I-3). Isabelle indicated that she never lost sight of the fact that Tyler was her student, and prepared to mentor him in a similar way that she prepared to teach her students. "Because if you can get a young student- If you can give the instruction to get a student to buzz correctly with great sound, and make improvements 
and refine that, you can apply those same techniques to helping a student teacher refine their teaching practice. In my mind, as the mentor that's a very similar process" (I-3). Just as she views the instructional cycle of giving feedback, reflecting, and applying changes similar between her ensembles and her student teachers, she views her task of adapting to her student teacher's needs in a similar fashion. She strives to figure out what their individual needs are at any given moment and help them to improve. "The process of seeing where a student is, seeing where a student teacher is, and giving them the next logical step and helping them to take that next logical step with whatever it is, whether they're developing classroom management or sequencing instruction or pieces or administrative tasks" (I-3).

A lot of Isabelle's feedback that she provided for Tyler was focused on his instructional process of listing to the students, providing feedback, and allowing them to improve. She made a point to compliment him when she saw an example of a good instructional process within his teaching. "Then you took a minute to clarify the whole note expression and I think that happened because you were conducting what you wanted, but it didn't happen... and so you stopped them and then clarified it and then went back" (I-4).

She also gave suggestions on how to improve his instructional process based on feedback from him when he told her that he was concerned about stopping the ensemble too much. “...address the corrections you know in advanced, then you can run longer chunks. Another approach to that is to try to run it longer, stop at a logical place musically, and then go back and fix more than one thing. That's another way to let them have a longer time playing" (I-4). 
Adapting to the student. In addition to articulating her own strategies of teaching, Isabelle appreciates learning from her student teacher because Tyler is so different from her. Just as Isabelle described Tyler as "deliberate," she was very deliberate in understanding and adapting to the individual needs and intricacies of her student teacher.

I really feel like $<$ pause $>$ all students and $<$ Tyler $>$ is a student in this instance, they all have their own style and their own pace of processing and I had noticed previously, um, I gave <Tyler > a task, I told him here are the scores for 6th grade 7th grade and 8th grade... and with other student teachers and with myself I can usually peruse a score, like look at the title, look at the content, and decide probably within about 2 minutes what type of piece I would want to do, and <Tyler $>$ sat in my office for 45 minutes and he studied and studied and went really, really in depth, and so that was a signal to me that his thought process is just different from mine and his process um, not like his rehearsal in the moment isn't slow, but some of his processing of certain instructional tasks is slower and I don't mean that in a bad way, I mean like he's very thoughtful and very purposeful (I-2).

Understanding Tyler's learning style allowed her to leave him space for processing information and asking questions in his own time. She also gently encouraged him to step out of his comfort zone when appropriate and necessary. “...so clearly, that was very deliberate, like taking his time and thoroughly processing all of the information is something that he's accustomed to doing, and actually in response to that I've tried to give him opportunities, not all the time because I don't want to overwhelm him, but give him opportunities to be a little more on the spot, where he has to be just a little bit faster" (I-2). She even understood the inflection in his voice, especially when he responded with his 
typical "okay." "...he kept saying okay, and his tone of voice when he says okay, I've also had to get used to, because the first few times he said that, it sounded like < pause $>$ almost like dismissive, but that's not how he means it. So it took me a little while to understand that when he says okay, he actually means, he's saying okay..." (I-4).

Psychological support. While most of the support that Isabelle provided for Tyler was more instructionally focused, she was still cognizant of providing a positive experience for him. She felt that a mentor needed to have "a level of diplomacy" (I-3). This meant that she chose her words and her tone of voice very carefully when communicating with him. "How do you offer critique and support in a way that does feel supportive and not, 'well, you did this wrong, and this wrong, and this wrong'” (I-3). Tyler really appreciated her positive approach and felt comfortable with her. By the end of his placement he felt good that he understood what she wanted and could implement it in his teaching. "Just in the way when I go up there and I teach, I know a lot of times what she wants me to do or things where I'd be like I know she wanted me to work on this, or I know what she's thinking I should hit that thing in the ensemble so I should look at that" (T-2). Over time they grew to understand each other and get along both personally and professionally.

\section{Relationship.}

I think <Tyler>, but student teachers in general, really benefit from having those times when you're not their overseer, because I think those are the times when they can feel supported and feel camaraderie...On the other hand with that as well, if he doesn't feel comfortable with me and that we have a collegial relationship and that I like him and he likes me, how likely is it that my advice or critique is going to mean something to him? There's definitely different levels to our relationship (I-3). 
As previously mentioned, Isabelle regularly took detailed notes on Tyler's teaching in order to debrief with him following the lesson. At the same time, she intentionally chose other times to not take notes and simply allow him to teach freely. She understood that it can be draining to feel the "pressure of being watched" all the time. She wanted Tyler to feel comfortable teaching in her classroom.

It was also clear that she considered him one of her students and he considers her his mentor and the "main person" in the classroom. "Yes, they're student teachers, but they're a student, and they become your student, and I think that perspective is really important" (I-1). According to Tyler in his second interview, this dynamic had not changed for them. He worked hard to process all of the feedback she gave him and apply it to his teaching. He had noticed that he had begun to emulate her in some ways. "I would think that I have acquired different qualities from her and maybe from my other mentor teacher too, just because I spent so much time with them..." (T-2). Isabelle had noticed him picking up some of her tendencies: "it's actually kind of flattering because I start to hear like my phrases and my inflection of the way I speak to students come out of him..." (I-4).

Personality impact. The personalities of both Tyler and Isabelle had a noticeable impact on their dialogues and was found to be connected with the instructional support provided by Isabelle (see Figure 7). As it has already been mentioned, Isabelle is very organized and tends to be quite talkative: "so I feel like we're connecting a lot more now, which is really important because, you know I need him to communicate what he needs to me so that I can support him...but it's taken some getting used to. Cause obviously I can be, I'm very verbose and expressive. I don't mind expressing things, and like I said before, $<$ Tyler> seems much more < pause> um, deliberate" (I-2). She has taken the time to get to 
know Tyler and appreciates their differences in personality tendencies. “...I prefer to try to be a little bit more open, and so you know when I say that < Tyler > is more deliberate, that also makes me reflect on are there things that I can be more deliberate on" (I-2).

Their contrasting personality types had an impact on the "one-sided" mentoring dialogues that were observed. While much of Isabelle's approach is deliberate and intentional as she focused on the instructional details and gives him direct advice and suggestions for improvement, the conversations might be more balanced with a different student teacher.

I: yes, and I have to um, I've noticed more since we've talked actually, um, I've just been more aware of like what like who talked first, and who, which one of us is the one bringing stuff up, and again it could just have to do with my personality and $<$ Tyler's> personality cause I've had other student teaching dynamics that are really similar to this where a lot of it comes from me, and then the student teacher's a little more receptive, not passive, yeah receptive is probably a better word, um and I've had other student teachers that are like after the lesson will come up to me like so how was that? What did you think? Or this and this and this happened, can you help me with this thing? So maybe some of it is just our dynamic, but I do notice that I'm the more verbose person <smiling $>(I-4)$.

She understood that Tyler was very deliberate and took his time to process information. She didn't worry when he didn't ask a lot questions, she knew that he was processing information and would apply it to his teaching. “...that's sort of my personality. Once I go on a tear, I'll kind of give him everything... <Tyler's $>$ personality is very much like take things in and process and then come back later with questions or information. I think part 
of it too, again with his personality is he's very trusting, which is a lovely feeling that he trusts me. He’s willing to listen to everything I have to say" (I-3).

Facets of the MERID model. The student teaching context and the perceived role of the cooperating teacher informed the mentoring dialogues between Isabelle and Tyler. Additionally, factors related to the MERID model such as topics of conversation, phases of the dialogues, and conversation timing informed the style and input as shown on the MERID model (Hennissen, Crasborn, et. al, 2008).

Topics of conversation. Just as in the case of Adam and Samantha, the topics of conversation were coded as instruction and organization, students, music, and miscellaneous topics such as administrative tasks or scheduling. The only observed conversation about students and classroom management or students occurred during the first recorded conversation as Isabelle was preparing Tyler to teach all of her classes in her absence. "I saw this as like another opportunity to make sure Tyler knew like what tools he had as his disposal...if you have a student who you just cannot control in your class, like this situation is out of hand and you suddenly don't have control of your class, cause that is a bad feeling" (I-2). She spent a great deal of time explaining the procedures for handling any disruptions at the middle school, such as sending a student to the office and calling home. Her purpose in doing this was out of concern for her students, since some of them have had negative experiences with substitutes in the past. “...something else that I see novice teachers do, and sometimes subs, is that when they're overly critical or they're not kind in their critique with students and I'm trying to foster a safe place for my students to grow" (I-2). 
Music and miscellaneous topics were also not very frequent or occurred in reference to Tyler's instructional process. Tyler reflected on how Isabelle gave her advice about how to approach the music. "...take a look in the score at this specific place, like maybe we can, you can think about what to work on in that area, or maybe intonation, or a note" (T-1). Miscellaneous topics such as administrative duties or scheduling came up primarily in the context of their first recorded conversation, since Isabelle was going over procedures for while she would be gone. "so I kind of used this as an opportunity for $<$ Tyler $>$ to see what information is important when you have a sub, so stuff like students who need paras, checking in to cover other classes when there's a big chunk of time when you are supposed to eat lunch, what kind of duties you have..." (I-2).

The most commonly occurring code for the topics of conversation was instruction and organization. Isabelle sees the instructional cycle as one of the most important things that happens for a student teacher. "I see it as a three-part process. That they're able to receive the critique, apply the critique, and then reflect on whether or not it worked for them and then why or why not...that's why they're paired with a mentor so we can facilitate that process" (I-3). This three-part cycle is similar to much of the feedback she gave to Tyler concerning his teaching cycle on the podium. "That was a really good example of a place where you had a good, complete teaching cycle. You stopped them, called attention to it, had a clear instruction again of what needed to happen and then gave them another chance to try it" (I-4). Later, she builds off of this comment by giving his advice on being more purposeful with his cycle by addressing known issues up front instead of stopping them in an effort to improve his pacing. She continues to give him advice on being more purposeful and clear in his feedback to students. "You started slowly and were speeding it 
up, so to me it sounded like you were working on accuracy, but I'm not sure they knew what it was that you wanted" (I-4).

Phases of the dialogue. Isabelle's overall pattern for conversations was praise and constructive critique followed by reflective questions. "I usually try to start with something positive and recognizing success. Then, if there was a place that I noticed where maybe pacing was inefficient or his wording was confusing or where I noticed maybe he stopped a line of instruction because it wasn't working. That would be the next thing that I would address and then we would come up with a plan" (I-3). This general pattern is observed consistently throughout the final recorded conversation. "You gave them some instructions to write in a crescendo, that was really good...uh let's see, I made a note at measure 33, trumpets and clarinets, oh you slowed it down, erred it faster, and asked for more articulation. Be clear about what you want" (I-4). Tyler appreciated that her feedback was generally positive and helped him to feel better about his teaching. "I think that she, well her feedback is positive and constructive in those ways, yeah, I'm trying to think of, well, and example is well, if a lesson went well, or was terrible, like she'll still you know, be there supporting and is like, well, it wasn't as bad as you thought" (T-1).

After Isabelle finished going through all of her notes, then she asked Tyler for his thoughts. "So now you tell me, I just dumped a bunch of information on you, what are some thoughts that you had, maybe like in the moment or finished with a rehearsal, you finished the piece, and it can be instructional things or just other things that you are going to work on in the future" (I-4). As it was nearing the end of the conversation, Tyler responded by reiterating each of the major points they had talked about from his teaching. In many cases 
Isabelle had explicit reasons why she took the approach that she did, so I wondered why she chose to begin with feedback before asking for his reflection.

I: I have no idea, and actually I've been thinking about that while watching this, is that I almost have to put that in there on purpose to make myself give him a chance to just <pause> like almost like debrief himself like vent a little bit. And I don't have a clear answer or a clear idea as to what is more effective for a student teacher to reflect first, and then me give feedback, or me give feedback and then they reflect, or if it's some kind of interspersed. And that's something, yeah I feel like that's something I can be more purposeful with and more reflective of (I-4).

Conversation timing. As Isabelle tends to be quite talkative, she recorded long videos with a lot of talking time. True to her organized nature, she regularly took detailed notes about Tyler's teaching and would debrief from her notes during their mentoring dialogues. Some of their conversations were one-sided, with Isabelle giving feedback or advice and Tyler responding with brief, one-word answers. This is reflected in the talking time of both of their dialogues.

Table 9: I-T Conversation Timing

\begin{tabular}{|l|l|l|}
\hline I-T Video 1 & I: $20: 25$ & $93.01 \%$ \\
\hline & T: $1: 32$ & $6.99 \%$ \\
\hline I-T Video 2 & I: $16: 34$ & $82.49 \%$ \\
\hline & T: $3: 31$ & $17.51 \%$ \\
\hline
\end{tabular}


Isabelle referred to their first conversation as a "brain dump" as she was talking about sub plans for Tyler to teach while she accompanied the Orion High School marching band on a trip. An excerpt from this conversation is included below.

I: So we have jazz band A day, $8^{\text {th }}$ grade, $7^{\text {th }}$ grade, that nice big block of time and then you're gonna do um, Aspen Creek in the afternoon, so for jazz band, they're pretty much gonna do what they did on Monday afternoon, open up Class Dojo, mark who's absent, and let them check themselves in, I know that you didn't feel like you needed to use <inaudible > that's what I do when a student is absent T: okay I: um, but what you can do is maybe write me a note or write me an email like here's the attendance for jazz band on this day. Um, and make sure that like you just double check at the end of the rehearsal to be like did that person ever show up or did they just forget to click their name, cause I have a handful of students who do that from time to time

T: okay

I: um, and you can rehearse Into to Sun which is in the book, Watermelon Man and In a Mellow Tone, you might start by having them do a sectional with alto 1 s on I think its Watermelon Man where they have that slow section, cause they just need more <inaudible> on that, and then you're gonna stop on, at about 8:30 or a little bit before 8:30 is okay.

T: okay

As indicated by the conversational timing, there was a little more input from Tyler during the second conversation as they reflected on his teaching. 
I: if you know that there's something that you didn't get to address last time or that you know you need to clarify, um you can do that before you run T: okay

I: and you don't always have to do that, but with a group like jazz band where we only see them twice a week, efficiency is pretty important T: and I think that could, um, cause I was kind of thinking about that and with the rehearsal and I was kind of playing, and when we come to those spots we'll do it, but I was like well, then, cause I was thinking, like was I stopping them too often, too much stopping isn't very fun, and I want them to play

I: so it's good that you notice that too, cause they'll um, when you have like pacing issues, you can feel it in the student feedback, like they're body language or how much they're talking or, just like how they hole themselves. Or if you stop them and they keep playing on purpose for a really long time, and they're being obnoxious about it, or if you stop them and you get like facial expression, that's like a signal that it's impacting them. So yeah, address the corrections you know in advanced, then you can run longer chunks. Another approach to that is to try to run it longer, stop at a logical place musically, and then go back and fix more than one thing. Um, and that's another way to let them have like a longer time playing (I-4).

Cooperating teacher input. Isabelle was intentionally more active in their mentoring dialogues, as she took on that responsibility in order to maintain consistency. "I usually start it, I don't know if that has anything to do with it being helpful to them or not. It usually just has to do with I feel the need to make sure that we are doing that step consistently and I just naturally take responsibility for that" (I-3). Throughout the 
dialogues, Isabelle would take the responsibility for shifting to a new topic, depending on what she had written down in her notes. During the final recorded dialogue this was usually feedback based on what she had observed during a previous rehearsal. "I was thinking about your process as a whole and like big picture cause like the rehearsal and the diagnosis, like every time you cycled through was really, really good, so, something you can think about is can you be more purposeful about that process?" (I-4).

Student Teacher Response. There was a noticeable shift from the first recorded conversation to their final recorded conversation, as Tyler was more responsive during the final one. In their first conversation Isabelle was sharing her sub plans and his typical response was "okay." There were some "natural pauses" in the conversation where she expected that he might have questions, but she indicated that he often would follow up with questions later. While he was still very quiet, there was more response from Tyler about his teaching during the final recorded conversation. "and now that I think about it, I don't think I had a clear goal in that measure, I was just thinking that it was a bad measure last time, so it kind of went a little funky so it's like, well, let's kind of separate it" (I-4). While he doesn't always respond to her feedback verbally, Isabelle believed that he would often respond by simply applying the advice that she had given. "and so it doesn't necessarily always happen conversationally where he'll be like okay, I'm gonna try this and this and this specific thing, he doesn't really tell me, he'll just do it" (I-4).

In the final recorded conversation, Tyler also expressed concern about his rehearsal pacing or keeping students engaged throughout the rehearsal. Isabelle would respond to his concerns by reassuring him that she understood why he might be concerned about that, especially because he was so often being observed. 
Absolutely, and I forget sometimes, because it's been so long since I've had, you know, an observer in my room, like asking me why aren't these students playing, what are these students doing at this time? That for me, I'm fairly comfortable isolating a group because I don't have someone holding me accountable except for me. Um, but usually what I'll do to mitigate that a bit is to ask the listeners questions, it's like my go to (I4).

Style and supervisory skills. In both conversations Isabelle used a direct approach with Tyler, giving him goals and advice to improve his teaching. This approach was confirmed by Tyler in his reflection about his experience teaching at the elementary schools. "I'll teach a lesson for one of the brass classes and then I can teach the same for the next brass class at the other elementary school, and so I can focus on some of the goals that she'll give me for the next one or think about the feedback that she has" (T-1).

As described previously, the first recorded conversation consisted of Isabelle explaining sub plans to Tyler, her instruction was very direct. It was early in his placement and therefore she was concerned with trying to prepare him for whatever might happen while she was gone, including what pieces to rehearse and what to expect from the students.

I: some kids will be able to play their parts, some kids won't, be like okay, cool, I heard this and this and this, let's do that once again, do it two times and move onto the next section and then like just kind of bounce around and play what needs to be played. Um, the more they play, the better their behaviors going to be for you.

T: okay

I: but, uh don't be afraid to send a kid out if they're being really disruptive 


\section{T: okay}

I: and it doesn't have to be a big deal, like you can go up to them really quietly and you don't have to say it in front of the class, cause the last thing you want is for them to like think that it's a confrontation, so give them a chance, give them clear communication, and if you have to ask them to leave be like get your stuff, you're going to go up to the office, I'm going to call and let them know that you're coming. And you don't have to like say anything more than that. Sometimes when kids get confrontational, that's an out of control situation and I don't want you to have to deal with that (I-2).

During the final recorded conversation, Isabelle's direct advice consisted of instances where she drew on her own experience as a teacher in order to explain what she might do in a given situation.

I: Now let's do it, let's practice it out of context, let's take it out of context then out it back in. Um, cause they will, they'll retain it better when you do that. So that's, um, that's a suggestion right there. So then that had me thinking, like when do, when should you as a teacher like isolate parts when you're rehearsing, and there's, at least for me there are two times when that happens. One time is just to check for understanding, so maybe in that previous spot, 33 we were just talking about, just having them play it and tell them the first time you played it I didn't really understand what it was supposed to be, let's play it again and see if it can be more clear (I-4).

Other times her advice for Tyler was more like a gentle suggestion, but ultimately leaving room for some freedom to choose what might work for him. "I usually try to give them like a sight reading, so whatever the concept is that you see in sight reading similar to what we've been doing, you can emphasize that as much or as little as you want" (I-2). She 
tries to keep her advice balanced: "I try to do both, like give him structure and other times let him do the structuring" (I-2). She strives to offer strategies that may enable Tyler to be successful, while still allowing some space for him to realize what strategies that might work for him.

I: well all of the strategies and all of the knowledge that I offer to < Tyler > and my other student teachers, it's my way of doing things, and it's what works for me, um, and I think it can be very limiting as a young teacher to think that there's one right way to do things, so that's why you'll usually hear me use a phrasing like, with my students this is what works, or for me this is what works, because every teacher is different and every group of kids is different, and I think context is important and I think knowing your practice is important (I-4).

Isabelle also reflected on why she so often gives Tyler strategies and ideas as opposed to allowing him to come up with them on his own. "Not that I don't think he could come up with those strategies, um, but for the sake of time, not the sake of time, but I don't feel like that's really something that he should have to discover on his own. Because there are good strategies for managing your rehearsal time and the flow of rehearsal and the process of rehearsal, um yeah, I don't see that as something that he should have to discover naturally if can give him some strategies" (I-4). True to her organized nature, she feels that it is important to be consistent with her feedback and advice. She has taken her cue from the university supervisors and takes detailed notes in order to address all of the important points with Tyler. "I do what most of the faculty do, I take notes on what is happening, in how the students are responding, the flow, the pacing, what gets accomplished, um and I try to help them refine their language" (I-1). 
Since Isabelle tended to be quite direct in her mentoring approach, if she implemented a more indirect approach it was noticeable. The time where Isabelle adopted a little bit more of an indirect approach was in their final recorded conversation when she asked for his reflection on his teaching: "yeah, the kids were really engaged. So now you tell me, I just dumped a bunch of information on you, what are some thoughts that you had, maybe like in the moment or finished with rehearsal, you finished the piece?" (I-4).

Mentor Roles in Dialogues (MERID) model. Investigation of the dialogues between Isabelle and Tyler placed Isabelle's mentoring approach within the imperator quadrant according to the MERID model (Hennissen, Crasborn et al. 2008). During both recorded conversations, her approach was observed as direct and active, steering the conversational topics and giving direct advice. Figure 8 maps Isabelle's approach as observed in the first recorded conversation. By counting code occurrences (direct: 24, indirect: 1 ; active: 25 , reactive: 1 ) her approach is shown to be highly direct and active.

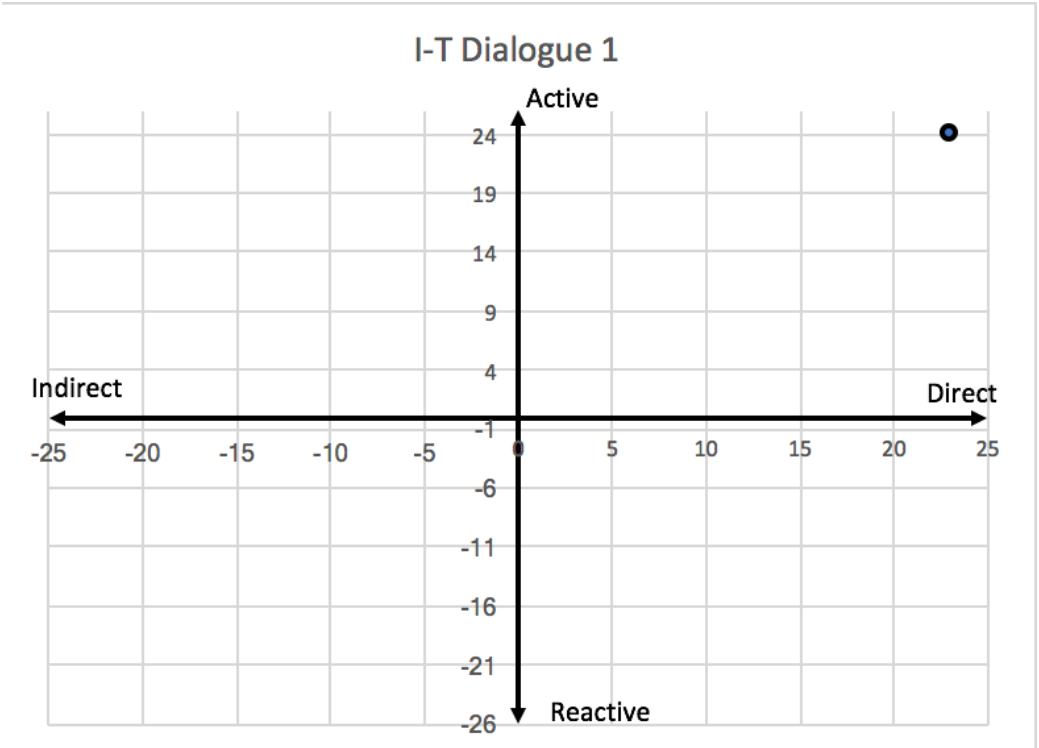

Figure 8: I-T Dialogue 1 
Figure 9 shows Isabelle's approach during the second recorded conversation. While there were more instances of an indirect (indirect: 4, direct: 21) and reactive approach (reactive: 7, active: 19) as indicated by coding, she still fell firmly in the imperator quadrant.

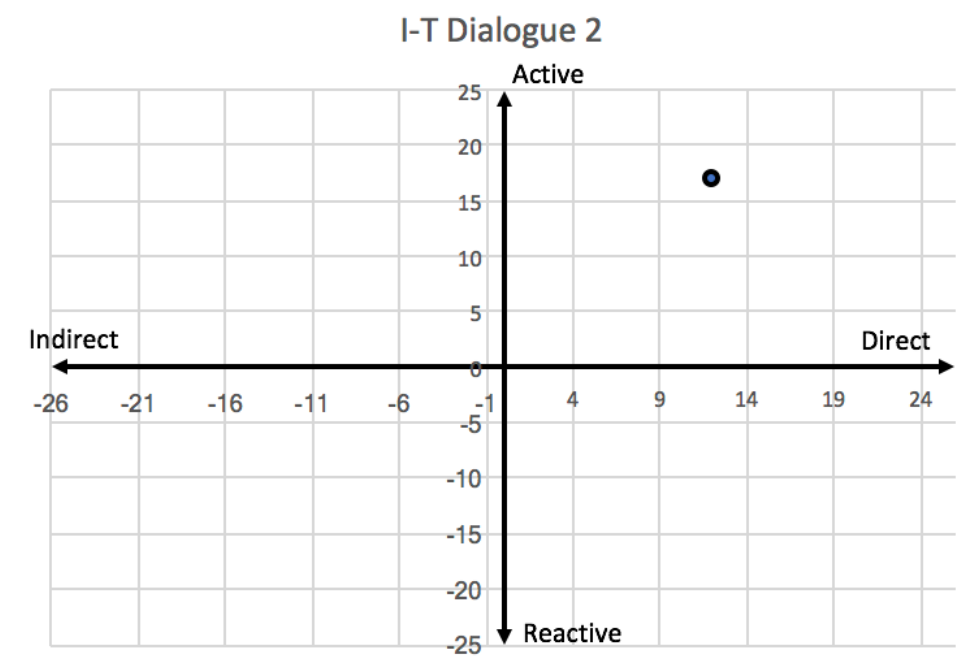

Figure 9: I-T Dialogue 2

\section{Joanna and Ellen: Elwood Middle School}

Site and participants. On a beautiful spring day that almost felt like summer I arrived at Elwood Middle School in River Valley School District. This was my second visit to the school following my first interview with Joanna a couple of weeks prior. My initial contact with Joanna about participating in the study had been made by phone and email. Just as I did the first time I came to Elwood, I brought Joanna a cup of tea. Since all of our meetings occurred after school, she seemed to appreciate some tea at the end of a busy day. I came into the school and signed in at the office. The office staff is accustomed to visitors heading to the music wing of the building, so they assumed that I knew where I was going. I remembered which way to go across the open atrium and down a crowded hallway. I arrived just as students were being released and heading to their lockers so I 
had to carefully dodge students and not spill tea all over the place. I found the orchestra room and had to wait for a minute until all of the students came out of the room. Once they had cleared the room I came in and found Joanna chatting with Ellen and putting away some music. The student chairs had been stacked and moved to the side so the center of the room was empty. Joanna and Ellen were at the back of the room near the office. They shared an office with the band and choir directors and the program assistants. When we were ready to start our interview Ellen went in the office and Joanna set up a couple of chairs and a stand for my computer near the front of the classroom.

As this was my first stimulated recall interview I wasn't sure how comfortable Joanna would be with pausing the video and volunteering information. Perhaps because Joanna was so easy-going and comfortable to talk to she had no trouble interrupting the video and telling me about her thoughts and actions. Joanna had been teaching for twenty years and had hosted numerous student teachers. She seemed very relaxed and confident, joking around with Ellen and with students when they come into the room to get their instruments. When two of them came in during our interview she teased them that they were being so loud and that we were talking about them.

Conceptual framework: Joanna and Ellen. Figure 10 depicts the conceptual framework model adapted to show the factors that were especially salient in the case of Joanna and Ellen. Encourager, psychological support, performance preparation/pressure, and co-teaching were all found to be important and therefore are shown in bold font with a box around them. Lines have been drawn showing the connections between co-teaching and psychological support and between psychological support and relationship. 


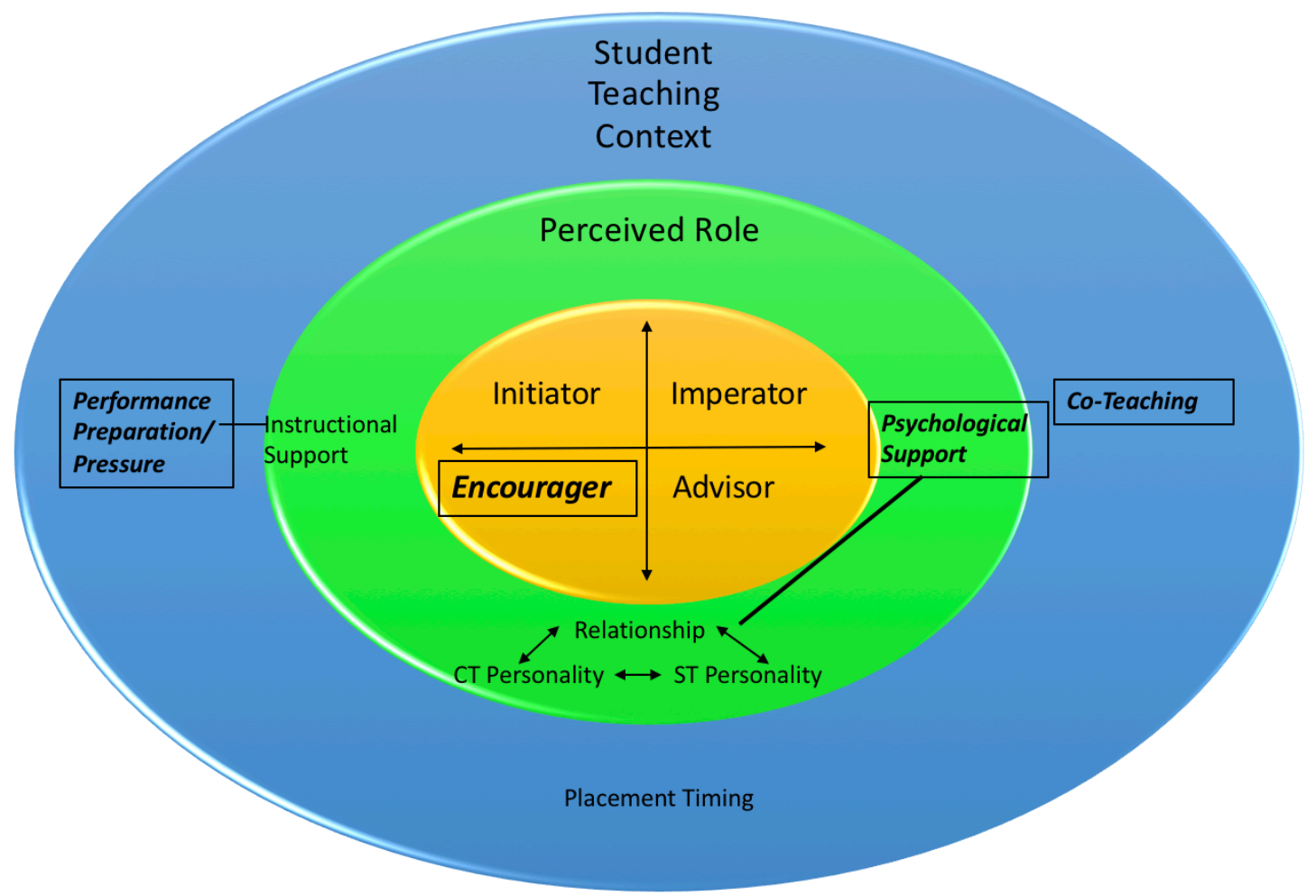

Figure 10: Model of Joanna and Ellen

Student teaching context. Ellen felt like a valued part of the team in the classroom at Elwood Middle School. “...We're talking more, being more friendly with each other. We're definitely more like co-teachers right now as opposed to student teacher/cooperating teacher" (E-2). The co-teaching relationship was very important to both Joanna and Ellen and therefore is shown in bold and connected to psychological support on the model (see Figure 10). Additionally, preparing for performances impacted Joanna's approach especially during rehearsals. Therefore performance preparation/pressure is shown in bold (see Figure 10).

Co-teaching. The daily working relationship between Joanna and Ellen was an important factor in their classroom and impacted their regular conversations. Both parties 
described it as co-teaching. Ellen thought that their individual teaching styles worked well together and by the end of the placement they functioned together very naturally.

It's a lot of, we have our pieces that we're working on and while we're doing that, the other person is in the back making comments, or I'll ask <Joanna $>$ 'what do you think? Do you hear this?' and she'll ask me the same thing because it sounds way different from the back of the room. Really we just bounce ideas off of each other and if I'm not hearing something, which happens, she'll just jump in and say 'do this.' It's good to go off of each other (E-2).

Most days throughout the placement they would take turns on the podium rehearsing the groups while the other person would observe, play with the group, or work with small groups. Toward the end of the placement there were more informal conversations during rehearsals where Joanna would interject feedback for the students or ask Ellen's opinion as an observer on the sound of the group. They each had their assigned pieces, as Ellen had chosen one or two pieces for each ensemble that she wanted to work on for the concert. Occasionally they would trade pieces and rehearse each other's and Ellen had a solo week near the end where she was responsible for teaching everything. "She worked on my pieces and I worked on hers, so first of all even for me it's good to hear a fresh set of eyes, a fresh set of ears. For her, I just wanted to make sure that some things were really getting worked on and ironed out before the performance" (J-3).

Joanna was always concerned that Ellen was getting enough time teaching. At the beginning of the placement she was trying to gauge if she needed more or less podium time so that she could adjust accordingly. “...does she feel like she's anxious to get up here more and teach more or is she overwhelmed? She seems like she, you know, like she's getting 
enough time, um, that she could even do a bit more and, and she has already had some experience and I haven't seen it" (J-2). She was willing to adjust according to Ellen's goals and needs as a student teacher. She was flexible and willing to give Ellen the freedom to try her own ideas in the classroom. "I invited her to do any kind of warm-up she wants. She doesn't have to follow my routine. The kids are getting sick of it and so am I. She can bring some creative juices to that" (J-3).

Performance preparation/pressure. As an ensemble director, Joanna always kept concert preparation and the musical experience of her students in mind. As she was concerned for her student teacher getting enough time in front of the groups, she had to weigh the balance between their needs and the needs of the program. Some of her student teachers have wanted even more time on the podium.. "And the one I had last year, he was gung ho and he would have just taken over if I'd let him, but I wasn't really comfortable with that, I mean you still have to maintain the integrity, it's still your program, so you still have to be, you know, it's hard with music" (J-1).

Joanna realized that she might feel differently if she taught a different content area. In a music program, she was feeling the pressure of being in the public eye through performances and having to maintain her students in her ensembles. As her classes are electives, she worries about losing students if the performance is not as strong. "Letting go-I think too, with music it's just different. We have this huge buy-in of whether the kid's education is being sustained when there's a student teacher there. Performances and things like that. You know? So do core teachers, they have testing, but I think it's just different. Ours is just so much more public" (J-3). As much as she trusted Ellen as a competent teacher, she had some trouble letting go before a performance. 
We discussed her doing a solo week, week after next. She sounds like she'd really like to do that. I'm having a little bit of a hard time letting go completely because we have our concert. You know, if it was at a different time of the year, I'd be fine. I have confidence in her. It's just hard for me to not have it be perfect, you know? It's the performance thing. It really is. If it was a regular classroom I would be all the way out. You know? You take over, you've got this. She's a really good teacher (J-3).

Placement timing. Though not as obvious as other factors, the timing of Ellen's placement did have an impact on their dialogues. Student teaching at Elwood during the second half of the semester did mean that the pressure of preparing for a performance is a challenge, it also meant that she was ready to be independent as a teacher and take on more responsibility. Ellen was building on instructional strategies that she had begun working on during her first placement, and therefore didn't need as much guidance from Joanna. "She did her edTPA in the last placement, so there was just a lot of things. And I think a lot, and of her teaching issues were addressed in her first placement, so um, she's worked really hard on fixing those things that were addressed, so it's just easier now" (J-4). "She's only here for 8 weeks, and basically three of them, two and a half are missed time, actually three, it was a good solid three weeks" (J-4). During the spring, the class schedule for the entire school was interrupted for state testing. This allowed them to get to know each other better as they had large chunks of time when they weren't teaching, supervising students outside, or even teaching a unit on sex education. This meant less teaching time for Ellen, less time to prepare for their concert, but also meant they developed a closer personal relationship. 
Perceived role of the cooperating teacher. Joanna perceived her role as a mentor broadly and included both psychological support and instructional support, yet the psychological support of creating a supportive learning environment came to the forefront for Joanna and Ellen. Therefore, it is shown in bold font on the model (see Figure 10) and connected with the relationship. Joanna considered it to be important to build a relationship instilling trust and confidence where they could work collaboratively.

Joanna first began working with student teachers because she wanted to give back to the university and it sounded like an interesting experience. Since then, she has enjoyed watching them develop as teachers. "just kind of watching them grow as they learn and get more and more comfortable, and I love watching how excited they get when they finally start to have a little success and see that, that what they're doing is working" (J-1).

Joanna encourages her student teachers to experiment with different strategies and try new things in the classroom. She is open to seeing what ideas they have and sometimes may learn something new from them. "...I would have tried a different approach, where you have the back row, and then layer them back in, um, but you know, she had them turn the stands around, so it's neat for me to see the student teacher and what tricks they come up with. You know, you can always learn from a student teacher" (J-4).

Psychological support. It was important to Joanna to establish a trusting relationship in which Ellen felt free to ask questions and felt trusted in the classroom. From the start Ellen mentioned that they didn't really talk about plans or plan together. Joanna didn't ask her about her objectives, she would just say “what are we going to do today?" (E-1). Ellen went on to explain that this made her feel trusted. "So it's just one of those things, it's like she doesn't feel like we really need to discuss the plans that much, just 
because we know what needs to be worked on" (E-1). Joanna agreed with this and showed her confidence in Ellen. "I think it's trusting, I think she trusts that she can ask me questions. I certainly have confidence in her. I think I show that I have confidence in her so I hope she feels confident in me. We kind of share our thoughts on what's going on rather than me just telling her" (J-3).

As Joanna encouraged Ellen to try out new ideas in her teaching, this contributed to Ellen's confidence as a teacher. Joanna also asked for Ellen's input during rehearsals about the sound of the ensemble, especially as they grew closer to the concert. At times she interrupted her teaching for feedback, and also let her know that it was okay for Ellen to interrupt as well. "and you know what, feel free to do that to me at this point too, cause if you're hearing something that I'm not hearing, we need to nail it right away cause we only have like four rehearsals" (J-4). Being asked for her input made Ellen feel trusted and more confident in her abilities as a teacher. "It makes me feel confident in my teaching and like I actually know what I'm doing, at least just a little bit. As much as it doesn't feel like it sometimes" (E-2).

Not only has Joanna encouraged Ellen to try out new strategies by allowing her freedom and adequate podium time, but she responds to her ideas positively. "I think she's really given me the confidence to know that I can be an effective music teacher. Every time I try something new, she'll come up after like, 'Oh I really liked what you did and I really heard the difference'” (E-2). Knowing that her efforts with the students has made a difference has given her a new sense of confidence in her abilities as a teacher.

Relationship. Ellen often reflected on how different her relationship with Joanna felt compared to her first cooperating teacher. Her first placement was with a local high 
school orchestra teacher who tended to be very direct with advice for student teachers.

With Joanna, she felt like she was able to collaborate and have her voice be heard.

It makes it feel more like a collaboration, and less like I'm the student and she is the teacher.. More like we're bouncing ideas off of each other because we're trying to solve a common problem. It's nice to feel like my ideas are being heard because that's something that I struggled with a little bit in my last placement where...I was just being told what to do, one thing after the next. I never felt like I got to make the decisions. Here, it feels like I'm getting to make the decisions about things"' (E-2). Joanna was very open to hearing Ellen's opinion and working collaboratively with her. In the second half of the placement she felt like their relationship was moving towards a more equal partnership. “I wouldn't say it's quite equal. It's still teacher and student, but maybe leaning a step up more towards equal than completely teacher and student. That's since she started" (J-3).

Personality impact. Both Ellen and Joanna described themselves as introverted. "I'm super introverted, but you would never know because I talk in front of groups all day long, but that's just how it is. It's your job and you get used to it" (J-2). Ellen tends to be very quiet and fairly serious. At first, this concerned Joanna because making connections with the kids is so important.

When she first started, she's pretty shy, and she's quiet, and that was kind of a little bit of a flag for me, I just kind of watched to make sure, you know, I just think that uh, those relationships you build with students are crucial, especially with an elective program, you know, you need to keep the numbers or you're not going to 
have a job, and she was a little soft-spoken at first, but she's starting to make connections... (J-2).

Joanna continued to encourage Ellen to make more connections with students and to loosen up and have fun with them. "She doesn't get as crazy with them or joke around with them as much. She's very professional with them. I wonder if it was her own group and she could relax a little bit, if she would be different. You can be goofy with middle schoolers, you know?" (J-4).

While some of Ellen's techniques and personality was a little more serious than Joanna, she understood that she was a different person, and she might approach things differently and develop a different teaching style. "She's a little more serious person than I am, overall, and so um, that's fine you know, and what she is going to do is gonna work for her, and I think she'll be very successful with it" (J-4). She also understood that she may still feel a little bit more reserved because it wasn't her classroom. "I think some if it's her personality and some of it could be still, you know, watching. It's hard to be funny in front of somebody else and to joke around with the kids when someone else is watching you (J3).

Instructional support. Joanna's instructional support was not as obvious as the psychological support, but it was still an important part of her role. From the beginning, she wanted to make sure that Ellen received whatever guidance she might need. She reflected on how she would adapt to the individual needs of the student teacher. "I use a different approach, but I always kind of start with the same things and I say, what do you want to get out of this? Do you feel like you just really need a lot of practice and need to get up there, so you feel like you need me to guide you more?" (J-1). She has had other student 
teachers, especially during their first placement, who need more guidance with lesson planning and modelling instructional strategies. As this was Ellen's second placement, there were instructional strategies that she had been working on through her first placement. Ellen mentioned that she had been working on having measurable objectives and Joanna noticed that she did that well. "Oh good, well I think I see a difference in the way you're doing it so the approach is really good, it's more like someone who's taught for a year and who's actually worked on concerts" ( $\mathrm{J}-2)$. By the end of the placement Joanna felt like she wasn't giving her a lot of feedback and wanted to make sure that she was being helpful. "Yeah, if she's, if there's anything in these last couple of weeks, just really tell me what I can do for you as far as feedback" (J-4).

Facets of the MERID model. The mentor dialogues between Joanna and Ellen were informed by the outer layers of the model including the student teaching context and the perceived role of the cooperating teacher (see Figure 10). Additionally, the role adopted by the cooperating teacher during dialogues was impacted by the facets of the MERID model including the topics of conversation, phases of the dialogue, conversation timing, cooperating teacher input, and style and supervisory skills.

Topics of conversation. The primary topic during the first recorded conversation between Joanna and Ellen was the music that Ellen was rehearsing. She was choosing which pieces she would rehearse for the concert and had sight read a very challenging swing style piece with the pops orchestra. The rhythm was especially challenging and Joanna was reassuring her that she wasn't the only one who struggled with the rhythm. "The first time we did that, that's what I had to do and still there will be times when I don't know the rhythms...so I completely understand how you feel about it. That's a struggle, and I 
think if we do sectionals" (J-2). It was a piece that Joanna had performed in the past, but only when she had a group that she thought could handle it. "Some things I recycle, and this one I only pull out for special groups" (J-2).

As this conversation was early in Ellen's placement, she was also making some comparisons between her teaching experience at a high school compared with middle school. She had been working on intonation with the middle school ensemble and realized that a different approach worked for them compared to what she used at the high school. "And I'm figuring out with the younger students you kind of have to trick them into doing, like intonation. I wasn't saying match your d-sharp to my d-sharp, I was saying fit your sound into my sound and just tricking them into doing it" (J-2). Joanna agreed with her observations and assured her that she may not see progress immediately with middle school students. "And, um, I think sometimes, especially at this stage they are, we are still learning notes and rhythms, you'll do something and it may not seem to have an impact, but you gotta just keep chipping away and all of a sudden it will start to sound better" (J-2).

In the second recorded conversation they shifted their focus to Ellen's connection with the students. As she had just finished solo teaching for a week, and Joanna had been encouraging her to connect with the students as much as possible. "I feel like you're connecting with the kids more, especially with me being out of the room kind of getting to know them a little bit better. It's hard when you don't have the whole semester" (J-4). Ellen responded that she still struggled with the eighth graders because she hadn't had as much time with them. Joanna reassured her, "I think they really respect you, and there's more of them too, and when the class is bigger it's harder to make one on one connections" (J-4). During her solo week, Ellen had tried out a few new techniques for tuning and warm-ups. 
While she had some success, some students were talkative and slow to catch on to the new routine. Joanna reassured her that she was doing a good job and that sometimes the kids are just talkative. "But you addressed it really really well, you were really patient with how you addressed it too, so you know..." (J-4).

When they talked about instruction, it was often in relation to students, such as when Ellen made comparisons between middle school and high school students. There's just been like little moments where I'm trying something and I'm not expecting it to work but it does, and I think I wasn't expecting it to work because it wasn't working at the high school when I started doing those kinds of things" (J-2). During the final recorded conversation Joanna also made sure to talk about Ellen's use of voice during her teaching. She was encouraging her to use her voice more while conducting. "And this was a big one, um she's quiet, so trying to get her to, uh, she talks to them just fine, but you know, there's a lot that can be done while you're conducting without having to stop...singing with the kids is huge for instrumental too, and she doesn't sing, so..." (J-4).

Sometimes miscellaneous topics of conversation might include administrative, or non-teaching duties. For Joanna and Ellen they chatted briefly about calling parents about students. While talking about student behavior and classroom management Ellen asked Joanna about calling parents, since this is not something she would experience in her short time at Elwood. "And you haven't had many opportunities to call home or communicate with parents in your short time here, so, but um that really does help, especially if you're really positive with the phone call. I love your kid to death, here's what he's doing, and do you have any advice on how I can get him to stop?" (J-4). 
Phases of the dialogue. Both of Joanna and Ellen's recorded conversations followed a similar pattern. Joanna liked to get her student teacher talking, reflecting on how they thought their teaching had gone. "I always start with um, so how do you think that went, you talk to me, how do you think that went? Um, what do you think went well?" (J-1). Later, she follows up with "what do you think you could have done better? Is there something that you would have changed if you could go back?" (J-1). She intentionally tried to begin with something that went well for them. " $<$ Student teachers $>$ usually start with the negative, which is funny because I always try to start with the positive. Here's what I think you're doing really well, but they start with the negative, 'I need to fix this and this, dah-dah-dah' (J-3).

It was very important to Joanna to have most of the reflection come from Ellen. "So last thing you want to, I feel, should be done where I say here's what I noticed (J-2). Once Ellen reflected on how she felt about her teaching, then Joanna would respond with her thoughts, which were primarily positive. "But you think you had a pretty good week? I thought you had an awesome one" (J-2).

In their first recorded conversation Joanna had a few topics that she planned to bring up about Ellen's first week if they didn't come up naturally. “Um, I was going to ask what you thought compared to high school, um, but it sounds like it's just easier to make connections?" (J-2). She also wanted to make sure that Ellen was comfortable with the amount of podium time that she was getting so that she might adjust accordingly. During the final recorded conversation Joanna only asked a couple of general questions about her solo week such as what some successes were and what some challenges were. Ellen freely reflected about how she felt and Joanna responded with positive reinforcement. She had a 
couple of topics in mind that she wanted to address such as connecting with students and Ellen's use of voice while teaching. Ellen brought up connecting with students on her own, and Joanna later shifted the conversation to talk about voice.. "Um, yeah, I think too, if you start with your teaching, trying to <pause> the use of your voice is so important" (J-4).

In both conversations, Joanna was trying to gauge what Ellen needed, whether it was more podium time or more feedback. "And if you feel like you need more feedback, let me know, because I don't feel like I'm giving you a ton" (J-4). Throughout both conversations the majority of Joanna's feedback was positive. "I liked how you said raise your hand if you're...I mean that wasn't your habit that you started with them, but you got them to think why do I even do this?" (J-4). Advice was given as gentle suggestions: "and I think if you just break it down like that, um, it becomes easier, so we'll do sectionals" (J-2). At the end of the placement, Joanna reflected that she didn't feel like she was giving very much feedback. "If there's anything in these last couple of weeks, just really tell me what I can do for you as far as feedback, and I think that's what I was trying to ask there. And I don't feel like I'm giving her a lot of criticism is more what I meant" (J-4).

\section{Conversation timing.}

E: I still don't know if my pacing was better or if they were more focused, but I just got a lot done yesterday.

J: I feel like you're connecting with the kids more, especially with me being out of the room kind of getting to know them a little bit better. It's hard when you don't have the whole semester

E: yeah, I still find 8th graders a little bit more challenging just because they're more used to you and I've been with them less 
J: yeah, they've had me for more years

E: and they're still like, sometimes they're just like why are you up here? Why are you telling us to do things?

J: I think that, I think they really respect you, and there's more of them too, and when the class is bigger it's harder to do, like, make one on one connections, and they're just so busy with that they have to do with all the extra stuff that I feel like we don't have as much time with them to really like, I don't know...

E: yeah

J: so what were some challenges?

E: um, <pause $>$ I think I had a difficult time, how do I want to say this...<pause> getting everyone kind of on the same page of what we were doing, um especially because there were kids like absent on Monday and Tuesday who missed like my introduction and like what I wanted to do, and I was hoping that people would like fill them in, at least on the hurry up and get ready side of things, but then, just keeping them engaged and like aware that it wasn't just on Monday, that we were doing this for the whole week and here I had trouble kind of reinforcing the habit and like keeping them aware that we're in the classroom to respect the music, we're not gonna talk, we're not gonna play out of turn. And especially I felt that like during last period today, 6th grade (J-4).

The previous excerpt from the final mentoring dialogue illustrates the back and forth nature of their conversations. As she reflected on the week that she had solo teaching the ensembles, Ellen was comfortable expressing both her successes from the week such as accomplishing a lot on one particular day and her struggles, such as connecting with eighth 
grade. Joanna responded to Ellen by interjecting her own opinion about her connections with students and by asking more guiding questions to encourage her reflection. The comfortable back and forth nature of their dialogues was reflected in the conversation timing as shown in table 10. In both conversations their talking time was approximately even.

Table 10: J-E Conversation Timing

\begin{tabular}{|l|l|l|}
\hline J-E Video 1 & J: 6:09 & $53.17 \%$ \\
\hline & E: 5:25 & $46.83 \%$ \\
\hline J-E Video 2 & J: 6:10 & $50.75 \%$ \\
\hline & E: 5:59 & $49.25 \%$ \\
\hline
\end{tabular}

Cooperating teacher input. "...and what do you want to work on, anything you could have worked on, and I don't feel like I'm ever the one that has to say so here's what I think, you know, you're not doing well with this, you need to improve that, um they're leading that conversation and then I'm giving advice <pause> and I think that's really important" (J-1). Joanna values allowing the student teacher to lead the conversation so that they can have their individual needs met. She tends to be active at the beginning of a conversation by asking general questions and steering them toward the positive aspects of their teaching. "She was saying there were good moments and bad moments and that's where I'm trying to lead them first in a positive way. Let's talk about the good things first and then when she says there's bad moments, you know, I like it to be led by them so they don't feel accosted" (J-2). She has realized that the student teacher will usually respond to general reflective question by focusing on something that didn't go well, something 
negative. Therefore, Joanna will be active in pointing them towards the positive aspects of their teaching. "If they haven't told me what they think they did well, I always ask 'what do you think you did well?' Or sometimes I'll start with 'what do you think went well?' Then, if there's something they missed, I kind of try to sneak it in" (J-3). From there, she will respond to the student teacher with positive feedback or reassurance. "J: it will start to sound better. It is tough to work right away and it takes several, that doesn't necessarily mean what you're trying isn't effective, it just may take a lot longer at this age level" (J-2). Student teacher response. Ellen also reflected on her conversations with Joanna and confirmed that the feedback that she received from Joanna was usually through reflective questions or in response to a concern that Ellen talked about.

A lot of what she's given me hasn't really been "I think you should do it this way or that way." It's been more of, "What do you think is working/not working?" Then she'll agree with me on that stuff. A lot of her feedback is driven by what I say. There is some advice like, "Why don't you try it this way?" and I usually take her advice and a lot of the time it has worked but I feel like a lot of the advice that she does give me comes from what I say (E-2).

Since Joanna approached their dialogues through reflective questioning and focusing on Ellen's success, most of Ellen's responses or input to the conversations were reflective statements, either focused on something that she felt good about or something she wanted help with. "I definitely heard that they were getting their instruments more in tune, I only had to make a couple of adjustments when I was going around, so I think that worked even though I didn't really explain like they're supposed to be listening for the overtones and like they're supposed to hear the fifth in it" (J-4). 
When reflecting on Ellen asking questions during their conversations Joanna said that oftentimes she would simply experiment with different strategies on her own as opposed to asking questions. “...she knows what she’s doing, and sometimes I think instead of asking me how can I get this measure to sound better in this section, she'll just try different things" (J-4). Ellen embraced the sense of freedom allowed by Joanna and wanted to become an independent teacher. "It gives me a chance to kind of like experiment and a lot of the times like I know if something's going wrong, and I don't need my teacher to tell me that it's going wrong...I think I like having the opportunity to fix it myself" (E-1).

Style and supervisory skills. During both of their recorded dialogues, Joanna did not have detailed notes to refer to, but usually had a couple of big ideas that she was prepared to discuss with Ellen. She allowed the conversation to flow naturally. The talking time was split evenly between the two of them during both recorded conversations. Joanna began each conversation with a general question and then followed up based on Ellen's responses. As their conversations reflected on a week at a time instead of on particular teaching episode, the questions focused on Ellen's perception of her strengths and weaknesses for the week and her goals or needs going forward. It was important to Joanna to allow Ellen to reflect on her own success. She tried not to tell her directly what her opinion was.

If they haven't told me what they think they did well, I always ask 'what do you think you did well?' Or sometimes I'll start with 'what do you think you did well?' Then if there's something they missed, I kind of try to sneak it in. You know, you could also try doing this, that, or the other. Whatever it is they're trying to do. I'm sneaky with that because I'll say we should. We should try to work on-“ (J-3). 
Her goal for both dialogues was to allow Ellen to reflect on how things went. "I think they feel better if it comes from them than from me" (J-3). During the first recorded conversation Joanna simply wanted to find out how Ellen was feeling after the week and make sure that she was getting enough podium time. She felt strongly that the student teacher should set that level according to their needs, since some want more, some want less, and for some it is perfect. "and how do you feel about tag teaming next week and doing some of the 'if I'm up here, you're with the group and vice versa?" (J-2). During the final recorded conversation they were nearing the end of Ellen's placement and approaching the concert. Ellen had completed a week of solo teaching and they were reflecting on her successes during the week. Joanna allowed Ellen to take the lead in the conversation and only had one big idea that she wanted to make sure that she talked about because she felt that it was an area where Ellen could improve her teaching. "Just the initial like, how did it go, and I wanted to make sure I kind of hit on the use of your voice more thing, I wanted to make sure I pointed out some things she's doing well, but other than that, none of it was planned" (J-4).

Especially considering the more direct approach of her first cooperating teacher, Ellen really embraced the freedom allowed by Joanna. "Because it felt like $<1^{\text {st }} \mathrm{CT}>$ didn't have that trust, but uh, <Joanna > definitely has trust and like, she will let me try pretty much anything <laugh> in front of the class" (E-1). Throughout the placement, Joanna encouraged her to do things her own way. During her solo week toward the end of the placement Joanna was gone during the first part of the week and Ellen really experimented with some different routines including a drone used for tuning and a competition to see who could get set up the fastest. Despite the fact that it was very different from what 
Joanna usually does with the students, she respected Ellen for trying something new. "It's hard too, for the student teachers to implement a new way of doing things. And I think if this was her program, she would set that up much differently than I did, and that would work for her and what I do works for me..." (J-4).

I observed very little direct advice during the recorded conversations, as Joanna believed in responding to her student teacher. "I think only once I've suggested that a certain thing get fixed in her piece. I don't feel like I need to be correcting her. I think it's more a sharing of ideas" (J-3). She reflected that she tends to be more direct in informal interactions and when they are getting close to a concert. These instances might be brief interactions following a lesson or also interruptions during rehearsal to address something important to their performance.

I give direct advice throughout the day, too. So maybe not in those formal conversations. I asked her permission, in our last conversation that we recorded talking about what she needed to work on, she's having some trouble with transitions in Pixar. That's a conducting issue. I asked permission, how would you feel if I stopped you in front of the class and we worked on some of this and I'll coach you through some of this conducting in front of the kids? Some are very sensitive to that. She's very open to it (J-3).

Toward the end of the placement when the concert was approaching, the brief interruptions became more frequent, as Joanna would notice something in the back of the ensemble that needed to be fixed. Most of the time, she didn't blame Ellen for missing something, as both understood that it was difficult to hear everything that happening in the ensemble. “...I wouldn't normally do this, but we're so close to the concert!" (J-3). 
Mentor Roles in Dialogues (MERID) model. Examination of the recorded dialogues between Joanna and Ellen place Joanna's approach within the Encourager quadrant of the MERID Model (Hennissen, Crasborn, et. al, 2008). During both of their conversations there was a lot of comfortable back-and-forth dialogue between them. Joanna would lead Ellen to reflect on certain topics through questioning and naturally responded to Ellen's statements and reflections. Figure 11 depicts Joanna's approach during the first recorded conversation according to the MERID model. According to code counting, her approach was coded as mostly indirect and reactive (direct: 10, indirect: 20; active: 10; reactive: 19). As shown in figure 12, there was little change from the first conversation to the second conversation. Her interactions were coded as direct eight times and indirect twenty times and coded as active thirteen times and reactive sixteen times.

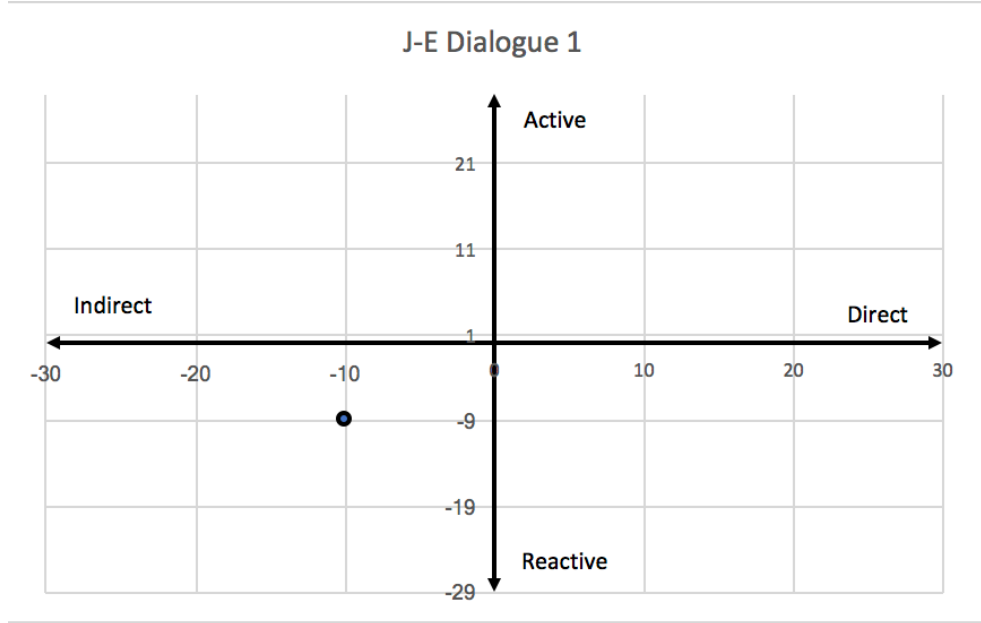

Figure 11: J-E Dialogue 1 


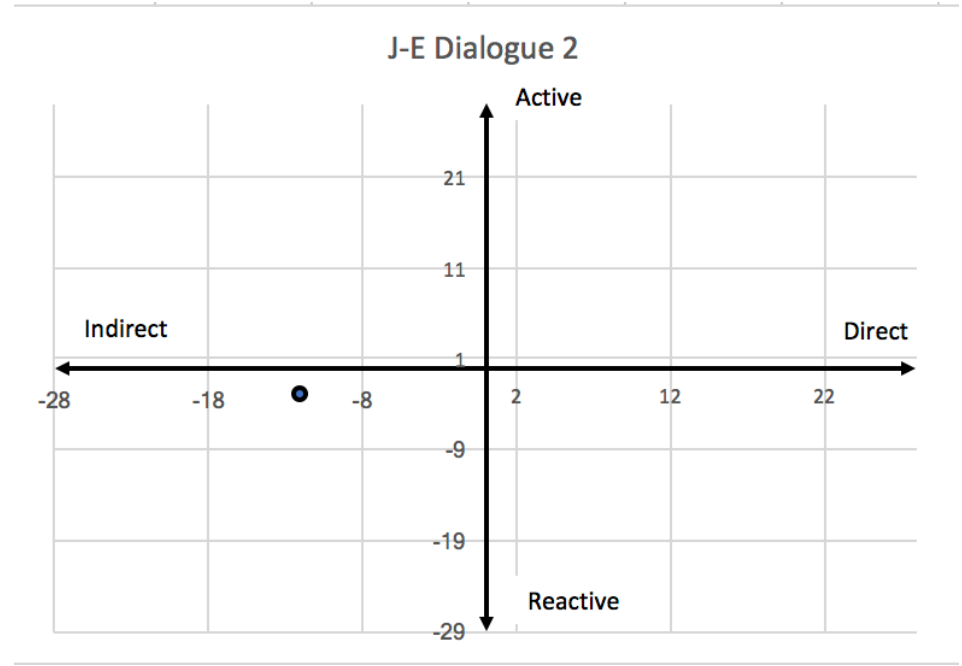

Figure 12: J-E Dialogue 2

\section{Bob and Charlie: Blue River High School}

Site and participants. I first contacted Bob about participating in the study by emailing him. At first he didn't respond, but when he did he was enthusiastic about the project. We spoke on the phone and he immediately said "sure, that all sounds good." When I came out to the school the first time it was late afternoon following an after-school rehearsal for the musical. Bob was directing the pit for the upcoming musical production, so he was very busy with extra rehearsals. He had told me that I would be able to get in the unmarked double doors right off the main road. They were near the front of the building, but not the main entrance to the school. When I walked up to the doors I saw another door nearby that was locked, but I heard music so I knew I was in the right place. I waited a few minutes until it sounded like rehearsal was over. When students started coming out I came in and began looking around for Bob. When I came for the first interview I still hadn't met him in person, so I was looking for Charlie or someone who looked like the band director. I easily found the band room and Bob was at the front closing his score and laughing with some students. "You must be Angela!" He invited me to follow him to the office, which was 
shared with the rest of the performing arts department faculty. I met the director of the musical and his student director. I was surprised that Charlie wasn't there, but Bob explained that he wasn't helping with the musical.

Bob and I chatted a bit and got to know each other better. He told me about his kids and his wife and his experience as a band director. He described himself as "laid back" and his demeanor matched this description. In the first interview he talked comfortably about how things were starting off with Charlie. He was excited to have a student teacher for the first time and thought that they were going to get along really well since they were both very calm and laid back. He seemed interested in the study and assured me that he would take care of recording conversations between him and Charlie and sharing the recordings with me. My intention was for the student teachers to take responsibility for that, but Charlie hadn't been very reliable about responding to emails or voicemails so I simply hoped that one of them would do it.

After the first interview in the office at school we set up appointments for the other three interviews. Since Bob wasn't always the most reliable with emails either, I wanted to make sure everything was scheduled up front. He suggested that we meet for the rest of them at a nearby coffee shop. He told me that they had the best coffee around and seemed a little more relaxed outside of school. The only interview that was adjusted was the third interview. Due to a schedule change we met at school and he found an empty room for us to meet in. I don't think he wanted to be interrupted or overheard by colleagues or students while we talked about Charlie.

During the third interview Bob's laid back and calm demeanor shifted a bit. He began to show more frustration and agitation with Charlie's teaching. Early in the 
interview he was happy that he had what he thought was a productive conversation with Charlie and that Charlie had been reflective and receptive to feedback. Bob described it as a "turning point." He was hopeful that Charlie would finish the semester strong. Later in the same interview he began to show more frustration at Charlie's teaching. He didn't think that Charlie wanted to be there at all and was simply going through the motions to finish his degree. He told me about how Charlie had struggled during observations with the university supervisor and by our fourth interview Bob knew that Charlie likely wasn't going to pass student teaching. Bob was visibly upset by this, concerned that this might be his fault as a cooperating teacher, even though he knew that Charlie had struggled throughout the semester. He realized that he should have noticed Charlie's lack of commitment and motivation earlier and tried to intervene, but as a first-time cooperating teacher he wasn't quite sure what to do. Based on our conversations, I don't think he talked openly with Charlie and was resistant to telling him when he wasn't doing a good job. I was never able to get ahold of Charlie for a final interview, so I was unable to find out more about his reaction to these events.

Conceptual framework: Bob and Charlie. Figure thirteen shows the conceptual framework model adapted to depict the factors that were especially prominent for Bob and Charlie. The recorded dialogues revealed that Bob adopted an imperator approach. Instructional support and the co-teaching relationship are shown in a box with bold font and co-teaching is connected to the timing of Charlie's placement as well as performance preparation and pressure. 


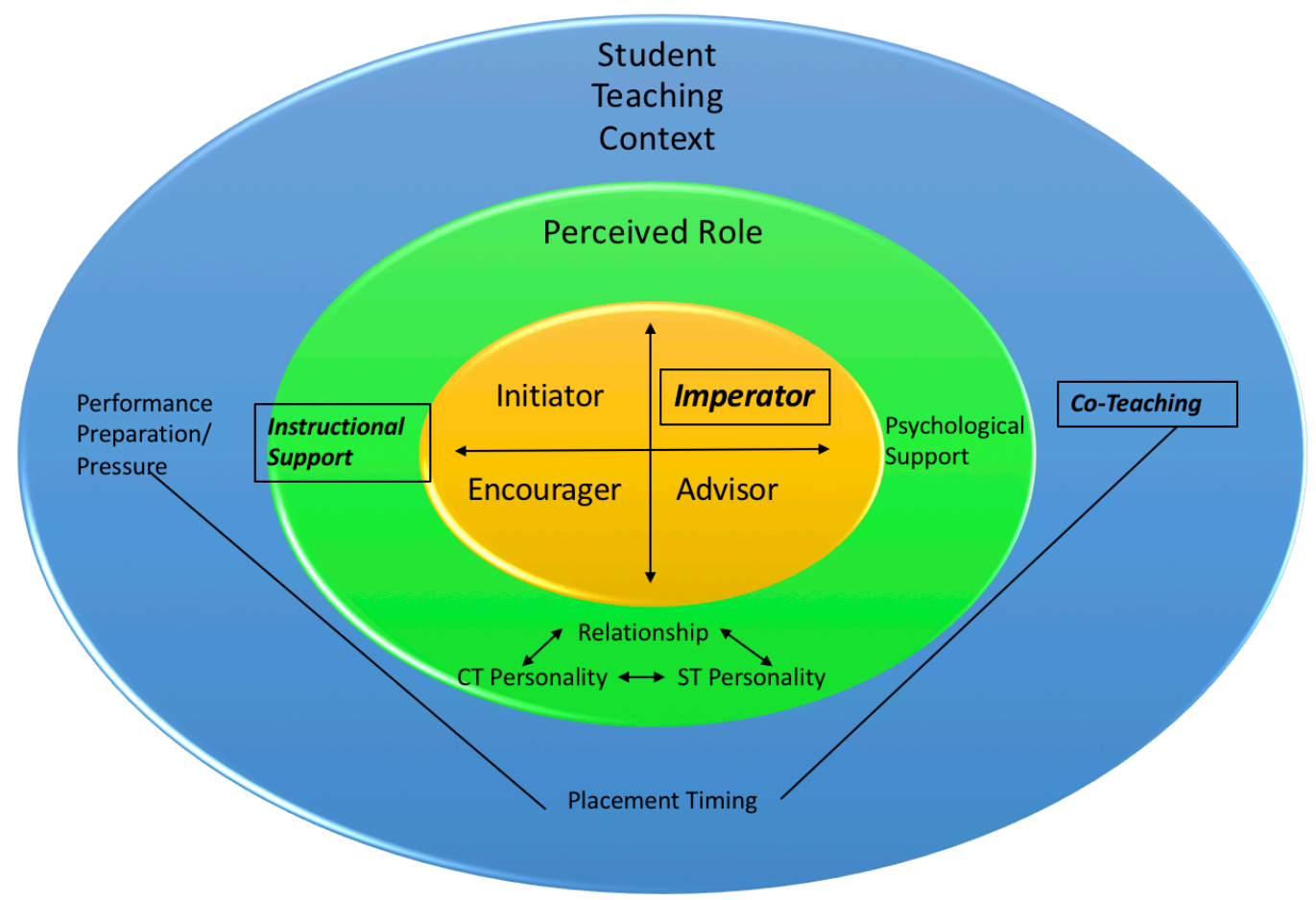

Figure 13: Model of Bob and Charlie

Student teaching context. Certain classroom factors had an impact on Bob's adopted approach during their conversations. It was very important to Bob to give Charlie plenty of teaching time. When Charlie failed to help the ensemble improve during his teaching time and the pressure of the upcoming performance was on his mind, Bob had to step in and take back some responsibility for his ensembles. Therefore, co-teaching is shown in bold on the model and connected to placement timing and performance preparation/pressure.

Co-teaching. At the beginning of his placement, Charlie was given the opportunity to choose a couple of pieces for jazz band and concert band and one piece for symphonic band that he would rehearse and conduct on the spring concert. He chose a variety of pieces that he had prior experience with either a collegiate or high school ensemble. Bob 
thought that it was smart for him to choose pieces that he was familiar with and agreed with his choices. "He chose some really cool stuff" (B-4). This meant that for most of the ensembles he was teaching for about two-thirds of the class. The only exception was symphonic band. "That's me, just not willing to give up the majority of the time with my symphonic band. You know, like, that's a big part of it, so he only gets to do one piece with symphonic band" (B-2). Bob held onto symphonic band because he traditionally programmed a symphony for the spring concert. "Then in symphonic band, that's the one I held onto, so he's doing one of the two pieces, but my piece is a 16-minute symphony. He's doing a march" (B-3). He realized that Charlie needed plenty of teaching experience and with the exception of symphonic band, he was willing to share the rehearsal time. "I want him to have as much contact time with the kids as possible" (B-3). He planned out the placement so that he could allow Charlie to have plenty of teaching time. "I chose pieces that I have played before with my groups so I could give $<$ Charlie $>$ the majority of the podium time, I'm still going to be able to get stuff done with the kids" (B-3).

During the first stimulated recall interview, Bob admitted that Charlie had been avoiding starting classes. "One thing I need to do for him, maybe this isn't the conversation we have in context of this video, but one thing I need to do for him is making him do the warm-ups more often" (B-2). At the time he thought that they still had plenty of time for him to start taking over the beginning of class. By the third interview he reflected that he still had to tell him to do it. "He doesn't seem eager to go, 'I want to try something.' You know? I'm still waiting for that sort of...enthusiasm and excitement to say, 'I want to try this in warm-ups.' I think the warm-up portion and the warm-up and lesson portion on the 
front end of class would be effective if I tried this. You know? For those kinds of things to set in. That hasn't happened yet" (B-3).

By the last couple weeks of the placement Bob began taking teaching responsibility away from Charlie. He had found out from the university supervisor that Charlie was most likely not going to pass his student teaching semester. "So...I'm trying to be nice with him, but I'm taking my classes back at this point, you know. He's excelling with one of my classes, so I'm going to let him continue to work with them, everything else, it's me, cause...He'll have one piece on the concert..." (B-4).

Performance preparation/pressure and placement timing. Placement timing and performance preparation impacted their dialogues, but not as clearly as their coteaching relationship. When Charlie began his placement with Bob they were about to perform a concert and the school was hosting a festival. "Had he started at the beginning of the semester we would have just planned everything together" (B-1). Charlie was able to assist with the festival, but there were rehearsals that he couldn't step in and teach because of the festival and performances. "Yeah, because I was rehearsing music for this performance and he gets here, pretty much done with it, but we need to keep working on it for these performances, so it's not like he can step in and now teach it, and he doesn't know where I'm at, where I have been since January on this stuff" (B-1). Therefore, the focus became choosing repertoire for the May concert.

At one point, Bob felt like Charlie was beginning to make some improvements in his teaching, in part because of feedback from his University supervisor and in part because of the approaching performance. "I don't know that you can pinpoint just one thing...in addition to his observation feedback from Dr. D...also, every music teacher is going to 
where you're going 'well, we've got this done and this done and this done. The concert is in, whoa-' that's starting to happen. Me being out of the classroom and him just having to do things" (B-3). Ultimately, the pressure of the upcoming performance and his concern for his students' musical experience meant that Bob had to step in and maintain responsibility for preparing them for the concert. Even with the one piece that Charlie was still rehearsing, Bob began stepping in and helping during rehearsal. "So they have a concert in a week and a half, so now I'm gonna make sure that they're gonna feel successful on this one too" (B-4).

Perceived role as a cooperating teacher. Bob went into his first experience as a cooperating teacher expecting it to be similar to his experience as a student teacher. He recalled his own experience when he was excited to take over in the class as much as possible. His cooperating teacher allowed him to be autonomous, and was also out of the classroom frequently due to personal issues. As a result, Bob found himself in a "sink or swim" situation where he had to take over primary teaching responsibilities while his cooperating teacher was absent.

You know <laugh> and honestly, that was my student teaching experience in a nutshell, the teacher's father-in-law passed away two weeks in, he's gone for a week and a half in California, he comes back for two days, I show up, he's wearing sandals and jeans and a t-shirt and I'm like, uh, and he's like yeah, my father just passed away and I'll be gone for a couple weeks. Holy smokes, so you're on (B-2). When Charlie started in his class, Bob assumed that he would be as enthusiastic and motivated as he was, excited to kick him out of the classroom and take over. "I just envisioned a student teacher being like me where I was just kind of ready to go. Some of us 
just need to get thrown to the wolves. Some of us come in and want to kick the teacher out of the room. I think he's one that needs to get thrown to the wolves. Figuring that out early on would be really beneficial" (B-3).

Drawing on his own experience as a student teacher, Bob thought that he could be "hands off" with support for his student teacher. Later on, he realized that he missed some cues from Charlie early in the placement. "Being perceptive to the needs of your students and also to the needs of your student teacher. I would say that's...I learned more about what that is here" (B-3). When he noticed Charlie struggling with his teaching, he began to provide more instructional support through modelling, teaching time, and recording teaching episodes. Therefore, instructional support is shown in bold on the model (see Figure 13).

Instructional support. As Bob began to realize that Charlie might need to be "thrown to the wolves" he began to push him into more teaching experiences. "So that's why I just started taking time off. They came to me and said we need somebody, we're struggling on what to do with choir and I said to them I have a choir credential, let's take advantage of my student teacher" (B-3). He thought that if he put him in a situation where he had full responsibility for the ensembles he might rise to the challenge. "To just make him go. I've been purposefully - he looks over his shoulder for the safety net constantly, and so I've just been trying to disappear" (B-3). Bob began spending more time in his office or meeting with faculty and administrators. He took a couple of days off and stepped in to teach vocal music when the choir director had to take a health leave. As a result, Charlie had approximately a week of solo teaching. Bob was hoping that Charlie would rise to the challenge and be excited to take over. "You've had the chance now to just be in there doing 
it. At some point you just go, 'Hey, I got this old man, get out of the way.' And it hasn't happened. I just kind of keep forcing it" (B-3).

Bob was also hopeful that if he modelled effective strategies, that Charlie would adopt them into his approach. He also spent time with Charlie studying scores and drawing attention to potential challenges in the music. "Our conversation this morning was extremely productive. We were just talking about - I had him look in my score for things that he thought would be, his eye would go right to 'this is going to be challenging" (B-3). He also occasionally interrupted Charlie while he was teaching to model effective teaching. He doesn't do it often, and tried to "pick his moments" (B-3), but he thought that it might also be beneficial for his students to see him working with a student teacher. "Yeah, it's good for the kids too. They understand their and my relationship. We get each other. Seeing that there's a grown-up - There's a couple kids in there that want to be music teachers. For a couple of them, that would be good, to watch me working with a student teacher" (B-3).

In an effort to facilitate the reflective process for Charlie, Bob also recorded his teaching once a week and uploaded it for him to view on his own. "I don't know that he does or doesn't look at them to see what worked and what didn't" (B-3). Additionally, since they were often splitting the time during rehearsals, Bob would record his own teaching and encouraged Charlie to reflect on Bob's teaching as well. "I'll just upload it to a file for him so that he can see in the 30-40 minutes that I was in front of the kids, what went well and what could have gone better, and things like that" (B-3).

Psychological support. Bob began his experience as a cooperating teacher expecting it to be similar to his own experience when he was a student teacher. As 
mentioned previously, his cooperating teacher faced personal issues during his placement and had to be out of the classroom for an extended period of time. Bob was proud of himself that he was able to step in and cover classes while he was gone. Nearing the end of Charlie's placement, he reflected on what he had expected. “...I really need to have that student teaching experience, who's excited to kick me out of the room. Where I'm having to come back in and go alright, I'm still wanting to have some face time with my kids" (B-4).

As the relationship between Bob and Charlie was strained by Bob's perception of Charlie's lack of commitment and motivation to student teaching, Bob did not provide much psychological support. He welcomed him into the school, gave him space to work, and provided him with resources. "I mean, he and I, we hit it off early, um, even last semester when I was just visiting once a week, uh, he was showing me all around the school, and um, introducing me to people and making sure I knew like what was going on, and what they were preparing, and um, yeah, he like talks to me like during rehearsals" (C1). Instead of them growing closer together over time, Charlie began pulling away and Bob began stepping back in and retaking control of his classes.

"I started out wanting it to feel equal" Bob went into the relationship wanting it to be an equal, collaborative relationship. It took him until the second half of the placement to realize that their relationship would not develop as he had expected.

Again, me not knowing what I didn't know as far as how he's going to be as a student teacher, and things like that. Had I known, now with hindsight 20/20 and everything, I would have just thrown him in. Said, 'Hey great, you're going to start classes right away.' And I would have let him start classes and sit up there going 'uhh...uhh...' and then have the conversation stem from that (B-3). 
Charlie's lack of motivation and commitment had a major impact on their relationship. During the third interview I asked him about their relationship and how it had changed during the placement. This was when his demeanor changed and he became more honest with his frustration toward Charlie. "I'm not sure he wants to teach music" (B3). He had consulted with Charlie's first cooperating teacher, who was the band director at Elwood Middle School nearby. "I was wondering, is it me? She went, no, I've had a lot of practicum students and that fire under his butt that makes him get excited, I don't know that it ever gets flipped on. I went, 'ugh, okay'” (B-3). Bob was still reluctant to address Charlie's shortcomings directly because he felt like it could have been his fault as a cooperating teacher. “I can't see how that plays out right now. I would like to. If I'm not up to snuff as a cooperating teacher, that might be where it is. I just don't know how to do that yet" (B-3). Instead he left the more difficult conversations and evaluation to the University Supervisor.

Personality impact. Going into the relationship, both of them thought that they were very similar. "He and I are a lot alike, we're really laid back, really laid back" (B-2). At the beginning he assumed that meant that they would get along really well. Early in the placement Bob picked up on some of Charlie’s “laid back" personality traits, such as responding to questions with short responses like "cool" or "pretty good" (B-2). Over time, Bob began to realize that Charlie's "laid back" attitude was becoming problematic. "You know, again, I'm a very laid back kind of guy, when I saw <Charlie> going through those motions, I'm just kind of thinking oh, okay <yawn> when laid back sort of became apathetic" (B-4). 
Facets of the MERID model. In addition to the student teaching context and the perceived role of the cooperating teacher, additional factors related to the Mentoring Roles in Dialogues (MERID) model such as topics of conversation, phases of the dialogue, and conversational timing impacted the mentor's input and style as enacted during mentoring dialogues (Hennisen, Crasborn, et al., 2008). Each of these facets as observed in the case of Bob and Charlie will be described in this section.

Topics of conversation. The most common topic of conversation for both recorded conversations as well as our other interviews was the music content. In our interviews and in their recorded conversations, Bob would often talk about his approach to rehearsal planning and analysis of the pieces they were playing. Therefore, any discussion of instructional techniques was related to the music. For example, Bob was very intentional about the types of warm-ups he chose for his ensembles, making sure that they were linked to the rehearsal objectives. "...we're going to be reading something in the key of $\mathrm{C}$, we have a chorale, where is it at, we have chorales in here in the key of C, concert C" (B-1).

Their first recorded conversation was focused on the two of them planning a lesson that Charlie was going to teach, introducing a song to the jazz ensemble. "We had found an arrangement of this tune Work Song, that we love and the kids love, but we had to order it, so we couldn't start on it right away, but we had another version of it in the library that we could introduce the tune with" (B-2). Bob recommended that he use the piece to teach a theory lesson on the blues scale. "...and then you know what we can do too is have everyone bounce around, play skips across that <pause $>$ now I'm thinking, I kind of want to write something out <singing > just write out a thing that's some kind of a lick and not just up and down so they get out of feeling it like a scale..." (B-2). 
In the final recorded conversation, they were talking about what Charlie had noticed about Bob's teaching when he stepped in to model some strategies. Bob made sure to point out certain phrases that he said and concepts that he focused on in hopes that Charlie would adopt some ideas to improve his own teaching.

...so if we get them to go that's a really cool chord, yeah, really cool, why don't we try playing it soft now it's really cool. Okay, but they have to understand what the chord is supposed to sound like, the verbiage that I said, understand right here, you're playing a part of a chord, you can't just think of it as I'm playing my note and that comes from listening, so understand that you're playing this chord (B-4).

During this conversation, Bob was also showing concern for the students' musical experience. He wanted his students to feel successful with the music. "I was hoping he would find the way that I got them to feel success and just have fun with it. Because he kept on finding small little detail-oriented things to work on" (B-4). He was concerned that the students were not feeling successful with the music and therefore not enjoying themselves or feeling positively toward the music.

Okay, um alright, so, yeah other than that, take anything that you can and inject it into rehearsing the march. I rehearsed that march that day that you were gone, and I just made them go and play everything big. And even if they kind of goofed up on a spot, I just went, we know we need to work on that part, right? Yeah, they played through everything and kept everything chopping along. And so that was a really good rehearsal and I didn't touch dynamics yet, I just wanted to get to feeling the thing and feeling success, on that song (B-4). 
There was also some discussion of miscellaneous topics. Bob wanted to give him experience with the online course platform. Early in the placement he also planned on getting him involved with planning concerts and trips and attending parent meetings. "He's in on scheduling meetings, we're planning next year's concerts, making sure that he's in on, we're planning a trip for the band to go to uh, Orlando next year...but try and get him to come to our parent group meetings so that he understands that" (B-1). Later in the placement it was evident that this had not happened. Whenever I showed up for an interview after school, Charlie was already gone for the day. "Some days, too, at the end of school where he's had to run out as well, this week, you know, he's a church musician and Easter is coming, so he's been slammed with that" (B-2).

Phases of the dialogue. It was important to Bob to encourage independence and reflection. He tried to do this through reflective questions. "I feel like I should help him to be somewhat reflective. I should try and assist him in things that might be challenging for him or something that didn't work...I want him to be introspective that way and seek out the help" (B-3). He preferred to have Charlie start the conversations, but he usually didn't so Bob would choose to begin.

In the first conversation they were co-planning for a lesson that Charlie was going to teach. Bob gave him some ideas for what to do during the lesson. "Why don't we do it, we'll print out some manuscript paper and just have them write it out themselves, so that they're going through that process as well" (B-2). Charlie would respond with questions for clarification throughout the conversation. "So, would we just do like an $f$ minor pentatonic?" $(B-2)$. They both worked together to figure out the notes in the scale by pulling out their instruments and playing. Bob reflected that he had "spoon-fed" a lot of information 
because Charlie often begins by asking him how to do something. "Oftentimes our conversations seem to start with him going 'how would you do that?' You know, so then I go 'okay, here's how I would do that;" (B-2).

The final recorded conversation was spent reflecting on a lesson where Bob had interrupted Charlie's teaching to model some strategies. Bob began by explaining why he had stepped in during the lesson. "Alright, so I kind of hijacked your tune a little bit, but I wanted to do that just so you could see someone else work through some of the other things that seemed to be um, I don't think overlooked is the right thing, cause maybe you had them in mind and you were getting there, but how to get there sooner with adding energy" (B-4). Bob asked Charlie to reflect on what he had learned from observing his teaching. "So what are the things that you saw that I did that might be useful, and then also other rehearsals?" (B-4). As Charlie responded, Bob explained his choices. "It's kind of one of those things, and I think you know this, but play louder. They're playing with more air" (B-4). He continued to ask more questions during the conversations to make sure that Charlie had noticed certain details during his teaching. "And then what was the head game? Did you catch the head game that I played with them? That I told them what level the music was at?" (B-4). He finished the conversation by reviewing his primary point that he expected the University Supervisor would address with him as well. "And so that was a really good rehearsal and I didn't touch the dynamics yet, I just wanted to get to feeling the thing and feeling success on that song" (B-4).

Conversation timing. In both recorded dialogues Bob spent more time talking than Charlie. During the first dialogue they were planning together, but Bob "spoon-fed" him a lot of answers. Charlie's input was mostly clarifying questions or short responses. In the 
final recorded conversation Bob asked more questions, but Charlie's responses were still primarily short answers. There was slightly more input from Charlie and this is reflected in the timing of each of the conversations.

Table 11: B-C Conversation Timing

\begin{tabular}{|l|l|l|}
\hline B-C Video 1 & B: $6: 20$ & $80.85 \%$ \\
\hline & C: $1: 30$ & $19.15 \%$ \\
\hline B-C Video 2 & B: $5: 45$ & $75.99 \%$ \\
\hline & C: $1: 49$ & $24.01 \%$ \\
\hline
\end{tabular}

The excerpt below from the final recorded conversations shows the questioning used by Bob and the short responses from Charlie:

B: so what are the things that you saw that I did that might be useful, and then also other rehearsals?

C: Well one of the biggest things that I hadn't thought of was having Dylan just play. Just bigger in general, because if he's playing bigger they're all going to do that. And that was one of the first things you did that I was like oh, duh.

B: So you mean that, that, that big fat part where the trumpets have to take it up?

C: yeah, because if I had done that any time sooner the entire thing would have been a lot bigger. Um, and then I mean, just really reinforcing that, yeah they're not going to play it out unless the rest of you are playing your parts out there too. Um, having doing fill to get into that and everything, that was like the main thing that I saw that was like, duh I should have done that sooner. 
B: I picked that up from Jason, I got to be honest with you. Cause I think you and I kind of briefly talked about this yesterday, cause you and I, we're horn players, so the first people were gonna go to if the horns aren't doing their job are in fact the horns. C: yeah

B: But we sort of forget that the rhythm section gives us so much energy, and if we get them locked in, that just makes the horns, they don't even realize that they're playing their part right at that point, it just feels better and cooler and they suddenly go, oh $C: \operatorname{right}(B-4)$.

Cooperating teacher input. An active cooperating teacher will begin the conversation, introduce topics, and steer the conversation according to what they would like to talk about (Hennisen, Crasborn, et al., 2008). As demonstrated by the uneven talking time during the recorded dialogues, Bob was observed as active in both conversations. In the first conversation Bob gave him advice and ideas to use during his upcoming lesson. “...have them write all these notes in and you and I can go around the room and check them and make sure they're doing it right, make the drummers do it on vibes <laugh> cause otherwise they'll sit there and check out" (B-2). During the final conversation he used more questioning, but was still active in steering the conversation toward topics that he felt were important for Charlie to notice. "Yeah, and so you noticed that when they're in the do-wah, do wah, do da <singing $>$ what did you see that made that part swing better than it has in a while? You know?" (B-4).

Though Bob was primarily active, there were a few points in each conversation where he was reactive to something that Charlie had contributed to the conversation. In the first recorded conversation Charlie suggested a sequence for his lesson and Bob gave 
him some advice on how he might do it. "I would honestly consider doing the theory lesson first" (B-2). During the final recorded conversation, Charlie responded to Bob's questions, and Bob would respond by explaining his choices. "I think some of the thing is that I would help them feel like, play this part bigger, play this part smaller, and sort of that Basie thing that you were talking about" (B-4). If Charlie didn't reflect on the important point that he was trying to make, then Bob reiterated what it was. "I think the overall concept is get them to feel success" (B-4).

Student teacher response. Charlie's responses were typically short, one or two word answers. Bob noticed that he tended to say "pretty good" often when asked how a lesson had gone. "But the frustrating part is, every time I would ask him how he thought something was going, the answer was always eh, pretty good" (B-4). During the first conversation Charlie appeared to be looking for advice from Bob on how to approach his lesson, so he would ask him what he might do. "How would you do that?" (B-2). He also asked some more specific questions. "...since you were talking about starting in major would you have them write out their F major scale first?" (B-2).

As Bob asked him more reflective questions during the final recorded conversation, Charlie responded to his questions. "Well one of the biggest things that I hadn't thought of was having Dylan just play, just bigger in general, because if he's playing bigger they're all going to do that. And that was one of the first things you did that was like, oh, duh" (B-4). Most of his responses were short, and often he simply restated what Bob had already told him. "I think that was mostly it, just kind of underlining play everything, louder dynamics so they can just hear it, and then dialing it back from there" (B-4). 
In the second half of his placement, Bob felt like they were making progress when he came to him and asked for advice. "Last week there was one day where he finally said, 'I don't really know what to do with this song, I'm kind of stumped on it"' (B-3). By the final interview he was more frustrated by his questions and the lack of progress. "Well, earlier, a week prior he said 'I'm kind of at a loss with what to work on in this', and I'm like 'really, the notes are a train wreck, they're all over the map. So, fix the notes'" (B-4).

Bob also noticed Charlie avoiding certain experiences in the classroom such as taking over the warm ups at the beginning of class. "He'll kind of be like, 'well, you need the majority with symphonic band cause you're working on this, so it doesn't really make sense for me to warm them up, I'm working on the march,' for instance (B-2). He also avoided rehearsing certain pieces during observations with the university supervisor. "Then he had this rehearsal Monday where <university supervisor $>$ was gonna come and observe and he has been not wanting to rehearse this piece in front of <university supervisor $>$ because he knew that he was struggling" (B-4). By the end he perceived that Charlie just didn't care and was "relieved" when Bob started taking his classes back. " $<$ Charlie $>$ told $<$ university supervisor> that he knew coming into student teaching that he had no intention of ever going on with it" (B-4).

Style and supervisory skills. During both recorded conversations, Bob was observed as more direct, giving advice and ideas based on his own experience as a teacher. B: cause to get to feel comfortable playing improv they just first have to be able to just get to those notes all the time and hear them and just hit em all the time. And then if they're looking at those notes while they're trying to do it, now they're just looking at those notes and they're like oh, we start at the bottom and they're always gonna just 
work up and down. That's why I was trying also get it on the, so start it here and start it here but they can play notes down here and they can play notes up here <gesturing with hand high and low lets write all those notes for two octaves so that you can tell yourself I have to start on this on this time you know, and go around, so sometimes what I'll do is I'll have the rhythm section play, break off into little groups around the room like get with a group of two players or three players and you guys are just gonna go you go then you go and you go (B-2).

At times he would give advice, but word it more as a suggestion, "trying to leave it open for him" (B-2). "And I'm not saying for sure, just saying that I might consider, if I were you, doing the theory component first, so that they're just thinking about this and then they go oh, it applies exactly to this" $(B-2)$.

In the final recorded conversation Bob was observed asking more questions of Charlie to find out what he had noticed when Bob had "hijacked" his lesson. "I mean just getting them to play, you know, and any time you have the band playing, what's the thing that I defaulted to that got them to play bigger?" (B-4). He was trying to get Charlie to take some ideas that he observed and apply them to other pieces that he was rehearsing. "How about what you saw me do in there that you could take into rehearsing Sheltering Skies and the march?" (B-4).

At times Charlie did not respond to a question or didn't respond as Bob expected or wanted him to. In this case, Bob would tell him the answer directly and explain his idea. B: what's kind of the thing that I defaulted to that got them to play bigger? C: um B: what did I just say? Play louder. <laughing > play louder 
C: yeah

B: It's kind of one of those things, and I think you know this, but play louder? They're playing with more air. Now the same amount of air, but just play it softer. And that's gonna help establish core to the sound and just...it's a pretty age old trick, that you can just play, especially on high school kids.

Though he was observed as being mostly direct during the recorded conversations, Bob valued adopting a more indirect approach. "I don't want him to think that I'm here professing to him because I'm the know-it-all guru" (B-4). While watching the video Bob realized that he was giving him a lot of answers and thought that he should be getting more information out of Charlie. "I think I could have answered that question with more questioning" (B-2). Even when he had interrupted Charlie's lesson his intentions were more indirect in nature. He wanted Charlie to take ideas from him, but synthesize them and make them his own.

Yeah, and if he tries to use my exact same one, he needs to try and synthesize it so it's genuine, so that it really is him. I'm not going to say, "Say this, say that." I'll say, "What did I do there?" Oh, well you made them do this and you made them do that. Yeah, what else could you do with that? You know? That's just one thing that seemed to serve the purpose then. You know, the tough part about teaching, and I would say teaching music but it's probably teaching anything, is that you may use something that worked like a charm and you apply it to another scenario where it's the same concept and for whatever reason it's not working and now you have to reinvent that wheel (B-4). 
Mentor Roles in Dialogues (MERID) model. Through counting codes from Bob and Charlie's two recorded conversations, Bob's approach fell within the imperator quadrant of the MERID model (Hennissen, Crasborn, et al., 2008). Bob's approach was primarily direct and active in both conversations. Figure 14 shows Bob's approach in the first dialogue (direct: 14 , indirect: 2 ; active: 12 , reactive: 3 ).

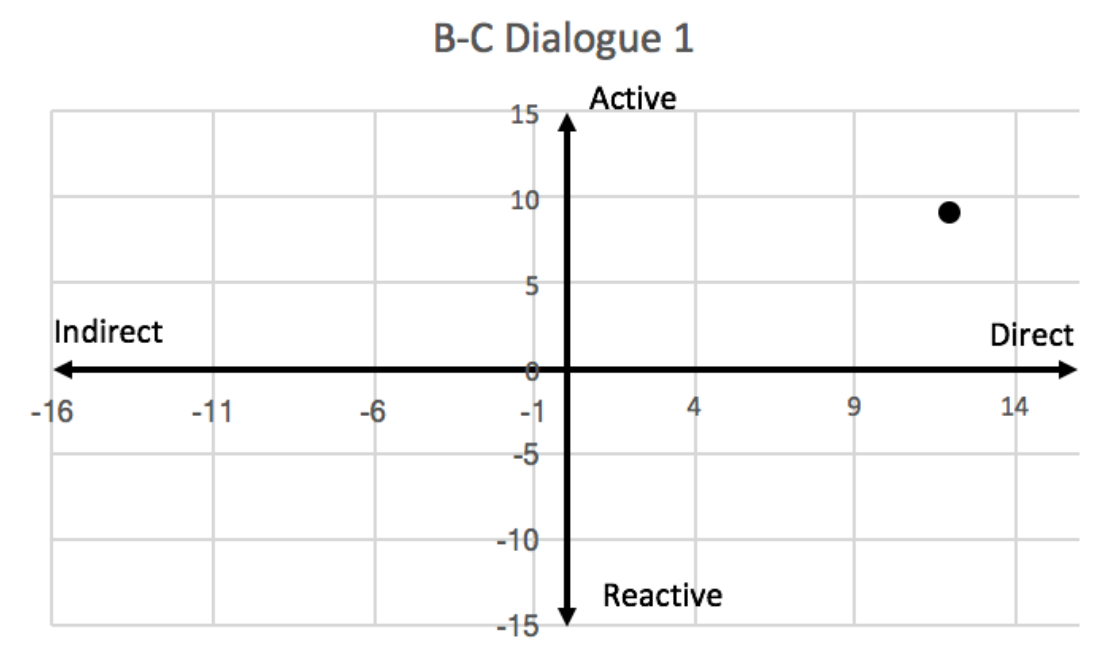

Figure 14: B-C Dialogue 1

Figure 15 shows his approach in the second recorded dialogue. There were more occurrences of an indirect style as well as more reactive to Charlie, but he was still primarily direct and active (direct: 12 , indirect: 8 ; active: 14 , reactive: 6 ). 


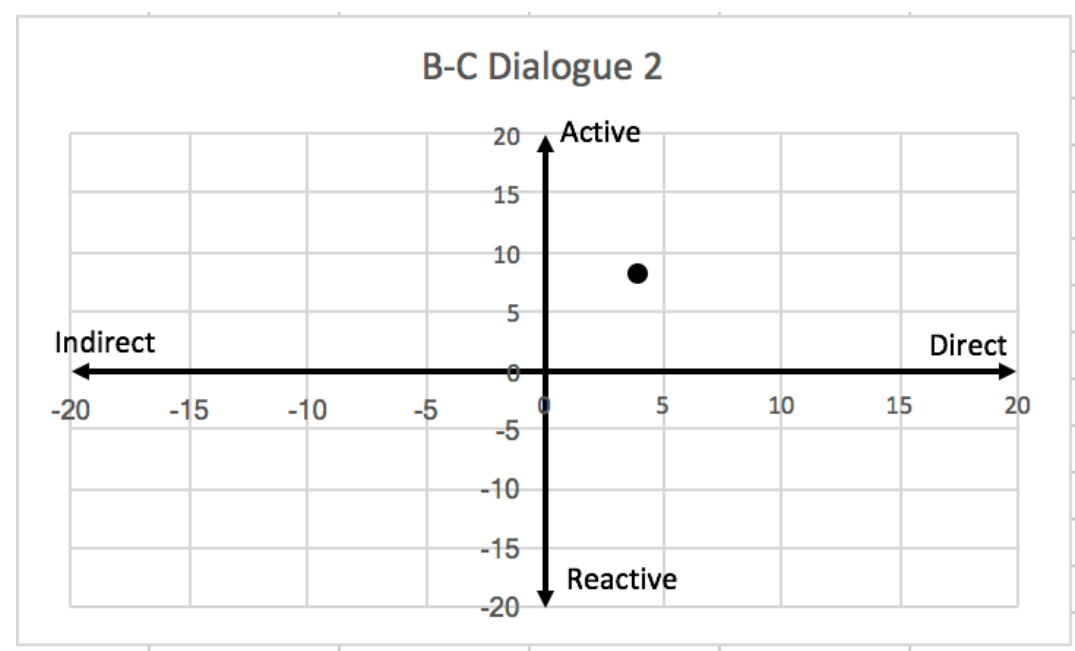

Figure 15: B-C Dialogue 2 


\section{CHAPTER V}

\section{Cross Case Analysis}

This chapter will focus on the similarities and differences between all four of the cooperating teachers' mentoring roles and styles during this study. In the first section of this chapter I will expand on findings aligned with research questions \#1: what factors impacted the mentoring roles assumed during mentoring dialogues and \#2: what mentoring role did the cooperating teachers assume during mentoring dialogues. In the second section of this chapter findings are presented for research question \#3: how did the cooperating teachers respond to video-based reflection on mentoring dialogues.

\section{Mentor Roles in Dialogues (MERID) Model}

According to the MERID model, developed by Hennisen, Crasborn, Brouwer, Korthagen, and Bergen (2008), the mentoring style can be classified according to the approach adopted during mentoring dialogues as observed by direct or indirect style and their level of input in the conversation. This may be influenced by the timing of the conversation, phases of the dialogue, and topics of conversation. In this study, the cooperating teacher and student teacher personalities and their relationship as well as aspects of the student teaching context impacted the observed role adopted by the cooperating teacher during mentoring dialogues.

In this study, two of the cooperating teachers, Isabelle and Bob adopted a direct and active approach during their recorded dialogues, placing them in the imperator quadrant of the MERID model. The other two cooperating teachers, Adam and Joanna, adopted a more indirect and reactive approach during their recorded dialogues, placing them in the encourager quadrant. In this section I will compare and contrast each cooperating 
teacher's mentoring style and impactful contextual factors as observed during the recorded mentoring dialogues.

The Imperators. For Isabelle, her decision to adopt a direct, active role during conversations with her student teacher was very intentional and consistent. She was observed as slightly more indirect and reactive in the second recorded conversation, which was due to the nature of the conversation. She referred to the first dialogue as a "brain dump," as she was giving him sub plans for while she was going to be gone for a week on a trip with the high school band. The second conversation was a post-lesson debrief and Tyler was a little bit more responsive. The conversation was still controlled by Isabelle, as she was giving him feedback from her notes. She was the only mentor who regularly took detailed notes while she observed him in order to give him detailed feedback in their postlesson conversation. "If I was observing him teach, I'll either give him sort of quick informal feedback, or if I was taking notes we'd go through and address everything that I wrote in the notes" (I-3). In much of the recorded conversations she gave him direct advice and asked only a few questions of Tyler. She described other times when she might ask him questions.

You know, there have been times where I'm asking him, "Why did you choose to do this?" or "What do you think of their reaction to this?" and he's said things like, "Oh, well I wasn't really sure so I just did this." And I'm like alright, that's a good place to open the dialogue for it's good to improvise. Here's how you decide what, for the students, is going to help them. That thought process is what I'm trying to nurture for him (I-3). 
She consistently took responsibility to beginning their conversations and steering them according to her notes from his lesson. "I just naturally take responsibility for that...I usually try to recognize what went well right off the bat" (I-3). Similar to other participants, she sees a parallel between her approach to giving feedback to Tyler and giving feedback to her students. "Just like with my normal students. If they do something well, I feel like you have to mark it, because otherwise they don't know that they did it right necessarily" (I-3).

Bob also approached Charlie in a similar way that he approached his students. Since he was the only participant who didn't have any prior experience as a cooperating teacher, his mentoring style was based on his own experience as a student teacher and his idea of what good teaching is in general. In the recorded conversations he was observed as being primarily direct and active, but he valued allowing Charlie to ask questions as needed. "I'll try and allow him to ask questions as needed to a point, and then the direct advice will come when...when I kind of feel like we're not getting to the point. I guess that's how I teach my own students too. I want to give them as many opportunities as possible to come to the answers or the conclusions on their own, and then, at some point, if it's not really working, alright, here it is" (B-3). Similar to Isabelle, there was a slight change from the first conversation to the second, showing a slightly more indirect style and more reaction to Charlie. Their first conversation was planning an upcoming lesson and the second was a post-lesson debrief from Bob's teaching. During the second conversation, Bob asked more questions to see what Charlie had noticed about his teaching techniques.

As a novice cooperating teacher, he also drew upon his own experience as student teacher. This was unique to Bob, as the others drew on their prior experience as 
cooperating teachers. His own cooperating teacher was very "hands off" and faced personal issues that kept him out of school for an extended period of time. Bob assumed that Charlie would be like him, and be excited to take over the classroom. When that didn't happen, he thought that he should just push him into teaching. “...Me not knowing what I didn't know as far as how he's going to be as a student teacher, and things like that. Had I known, now with hindsight 20/20 and everything, I would have just thrown him in" (B-3). He envisioned that he could be "hands off" and didn't realize at first that this approach wasn't going to work for Charlie, and that Charlie wasn't "kicking him out of the room."

Impact of personality. Both student teachers working with the "Imperators" were described as quiet and receptive. For both Isabelle and Bob, this sometimes meant that they would talk more, since the student teachers were so quiet. Tyler had a very quiet, receptive personality and was open to whatever advice Isabelle gave him. He respected her position as the master teacher and was ready to learn from her. Other student teachers felt this way about their cooperating teachers as well, but Tyler was more reticent than the others. Isabelle tended to be very talkative, so when Tyler didn't talk much, she filled in the space. "I probably dominate conversations. Probably. Mostly because that's....especially with teaching things, that's sort of my personality. Once I go on a tear, I'll kind of give him everything" (I-3). Isabelle realized that this became a natural dynamic for them, since Tyler was usually quiet and she was very "verbose." She had the most talking time and the longest recorded conversations out of all of the participants.

Charlie was also quiet, partially because he lacked the motivation to jump in and teach. As it was discovered later in the placement, he didn't really want to be there, so he was comfortable with being "spoon-fed" advice from Bob. Therefore, he would often ask 
him how he would do something. This was part of the reason that Bob's observed role was more direct than he described himself to be. Unlike Isabelle, Bob perceived himself as more indirect, but not having any experience or preparation for mentoring, he had nothing to base his decisions on. He intended to be more "hands off" and ask Charlie questions, but Charlie didn't talk much when asked questions. His typical response was "pretty good" or "okay." When Charlie didn't talk much, Bob talked more.

Bob described himself as being very "laid back." This was also how he approached working with Charlie. He thought that Charlie was "laid back" too, and so didn't worry at first when Charlie didn't jump in to the classroom routine right away. As Bob was so "laid back," it took him a while before Charlie's lack of improvement bothered him. This was also due to his lack of experience as a cooperating teacher. A more experienced cooperating teacher would have noticed issues with Charlie's attitude and teaching earlier based on comparisons with previous student teachers.

Impact of relationship. Isabelle and Tyler were sometimes collaborative, but both described it as primarily a teacher-student relationship. Since Isabelle naturally took the responsibility to lead conversations and organize the classroom environment, she was the primary teacher in the relationship. Tyler reflected that while they had grown closer and more comfortable over time, their teacher-student arrangement had not changed much over the course of his placement. "She still has control over a lot of different things in the classroom and I go up and teach and stuff. That aspect is still the same. She's still that main person and then I'm the second person at the place" (T-2). Tyler respected her opinion and tried to adopt many of her teaching techniques. When asked about their relationship he talked about pleasing her with his teaching. "Just in the way when I go up there and I teach, 
I know a lot of times what she wants me to do or things where I'd be like I know she wanted to me to work on this, or I know what she's thinking I should hit that thing in the ensemble so I should look at that" (T-2). They were the only pair that referred to the student teacher emulating the cooperating teacher. "and he's actually, I've seen him do this now cause he's um, it's actually kind of flattering because I start to hear like my phrases and my inflection of the way I speak to students come out of him..." (I-4).

For Isabelle and Tyler, the comfort level of having a personal relationship was also very important. Just as Isabelle reflected on her own cooperating teacher being personally supportive to her by taking her "out for margaritas after a bad day" (I-1), she understood that her student teachers needed to "feel supported and feel comradery" (I-3). "I think that's really important, because I want <Tyler> to have a positive experience. I want him to enjoy it. If you can't enjoy the job, it doesn't really matter how good you are at it" (I-3).

In some ways, the relationship between Bob and Charlie was similar. Their relationship remained primarily as teacher-student, though even that was strained due to Charlie's lack of commitment and effectiveness in the classroom. Over time, Bob grew more and more frustrated with Charlie's lack of progress in the classroom. By the midpoint of our third interview, Bob sounded less hopeful and more anxious about his mistakes while teaching. He began to sound more and more exasperated while remembering a point in rehearsal when Charlie failed to fix a pretty obvious mistake in the baritone section. "And so they were missing it, every time. I was watching them and they were definitely playing it open. Can you not hear that?! He's working on dynamics and control, and I'm going like...they can play the wrong notes with great dynamics!" (B-3). This was clearly 
unique in this study. None of the other participants expressed any open frustration or animosity of any sort.

When asked about their relationship, Bob responded “I would say it's a positive relationship, but I don't have any point of reference there since he is my first student teacher" (B-3). He realized that he began the semester wanting their relationship to "feel equal - too soon" (B-3). In the first interview Bob referred to their relationship as collaborative. "I mean we have our plan period, and so the plan period is not only planning for the next class, but also doing it collaboratively with him" (B-1). Later, he realized that it wasn't collaborative and Charlie just wanted to watch him teach. "'I don't really know what to do, so let me watch you.' Okay. Watching me ended up lasting a little bit too long'” (B-4). Unlike the other cooperating teachers, Bob and Charlie did not mention a personal relationship or psychological support of any kind. Charlie appeared to be distant throughout the placement, leaving as soon as school was finished and not participating in any extra duties with Bob. Unfortunately, I did not have the chance to ask Charlie about it because he did not complete a second interview.

Impact of student teaching context. For Isabelle and Tyler the pressure of an upcoming performance decreased the amount of podium time that Tyler had, but did not appear to influence Isabelle's mentoring style. Her approach stayed consistent across both recorded conversations. Isabelle made sure that his time with the students was balanced throughout his placement. "My objectives for him and how close we are to the concert and our ensemble objectives. When I think about his whole student teaching placement with me, I try to make sure he gets a decent amount of podium time..." (I-3). Tyler remained past his graduation date in order to conduct one piece with each ensemble on the middle 
school concert. She was also happy to have him available to be at an elementary concert when she was supposed to be at a high school concert at the same time.

Like other participants, their schedule was interrupted by state testing, meaning that they lost instructional time. As the student teaching placement is only eight weeks long, losing a week or more of teaching time can be frustrating. While Isabelle was bothered by the interruption, she knew it was out of her control and took it in stride. Given her organized nature, she likely planned her rehearsal schedule around the testing weeks.

Similar to Adam and Samantha in the other high school setting, there were more performances for Bob and Charlie, and Charlie was unable to take over much responsibility at the beginning of his placement due to an upcoming performance and festival. This slowed down his induction into the classroom, and for Charlie, may have given him an excuse to not step in more at the beginning. Near the end of his placement, Charlie was slated to conduct multiple pieces on the concert. Given his lack of progress, Bob began to take responsibility back from Charlie on most of the pieces for the performance. His primary concern was for his students to have a positive experience during their performance.

Out of all of the sites, testing was less of a schedule interruption for Bob and Charlie. Bob was the only cooperating teacher who did not mention that testing impacted their schedule. For the middle school sites, state testing was a lengthy interruption for the entire school. For high schools, testing impacted a portion of the school, and Bob's school was not an International Baccalaureate school like Adam's, which involved more testing for a large number of his students. Bob was out of the classroom for approximately a week while subbing for the choir director during an extended leave of absence, but this was partially 
intentional, as he thought it was time to "force" Charlie into taking over more teaching responsibility.

The Encouragers. Adam and Joanna both adopted the role of the encourager during their recorded conversations. This meant that they asked more reflective questions of their student teachers as opposed to giving direct advice. Adam thought it was important to get Samantha's immediate reaction to her teaching and not influence her thoughts with his ideas. Joanna also wanted the conversation to stem from the student teacher. It was important to both of them for the student teacher to reflect on their practice, make their own decisions, and take ownership over their teaching. They saw their role as a coach or a guide.

Joanna was especially open to Ellen developing her own ideas in the classroom. "She's very open with me, just like trying new things with their technique and like experimenting and all of that" (E-1). She wanted Ellen to develop her own teaching style, even if it was completely different from what Joanna might do herself. This contributed to her indirect and reactive style during the recorded dialogues. During their final recorded conversation, Ellen excitedly reflected on her week of solo teaching. During that week, she had the chance to try out some completely new ideas with the students. Joanna acknowledged that they were different from how she usually does things, but that it could work for Ellen.

Adam and Joanna also reflected on what their off-camera conversations were like. Adam was observed as primarily indirect and reactive, yet he still thought that he talked more on camera than he might in their more informal conversations. Most of their conversations were short, informal conversations, as opposed to more extended and 
formal as observed in their videos. In their informal conversations he tended to be even more reactive, as Samantha often began the conversation with a question or reflection about her teaching. Joanna, on the other hand, said that her approach tended to be more direct in their informal, off-camera conversations. This is primarily due to the lack of time during the day to sit down and talk. "When it's throughout the day and it's tiny little things, it's direct advice. When we're having a formal conversation, then it's more directed by her...I just thought of this and I want to tell you really quick, you know?" (J-3).

Impact of personality. Similar to Tyler and Charlie, Ellen also had a relatively quiet personality, which Joanna was concerned about when she first met her. She thought it might make it more difficult for Ellen to make connections with students, which she feels are very important and a challenge for a student teacher who is only there for eight weeks. Unlike Charlie, Ellen was excited to step into a leadership role in the classroom. Joanna instilled a sense of trust and ownership and Ellen embraced that and felt empowered to try out new and different ideas with the students. Joanna described herself as introverted, but not around her students.

Samantha was inquisitive and ready to step in and teach. She was constantly asking Adam questions about different techniques or asking for feedback on her teaching. Adam realized that his approach might be different with a different student teacher who was not so inquisitive. "It's different from student teacher to student teacher. Some of the kids I have to pry out how they're feeling. $<$ Samantha $>$ will just tell me, and so all I have to do sometimes is just ask, if she asks a question that's fine, it I just open it up generally, she usually just tells me" (A-4). Similar to Bob, Adam was also very laid back and informal. This was immediately noticeable by his messy office and adaptable attitude about student 
teachers in general. This meant that he was very flexible and adapted to his student teacher's needs. This flexibility influenced his more indirect mentoring style.

Impact of relationship. Both Adam and Samantha as well as Joanna and Ellen described their relationships as collegial and collaborative. Both cooperating teachers fostered this climate by being open to their student teacher's questions and ideas. Joanna described their relationship as "trusting." Ellen gained a sense of confidence in her teaching because she felt trusted by Joanna. "We definitely go back and forth a lot and we're helping each other grow" (E-1).

In addition to a comfortable and safe learning environment, both Adam and Joanna provided personal and psychological support for their student teachers by getting to know them personally. Just like Tyler and Isabelle, Samantha and Ellen both expressed feeling more comfortable and getting to know their cooperating teacher better over time. Adam made efforts to welcome Samantha and make sure that she feels comfortable both teaching his classes and asking questions as needed. He encouraged students to view her as a teacher. By the end of her placement, Samantha described Adam as an "amazing friend and colleague and mentor" (S-2). Joanna and Ellen also got to know each other personally over time. For them, the testing interruption meant more time to talk to each other about more personal topics and just get to know each other better. "I feel like I know what her goals are for the next several years, what she plans on doing in the future with her teaching. We know kind of personal stuff about each other, family life" (J-3).

For both Samantha and Ellen, the comfortable and safe learning environment and feeling trusted by their cooperating teacher helped them feel more like co-teachers than students. Samantha felt trusted and noticed the "feeling of being watched" (S-2) go away. 
For Ellen as she grew more comfortable she felt like a valued and trusted teacher. “...we're talking more, being more friendly with each other. We're definitely more like co-teachers now as opposed to student teacher/cooperating teacher" (E-2). Though the feeling of trust was evident for both Ellen and Samantha, it was especially obvious for Ellen in the way that she felt more confident in her teaching than she ever felt possible. Joanna showed that she valued her opinion by asking her for feedback during rehearsals, even when Joanna was on the podium. Adam and Bob both mentioned asking their student teacher for input or allowing their student teacher to interrupt them, but Joanna was more consistent and intentional about it. At the beginning of the placement she didn't feel like she would be on the same level with her cooperating teacher.

I didn't think I could be, just because I felt like I still had so much to learn. I felt like, I was kind of afraid to make comments to her about what was happening in the group because I was afraid that I would be wrong, or that she would disagree with me. I was scared to make those comments, and so I didn't really. Then, she kept asking for my input and every time I gave her the input she was like, 'oh, I didn't hear that. I'm going to listen for that this time.' It's a very natural way, to kind of go back and forth (E-2).

Impact of student teaching context. Similar to Bob and Charlie in the other high school context, Samantha stepped into a situation where Adam was preparing for a festival, a concert, and a trip to Boston. Unlike Charlie who said that he hadn't been able to do much at the beginning, Samantha jumped right in and conducted a piece at a festival. This could have been because of her limited experience with Adam during her first placement, but Adam also felt strongly that she should be given opportunities like that. Throughout the 
placement, the timing of performances impacted how much Samantha was able to take over with each ensemble. “The jazz band has a lot of performances coming up, I don't have a chance to get her in front of them too much" (A-3). She was responsible for pieces with other ensembles, but out of concern for the students he didn't feel like he could give her any more podium time.

For Joanna and Ellen, the performance pressure was more pronounced near the end of the placement when the spring concert was approaching. Just like the other student teachers, Ellen was staying past graduation to conduct pieces on the concert. Joanna admitted that she was a bit of a perfectionist, and putting on a good concert was very important to her. Therefore, she talked a lot about how it was hard to let go of her ensembles with a student teacher. "I mean you still have to maintain that integrity, it's still your program...it's hard with music I think to let go" (J-1). Concert preparation also became a focus of their dialogues more than the other participants. Since they had such a collaborative relationship, it was a team effort to make sure that the students were wellprepared. Even when one of them was conducting, the other one was listening and giving feedback to the teacher or the students. As mentioned previously, Joanna and Ellen also had their schedule interrupted by state testing. It gave them time to get to know each other better, but Joanna also felt the pressure of giving Ellen enough teaching time while also preparing students for their concert. "...in our last conversation I was trying to think why do I feel so panicky, cause we missed so much time with them during her placement. She's only here for eight weeks and basically three of them, two and half are missed time" (J-4).

Placement timing. For all of the participants, this was their second student teaching placement, which meant that they came into the situation with some related 
teaching experience under their belt. Both middle school student teachers, Tyler and Ellen, had previously student taught in a high school instrumental setting. Both high school student teachers, Samantha and Charlie, had already student taught in middle school band settings. For all of them, that meant that they had already gained valuable teaching experience, been evaluated and set midterm goals, and completed the edTPA, a high-stakes, external teaching assessment. This made the student teacher feel a bit more relaxed. Ellen, Tyler, and Samantha even had jobs lined up for the fall before graduation.

Each student teacher made some comparisons between their two placements, whether referring to differences in students or the cooperating teacher. Charlie felt more comfortable with high school students, primarily because of classroom management issues with middle school. Tyler came to realize that each of his cooperating teachers were different, and therefore the relationship and level of responsibility in the classroom differed. "I just think that each different place is going to have its own kind of environment and the relationship is different" (T-2). In his first placement, he became more of the "main teacher figure" because his cooperating teacher left him alone more.

I still think that <Isabelle > allows me to be...go out and do those, like be the teacher in the classroom and make my own decisions but I still, for $<$ Grapevine $>$ the environment that's kind of set up there for me is kind of like she's still making those big decisions and she's still teaching the kids, too. It's kind of more of a balance of we're both the teacher kind of thing, rather than I become the teacher more of one class (T-2).

Samantha's first placement was with Isabelle at Grapevine, and so she experienced some level of continuity since Isabelle assists at Orion with Adam and Adam assists at 
Grapevine with Isabelle. Samantha noticed that Isabelle was much more organized and structured than Adam. During her second placement with Adam she felt less pressure. "When I first got here, and at my last student teaching placement, I definitely felt the pressure...I feel more comfortable with him, less like I'm being watched for a job or something" (S-2). She had grown more comfortable over time, and she attributed the change to a sense of freedom and autonomy at Orion.

Ellen also developed a sense of freedom and autonomy, as Joanna encouraged her to experiment with new ideas in the classroom. She contrasted her two cooperating teachers more than the others simply because they were so different. Immediately she noticed that things were "less structured at the middle school level, I think it's just the nature of my cooperating teacher" (E-1). She described Joanna as more "laid back." She was used to her cooperating teacher interrupting her lesson to tell her she was doing something wrong in front of the kids. "At my other placement, uh, I would be up there and something would be going horribly wrong and my teacher would just come up, and she would just take over or like start putting me on the spot or something" (E-1). With Joanna she felt like more of a teacher. "I'm not being treated like a student in front of the students and they treat me more like a teacher" (E-1). Her first cooperating teacher referred to their relationship as co-teaching, but Ellen didn't see it that way. "She was thinking that she was doing a coteaching effort, but it felt like I was being taught in that co-teaching effort so it didn't feel like I was the teacher. Here, it...this is what I think of when I think of co-teaching because I feel like one of the teachers" (E-2). Ellen believed that she had gained valuable teaching skills during her first placement, and she flourished with a sense of trust and confidence in her teaching ability instilled in her by Joanna. 


\section{Impact of Video-Based Reflection}

Research question \#3 refers to the cooperating teachers' response to video-based reflection of mentoring dialogues. In this section I will describe how each cooperating teacher reflected on their approach or what they could have done differently while watching the videos. Additionally, taking part in the study essentially forced them to have more formal conversations with their student teachers than they were used to.

"I didn't realize I spoke that much." Especially in the case of Adam, his reflection during our interviews appeared to influence their approach observed in the final recorded conversation. In the final recorded conversation, Adam was observed as being more indirect and more reactive than he was in the first. This also resulted in a shift in their talking time, with Samantha talking more during the second conversation. As we watched the videos Adam would often comment on what he could have or should have done differently. Asking reflective questions was very important to him, as he would often comment that he could have asked a better question in order to get a better response out of Samantha. "And I could have just asked her, how did you think the pacing was before I actually gave my two cents on how it actually was...I definitely could have let her find the answers as opposed to tell her the answers" (A-2). He wanted Samantha to be allowed to take the lead during their conversations and not share his own opinion until she has had a chance to reflect, therefore when he realized that he had been doing most of the talking during their first recorded conversation he wasn't very happy with himself. Throughout his reflections if she didn't respond as he hoped or expected that she would he would reflect about the question that he asked. He never critiqued her response, instead turning on his own approach saying that "a better question would have been..." (A-2, 4). He 
thought that if he had asked more detail-oriented questions, she would have been able to reflect more clearly and get to the point he was hoping for faster. "So I watched this and I'm like uh, you're such a dumbass. You know, like seriously, you could have got there so much quicker!" (A-4).

Reflecting on his own questioning of Samantha he also began to think about using questions to give his students more ownership over musical decisions. As a result of this reflection during the first stimulated recall interview, this led him to reflect with Samantha on their questioning of students. "So a topic that we've been discussing, that has been since the last time you and I talked was that I want you to answer the question, and then we said okay, now we need to let the kids answer the question" (A-4). Through reflecting on his questioning of Samantha and his desire to have her reflect and come to her own conclusions that also led him to encourage that ownership with his students.

"He lets me rant." Similar to Adam, watching the videos prompted Isabelle to realize how talkative she was. As their first recorded conversation was a one-sided explanation of sub plans, her first comment upon viewing was “this probably doesn't seem much like a conversation" (I-2). This prompted her to reflect on why that was the case. “...this was me laying out the plan, so obviously a ton of information from me going to $<$ Tyler>, but there were some natural pauses in there, cause lunchtime, you gotta chew, where I thought he might ask a question" (I-2). She also realized how Tyler's personality was a factor in the nature of their conversation. "Well, and some of it too, is $<$ Tyler $>$ is a good listener and he's very polite and he lets me rant" (I-2).

During the first stimulated recall interview we were both reflecting on why Tyler seemed so awkward and thought it may have been due to the camera. "It's hard, it's hard to 
be on camera. I'm used to it because I did my national board, so you just do it" (I-2). Later on, in the second stimulated recall interview she realized that they were both a little bit awkward on camera. "I mean it always feels slightly contrived, talking to a video camera, so I think a little bit of that kind of comes through for both < Tyler > and I. Interestingly enough, I think we have opposite reactions to that, I think his reaction is to be more taciturn and my reaction is like word vomit sometimes" (I-4).

"A better way to ask." Though not nearly as much as Adam, Joanna also reflected on asking better questions. "...what do you think in your teaching you could improve on?...would be a better way to ask it" (J-2). Watching the video also made her realize that she didn't give Ellen much time to ask questions herself. "I asked if she had questions...but I didn't listen to her. I didn't wait for her to ask questions, I was just like well, do you feel like you're getting up there enough, kind of bunched it all into one little thing" (J-2). Especially near the end of the study, Joanna also realized that how much she had been reflecting along the way about her mentoring approach while watching the videos and talking with me. "Thank you, this was great, it's actually made me look into what I'm doing a little bit more...I don't know if I should do this a little bit more, or this..." (J-4).

"I just spoon fed him a whole lot." Reflecting through watching the videos led Bob to realize things about Charlie and prompted him to think about his mentoring approach, which he had never done before since he was a novice cooperating teacher. Both as a teacher and as a mentor, he seemed to want to adopt an indirect approach, guiding students to their own conclusions. Through watching the videos, he realized that he gave him a lot of answers. "I think I just spoon fed him a whole lot, a whole lot of concepts that you can use to do this and didn't infer more of his ideas to let him try something that was in 
his head" (B-2). He also realized that he was doing most of the talking, yet he justified his reasoning for this in the first recorded conversation. “...as I've been watching, I'm like man, I've been talking a lot, but there is some background information that's good for him to know, like okay, we're going to start by the teaching the F major scale, which they've already played" (B-2).

When asked about cooperating teacher qualities, the first thing he said was "being perceptive to the needs of your students and also to the needs of your student teacher" (B3). Through watching the videos and as a result of his struggle with Charlie, he realized that he realized that he should have noticed that sooner. "I started noticing that about a month ago, I guess whenever it was that we had our last conversation" (B-4). He was realizing that Charlie wasn't fully invested into student teaching. "As opposed to 'I don't really know what to do, so let me watch you. Okay. Watching me ended up lasting a little bit too long. He just needed to do it and learn from not knowing what to do" (B-3).

Formal conversations. For each of the participants, sitting down to record the videos for the purpose of this study forced them to have more formal conversations than they might normally have. As mentioned previously, Adam wasn't accustomed to having formal conversations with Samantha. Sitting down and recording a formal conversation felt awkward, and very different from how they normally operated. "And so this is maybe a little bit of a role reversal, in terms of how we typically do it. So she'll go hey, what about this, and then we'll talk about that, as opposed to me leading, initiating the question, she usually maybe more often initiated the question. Maybe that's why this feels kind of contrived, I don't know" (A-4). Even though Isabelle was very organized and took formal notes to guide their debrief conversations, she also thought that sitting down for a formal, 
extended conversation felt different. "It's a little more sporadic I think, because we don't feel the need to sit and have an extended conversation, and in reality the way we speak to each other is like fits and start throughout the day because we're both working..."

Joanna and Ellen probably seemed the most comfortable with the videos. They were very formal, with the two of them sitting in chairs in the classroom and talking. Joanna had a few planned topics, but they did not sound rehearsed or scripted. They were also very consistent with recording them weekly, except when their schedule was interrupted by testing and spring break. Even with this comfort level and consistency, she sometimes mentioned that it was awkward to record themselves. "We don't know how to wrap up our conversations...yeah, I mean if it was just a normal conversation we would have already got a little bit sidetracked. We're getting more used to it" (J-2).

Bob also appeared to be comfortable recording the videos. He took responsibility for recording their conversations and sharing the videos with me. He wasn't always consistent with the dialogues near the end of the placement, but there were other issues on his mind and was out of the classroom for approximately a week. He was the only participant who didn't talk about the videos being more formal than their usual conversations. Since this was his first student teacher, I think he just stepped into the routine of sitting down and recording a conversation and therefore became used to it. For the other cooperating teachers, they had a somewhat established routine for working with student teachers, and recording a weekly conversation wasn't part of it. 


\section{Comparison of the Models}

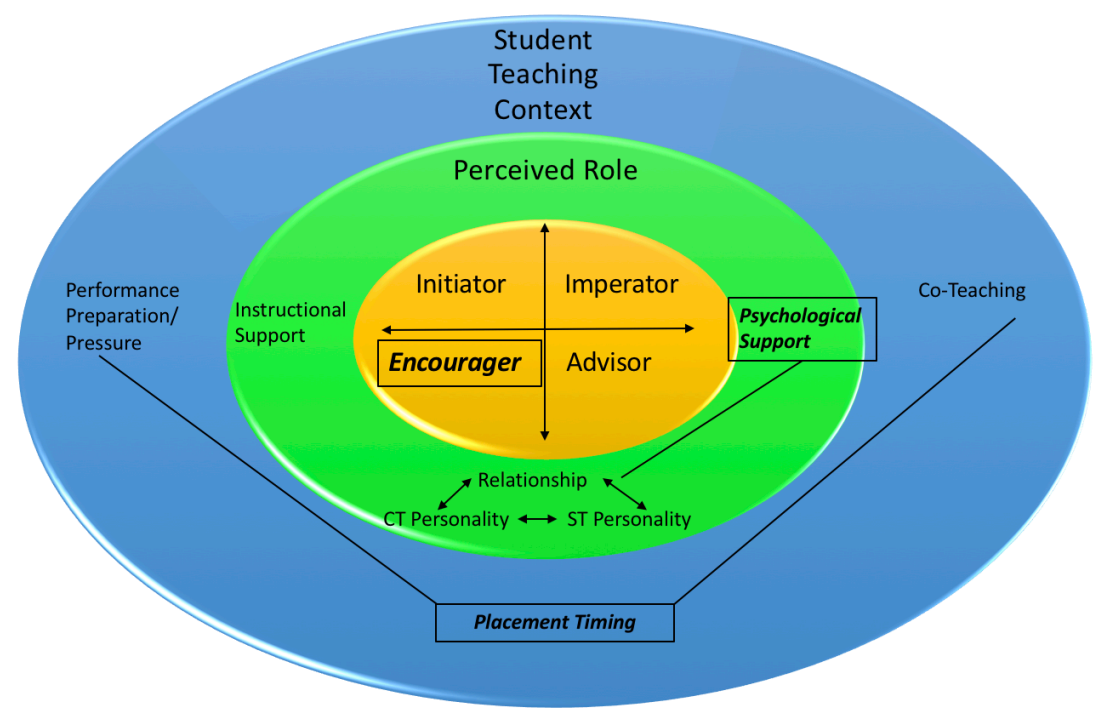

Adam-Samantha

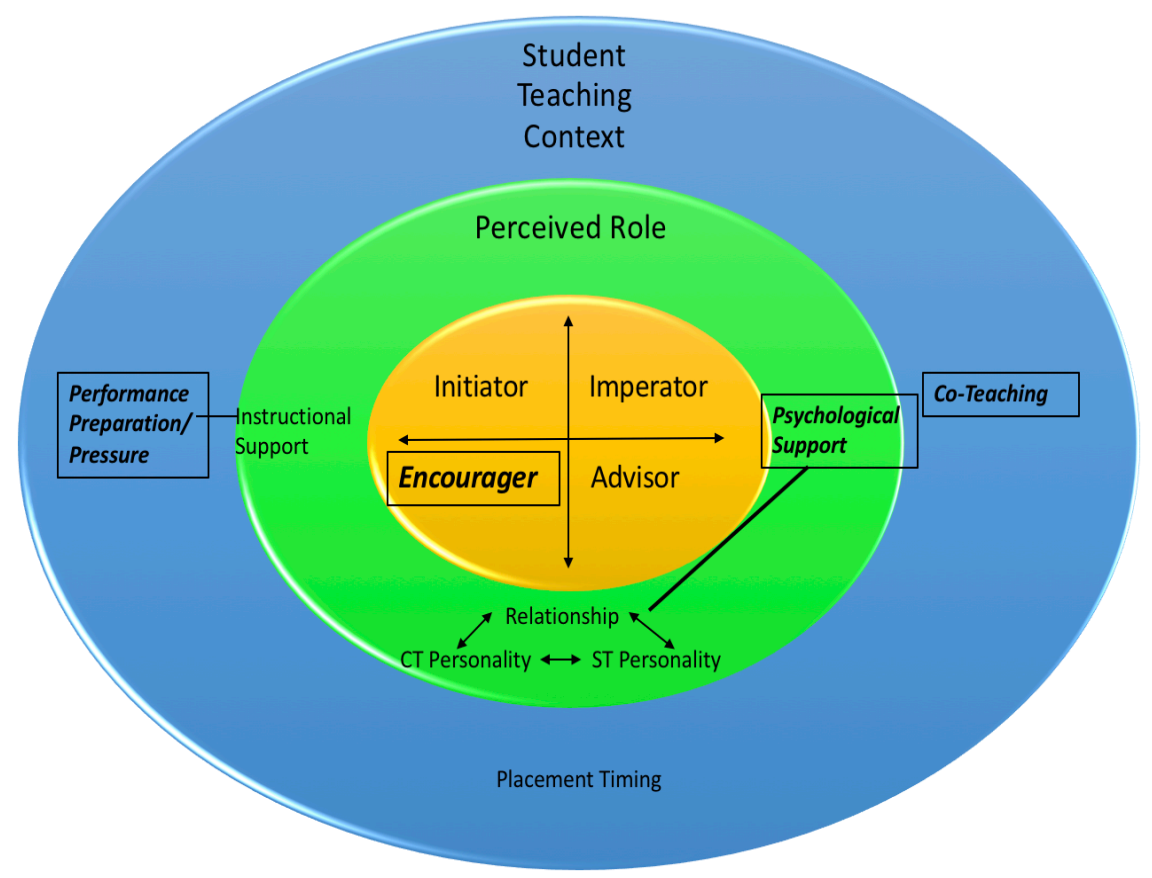

Joanna-Ellen

Figure 16: 'Encourager' Models

While one factor, psychological support, had a more noticeable impact on the mentoring dialogues for both of the encouragers, other factors including co-teaching 
approach, performance preparation and pressure, and placement timing had a differential impact on mentoring dialogues. As shown in Figure 16, providing psychological support was an important part of the mentoring role for each of the encouragers: Adam and Joanna. Shown in bold and connected to the cooperating teacher/student teacher relationship, they provided support by building a trusting and collegial relationship. This was evident in mentoring dialogues through their use of questioning and fostering student teacher reflection. For Joanna and Ellen psychological support was also connected to co-teaching, as demonstrated by Joanna instilling confidence in Ellen as a trusted teacher. For Adam and Samantha, their co-teaching arrangement was connected to the timing of the placement which was also impacted by the pressure to prepare for upcoming performances. Therefore the placement timing is shown in bold for Adam and Samantha. Performance preparation/pressure was shown in bold for Joanna and Ellen because the upcoming performance was at the forefront of their minds and limited Joanna's willingness to relinquish control of her classes.

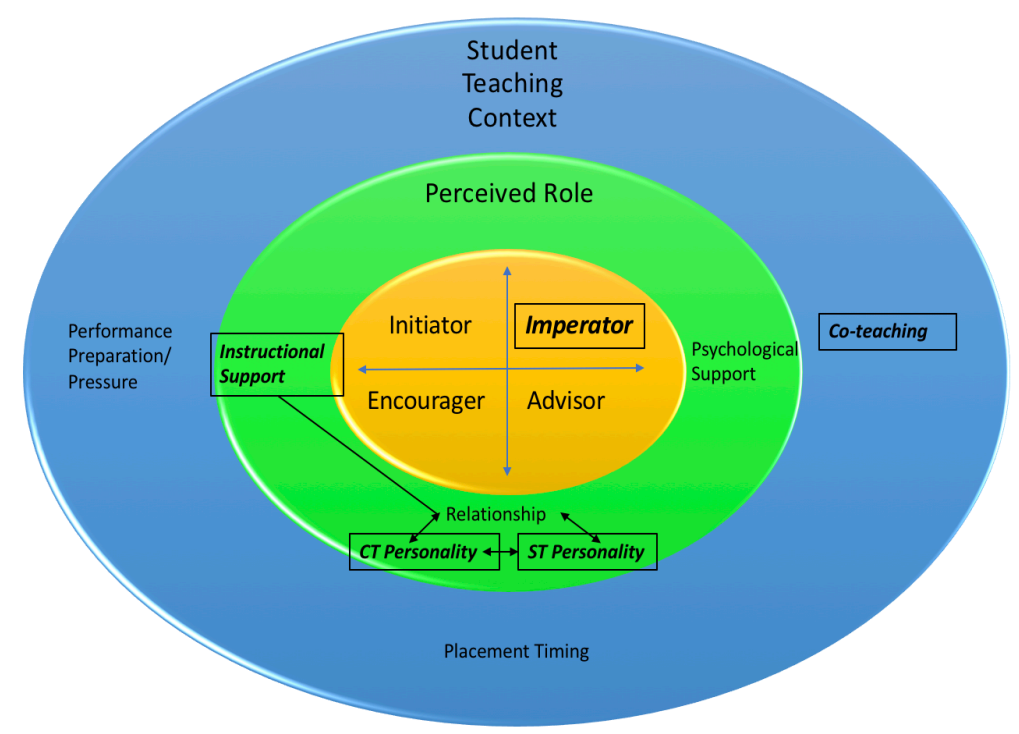

Isabelle-Tyler 


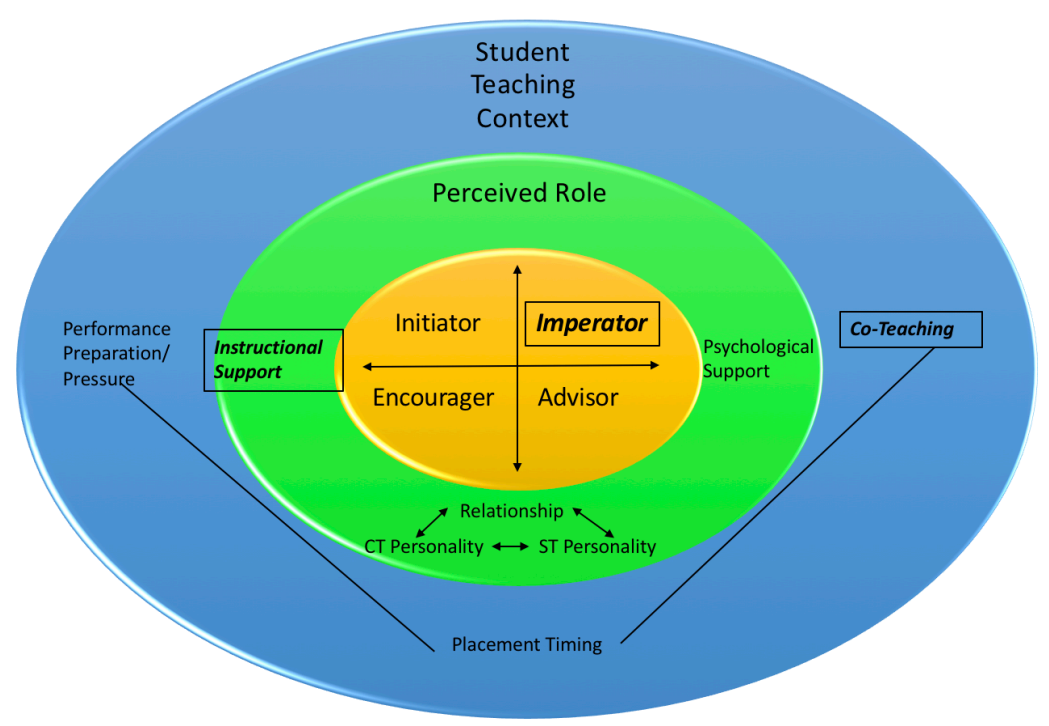

Bob-Charlie

Figure 17: 'Imperator' Models

Unlike the encouragers, for both of the imperators, providing instructional support was valued by the cooperating teacher and shown in bold. Additional factors including the cooperating teacher-student teacher relationship, co-teaching approach, performance preparation/pressure, and placement timing also influenced the dialogues, but in different ways than the encouragers. For Isabelle and Tyler this type of support informed their relationship and was connected to their personalities. Isabelle was observed controlling the conversation and giving direct advice in keeping with her distinct personality. Isabelle tended to be very talkative, while Tyler was much more quiet and "let her talk." However, for the other pair, instructional support was not connected to their relationship or personalities, and therefore Bob's focus on providing instructional support during dialogues did not contribute to building a personal relationship between the two, nor did it take into account their personalities. Each of the imperators adopted a similar approach to co-teaching in which one taught while the other observed and/or played with the ensemble. For the cooperating teacher this allowed them to observe the student teacher 
and follow up with detailed feedback. For Bob this was also connected with the placement timing and performance preparation and pressure as he was busy with performances at the beginning and the end of the placement, limiting Charlie's teaching time.

When comparing all four models, it was also notable that placement timing, performance preparation/pressure, and co-teaching were connected for both of the high school contexts. Both Adam and Bob had performances at the beginning and the end of the placement. While this impacted the co-teaching approach used in each case, Samantha was trusted with more teaching responsibility and Charlie was allowed less teaching time. Performances were a factor in the middle school contexts, but only at the end of the placement. While it was different for each middle school teacher, the co-teaching strategy was central to the student teaching context and influenced the mentoring dialogues. For both middle school teachers the support provided, whether it was primarily instructional or psychological, was connected to the relationship between the cooperating teacher and the student teacher. This was also true for Adam and Samantha, as all three experienced cooperating teachers adapted to the individual needs of the student teacher. As the cooperating teachers better understood the student teachers' goals and teaching development, they were able to personalize their feedback during mentoring dialogues. 


\section{CHAPTER VI}

\section{Summary and Conclusions}

\section{Introduction}

In this study, I examined the roles assumed by music cooperating teachers during mentoring dialogues with their student teachers. Four cooperating teacher/student teacher pairs were selected for participation in the study and data were collected through semi-structured interviews and stimulated recall interviews. Specifically, I sought to determine the cooperating teachers' mentoring style adopted during mentoring dialogues and what factors might influence their mentoring style. Analysis of the mentoring dialogues was guided by the Mentoring Roles in Dialogues (MERID) Model (Hennissen et al., 2008). Additionally, I noted the impact of the process of viewing video recordings of their mentoring dialogues.

This chapter will begin with a brief summary of the findings, followed by a discussion of the relationship between the findings and previous research or theory. Finally, I will provide recommendations for music cooperating teacher development as well as implications for future research.

\section{Summary of the Findings}

Factors contributing to mentoring roles during dialogues. The student teaching context and the mentor's perceived role were factors that contributed to the mentoring style adopted during mentoring dialogues.

Student teaching context. For each of the pairs, the student teaching context contributed to the mentoring style used during dialogues. Co-teaching was apparent in all of the cases, but looked different for the encouragers and the imperators. For the 
encouragers, they fostered a trusting and collaborative environment which informed the instructional approach used during rehearsals. This was especially apparent in the case of Joanna and Ellen, as Ellen referred to their classroom working relationship as "team teaching" since Joanna asked for her feedback about the sound of the ensembles during rehearsals, making Ellen feel trusted as a teacher. Adam also cultivated an environment where Samantha felt trusted and asked her for feedback about the ensemble during rehearsals, although less regularly.

In the imperator's classrooms, there was still co-teaching happening, but it was more similar to a one teach/one observe strategy, taking turns teaching with less collaboration during instruction (Cook \& Friend, 1995). Isabelle and Tyler took turns rehearsing each of their assigned pieces. At times, Isabelle would teach a lesson to an elementary ensemble and Tyler would repeat the same lesson with a different ensemble. While one was teaching the other would observe or play with the students. Later in the placement, Bob began stepping in and helping more and taking over responsibility for rehearsing all of the pieces due to Charlie's lack of progress before the concert.

Timing of the placement and performance preparation and pressure also impacted the mentoring role adopted by the cooperating teacher. As this was the second placement for each of the student teachers, they came into it with prior teaching experience. Each of the cooperating teachers realized this and knew that the student teachers were ready to step in and take responsibility for the ensembles a little sooner than they would if they had been in their first placement. Joanna and Adam both noticed how their student teachers were building off of their prior experience from their first placement. They reflected during interviews how they adjusted their mentoring approach to meet the current needs 
of the student teacher. Adam knew that Samantha was very reflective and inquisitive, asking questions frequently. Joanna used questioning during mentoring dialogues to gauge how Ellen was feeling about her teaching so that she might adjust her mentoring style or teaching time accordingly.

Being in the second placement also meant that each of the pairs were preparing their ensembles for a spring concert. Both high school settings had performances at the beginning and at the end of the student teacher's placement. For Charlie, this meant less teaching time at the beginning. For both high school placements this also meant less time for formal mentoring dialogues in the weeks leading up to the concert. For Isabelle and Tyler, the pressure of the upcoming performance impacted his teaching time, but not their dialogues directly. Adam and Joanna both talked about how the upcoming performance impacted the content of their dialogues. As the performance grew closer they functioned like colleagues, talking about their common goal of preparing the students for the concert. Especially for the two encourager pairs, this was a positive outcome related to performance pressure. The student teachers felt like valuable contributors to student performance preparation.

Perceived role. Each of the cooperating teachers hosted student teachers out of a sense of duty to the profession and the desire to give back to the profession. Adam, Joanna, and Isabelle also had a connection to the university and wanted to give back to the school. Isabelle and Bob also talked about their experience as a student teacher and wanted to provide that opportunity for someone else.

Cooperating teachers were observed providing both psychological support and instructional support. Psychological support contributes to establishing a personal 
relationship between the cooperating teacher and the student teacher. The cooperating teacher made an effort to create a comfortable and safe learning environment for both their students and the student teacher. This was very evident for Adam and Joanna as they encouraged reflection during dialogues and offered to answer questions and provided resources. Isabelle also offered psychological support by getting to know Tyler personally, but it was not as clearly evident during dialogues. Bob was the only one who did not mention their personal relationship or the learning environment for his student teacher. Rather he commented more about his students' learning environment. The relationship between Bob and Charlie was also likely strained by Charlie's lack of commitment to his student teaching placement and failure to progress in his professional practice.

Each of the cooperating teachers provided instructional support through modelling teaching strategies and through ongoing feedback during their dialogues. This was especially apparent for Isabelle who took detailed notes while Tyler was teaching so that she could debrief with him afterwards. Bob used modelling to show Charlie effective strategies and then asked him about the strategies afterwards. Joanna and Adam used questioning and direct advice in order to guide their student teachers to certain areas for improvement.

The personality of the student teacher had an impact not only on their relationship, but also on the mentoring style adopted by each of the cooperating teachers. The cooperating teachers felt the need to understand their student teacher's personality, the cooperating teacher was aware of their student teacher's personality and how they might respond to feedback and mentoring. This awareness impacted the mentoring role they adopted during mentoring dialogues. Each of the experienced mentors talked about how 
they have approached other student teachers differently. Isabelle understood that Tyler was quiet and took time to process feedback. Joanna also knew that Ellen was introverted and encouraged her to relax and have fun with the students in order to develop rapport. Bob thought that he would get along well with Charlie because they were both "laid back." Charlie was very quiet during their conversations. Adam knew that Samantha was very forthcoming with questions and reflection, so he didn't have to "pull it out of her."

In each case, personality traits of the cooperating teacher and the student teacher influenced the dialogues. Isabelle was aware of how talkative she was and knew that meant she would dominate their conversations, especially since Tyler tended to be so quiet. Joanna described herself as an introvert, and was observed eliciting reflection and reacting to Ellen during their conversations. Bob was observed as talkative during dialogues, potentially because Charlie was so quiet. Adam characterized himself as laid back and relaxed, and his relationship with Samantha grew closer and more comfortable over time. Their conversations appeared natural, despite his lack of comfort with recording themselves.

Mentoring role assumed during mentoring dialogues. The Mentoring Roles in Dialogues (MERID) Model (Hennisen, Crasborn, et. al, 2008) was used to analyze the mentoring role adopted by the cooperating teachers during the recorded dialogues. The style (direct and indirect) and the input of the cooperating teacher (active and reactive) were used to map the cooperating teacher's observed role during mentoring dialogues. Mentors were categorized as either an initiator (indirect and active), imperator (direct and active), advisor (direct and reactive), or encourager (indirect and reactive). Topics, phase, or overall pattern of the conversation, and the timing of the conversations informed the 
mentor teachers' style and input classification. Isabelle and Bob were both classified as imperators, while Adam and Joanna were classified as encouragers.

For Adam and Samantha, the most common topic of conversation was students while Bob and Charlie focused on music and Isabelle and Tyler talked primarily about instruction. Joanna and Ellen talked about music more in the first conversation and focused more on the students in the second conversation.

Adam, Joanna, and Bob all began conversations by asking their student teachers a reflective question and followed up with direct advice or feedback. Isabelle adopted the opposite approach, beginning with feedback on Tyler's teaching and direct advice for improvement and ending the conversation with reflective questioning. While both Bob and Isabelle were observed to be an imperator, Bob assumed this role as a result of Charlie's lack of response. At the beginning of the mentoring dialogue, Bob wanted Charlie to be reflective about his teaching or rehearsal planning, but when he didn't respond to a question posed by Bob, Bob took control of the conversation by introducing topics and directly telling him what he should do in an upcoming lesson. He gave direct advice, but appeared hesitant to give feedback about the areas that Charlie struggled with such as instruction and students.

The timing of the conversations was indicative of the cooperating teachers' style. The two imperators dominated the conversations, talking $80-90 \%$ of the conversation, while the encouragers' conversations were more evenly split between both parties.

Adam shifted to being slightly more active and more indirect in the second recorded conversation while Joanna remained fairly consistent between the two conversations. Isabelle's style (direct) and input (active) stayed consistent between both conversations, 
while Bob was more indirect and reactive in the second conversation, although he still remained in the imperator quadrant of the MERID model.

Impact of video-based reflection. As part of the study, each cooperating teacher/student teacher pair was asked to video-record a weekly conversation. This required them to schedule an extended conversation, which two of them were already doing, but two of them were not. Along with scheduling time to speak, they had to have a plan for what they would talk about and record the conversation. Though cooperating teachers and student teachers are naturally talking throughout the week, not all of them have regular formal conversations. Especially for Adam and Samantha, many of their conversations were brief or informal, happening immediately following a teaching experience. For Isabelle and Tyler, they might even chat in the car between schools.

Other impacts of engaging cooperating teachers in video-based reflection on their mentoring were noted. Some of the cooperating teachers mentioned feeling awkward watching themselves mentoring via video. Joanna, Isabelle, and Bob said that they were comfortable with recording themselves, but Joanna and Isabelle still mentioned how recording changed the balance of the conversation or how it was awkward to watch themselves. Bob took responsibility for recording their conversations each week, making it part of their regular routine. Adam was the most uncomfortable with the videos because he did not usually have such formal conversations with Samantha. Many of their informal conversations were begun by Samantha asking Adam a question or asking for his opinion. Recording the videos forced them into a "role reversal" as Adam felt responsible for leading the formal conversation, while Samantha would often steer the informal conversations by asking questions. 
At the same time, the process of video-based reflection resulted in all of the cooperating teachers reflecting on their own mentoring style. All of the cooperating teachers also reflected upon their own mentoring style while watching the videos and during interviews with me. For Adam, he realized that he talked more than he thought and began to question if he was being consistent with his style during the rest of their conversations. This also caused him to reflect on his questioning approach with his students and encouraged Samantha to invite student input as well. Joanna didn't reflect as much as the others, but did talk about needing to ask better questions. While Isabelle knew that she tended to be talkative, she thought that the camera had an impact, making her talk even more and Tyler talk even less. Bob realized that he was giving Charlie all the answers and giving direct advice, when he intended to get Charlie to reflect and answer questions on his own.

\section{Discussion}

The cooperating teachers in this study assumed various roles in mentoring dialogues. Aspects of the student teaching context as well as the cooperating teacher's perceived role contributed to the role assumed during mentoring dialogues. In the next section I will discuss the findings from this research in relation to prior research or theoretical concepts.

Student teaching context. The student teaching experience can be impacted by a variety of contextual factors including the co-teaching approach used during instruction, placement timing, and pressure related to performance preparation (Draves, 2013; Krueger, 1985). Though their mentoring role stayed consistent, the mentoring style adopted by the cooperating teacher during mentoring dialogues was also impacted by 
these contextual factors. Some factors, including placement timing and performance pressure may be unique to music classrooms.

Co-teaching. All pairs engaged in co-teaching to some degree. Teachers that were characterized as imperators tended to use a strategy labelled by Cook and Friend (1995) as one teach, one observe, in which they took turns teaching. Being in an ensemble setting, the observer often played with the ensemble. This strategy allowed the cooperating teacher to model teaching strategies as well as actively observe and give feedback for the student teacher. For the encouragers, there tended to be more interaction between the cooperating teacher and the student teacher during rehearsals through questioning each other or helping students. No matter who was on the podium, they shared the common goal of preparing the students for the performance, fostering a positive and respectful environment where both teachers were comfortable working together, which is indicative of a team teaching strategy (Cook \& Friend, 1995; Hildenbrand, 2009). The encouragers encouraged the student teachers to speak freely during dialogues, which allowed the student teacher to interact and reflect on their teaching openly with their cooperating teacher, creating a positive instructional environment in which team teaching was possible.

Placement timing/performance preparation and pressure. The teaching schedule and concert schedule, both "structural norms" identified by Krueger (1985), were aspects of the student teaching context in this study that informed mentoring dialogues. While Krueger referred to the daily teaching schedule, in this study the testing schedule rather than the daily schedule impacted mentoring dialogues. In all cases, there was lost teaching time due to the standardized testing schedule. This resulted in less teaching time for the student teachers as well as less rehearsal time for upcoming performances. 
Positively, the cooperating teacher and student teacher had more time to talk during scheduled testing time.

Since music student teachers often have two student teaching placements as a result of earning a K-12 teaching license, the length of time to learn about the school context becomes shortened (May, Willie, Worthen, \& Pehrson, 2017). Krueger (1985) found that student teachers may struggle to adapt to the new school setting, yet the student teachers in this study appeared to adapt to their new placement quickly. Similar to Krueger's (1985) participants, the student teachers in this study had two eight-week placements, but since they had practicum teaching experience at their student teaching sites during the previous semester, they had some prior experience in the schools which may have eased their transition into their placements, allowing them to gain confidence more quickly. While Krueger (1985) found that given the short time period, the student teacher rarely developed the confidence to experiment with new teaching strategies in either placement, this did not appear to be the case for one student teacher in this study. Though observation of student teacher experimentation with new teaching strategies was beyond the scope of this study, Ellen seemed to have developed confidence and reflected on the freedom allowed to her during her solo week of teaching during mentoring dialogues. The trust instilled by Joanna and reflection during dialogues along with Ellen's experience gained over the course of her student teaching semester contributed to her level of confidence. Though others mentioned feeling free to try new things, the topic was not introduced during dialogues.

Each of the student teachers stepped into an existing classroom and school structure. This limited their degree of choice when it came to certain elements established 
by the cooperating teacher such as repertoire selection and the concert calendar. While Powell (2017) found that student teachers felt like they lacked the "agency" to make their own decisions and lacked the autonomy to plan or make teaching decisions in the classroom, the participants in this study were afforded some choice in repertoire from options provided by the cooperating teacher, amount of podium time, and rehearsal planning. The participants in Powell's study were all student teaching in large, rigid, competitive band programs, which may account for the difference in student teacher choice and autonomy in this study. Even though the student teachers may have had limited choice in repertoire or in the concert calendar, the encouragers in this study fostered student teacher autonomy during dialogues through their indirect style, use of questioning and encouragement of reflection. Even the imperators, though their advice and feedback was more direct, allowed the student teacher some autonomy by suggesting changes instead of insisting that they use a certain instructional strategy.

Similar to Helman (2006), cooperating teachers believed that certain external expectations such as student performance standards and evaluations led to increased accountability in the mentoring dialogue. In this study the increased accountability was not connected to district-level standards, but to the teachers' self-imposed performance standard of the ensemble. This contributed to a perceived pressure for performance achievement on teachers and students, which impacted the mentoring dialogues.

Not surprisingly, as the concert grew closer this also influenced the topics discussed during dialogues and the style adopted by the cooperating teacher. Due to lack of time, their informal and formal conversations were brief. Even the cooperating teachers classified as encouragers described their advice in informal conversations as being more 
direct. Just as Orland-Barak and Klein (2005) compared the "expressed" vision of mentoring with the "realized" mentoring practice, the cooperating teachers in this study expressed value in a reflective, collaborative approach to mentoring, but their realized approach was more prescriptive or instructional, especially in the weeks prior to a performance. Participants in this study weren't guided as much by district standards, but by the pressure of performance preparation.

Additionally, cooperating teachers had varying viewpoints and responses related to performance preparation. In this study Joanna and Bob were impacted by the pressure of the upcoming performance as evident in their dialogues and direct advice, thus seeming to view the performance itself as a "threat" to their program or their reputation. On the other hand, Adam and Isabelle were more impacted by the time required to prepare for the performance. While their mentoring dialogues were impacted by the upcoming performance, this impact was related to the "challenge" of finding enough time to prepare (Osborne \& McPherson, 2018). It is possible that for Joanna and Bob, their primary concern was the importance of the concert, which contributed to this event seeming to pose pressure that was experienced as a "threat". For Adam and Isabelle their attention seemed more focused on logistics and the skills required for the performance, which was experienced as a "challenge" rather than a "threat".

The value that a teacher places on the upcoming performance may also be influenced by their ego and unwillingness to allow a student performance to reflect poorly on themselves. This may be connected to the cooperating teachers' bifocal perspective on students and the student teacher and the amount to which mentoring a student teacher contributes to their personal sense of musical accomplishment. This viewpoint may impact 
the socialization of the student teacher and their orientation toward valuing the musical product over the musical process in their future classroom. While it is unclear from the findings of this study, the school and district context may also influence the value placed on public performances (Powell, 2017) and may be taken into account when pairing cooperating teachers and student teachers. Preservice teachers should be prepared for the challenge of performance preparation while also being encouraged to reflect on how this preparation can be experienced as a challenge rather than a threat.

Similar to Foreman-Peck and Travers' (2015) findings, there was a clash between the cooperating teacher's goals for their ensemble and the development of their student teacher. Some of the cooperating teachers felt the pressure of maintaining the integrity of their program, yet wanted to give their student teacher as much teaching experience as possible. This is indicative of the cooperating teachers' bifocal perspective on both student teacher and student development (Achinstein \& Athanases, 2006; Feiman-Nemser, 2001b), as well as the challenge cooperating teachers experience with maintaining this bifocal perspective. Perhaps this is heightened in a performing arts setting given the public display of student work and the process of preparing for an ensemble performance. While some may view this as a drawback of maintaining a traditional ensemble curriculum (Allsup \& Benedict, 2008; Williams, 2011), for the student teachers whose cooperating teacher was classified as an encourager, this bifocal perspective led not to a point of tension where the student teacher might have less teaching time, but to both the student teacher thinking more about the students as opposed to teacher concerns (Fuller \& Bown, 1975) as the performance grew closer. 
Perceived role. Similar to Borko and Mayfield's (1995) findings, the mentoring role observed during mentoring dialogues was also influenced by the cooperating teachers' perception of their role as a mentor, including the types of support they provide, the relationship with the student teacher, cooperating teacher and student teacher personality, and their beliefs about learning to teach. Similar to Sudzina and Coolican (1994) the participants in this study perceived their role as being either "in charge" or a shared responsibility between the cooperating teacher and the student teacher. The two encouragers in this study viewed their role as a cooperating teacher as shared responsibility, fostering an environment of collaborative co-teaching. On the other hand, Isabelle, an imperator viewed herself as the primary teacher, thus perceiving of her role as being "in charge." Bob, however, didn't fit into either one of these categories. Since he avoided giving negative feedback to Charlie or facing the reality of his lack of progress, he didn't seem to perceive his role as "in charge," though he did model teaching techniques and expected that Charlie would be willing to step in and take responsibility. As evidenced by his reflection on their relationship, his intention was to foster shared responsibility, but his student teacher was not ready and willing to accept the responsibility. As the cooperating teacher-student teacher relationship is a reciprocal relationship and dependent upon individual viewpoints from both the cooperating teacher and the student teacher (Bakhtin, 1981a; Kim, 2011), the cooperating teacher may not be able to foster shared responsibility when the student teacher is not willing to accept it.

While some cooperating teachers recall their own mentors from their student teaching experience as disappearing from the classroom and leaving them on their own (Clarke, Triggs, \& Neilsen 2014), this was not the case for three of the cooperating teachers 
in this study, but it was for Bob. Three cooperating teacher participants accepted their role as a "teacher educator," and drew on their past experience as a cooperating teacher (Clarke et al., 2014). With no formal preparation or experience as a cooperating teacher, Bob drew on the only resources he had, which was personal experience and the University Supervisor. Bob provided support by modelling practice as opposed to supporting student teacher reflection (Clarke, et al., 2014).

Similar to Borko and Mayfield (1995) the mentoring style of the cooperating teachers in this study varied according to their perceived role and beliefs about learning to teach. The imperators, Isabelle and Bob believed that they should take an active role in instructing and coaching. Adam and Joanna, on the other hand, thought that the student teacher should figure things out on their own. My participants also based this on their views of learning in general and would approach their student teacher similar to how they would approach their students (Achinstein \& Athanases, 2006).

While one function of the cooperating teacher's role is to evaluate the student teacher (Anderson, 2004; Borko \& Mayfield, 1995; Clarke et al., 2014; Sudzina \& Coolican, 1994), this was not an important factor in this study. In three out of four cases open communication between the cooperating teacher and the student teacher throughout the placement facilitated ongoing feedback. Even though his student teacher was struggling, Bob did not view his role as an evaluator and may have felt unprepared for this aspect of being a cooperating teacher (Clarke et al., 2014). As the student teaching semester is ultimately evaluated as either pass or fail by the university, the cooperating teacher may feel detached from the process. Bob may have been more invested in this function of his role if he had to assign a letter grade to his student teacher. He supported the university 
supervisor's evaluations, and relied on him to handle the more uncomfortable conversations with the student teacher about lack of student teacher development.

As a mentor, the cooperating teachers provided both instructional and psychological support (Rajuan, Beijaard, \& Verloop, 2007) although different support approaches were used by imperators and encouragers. Cooperating teachers were observed providing instructional support through modelling, sharing resources, and feedback (Anderson, 2004; Borko \& Mayfield, 1995; Rajuan et al., 2007). Modelling and feedback was especially evident for the two imperators, Isabelle and Bob, as evidenced by their modelling techniques and using detailed notes during mentoring dialogues. The two encouragers, Adam and Joanna, provided instructional support by providing resources and feedback, but tended to make their feedback more indirect, guiding their student teacher to their own conclusions and reflections, similar to Strong and Baron's (2004) observations of mentors who gave subtle suggestions or prodding the student teacher through questioning. In addition to instructional support, the cooperating teachers provided psychological support by making time to talk to them and get to know them both personally and professionally (Hobson, et al., 2009). Notably, each of the more experienced mentors, Adam, Joanna, and Isabelle, realized the importance of providing psychological support for their student teacher and did so by creating a collaborative learning environment and adapting to the student teacher's needs (Feiman-Nemser \& Parker, 1993; Jonson, 2002; Rajuan et al., 2007; Stanulis, 1994). Psychological support was also evidenced by the cooperating teachers' attentive listening during dialogues. Especially for the encouragers, when they asked questions of the student teachers they were interested in their reflection and learning more about their individual needs. 
For Bob, the first-time cooperating teacher, there was little mention of providing psychological support for Charlie. Their relationship was strained by Charlie's apparent apathetic attitude and lack of effectiveness in the classroom. Similar to Sudzina and Coolican (1994), within their strained relationship Charlie appeared to be resistant to mentoring due to his lack of commitment. In addition to the strain of Charlie's attitude, Bob's lack of focus on providing psychological support was limited by his lack of experience. In this study, the novice cooperating teacher remained focused on his own tasks as a band director and his students as opposed to focusing on these as well as his student teacher's need for psychological support. Additional experience and training could have helped this novice cooperating teacher learn about and begin to develop a bifocal perspective on both the students and the student teacher (Achinstein \& Athanases, 2006; Feiman-Nemser, 2001b).

In each case the personality of the student teacher and the cooperating teacher impacted the role assumed by the cooperating teacher during the mentoring dialogues (Abrahams, 2009; Sudzina \& Coolican, 1994). The personality, or tendency toward introversion or extraversion of the cooperating teachers also contributed to the mentoring style observed in dialogues (Goldberg, 1990). Tyler and Charlie, who were described as reserved and quiet, worked with cooperating teachers who were more talkative and adopted a direct mentoring style. These personality traits contributed to the direct and active mentoring role adopted by Isabelle and Bob. Joanna and Ellen were also both described as quiet, but didn't appear that way during dialogues. Joanna's questioning as well as her encouragement of a trusting and collegial environment allowed Ellen to feel comfortable talking during dialogues (Draves, 2008a). As Adam displayed a very "laid 
back" demeanor, most of their conversations were informal and brief, often initiated by Samantha as she was very inquisitive.

While Hagen (2011) observed cooperating teachers who valued a personality "match" with their student teacher, the cooperating teachers in this study reflected on adapting to the personality and needs of their student teacher, similar to Lawley (2012) who found that pairs were able to understand each other's personality and work together. Especially in the case of Isabelle and Tyler, whose personalities were very different from each other, their relationship flourished due to an understanding of each other's role and personality.

The personality of the student teacher can have an impact on the relationship and the mentoring style adopted by the cooperating teacher (Palmer, 2018). Isabelle adopted a very direct mentoring style, partially due to her own beliefs about learning to teach and teaching, but also in response to Tyler's very quiet, reserved personality. Similarly, Adam and Joanna worked with more responsive student teachers and responded accordingly. Bob also responded to Charlie's personality and lack of work ethic by adopting a direct and active mentoring role. Similar to Palmer's participants who valued having a student teacher as a second adult to work with students, the encouragers in this study collaborated with their student teachers through co-teaching. Joanna especially valued Ellen's input and opinion as they prepared for performances. While other research has noted the impact of student teacher personality on the cooperating teacher-student teacher relationship, it might be the case that the teaching competence of the student teacher in the classroom influences the relationship and the mentoring role adopted by the cooperating teacher. Charlie lacked competence as a music teacher and therefore the relationship with his 
cooperating teacher suffered. Even though they had similar personalities, there were mitigating factors influencing Bob’s mentoring role (Palmer, 2018). On the other hand, Tyler and Isabelle had very different personality traits, but Tyler had a higher level of confidence in the classroom. Isabelle was able to adapt to his particular needs and learning process.

In addition to the connection between the co-teaching relationship in the classroom and the perceived role that included providing instructional and psychological support from the mentor, the relationship between the cooperating teacher and the student teacher influenced the mentoring role adopted during dialogues. Similar to Helman (2006), the style adopted by the mentor depended on a variety of factors including the relationship between the cooperating teacher and the student teacher, and the novice teacher's emotional state. As the cooperating teacher better understood their student teachers' needs, they were able to adjust their strategy or tailor their feedback to the student teacher's individual needs (Estabrooke \& Goldsberry, 1995). This was especially true for Isabelle, Joanna, and Adam. Over time they felt like they understood their student teachers' needs and could anticipate how they would process feedback during mentoring dialogues. This is similar to Grabis-Bunker (1995) who found that the cooperating teacher/student teacher relationship changed over time and the cooperating teacher adjusted to the needs and personality of the student teacher.

In the relationship between the student teacher and the cooperating teacher there is naturally a power differential , though in some cases the pair may be more or less collaborative and may be impacted by context, performances, and level of student teacher responsibility (Draves, 2008a). Especially in the case of Isabelle and Tyler, the power 
differential was evident during their dialogues as Isabelle controlled the conversations giving direct advice (Britzman, 1991). Rather than this resulting in a power struggle between Isabelle and Tyler, as may be the case in a hierarchical relationship (Bahktin, 1981b), Tyler respected Isabelle's position as an expert and strived to learn everything that he could from her. In this case the power differential remained consistent throughout the placement. While Tyler gained responsibility as a teacher, Isabelle did not relinquish her responsibility as the teacher for both her students and Tyler, maintaining a bifocal perspective on both students and student teacher (Achinstein \& Athanases, 2006).

Mentoring Roles in Dialogues (MERID) model (Hennissen, et al., 2008). The recorded mentoring dialogues were analyzed using the Mentoring Roles in Dialogues (MERID) Model (Hennissen, et al., 2008). As illustrated by the above findings, two of the participants in this study were observed to adopt a primarily direct and active style during the recorded mentoring dialogues, while the other two participants adopted a more indirect and reactive style.

Topics of conversation. For Isabelle and Tyler, the most common topic of conversation for both recorded conversations was instruction, which was intentional, as she felt like this was a priority and a strength of hers as a mentor. This was similar to findings by Coulon (1994) and Edwards and Protheroe (2013) who found that instruction and organization was the most common topic, while students and content were less prevalent. On the contrary, the other imperator focused on music most often. Since Bob was a first-time cooperating teacher, his concerns remained focused on what he knew well, which was the music. While he also discussed instructional technique, it was most often in conjunction with the musical score. 
For both of the encouragers, Adam and Joanna, there was shift from talking about the music in the first mentoring dialogue to students in the final conversation. At the same time, nearing the end of the placement, Samantha and Ellen's focus as a novice teacher had begun to shift to students. This change in cooperating teacher and student teacher focus over the course of the placement mirrored Fuller and Bown's (1975) observations that novice teacher concerns shifted from self and task to also include student impact concerns as they gained additional teaching experience.

Unlike other research where mentoring dialogue topics centered around classroom management (Sempowicz \& Hudson, 2011), this was not a frequent topic of conversation in this study. All of the cooperating teachers said that their classes were well-behaved and didn't push the student teachers while the cooperating teacher was in the room, which contributed to student teachers not struggling with this area. The only time classroom management issues were raised during mentoring dialogues were after Samantha and Ellen had taught independently for a full week near the end of their placement. Limited mentoring dialogue discussion of classroom management may not be the case in a different music classroom context or grade level.

While prior researchers have cited the frequency of miscellaneous topics (Hennissen, et al., 2008) or "critical discourse" related to the values and assumptions of curriculum and instruction (Zeichner \& Liston, 1985), this was not a frequent topic of conversation in this study. There was some discussion of miscellaneous topics, but they were more frequently related to details scheduling logistics or planning for concerts. The participants in this study were not observed discussing the value of certain curricular choices. While they did talk about the effectiveness of instructional decisions, curricular 
choices in a music ensemble are closely related to repertoire choice or the concert calendar. Given the timing of the placements, most repertoire choices and concert scheduling had already been completed by the cooperating teacher. While it is unclear based on the findings from this study, it is possible that as ensemble directors, they are so entrenched in the traditions of performances and repertoire that they do not question the critical assumptions of the curriculum (Allsup \& Benedict, 2008).

Phases of the dialogue. Even though some researchers have noticed a common pattern adopted by the mentor in a mentoring dialogue in which they begin with a compliment, summarize the lesson, offer comments or questions, and finish with suggestions (Feiman-Nemser, Parker, \& Zeichner, 1992; Wang, Strong, \& Odell, 2004), none of the participants in this study were consistent with this pattern. Instead, the phases of the dialogue reflected their perceived role. The imperators believed they needed to give feedback, and the encouragers thought that they should encourage reflection. Similar to Isabelle, most mentors who have adopted a direct approach have been observed looking back on what happened instead of looking ahead to future lessons (Crasborn et al., 2011; Hennissen et al., 2008). One explanation for this was that she felt the need to discuss all of the points in her notes during the mentoring dialogue. The other imperator, Bob, began with a question, but promptly gave Charlie his opinion or advice when Charlie did not come up with an answer on his own. Consistent with looking back on the lesson and giving feedback, the imperators were most often observed offering factual information or advice as opposed to eliciting information and reasoning from the student teacher (Tsui et al., 2001; Zeichner \& Liston, 1985). The encouragers adopted an opposite mentoring style, intentionally asking their student teacher for their reflection, reasoning behind decisions, 
and ideas for improvement first before sharing their observations or opinions (Zeichner \& Liston, 1985). Similar to encouragers in other research, they found it important to not influence the student teacher with their opinion until they had the chance to reflect on their own teaching (Strong \& Baron, 2004).

Time aspects. Similar to Ben-Peretz and Rumney (1991), the recorded dialogues in this study were approximately 10-20 minutes in length. The direct, active mentors spent more time talking and leading the conversations while the more indirect and reactive mentors talked less and allowed the student teacher to introduce topics and answer or ask questions (Ben-Peretz \& Rumney, 1991; Dunne \& Bennett, 1997).

While Hawkey (1998a) collected weekly mentoring dialogue recordings from a cooperating teacher in an English class, this was a challenge for the music cooperating teacher participants in this study. Even cooperating teachers who said that scheduling their dialogues would not be an issue struggled with consistency, especially as the performance drew nearer or when their teaching time was interrupted by standardized testing. While Isabelle and Joanna both customarily did this, it was not necessarily every week. For Adam, this was a change from his normal routine. Being a first-time cooperating teacher, Bob willingly accepted this responsibility. Especially for ensemble teachers, scheduling time for a regular, extended conversation may be challenging, yet this regular interaction is essential for effective mentoring (Coulon, 1994). Perhaps this is more difficult for music teachers than it is for teachers in other content areas due to the time required to prepare for performances, or there could be a lack of clarity on their mentoring role and expectations due to inconsistent communication from the university. It is also possible that music cooperating teachers, or at least the teachers in this study, have not 
realized that they, along with the university faculty, function as teacher educators. At the same time, it's possible that they might not realize the educative function (Feiman-Nemser, 2001b) of regular extended mentoring conversations.

Mentoring style and input. Unlike Stanulis (1994), who observed a cooperating teacher shift from giving direct advice to a more indirect style through questioning and reflection, there were only slight changes observed in this study, with the student teacher taking more ownership over reflection and talking more during mentoring dialogues. This slight change in mentoring style or input provides evidence for these aspects of the mentoring dialogue being characterized along a continuum, similar to Glickman (2002). While the cooperating teacher adapted to the needs of the student teacher over time (Van Ginkel, et al., 2016) their role was observed as remaining within the same quadrant. As the placements in this study were only eight weeks long, this may explain the lack of change in mentoring style. Perhaps if they had more time with the same cooperating teacher, the student teacher may have shifted to a more facilitative role.

While Grabis-Bunker (1995) observed the role of a cooperating teacher shift over time to become more facilitative, the concept of adaptive mentoring in this study may be more applicable to the cooperating teacher adapting to the individual needs of the student teacher (Van Ginkel, et al., 2016). Especially for the experienced cooperating teachers, they inquired about their student teacher's goals and needs and were able to adapt their mentoring style and feedback to the individual needs of the student teacher. The mentoring role of each cooperating teacher was influenced by the student teacher's needs and personality (Draves, 2008a; van Ginkel, et al., 2016). Isabelle's direct mentoring style may be different with an early career teacher as opposed to a student teacher. Isabelle 
never forgot that Tyler was a student, which influenced her perceived role as a mentor. A more encouraging, non-evaluative approach may be more appropriate with early career teachers (Conway \& Holcomb, 2008). Isabelle also talked about adapting to the personality of the student teacher, and may have adopted a less direct style with a different student teacher, though this is unknown based on the findings from this study. As Isabelle's role was influenced by her talkative personality, organized nature, and beliefs about instructional support, it is unclear how much her role would change according to the student teacher. Responding to Charlie's lack of ideas for improvement, Bob adopted a direct mentoring style (Helman, 2006). On the contrary, a mentor may respond to a more knowledgeable student teacher by asking questions to extend their thinking (Helman, 2006), similar to Joanna using questioning to guide Ellen's reflection.

Contrary to the findings of this study, Crasborn, Hennissen, Brouwer, Korthagen, and Bergen (2011) found that most cooperating teachers were imperators and only characterized two mentors as encouragers. While two of the participants in this study adopted a direct style, the other two were categorized as more indirect and reactive. While this was a limited sample, these two encouragers were influenced by their perceptions of their role and learning to teach, as well as the student teacher's response during dialogues. While none of the cooperating teachers in this study were characterized as an initiator (indirect and active) (Hennissen, et al., 2008), it's possible that the cooperating teacher's role was impacted by the student teacher. The encouragers were placed close to the center on the active-reactive axis of the MERID model. They were observed to be slightly more reactive because the student teachers, Samantha and Ellen, were more talkative and active. Adam and Joanna might have adopted an active role and been characterized as an initiator 
if they were working with student teachers who were more reserved. None of the cooperating teacher participants in this study were categorized as an advisor either. The advisor role is characterized by a direct and reactive style in which the cooperating teacher responds to student teacher concerns with direct advice, but topics would be introduced by the student teacher (Hennissen et al., 2008). As described by Adam, their informal, offcamera conversations were often initiated and steered by Samantha. The scheduled, formal dialogues influenced Adam to take responsibility for steering the conversation and introducing topics. In all cases the cooperating teacher took responsibility for steering the conversation, and the student teachers perceived their role in the mentoring dialogue to respond to topics introduced by the cooperating teacher.

The Imperators. Two of the cooperating teacher participants in this study adopted a primarily direct and active style during the mentoring dialogues, placing them in the imperator quadrant of the MERID model (Hennissen et al., 2008). Similar to Bob, the direct mentor may ask questions, but they tend to be rhetorical or meant to elicit information (Hawkey, 1998b; Williams et al., 1998). Helman (2006) found that mentors using a direct style explicitly taught or made suggestions. Especially for Isabelle, this was a very intentional choice, sharing her experience and knowledge with Tyler. She used her experience and knowledge to offer analysis, information, and evaluation of Tyler's teaching (Tsui, et al., 2001). As a result, she elicited reflection from Tyler as evidenced by his improved practice. Additionally, an inexperienced mentor may prefer a more direct style (Hennissen, et al., 2008), which may account for Bob falling into this category. Bob also adopted this style in response to Charlie's lack of improvement and motivation. 
The imperators were also observed introducing topics of conversation and steering the conversation according to their thoughts or plan (Hennissen, et al., 2008). This is similar to Haggarty (1995) who found that most mentors tended to dominate the conversation with their ideas and experiences. Similar to both Charlie and Tyler, Haggarty (1995) also found that some of the student teachers allowed the mentor to take control of the conversation. Tyler respected Isabelle's opinion and wanted to hear her feedback. While he didn't always respond verbally, he heeded her advice and implemented changes in his teaching. Charlie also respected Bob's opinion, and seemed comfortable allowing Bob to take on that responsibility.

The Encouragers. Adam and Joanna were observed to be encouragers, adopting an indirect and reactive style and probing the mentee in order to develop their thinking (Helman, 2006). Joanna and Adam thought carefully about what questions would encourage their student teacher to reflect on their teaching more independently (Draves, 2013). They also held back their own opinion or thoughts so that the student teacher would reflect on their own (Clarke, 2006; Clarke, et al., 2014; Strong and Baron, 2004). This style of mentoring can be effective at encouraging student teacher reflection (Harrison et al., 2005), as was the case in this study.

Student teacher response. Just as Bakhtin (1986) studied the interactive nature of language, the mentoring dialogue is not one-sided. Even in the case of Isabelle and Tyler, where she did most of the talking and Tyler's response was at times, minimal, according to Isabelle he would respond by reflecting internally and by implementing her advice during his next teaching episode. Other student teachers, like Ellen and Samantha, respond actively and verbally. In the case of Joanna and Ellen, I observed a subtle shift over the 
course of the placement toward Ellen being a more active participant in the conversation, stating her opinion and reflecting more openly. This shift was in keeping with their relationship developing over time and the trusting, collegial team-teaching approach in the classroom. This is similar to Shields (2007), who observed cooperating teachers speaking less and listening more over time, as the student teacher develops their voice.

Video-based reflection. As a result of participation in the study, the cooperating teachers were each impacted by viewing video-recordings of their mentoring dialogues, noticing details about their mentoring style. Especially notable was Adam who noticed his own tendency to talk too much or ask ineffective questions (Crasborn, et al., 2010). He thought of himself as a mentor who doesn't give direct advice and would guide the student teacher's reflection, but watching the videos made him question his perception of his own style. Adam, Joanna, and Isabelle also began to question the impact of their style on the student teacher's learning (Crasborn, et, al., 2010). Adam and Joanna were led to ask different questions in order to guide reflection. Isabelle was influenced to think more explicitly about how she led conversations and questioned her usual pattern of asking for Tyler's reflection at the end of the dialogue.

On the contrary, Bob made fewer judgements about his own mentoring style, consistent with his lack of experience as a mentor (Crasborn, et al., 2010). Bob's reflections tended to be more explanatory in nature. As a first-time cooperating teacher, connections may be made to preservice teacher concerns about task and themselves (Fuller \& Bown, 1975). For Bob, he began to notice more about Charlie later in the placement, during our third and fourth interviews, including during the final mentoring dialogue. This is similar to Hawkey (1998a) who studied an inexperienced teacher in her first mentoring situation 
who was unaware of the student teacher's difficulties in transitioning from a student to a teacher.

For one of the cooperating teachers in this study, reflection on the mentoring dialogues influenced him to reflect on his teaching practice thus serving an educative function for this cooperating teacher (Achinstein \& Athanases, 2006). Through reflectionon-action of his mentoring process he was able to reflect on his teaching practice as well (Schön, 1983). Adam began to reflect on his approach with students and realized that he should be questioning them more and giving them a voice in rehearsals. He began to encourage Samantha to ask for student input as well. In this case reflecting on his style as a mentor influenced his approach with his students, consistent with his bifocal perspective on both student teacher and students (Achinstein \& Athanases, 2006). While other cooperating teachers may have reflected on their teaching similarly, it was not observed in dialogues or interviews. They maintained a similar bifocal perspective as evidence by their reflection on using similar strategies with their students and student teachers. This level of reflection may have been more obvious with Adam because he was very comfortable being self-reflective about his style (Achinstein \& Athanases, 2006), being openly critical of himself during the stimulated recall interviews.

While others may not have been led to adjust their teaching strategies as a result of video-based reflection, they did reflect on learning from their student teacher throughout the placement. Cooperating teachers view mentoring as professional development (Palmer, 2018) learn new ideas and reflect on their own strategies. All of the cooperating teachers in this study reflected on learning new techniques from their student teacher, as well as being led to reflect more deeply on their own teaching practice. 


\section{Implications}

Cooperating teacher development. Participants in this study were asked to record a weekly conversation. Having a regular time to check in on progress, reflect on student teacher growth, and collaboratively plan can be beneficial for student teacher learning (Palmer, 2018; Zeichner \& Liston, 1985). Despite the fact that this is recommended by the university's student teacher handbook, not all of the cooperating teachers in this study implemented this practice. This has implications for both experienced and novice cooperating teacher training. More experienced mentors may be resistant to adding to or changing their routine or usual way of functioning. Cooperating teachers should be prepared to prioritize regular conversations through modelling of formal conversations during mentor training. Additionally, university supervisors should reinforce the importance of regular dialogues. Not only may this improve the student teacher experience, but the findings from this study imply that cooperating teachers may engage in reflection on their mentoring approach and teaching strategies through engaging in mentoring dialogues, thus increasing the educative function of the mentoring process (Feiman-Nemser, 2001b).

Cooperating teacher training was not the focus of the current study and there are no findings related to the impact of cooperating teacher training, since Joanna was the only one who had undergone any formal mentor training. She had taken a professional development course through her school district and felt like she had gained a lot from the experience. In fact, she talked about how useful it was and wanted to take the course again. As the others had not experienced any training or development, they drew primarily from their experience as a teacher, mentor, or student as well as their beliefs about 
teaching and learning in general. This has implications for the potential impact of professional development for music cooperating teachers. Though some mentoring programs exist, many music cooperating teachers have not had any formal professional development for their role as a cooperating teacher (Berg \& Rickels, 2018). Cooperating teacher participants in this study approached mentoring their student teacher similar to how they approached their students. While there are parallels between mentoring a student teacher and teaching students, mentoring requires unique skills in order to meet the individual needs of the student teacher (Helman, 2006). Mentor training should be provided by music teacher educators or school districts in order to help meet the unique needs of music cooperating teachers. Mentor training that includes mentor dialogue videos may also enable the cooperating teacher to facilitate a dialogue in which they ask for student teacher input and concerns, thus supporting student teacher reflection (Clarke, et al., 2014; Timperly, 2001).

As one of the cooperating teacher participants in this study was a novice mentor, there were a variety of differences between this cooperating teacher and the other cooperating teachers. He did not have experience to draw upon as he reflected on his mentoring style and was unprepared to meet to the varied instructional and psychological needs of the student teacher. Similar to a novice teacher who is concerned about themselves and the task at hand, his focus remained on the content and his own students (Fuller \& Bown, 1975). Novice cooperating teachers should be prepared to lead an effective mentoring dialogue. Especially in the case of Bob and Charlie, where the student teacher was struggling, Bob lacked the tools necessary to adopt a more "hands on" approach (Palmer, 2018). Cooperating teacher development that includes modelling of the 
various mentoring roles enacted through mentoring dialogues may equip a novice cooperating teacher with strategies to adapt to the student teacher's individual needs.

The two imperators, Isabelle and Bob, were observed giving direct advice and controlling the conversation. While Isabelle consciously made this choice as a mentor, Bob also believed that he had a great deal of valuable experience to share and that Charlie could learn from his ideas. In both cases, the student teacher was more reserved and quiet, and in the case of Charlie, was struggling. Cooperating teachers should be prepared to adapt their approach according to the characteristics of the student teacher (Estabrooke \& Goldsberry, 1995). Other times a cooperating teacher may adopt a direct approach when the student teacher lacks knowledge or does not contribute their own ideas (Helman, 2006; Palmer, 2018), such as when Charlie struggled to improve his teaching. Cooperating teacher training should include strategies to adapt to the personality and learning needs of the student teacher. Additionally, a mentor may adjust their approach according to the teaching context. Though it was not the case in this study, a cooperating teacher may adopt a more direct approach in an elementary or middle school setting due to the varied student needs and lesson planning demands (Palmer, 2018).

There is not a single mentoring role that will be effective in any context, responding to the individual needs of the mentee (Crasborn et al., 2011). The findings from this study suggest that a variety of factors may impact the mentoring role. Consistent with their beliefs about learning to teach, a cooperating teacher may adjust their role according to the needs and personality of the student teacher. The imperator role may be appropriate, especially for a student teacher who is more reserved or may be struggling. On the other hand, the encourager role may be effective to foster responsibility and reflection when the 
student teacher is inquisitive and capable. Cooperating teacher training should involve modelling and experience with the various mentoring roles.

Similar to Draves (2008a), the relationship between Charlie and Bob and level of responsibility for Charlie was strained by his lack of motivation. While Bob wanted to share his experience as well, he also responded to Charlie's lack of response by telling him what to do. In this situation it may have been useful for Bob to refer to teaching standards, for example NAfME content standards, to provide a structure for goal setting (Helman, 2006). This has implications for the need to prepare cooperating teachers to meet the needs of student teachers who are struggling. Additionally, as a novice cooperating teacher, Bob was unprepared to evaluate Charlie. Cooperating teachers should be prepared for all functions of their role including meeting the varied needs of student teachers through communication and training from the university.

As the findings from this study imply, mentors can develop their awareness and skills through reflection on their mentoring practice (Achinstein \& Athanases, 2006). The cooperating teachers in this study reflected and responded critically during stimulated recall interviews. This implies that experienced music teachers can develop mentoring approaches and that watching video of oneself mentoring holds promise as one approach to mentor professional development. Helman (2006) found that mentors could more easily describe when to use a specific mentoring strategy during a dialogue than how or why. Cooperating teacher development may include the use of video-based training in which trainees may pause a video to discuss how and why a teacher employed a certain strategy.

Implications for future research. While prior researchers have used stimulated recall to facilitate cooperating teacher reflection of mentoring dialogues, previous 
participants have not been music teachers (Crasborn et al., 2010). Therefore, additional research is needed not only with teachers in the performance ensemble context, but in other music learning contexts as well.

Similar to Hildenbrand (2009), the cooperating teachers and student teachers in this study spent time together co-planning in addition to reflecting on teaching and ideas for improvement. In this study, some of the earlier mentoring dialogues involved co-planning, while the later conversations were focused on the student teacher's instructional experiences. This has implications for further research focused exclusively on the coplanning sessions between cooperating teachers and student teachers. Video based reflection might be used to study the nature of the co-planning dialogues.

As the cooperating teacher participants in this study were very busy full-time teachers, the time commitment of recording weekly dialogues and scheduling interviews presented a challenge. Maintaining a regular weekly mentoring dialogue may be more challenging in an ensemble setting due to the impact of performance preparation. Conducting the stimulated recall interviews immediately after the recorded event results in the most accurate recall (Lyle, 2010), but this was not always possible due to scheduling limitations. This has implications for additional research in which the stimulated recall interviews are scheduled according to the timing of the mentoring dialogues. Additionally, stimulated recall relies on the participants to recall an event retrospectively instead of in the moment (Crasborn et al., 2010). Further research may employ data gathering techniques from mentoring dialogues via firsthand observation by the researcher.

As some of the cooperating teachers in this study were uncomfortable with recording their mentoring dialogues, if they recorded more dialogues over time they may 
have become more accustomed to it. Though the participants in this study were asked to record a dialogue once per week, not all participants were consistent with this. Recording more videos over a longer period of time might raise the comfort level of the participants with the recording process.

In addition to scheduling challenges, this study was limited to data obtained from interviews and recordings and did not include firsthand observation of teaching or interactions between the cooperating teacher and the student teacher. Observational data could have been a source for triangulating the findings. Additional research may include observations of both formal and informal conversations between the cooperating teacher and the student teacher as well as classroom observations of the student teacher.

As noted in chapter 4, Samantha was present for one of the stimulated recall interviews with Adam. While they both appeared to be comfortable with the conversation, this could have changed his level of candor during the interview. Positively, he paused the video of their dialogue to follow up on a topic from the dialogue, as he reflected on something else he wanted to ask her. Further research may limit participants in the stimulated recall interviews to the cooperating teacher. Additionally, additional research may include student teachers during stimulated recall interviews in order to gain more information about their perspective.

Findings in this study indicated that the nature of the co-teaching relationship between the cooperating teacher and the student teacher may impact the mentoring style of the cooperating teacher. Draves (2008b) discussed the differences in power sharing between a general (music) classroom and an ensemble setting. Consistent with the current study, in an ensemble setting the student teacher tends to take over 1-2 pieces for a given 
ensemble, but not the whole concert. They are given less responsibility and freedom than in a general classroom due to the concert structure. This may have implications for further research in a different context such as a non-performance class. As this study was limited to instrumental ensemble settings, the impact of the concert schedule on mentoring dialogues may be lessened in a general music context. Additionally, cooperating teacher participants mentioned that the student teacher's choice in repertoire and co-teaching arrangement was influenced by the timing of the placement being in the spring. This warrants further research on mentoring roles assumed by ensemble teachers during a different time of year. Although this didn't emerge in my study, other researchers may examine the impact of variables such as teaching level (elementary, middle school, high school), instructional focus (general, choral, band, orchestra), teacher gender, or teacher cultural background.

While the findings from this study indicated that the personality of the cooperating teacher and the student teacher may influence the mentoring role adopted by the cooperating teacher, similar to prior research, personality match was not a factor (Hagen, 2011; Lawley, 2012). This study did not examine the impact of pedagogical and musical competencies of the cooperating teacher or the student teacher. Isabelle felt strongly about her mentoring skills as related to the instructional process, but this might be adjusted if the student teacher was struggling with other areas. This has implications for further research related to the influence of pedagogical and musical competencies on the mentoring role.

Cooperating teacher participants in this study engaged in both instructional and psychological support. Especially for the encouragers, psychological support was evident in their dialogues through the open reflection by the student teachers. The cooperating 
teacher's role in fostering this learning environment was also clear from their attentive listening and adapting to the student teachers' needs. This had implications for future research related to the different types of psychological support provided by cooperating teachers and how it is manifested during mentoring dialogues.

While there were subtle changes observed in the cooperating teachers' roles, their observed role remained in the same quadrant. Codes for mentoring style and input were counted for each mentoring dialogue, resulting in an average mentoring role. This has implications for additional research that accounts for subtle shifts in mentoring style during a dialogue. Shifts within a dialogue may be tracked in order to ascertain what contributed to these shifts over the course of a single dialogue. Cooperating teachers may adjust their style throughout the dialogue according to topics discussed or varying needs of the student teacher. As some of the participants in this study were mapped near the center of the graph (See figures 3 and 10) subtle changes in their mentoring role may be observed during a single dialogue resulting in a more nuanced characterization of mentoring style, which could include a teacher who toggles between different mentoring roles rather than remaining in one quadrant.

This study was limited to an eight-week time period, as this was the existing length of one student teaching placement. Changes in the mentoring role may also be more evident during a longer period of time. Therefore, further research is warranted on the cooperating teacher mentoring role, and perhaps changes in mentoring style in a full semester (sixteen-week) or quarter (ten-week) placement. As each cooperating teacher was observed adapting to the individual needs of the student teacher, their role may be 
realized differently with a different student teacher. Additional research is implied involving a single cooperating teacher over time with multiple student teachers.

As one of the cooperating teacher participants in this study was a novice mentor, there were a variety of differences between this cooperating teacher and the other cooperating teachers. This has implications for additional research related to the development and concerns of a novice cooperating teacher. A first-time cooperating teacher may be unaware when a student teacher is struggling or lack the bifocal perspective necessary for educative mentoring (Achinstein \& Athanases, 2006; Hawkey, 1998a).

The focus of this study was primarily on the cooperating teacher's perspective of their mentoring role during dialogues. While findings were supported by data from interviews with the student teacher participants, more insight could be gained by examining the student teacher's perspective on the cooperating teacher's style during mentoring dialogues (Hennissen et al., 2011). For instance, researchers might study the student teacher's varied responses to a direct or indirect mentoring style.

\section{Conclusion}

A cooperating teacher has a profound impact on the development of the student teacher through their daily interactions. While prior music education researchers have examined the cooperating teacher-student teacher relationship, experience, and reflective conversations (Draves, 2008b; Krueger, 1985), the mentoring role adopted by the music cooperating teacher during mentoring dialogues has not been previously studied. Through talking to their student teacher during a mentoring dialogue, the cooperating teachers in this study influenced the learning and development of the student teachers. 
Just as a multitude of factors impact discourse between human beings (Britzman, 1991), the findings of this study indicated that a variety of factors influenced the mentoring role adopted by the music cooperating teacher during mentoring dialogues. Just as the MERID model includes multiple mentoring roles (Hennissen, et al., 2008), a multi-faceted approach to mentoring may be effective in varied contexts of music learning. As each student teacher brings their unique background to the student teaching experience and has diverse learning goals, music cooperating teachers can consider how they may adjust their role during an effective mentoring dialogue in order to more effectively meet the needs of the student teacher while simultaneously reflecting on their professional growth as a music teacher and mentor. 


\section{References}

Abrahams, F. (2009). Examining the preservice practicum experience of undergraduate music education majors-- Exploring connections and dispositions through multiple perspectives A critical grounded theory. Journal of Music Teacher Education, 19(1), 8092. https://doi.org/10.1177/1057083709344044

Achinstein, B., \& Athanases, S. Z. (Eds.). (2006). Mentors in the making: Developing new leaders for new teachers. New York \& London: Teachers College Press.

Allsup, R. E., \& Benedict, C. (2008). The problems of band. Philosophy of Music Education Review, 16(2), 156-173. https://doi.org/10.1353/pme.0.0009

Anderson, D. (2004). The role of cooperating teachers' power in student teaching. Education, 128(2), 307-324.

Armstrong, S., Allinson, C. W., \& Hayes, J. (2002). Formal mentoring systems: An examination of the effects of mentor/protégé cognitive styles on the mentoring process. Journal of Management Studies, 39(8), 1111-1137. https://doi.org/10.1111/1467-6486.00326

Awaya, A., McEwan, H., Heyler, D., Linsky, S., Lum, D., \& Wakukawa, P. (2003). Mentoring as a journey. Teaching and Teacher Education, 19(1), 45-56. https://doi.org/10.1016/S0742-051X(02)00093-8

Bakhtin, M. M. (1981a). Discourse in the novel. In C. Emerson \& M. Holquist (Eds.), The dialogic imagination (pp. 259-422). Austin, TX: University of Texas Press.

Bakhtin, M. M. (1981b). The dialogical imagination. (M. Holquist, Ed.). Austin, TX: University of Texas Press.

Bakhtin, M. M. (1986). Speech genres and other late essays. (C. Emerson, M. Holquist, \& 
Translated by Vern W. McGee, Eds.). Austin, TX: University of Texas Press.

Barrett, J. R. (2014). Case study in music education. In C. M. Conway (Ed.), Qualitative Research in American Music Education (pp. 113-132). New York: Oxford University Press.

Ben-Peretz, M., \& Rumney, S. (1991). Professional thinking in guided practice. Teaching and Teacher Education, 7(5-6), 517-530. https://doi.org/10.1016/0742-051X(91)90046$\mathrm{R}$

Berg, M. H., \& Miksza, P. (2010). An Investigation of Preservice Music Teacher Development and Concerns. Journal of Music Teacher Education, 20(1), 39-55. https://doi.org/10.1177/1057083710363237

Berg, M. H., \& Rickels, D. A. (2018). Mentoring for Mentors: The Music Mentor Plus Program. Journal of Music Teacher Education, 27(2), 39-51. https://doi.org/10.1177/1057083717720634

Berg, M. H., Woody, R. H., \& Bauer, W. I. (2002). Cognitive processes of preservice music teachers during observation of music instruction. Music Education Research, 4(2), 275287. https://doi.org/10.1080/1461380022000011966

Bertone, S., Chaliès, S., Clarke, A., \& Méard, J. (2006). The dynamics of interaction during post-lesson conferences and the development of professional activity: Study of a preservice physical education teacher and her co-operating teacher. Asia-Pacific Journal of Teacher Education, 34(2), 245-264. https://doi.org/10.1080/13598660600720660

Bogdan, R. C., \& Biklen, S. K. (1998). Qualitative research in education: An introduction to theory and methods. Boston, MA: Allyn and Bacon.

Boreen, J., Johnson, M. K., Niday, D., \& Potts, J. (2000). Mentoring beginning teachers. York, 
ME: Stenhouse.

Borko, H., \& Mayfield, V. (1995). The roles of the cooperating teacher and university supervisor in learning to teach. Teaching and Teacher Education, 11(5), 501-518. https://doi.org/10.1016/0742-051X(95)00008-8

Britzman, D. P. (1991). Practice makes practice: A critical study of learning to teach. Albany, NY: State University of New York Press.

Bullough, R. V. (2005). Teacher vulnerability and teachability: A case study of a mentor and two interns. Teacher Education Quarterly, 32(2), 23-40.

Butke, M. A. (2006). Reflection on practice: A study of five choral educators' reflective journeys. Applications of Research in Music Education, 25(1), 57-69. https://doi.org/10.1177/87551233060250010107

Byra, M. (1994). Supervisory conferences: Promoting inquiry and reflection in preservice teachers. In AERA Annual Meeting.

Cage, T. L., Bob, N., \& Price, E. (1980). Personality influences on student and cooperating teacher attitudes toward teaching. In Mid-South Educational Research Meeting.

Clarke, A. (2006). The nature and substance of cooperating teacher reflection. Teaching and Teacher Education, 22(7), 910-921. https://doi.org/10.1016/j.tate.2006.04.039

Clarke, A., Triggs, V., \& Nielsen, W. (2014). Cooperating teacher participation in teacher education: A review of the literature. Review of Educational Research, 84(2), 163-202. https://doi.org/10.3102/0034654313499618

Conway, C. (2002). Perceptions of beginning teachers, their mentors, and administrators regarding preservice music teacher preparation. Journal of Research in Music Education, 50(1), 20. https://doi.org/10.2307/3345690 
Conway, C. \& Holcomb, A. (2008). Perceptions of experienced music teachers regarding their work as music mentors. Journal of Research in Music Education, 56(1), 55-67. https://doi.org/10. 1 177/0022429408323073

Cook, L. \& Friend, M. (1995). Co-teaching: Guidelines for creating effective practices. Focus on Exceptional Children, 28(3), 1-16. https://doi.org/10.1007/s13398-014-0173-7.2

Coulon, S. C. (1994). The effect of post teaching conferences on the instructional behaviors of student teachers. In AERA Annual Meeting.

Crasborn, F., Hennissen, P., Brouwer, N., Korthagen, F., \& Bergen, T. (2008). Promoting versatility in mentor teachers' use of supervisory skills. Teaching and Teacher Education, 24(3), 499-514. https://doi.org/10.1016/j.tate.2007.05.001

Crasborn, F., Hennissen, P., Brouwer, N., Korthagen, F., \& Bergen, T. (2010). Capturing mentor teachers' reflective moments during mentoring dialogues. Teachers and Teaching, 16(1), 7-29. https://doi.org/10.1080/13540600903475462

Crasborn, F., Hennissen, P., Brouwer, N., Korthagen, F., \& Bergen, T. (2011). Exploring a two-dimensional model of mentor teacher roles in mentoring dialogues. Teaching and Teacher Education, 27(2), 320-331. https://doi.org/10.1016/j.tate.2010.08.014

Davis, B. (2006). Curriculum to support mentor development. In B. Achinstein \& S. Z. Athanases (Eds.), Mentors in the making: Developing new leaders for new teachers (pp. 109-121). New York \& London: Teachers College Press.

De Jong, R., Mainhard, T., van Tartwijk, J., Veldman, I., Verloop, N., \& Wubbels, T. (2014). How pre-service teachers' personality traits, self-efficacy, and discipline strategies contribute to the teacher-student relationship. British Journal of Educational Psychology, 84(2), 294-310. https://doi.org/10.1111/bjep.12025 
Dewey, J. (1933). How We Think. New York: D.C. Heath and Company.

Dewey, J. (1938). Logic: The Theory of Inquiry. Troy, MN: Rinehart \& Winston.

Diana, T. J. (2014). Co-teaching: Enhancing the Student Teaching Experience. Kappa Delta Pi Record, 50(2), 76-80. https://doi.org/10.1080/00228958.2014.900849

Draves, T. J. (2008). "Firecrackers” and “Duds." Journal of Music Teacher Education, 18(1), 6-15.

Draves, T. J. (2008). Nurturing our future colleagues: Cooperating music teachers' relationships with their student teachers. Michigan State University.

Draves, T. J. (2013). Transition from Student to Teacher-Student Teaching: The Capstone Experience. Journal of Music Teacher Education, 23(1), 50-62. https://doi.org/10.1177/1057083712474935

Dunne, E., \& Bennett, N. (1997). Mentoring Processes in School-based Training. British Educational Research Journal, 23(2), 225-237. https://doi.org/10.1080/0141192970230208

Edwards, A., \& Protheroe, L. (2013). Teaching by proxy: Understanding how mentors are positioned in relationships. Journal of Chemical Information and Modeling, 53(9), 1689-1699. https://doi.org/10.1017/CB09781107415324.004

Ericsson, K. A., \& Simon, H. A. (1999). Protocol analysis: Verbal reports as data. Cambidge, MA: The MIT Press.

Estabrooke, M., \& Goldsberry, L. (1995). Learning Side by Side. In AERA Annual Meeting. San Francisco; CA.

Evertson, C. M., \& Smithey, M. W. (2000). Mentoring Effects on Proteges' Classroom Practice: An Experimental Field Study. The Journal of Educational Research, 93(5), 
294-304. https://doi.org/10.1080/00220670009598721

Fecho, B., \& Botzakis, S. (2007). Feasts of becoming: Imagining classroom based on dialogic literacy beliefs. Journal of Adolescent \& Adult Literacy, 50(7), 548-558. https://doi.org/10.1598/JAAL.50.7.4

Feiman-Nemser, S. (2001). From preparation to practice: Designing a continuum to strengthen and sustain teaching. Teachers College Record, 103(6), 1013-1055. https://doi.org/10.1111/0161-4681.00141

Feiman-Nemser, S. (2001). Helping Novices Learn to Teach: Lessons from an Exemplary Support Teacher. Journal of Teacher Education, 52(1), 17-30. https://doi.org/10.1177/0022487101052001003

Feiman-Nemser, S., \& Parker, M. B. (1993). Mentoring in context: A comparison of two U.S. programs for beginning teachers. International Journal of Educational Research, 19(8), 699-718. https://doi.org/10.1016/0883-0355(93)90010-H

Feiman-Nemser, S., Parker, M. B., \& Zeichner, K. (1992). Are mentor teachers teacher educators. East Lansing, MI. Retrieved from http://education.msu.edu/NCRTL/PDFs/NCRTL/ResearchReports/Rr9211.pdf

Fernandez, M. L., \& Erbilgin, E. (2009). Examining the supervision of mathematics student teachers through analysis of conference communications. Educational Studies in Mathematics, 72(1), 93-110. https://doi.org/10.1007/s10649-009-9185-1

Flyvbjerg, B. (2011). Case study. In N. K. Denzin \& Y. S. Lincoln (Eds.), The Sage Handbook of Qualitative Research (pp. 301-316). Thousand Oaks, CA: Sage Publications.

Fredrickson, W. E., \& Pembrook, R. G. (1999). “I got to teach all day!” (Perceptions of student teachers). Bulletin for the Council of Research in Music Education, 141. 
Friebus, R. J. (1977). Agents of socialization involved in student teaching. The Journal of Educational Research, 70(5). https://doi.org/10.1080/00220671.1977.10885001

Frykholm, J. A. (1998). Beyond supervision: Learning to teach mathematics in community. Teaching and Teacher Education, 14(3), 305-322.

Fuller, F., \& Bown, O. H. (1975). Becoming a teacher. In K. Ryan (Ed.), Teacher Education (pp. 25-52). Chicago, IL: University of Chicago Press.

Glenn, W. J. (2006). Model versus mentor: Defining the necessary qualities of the effective cooperating teacher. Teacher Education Quarterly, 33(1), 85-95.

Glickman, C. D. (2002). Leadership for learning: How to help teachers succeed. Alexandria, VA: Association for Supervision and Curriculum Development.

Goldberg, L. R. (1990). An Alternative "Description of Personality”: The Big-Five Factor Structure. Journal of Personality and Social Psychology, 59(6), 1216-1229. https://doi.org/10.1037/0022-3514.59.6.1216

Grabis-Bunker, M. J. (1995). Stages of the cooperating teacher-student teacher relationship: The changing status of roles between cooperating teachers and student teachers. Dissertation. University of Maryland. https://doi.org/10.16953/deusbed.74839 Grossman, P. L., Smagorinsky, P., \& Valencia, S. (1999a). Appropriating tools for teaching English: A theoretical framework for research on learning to teach. American Journal of Education, 108(1), 1-29. https://doi.org/10.1086/444230

Grossman, P. L., Smagorinsky, P., \& Valencia, S. (1999b). Tools for teaching English : A theoretical framework for research on learning to teach. American Journal of Education, 108(1), 1-29.

Hagen, J. K. (2011). Mentoring through collaboration: Investigating the impact of a teacher 
research project on the cooperating teacher/student teacher relationship. Michigan State University.

Haggarty, L. (1995). The Use of Content Analysis to Explore Conversations between School Teacher Mentors and Student Teachers, 21(2).

Harrison, J. K., Lawson, T., \& Wortley, A. (2005). Mentoring the beginning teacher: Developing professional autonomy through critical reflection on practice. Reflective Practice, 6(3), 419-441. https://doi.org/10.1080/02619760500269392

Hawkey, K. (1998a). Consultative Supervision and Mentor Development: an initial exploration and case study. Teachers and Teaching, 4(2), 331-348. https://doi.org/10.1080/1354060980040209

Hawkey, K. (1998b). Mentor pedagogy and student teacher professional development. Teaching and Teacher Education, 14(6), 657-670. https://doi.org/10.1016/S0742051X(98)00015-8

Helman, L. (2006). What's in a conversation? Mentoring stances in coaching conferences and how they matter. In B. Achinstein \& S. Z. Athanases (Eds.), Mentors in the making: Developing new leaders for new teachers (pp. 69-82). New York \& London: Teachers College Press.

Hennissen, P., Crasborn, F., Brouwer, N., Korthagen, F., \& Bergen, T. (2008). Mapping mentor teachers' roles in mentoring dialogues. Educational Research Review, 3(2), 168-186. https://doi.org/10.1016/j.edurev.2008.01.001

Hennissen, P., Crasborn, F., Brouwer, N., Korthagen, F., \& Bergen, T. (2010). Uncovering contents of mentor teachers' interactive cognitions during mentoring dialogues. Teaching and Teacher Education, 26(2), 207-214. 
https://doi.org/10.1016/j.tate.2009.02.022

Hennissen, P., Crasborn, F., Brouwer, N., Korthagen, F., \& Bergen, T. (2011). Clarifying preservice teacher perceptions of mentor teachers' developing use of mentoring skills. Teaching and Teacher Education, 27(6), 1049-1058. https://doi.org/10.1016/j.tate.2011.03.009

Hildenbrand, S. M. (2009). Designing effective experiences for preservice inclusion teachers for co-teaching: an action research study. University of Rochester. https://doi.org/Related link: URL: <http://gateway.proquest.com/openurl?url_ver=Z39.88-2004\&rft_val _fmt=info:ofi/fmt:kev:mtx:dissertation\&res_dat=xri:pqdiss\&rft_dat =xri:pqdiss:3367263>

Hobson, A. J., Ashby, P., Malderez, A., \& Tomlinson, P. D. (2009). Mentoring beginning teachers: What we know and what we don't. Teaching and Teacher Education, 25(1), 207-216. https://doi.org/10.1016/j.tate.2008.09.001

Holquist, M. (1990). Dialogism: Bakhtin and his world. New York: Routledge.

Hunt, D. E. (1977). Conceptual Level Theory and Research as Guides to Educational Practice. Interchange, 8(4), 78-90.

John, P. D., \& Gilchrist, I. (1999). Flying Solo: understanding the post-lesson dialogue between student teacher and mentor. Mentoring \& Tutoring: Partnership in Learning, 7(2), 101-111. https://doi.org/10.1080/1361126990070201

Jonson, K. F. (2002). Being an effective mentor. Thousand Oaks, CA: Corwin.

Kelting, T., Jenkins, J. M., \& Gaudreault, K. L. (2014). I Could Really Focus on the Students. Journal of Physical Education, Recreation \& Dance, 85(8), 32-37. 
https://doi.org/10.1080/07303084.2014.946192

Kim, G. (2011). Mikhail Bakhtin: The Philosopher of Human Communciation. The Unviersity of Western Ontario Journal of Anthropology, 12(1), 53-62.

Koerner, M. E. (1992). The cooperating teacher: An ambivalent participant in student teaching. Journal of Teacher Education, 43(1), 46-56.

Kokkinos, C. M. (2007). Job stressors, personality and burnout in primary school teachers. British Journal of Educational Psychology, 77(1), 229-243. https://doi.org/10.1348/000709905X90344

Krueger, P. J. (1985). Influences of the hidden curriculum upon the perspectives of music student teachers: An ethnography. University of Wisconsin - Madison.

Kruse, N. B. (2011). Navigating on-site teaching experiences: Multiple perspectives from two school-university partnerships. Visions of Research in Music Education, 19.

Lave, J. (1996). Teaching, as learning, in practice. Mind, Culture, and Activity, 3(3), 149-164.

Lave, J., \& Wenger, E. (1991). Situated learning: Legitimate peripheral practice. New York: Cambridge University Press.

Lawley, J. A. (2012). Pairing of pre-service and cooperating teachers during student internship: Opinions of collaborative relationships. University of Alabama.

LeCompte, M. D., \& Schensul, J. J. (2013). Analysis and interpretation of ethnograohic data: A mixed methods approach, Book 5 (2nd ed.). Plymouth, UK: AltaMira Press.

Leech, N. L., \& Onwuegbuzie, A. J. (2008). Qualitative data analysis: A compendium of techniques and a framework for selection for school psychology research and beyond. School Psychology Quarterly, 23(4), 587-604. https://doi.org/10.1037/10453830.23.4.587 
Lieberman, A., Hanson, S., \& Gless, J. (2012). Mentoring teachers: Navigating the real-world tensions. San Francisco; CA: Jossey-Bass.

Lincoln, Y. S., \& Guba, E. G. (1985). Naturalistic inquiry. Beverly Hills: Sage Publications.

Lyle, J. (2010). Stimulated recall: a report on its use in naturalistic research. British Educational Research Journal, 29(6), 861-878. https://doi.org/10.1080/0141192032000137349

May, B. N., Willie, K., Worthen, C., \& Pehrson, A. (2017). An Analysis of State Music Education Certification and Licensure Practices in the United States. Journal of Music Teacher Education, 27(1), 65-88. https://doi.org/10.1177/1057083717699650

McCrae, R. R., \& Costa, P. T. (1989). Reinterpreting the Myers-Briggs Type Indicator From the Perspective of the Five-Factor Model of Personality. Journal of Personality, 57(1), 17-40. https://doi.org/10.1111/j.1467-6494.1989.tb00759.x

McFaul, S. A., \& Cooper, J. M. (1983). Peer Clinical Supervision in an Urban ElementarySchool. Journal of Teacher Education, 34(5), 34-38. https://doi.org/10.1177/002248718303400510

Mena, J., García, M., Clarke, A., \& Barkatsas, A. (2015). An Analysis of Three Different Approaches to Student Teacher Mentoring and their Impact on Knowledge Generation in Practicum Settings. European Journal of Teacher Education, 9768(March), 1-24. https://doi.org/10.1080/02619768.2015.1011269

Merriam, S. B. (2009). Qualitative research: A guide to design and implementation. San Francisco; CA: John Wiley \& Sons, Inc.

Miksza, P., \& Austin, J. R. (2010). Eyes wide open: High school student reflections on music teaching experiecnes within a pre-collegiate recruitment program. Bulletin of the 


\section{Council for Research in Music Education, 185.}

Miles, M. B., \& Huberman, A. M. (1994). Qualitative data analysis: An expanded sourcebook (2nd ed.). Thousand Oaks, CA: Sage Publications.

Miles, M. B., Huberman, A. M., \& Saldana, J. (2014). Qualitative data analysis: A methods sourcebook (3rd ed.). Los Angeles, CA: Sage Publications.

Myers, S. (2016). Myers-Briggs typology and Jungian individuation. Journal of Analytical Psychology, 61(3), 289-308. https://doi.org/10.1111/1468-5922.12233

Onwuegbuzie, A. J., \& Leech, N. L. (2010). Generalization practices in qualitative research: A mixed methods case study. Quality and Quantity, 44(5), 881-892. https://doi.org/10.1007/s11135-009-9241-z

Orland-Barak, L., \& Klein, S. (2005). The expressed and the realized: Mentors' representations of a mentoring conversation and its realization in practice. Teaching and Teacher Education, 21(4), 379-402. https://doi.org/10.1016/j.tate.2004.05.003

Osborne, M. S., \& Mcpherson, G. E. (2018). Precompetitive appraisal, performance anxiety and confidence in conservatorium musicians: a case for coping. Pyschology of Music. https://doi.org/10.1177/0305735618755000

Palmer, C. M. (2018). Perceptions of Cooperating Music Teachers on Service Motives, Relationships, and Mentoring Strategies During Student Teaching. Journal of Music Teacher Education, 105708371775007. https://doi.org/10.1177/1057083717750078

Patton, M. (1990). Qualitative research and evaluative methods. Thousand Oaks, CA: Sage Publications.

Pellegrino, K. (2015). Student, Cooperating, and Supervising Teacher Perceptions of Educational and Musical Interactions During Student Teaching. Journal of Music 
Teacher Education, 24(2), 54-73. https://doi.org/10.1177/1057083713508653

Powell, S. R. (2011). Examining preservice music teachers' perceptions of initial peer and field teaching experiences. Journal of Music Teacher Education, 21(1), 11-26. https://doi.org/10.1177/1057083710386751

Powell, S. R. (2014). Examining preservice music teacher concerns in peer and fieldteaching settings. Journal of Research in Music Education, 61(4), 361-378. https://doi.org/10.1177/0022429413508408

Powell, S. R. (2017). Structure and agency in novice music teaching. In International Symposium on the Sociology of Music Education. London, UK.

Ragin, C. C. (1987). The comparative method: Moving beyond qualitative and quantitative strategies. Berkeley, CA: University of California Press.

Rajuan, M., Beijaard, D., \& Verloop, N. (2007). The role of the cooperating teacher: bridging the gap between the expectations of cooperating teachers and student teachers. Mentoring \& Tutoring: Partnership in Learning, 15(3), 223-242. https://doi.org/10.1080/13611260701201703

Rajuan, M., Beijaard, D., \& Verloop, N. (2010). The match and mismatch between expectations of student teachers and cooperating teachers: exploring different opportunities for learning to teach in the mentor relationship. Research Papers in Education, 25(September 2016), 201-223. https://doi.org/10.1080/02671520802578402

Rideout, R., \& Feldman, A. (2002). Research in music student teaching. In R. Colwell \& C. Richardson (Eds.), The new handbook of research on music teaching and learning. Oxford: Oxford University Press. 
Rogoff, B. (1990). Apprenticeship in thinking: Cognitive development in social context. New York: Oxford University Press.

Rosen, H. (1985). Stories and meanings. London: The National Scholastic.

Roulston, K., Legette, R., \& Womack, S. T. (2005). Beginning music teachers' perceptions of the transition from university to teaching in schools. Music Education Research, 7(1), 59-82. https://doi.org/10.1080/14613800500042141

Rowe, V. C. (2009). Using video-stimulated recall as a basis for interviews: some experiences from the field. Music Education Research, 11(4), 425-437. https://doi.org/10.1080/14613800903390766

Saldana, J. (2013). The coding manual for qualitative researchers (2nd ed.). Los Angeles, CA: Sage Publications.

Schensul, J. J., \& LeCompte, M. D. (2013). Essential ethnographic methods: A mixed method approach, Book 3 (2nd ed.). Plymouth, UK: AltaMira Press.

Schon, D. A. (1983). The reflective practicioner: How professionals think in action. New York: Basic Books.

Seidman, I. (2006). Interviewing as Qualitative Research: A Guide for Researchers in Education and the Social Sciences. New York: Teachers College Press.

Sempowicz, T., \& Hudson, P. (2011). Analysing mentoring dialogues for developing a preservice teacher's classroom management practices. Australian Journal of Teacher Education, 36(8), 1-16. https://doi.org/10.14221/ajte.2011v36n8.4

Shea, G. (1995). Can a supervisor mentor? Supervision, 56(11).

Shields, C. M. (2007). Bakhtin primer. New York: Peter Lang Publishing, Inc. Spradley, J. P. (1979). The Ethnographic Interview. Belmont, CA: Wadsworth, Cengage 
Learning.

Stake, R. (1995). The art of case study research. Thousand Oaks, CA: Sage Publications.

Stake, R. E. (2006). Multiple case study analysis. New York: The Guilford Press.

Stanford Center for Assessment Learning and Equity. (2016). Making good choices: A support guide for edTPA candidates.

Stanulis, R. N. (1994). Fading to a whisper: One mentor's story of sharing her wisdom without telling answers. Journal of Teacher Education, 45(1).

Stanulis, R. N., \& Russell, D. (2000). "Jumping in": trust and communication in mentoring student teachers. Teaching and Teacher Education, 16(1), 65-80. https://doi.org/10.1016/S0742-051X(99)00041-4

Stegman, S. F. (2007). An exploration of reflective dialogue between student teachers in music and their cooperating teachers. Journal of Research in Music Education, 55(1), 65-82. https://doi.org/10.1177/002242940705500106

Strong, M., \& Baron, W. (2004). An analysis of mentoring conversations with beginning teachers: Suggestions and responses. Teaching and Teacher Education, 20(1), 47-57. https://doi.org/10.1016/j.tate.2003.09.005

Sudzina, M. R., \& Coolican, M. J. (1994). Mentor or tormentor: The role of the cooperating teacher in student teacher success. In Paper presented at the Annual Meeting of the Association of Teacher Educators. Atlanta, GA.

Teachout, D. J. (2001). The relationship between personality and the teaching effectiveness of music student teachers. Psychology of Music, 29, 179-192. Retrieved from http://search.proquest.com/pqdt/docview/304383407/abstract/34B0B05DD4514F $69 \mathrm{PQ} / 10$ ?accountid=14537 
The Myers \& Briggs Foundation. (2018). MBTI Basics. Retrieved March 26, 2018, from http://www.myersbriggs.org/my-mbti-personality-type/mbti-basics/

Timperley, H. (2001). Mentoring Conversations Designed to Promote Student Teacher Learning. Asia-Pacifc Journal of Teacher Education, 29(2), 111-123. https://doi.org/10.1080/13598660120061309

Tsui, A. B. M., Lopez-Real, F., Law, Y. K., Tang, R., \& Shum, M. S. K. (2001). Roles and relationships in tripartite supervisory conferencing processes. Journal of Curriculum and Supervision, 16(4), 322-344.

van Ginkel, G., Oolbekkink, H., Meijer, P. C., \& Verloop, N. (2016). Adapting mentoring to individual differences in novice teacher learning: the mentor's viewpoint. Teachers and Teaching, 22(2), 198-218. https://doi.org/10.1080/13540602.2015.1055438

Wang, J., Strong, M., \& Odell, S. J. (2004). Mentor-novice conversations about teaching: A comparison of two U.S. and two Chinese cases. Teachers College Record, 106(4), 775813. https://doi.org/10.1111/j.1467-9620.2004.00358.x

Weaver, D., \& Stanulis, R. N. (1996). Negotiating preparation and practice: Student teaching in the middle. Journal of Teacher Education, 47(1).

Weller, R. (1971). Verbal communication in instructional supervision. New York: Teachers College Press.

West, C. (2012). Teaching Music in an Era of High-Stakes Testing and Budget Reductions. Arts Education Policy Review, 113(2), 75-79.

https://doi.org/10.1080/10632913.2012.656503

Whitaker, N. L. (1996). A theoretical model of the musical problem solving and decision making of performers, arrangers, conductors, and composers. Bulletin of the Council 
for Research in Music Education, 128(128), 1-14. Retrieved from http://www.jstor.org/stable/40318784

Williams, D. A. (2011). The elephant in the room. Music Educators Journal, 98(1), 51-57. https://doi.org/10.1177/0027432111415538

Williams, E. A., Butt, G. W., Gray, C., Leach, S., Marr, A., \& Soares, A. (1998). Mentors' Use of Dialogue within a Secondary Initial Teacher Education Partnership. Educational Review, 50(3), 225-239. https://doi.org/10.1080/0013191980500302

Yin, R. K. (2012). Applications of case study research. Thousand Oaks, CA: Sage Publications. Young, B. N. (1995). Student-teacher placement: Three case studies in match mismatch contexts. https://doi.org/ED 392755

Zeichner, K. (2002). Beyond traditional structures of student teaching. Teaching Education Quarterly, (Spring), 59-65. https://doi.org/10.2307/23478291

Zeichner, K. M., \& Liston, D. (1985). Varieties of discourse in supervisory conferences. Teaching and Teacher Education, 1(2), 155-174. https://doi.org/10.1016/0742051X(85)90013-7 


\section{Appendix A}

\section{School District Permission}

\section{DISTRICT A:}

From: $\langle\mathrm{g}>$ on behalf of $\square$ Research $<>$

Date: Wednesday, November 2, 2016 at 1:41 PM

To: Margaret H Berg <margaret.berg@colorado.edu>

Cc:

Subject: Re: research approval question

Margaret,

If Angela recruited and collected all her data outside of teacher contract hours then she would NOT need to go through the District approval process. However, if she intends to recruit through the schools and/or observe classes then she would need to go through our research review process which is outlined here. Unfortunately, the deadline to collect data this winter and spring has already past. She is welcome to submit an application for data collection next fall.

Please feel free to contact me if you have any additional questions.

On Wed, Nov 2, 2016 at 12:25 PM, wrote:

I've included our research helpdesk on you research inquiry. Someone will follow-up with you with regards to your questions.

Assistant Director of Research \& Assessment

Office of Student Assessment \& Program Evaluation,

CONFIDENTIALITY NOTICE: The information contained in this message may be legally privileged and confidential information and is intended only for the use of the individual or entity named above. If the reader of this message is not the intended recipient, or the employee or agent responsible to deliver to the intended recipient, you are hereby notified that any release, dissemination, distribution, or copying of the communication is strictly prohibited. If you have received this communication in error, please notify the author immediately by replying to this message and delete the original message.

\section{DISTRICT B:}

I don't need to approve your project.

Good luck and thank you for asking,

\section{Assistant Superintendent}




\section{Assessment, Curriculum, and Instruction}

On Tue, Feb 7, 2017 at 9:54 AM, Angela Munroe <munroeam@colorado.edu> wrote:

No - not at all. All school district, schools, teachers, and student teachers will be assigned a pseudonym. All identifying information will be stored by myself and will not be shared.

Angela Munroe

PhD Candidate in Music Education

University of Colorado at Boulder

On Feb 7, 2017, at 9:52 AM, $<$ wrote:

Will the schools and teacher names be identified in the published paper?

\section{Assistant Superintendent}

Assessment, Curriculum, and Instruction

On Tue, Feb 7, 2017 at 9:37 AM, Angela Munroe<munroeam@colorado.edu> wrote:

Dear Ms.

I just spoke with and she asked me to email you with my question. I am a PhD Candidate in Music Education at University of Colorado Boulder and I am beginning my dissertation project focused on the dialogues between music cooperating teachers and student teachers. We have a couple of music education student teachers in $\quad$ this semester, so I would love the opportunity to include them in my project.

I would like to determine if I am required to complete the formal research request for this project. I will be completing interviews with student teachers and cooperating teachers outside of school time. I will not be observing any classes and there will be no contact with students. Potential participants would be 1 or 2 music teachers. I would like to complete my first interview in early March when our music student teachers begin their second student teaching placements.

Please let me know if you have any questions or require any additional information.

Thank you for your time,

Angela Munroe

PhD Candidate in Music Education

University of Colorado at Boulder 


\section{Appendix B}

\section{Institutional Review Board Permission}

University of Colorado

Boulder

20-Feb-2017 Dear Angela Munroe,

On 20-Feb-2017 the IRB reviewed the following protocol:

\section{APPROVAL}

Institutional Review Board 563 UCB Boulder, CO 80309 Phone: 303.735.3702 Fax:

303.735.5185 FWA: 00003492

\begin{tabular}{|l|l|}
\hline $\begin{array}{l}\text { Type of } \\
\text { Submission: }\end{array}$ & Initial Application \\
\hline $\begin{array}{l}\text { Review } \\
\text { Category: }\end{array}$ & Expedited - Category 6,7 \\
\hline Title: & $\begin{array}{l}\text { An Examination of Music Mentor Teacher Roles in } \\
\text { Mentoring Dialogues }\end{array}$ \\
\hline Investigator: & Munroe, Angela \\
\hline Protocol \#: & $17-0070$ \\
\hline Funding: & None \\
\hline $\begin{array}{l}\text { Documents } \\
\text { Approved: }\end{array}$ & $\begin{array}{l}\text { CT Interview 1; 17-0070 CT Consent Form (20Feb17); } \\
\text { STterview 3; 17-0070 Protocol (20Feb17); 17-0070 ST } \\
\text { Consent Form (20Feb17); }\end{array}$ \\
\hline $\begin{array}{l}\text { Documents } \\
\text { Reviewed: }\end{array}$ & Protocol; HRP-211: FORM - Initial Application v7; \\
\hline
\end{tabular}

The IRB approved the protocol from 20-Feb-2017 to 19-Feb-2018 inclusive. Before 20-Jan-

2018, you are to submit a Continuing Review and required attachments to request continuing approval or

closure.This protocol will expire if continuing review approval is not granted before 19-Feb-

2018. Click the link to find the approved documents for this protocol: Summary Page Use copies of these documents to conduct your research. In conducting this protocol you must follow the requirements listed in the INVESTIGATOR MANUAL (HRP-103).

Sincerely, Douglas Grafel IRB Admin Review Coordinator Institutional Review Board 


\section{Appendix C Consent Forms}

\section{Cooperating Teacher Consent Form:}

Title of research study: An Examination of Mentor Music Teacher Roles in Mentoring Dialogues

Investigator: Angela Munroe

Why am I being invited to take part in a research study?

We invite you to take part in a research study because you are a cooperating teacher working with a music student teacher.

What should I know about a research study?

- Someone will explain this research study to you.

- Whether or not you take part is up to you.

- You can choose not to take part.

- You can agree to take part and later change your mind.

- Your decision will not be held against you.

- You can ask all the questions you want before you decide.

Who can I talk to?

If you have questions, concerns, or complaints, or think the research has hurt you, talk to the research team at angela.munroe@colorado.edu

This research has been reviewed and approved by an Institutional Review Board ("IRB"). You may talk to them at (303) 735-3702 or irbadmin@ colorado.edu if:

- Your questions, concerns, or complaints are not being answered by the research team.

- You cannot reach the research team.

- You want to talk to someone besides the research team.

- You have questions about your rights as a research subject.

- You want to get information or provide input about this research.

Why is this research being done?

The purpose of this study is to examine the interactions between cooperating teachers and their music student teacher. Student teaching is the capstone experience of the music teacher preparation program and as a cooperating teacher you play an important role in the development of student teachers.

How long will the research last?

We expect that you will be in this research study for eight weeks.

How many people will be studied?

We expect 8 people will be in this research study.

What happens if I say yes, I want to be in this research?

This will be an eight-week study during which the student teacher will video-record your weekly mentoring conversations with your student teacher. All videos will be shared with the researcher. You will view two of these videos with the researcher and talk about the recorded 
conversation with your student teacher. Additionally there will be two interviews with the researcher regarding your background, experience, and role as a cooperating teacher. Each interview will last approximately 1 hour.

What happens if I do not want to be in this research?

You can leave the research at any time and it will not be held against you.

What happens if I say yes, but I change my mind later?

You can leave the research at any time it will not be held against you.

If you decide to leave the research, contact the investigator so that the investigator can debrief you before you leave.

If you stop being in the research, already collected data may not be removed from the study database. This data will be password-protected on a personal computer, pseudonyms will be used to protect anonymity, and any personally-identifying information will be deleted.

Is there any way being in this study could be bad for me?

All research involves risk. The most likely risk from your participation in this study, although minimal, is the accidental release of confidential information you provide. The researcher will be safeguarding against this risk by using changing all personal information such as name and school name in written reports as well as storing all data on a password-protected computer. Additionally, participants may initially feel some discomfort at viewing themselves on video, though this is expected to subside during the first few minutes of conversation about the content of the dialogues.

Will being in this study help me in any way?

We cannot promise any benefits to you or others from your taking part in this research. However, possible benefits include reflection on your practice as a cooperating teacher.

\section{What happens to the information collected for the research?}

Efforts will be made to limit the use and disclosure of your personal information, including research study and personally identifiable information to people who have a need to review this information. We cannot promise complete secrecy.

Your confidentiality will be protected throughout this study. Data will be stored on a passwordprotected personal computer and pseudonyms will be assigned to all participants.

Organizations that may inspect and copy your information include the IRB and other representatives of this organization.

What else do I need to know?

Taking part in this study is your choice. You may choose to participate and you may choose to leave the study at any time.

\section{Signature Block for Capable Adult}

Your signature documents your permission to take part in this research.

Signature of subject

Date

Printed name of subject 
Signature of person obtaining consent

Printed name of person obtaining consent

Date

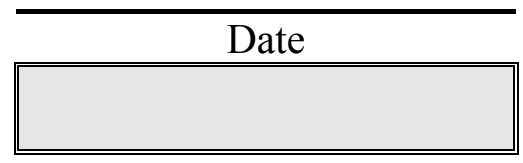

IRB Approval Date

\section{Student Teacher Consent Form:}

Title of research study: An Examination of Mentor Music Teacher Roles in Mentoring Dialogues

Investigator: Angela Munroe

Why am I being invited to take part in a research study?

We invite you to take part in a research study because you are a music student teacher. What should I know about a research study?

- Someone will explain this research study to you.

- Whether or not you take part is up to you.

- You can choose not to take part.

- You can agree to take part and later change your mind.

- Your decision will not be held against you.

- You can ask all the questions you want before you decide.

Who can I talk to?

If you have questions, concerns, or complaints, or think the research has hurt you, talk to the research team at angela.munroe@colorado.edu This research has been reviewed and approved by an Institutional Review Board ("IRB"). You may talk to them at (303) 735-3702 or irbadmin@colorado.edu if:

- Your questions, concerns, or complaints are not being answered by the research team.

- You cannot reach the research team.

- You want to talk to someone besides the research team.

- You have questions about your rights as a research subject.

- You want to get information or provide input about this research.

Why is this research being done?

The purpose of this study is to examine the interactions between cooperating teachers and their music student teacher. Student teaching is the capstone experience of the music teacher preparation program. Conversations between cooperating teachers and student teachers can have a profound impact on the development of the student teacher.

How long will the research last?

We expect that you will be in this research study for eight weeks.

How many people will be studied?

We expect 8 people will be in this research study. 
What happens if I say yes, I want to be in this research?

This will be an eight-week study during which you will video-record your weekly meetings with your cooperating teacher. All videos will be shared with the researcher. Additionally there will be two interviews with the researcher regarding your experiences with your cooperating teacher and you perspective on their role. Each interview will last approximately 1 hour.

What happens if I do not want to be in this research?

You can leave the research at any time and it will not be held against you.

What happens if I say yes, but I change my mind later?

You can leave the research at any time it will not be held against you.

If you decide to leave the research, contact the investigator so that the investigator can debrief you before you leave.

If you stop being in the research, already collected data may not be removed from the study database. This data will be password-protected on a personal computer, pseudonyms will be used to protect anonymity, and any personally-identifying information will be deleted.

Is there any way being in this study could be bad for me?

All research involves risk. The most likely risk from your participation in this study, although minimal, is the accidental release of confidential information you provide. The researcher will be safeguarding against this risk by using changing all personal information such as name and school name in written reports as well as storing all data on a password-protected computer.

Will being in this study help me in any way?

We cannot promise any benefits to you or others from your taking part in this research. However, possible benefits include reflection on your practice as a student teacher.

What happens to the information collected for the research?

Efforts will be made to limit the use and disclosure of your personal information, including research study and personally identifiable information to people who have a need to review this information. We cannot promise complete secrecy.

Your confidentiality will be protected throughout this study. Data will be stored on a passwordprotected personal computer and pseudonyms will be assigned to all participants.

Organizations that may inspect and copy your information include the IRB and other representatives of this organization.

What else do I need to know?

Taking part in this study is your choice. You may choose to participate and you may choose to leave the study at any time.

\section{Signature Block for Capable Adult}

Your signature documents your permission to take part in this research.

Signature of subject

Date

Printed name of subject

Signature of person obtaining consent

Date 


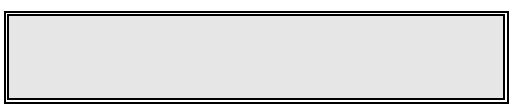

IRB Approval Date 


\section{Appendix D \\ CT Interview Guides 1 \& 3}

\section{Interview 1 Guide:}

Thank you for speaking with me, I would like to record our conversation, if that's ok? Background information

1. How long have you taught in this school?

2. Have you always taught in this school?

3. Have you always taught choir/general music/band?

4. Why did you first start working with student teachers?

5. And how about your background working with student teachers? How many have you hosted? Are they all from the University of ?

6. What is your favorite thing about working with student teachers?

7. Tell me about a feeling of success you have experienced with a student teacher?

8. How about a challenge you have experienced?

9. Do you approach each student teacher in a similar way?

10. How have you prepared for mentoring student teachers?

11. Describe your usual pattern for conversations.

a. Do you meet regularly to discuss their progress?

b. Do you have formal conversations after they teach a lesson? 


\section{Interview 3 Guide:}

1. Can you take me through your typical day as a cooperating teacher?

2. Tell me about your major responsibilities?

3. Can you describe your relationship with your current student teacher?

4. Has this changed at all since the beginning of the semester? How?

5. What do think are the important qualities of a cooperating teacher?

6. What does it mean to be a mentor?

7. What qualities do you think are important in a student teacher? 


\section{Appendix E}

\section{Interview Guide: Stimulated Recall}

The second and fourth interviews will be stimulated recall interviews in which the researcher and the cooperating teacher participants will view videos of mentoring dialogues in order to aid the participants in recalling their intentions within the conversations (Crasborn et al., 2010). Existing literature has indicated that the researcher may stop the video to ask questions (Berg et al., 2002; Bertone et al., 2006)or the participants may pause the video whenever they see something significant (Crasborn et al., 2010; Kelting et al., 2014; Miksza \& Austin, 2010; S. R. Powell, 2011). This study will adopt a combination approach in which either participant may pause the video to make a statement (Bertone et al., 2006). While viewing the video, the researcher may stop the video to prompt reflection from the participant (Berg et al., 2002). Additionally, the cooperating teacher will be instructed to pause the video if they see a significant moment in which they recalled making an intentional mentoring choice. The questions that will likely be asked by the researcher have been adapted from Bertone, Chaliès, Clarke, and Méard (2006) and Miksza and Austin (2010).

\section{Open ended prompts ( $1^{\text {st }}$ viewing)}

As you watch this video, I'd like for you to comment on what you noticed about the conversation. You might notice how much guidance you give or who asked questions during the conversation. When watching the video other things might occur to you like questions you could have asked or additional ideas that might have been discussed. Please feel free to stop and start the video to talk about what you noticed.

Open-ended prompts (1 $1^{\text {st }}$ viewing)

- What did you notice about the conversation?

- Are there points where you notice you needed to provide more or less guidance?

- Did you notice any points where you might have asked a question?

$2^{\text {nd }}$ viewing: prompts based on each individual video, follow up from $1^{\text {st }}$ viewing. 


\section{Appendix F}

\section{Transcript Excerpts}

\section{Excerpt from Isabelle-Interview 1}

I: Yes

R: So, um did you start working with practicum students first, or with student teachers?

I: Yeah, um the practicum students were first, I had a couple of them and then I think it was because there's a rule that you have to be in the same position or in the district for three years before you can start taking student teachers, but um, I don't think that same rule applied to practicum students, so I had them first.

R: Oh, ok, I see

I: So that was my understanding.

R: Ok, so practicum started first, and now you've continued to do both? Is that right?

I: yeah, and generally that's how, um student teachers come to me, is they'll do some

practicum with me and then they're like 'oh, this might be a good placement.'

R: $\mathrm{mm}$ hmm - So you get them in their Teaching Instrumental Music class?

I: Sometimes, yeah

R: Have you had the intro class as well?

I: Honestly, I don't know, I'm not totally sure which class they're taking.

R: I know, it's not always clear where they're coming from exactly

I: I'm just usually happy to have them, so...

R: yeah, good, so if you could think back to the first student teacher that you worked with, why did you first decide to work with student teachers?

I: Um, for a few reasons - I really appreciated my mentor teacher, her name was Crystal, and she did a lot to support me, and befriend me, and make my transition into becoming a real - a 'real teacher' much more accessible, and you know, I was, when I look back at my teaching practice when I first started, I wouldn't call myself a strong teacher at that time, and so I felt like I had a lot of good insight to give student teachers who were maybe struggling with like classroom management or delivery of instruction, or all of those things that they're trying to master the first few times that they're in front of kids, um, and so that was I guess that was my main motivation was that I had someone who did a really great job for me

R: $\mathrm{mm}$ hmm

I: and I wanted to kind of give back. On the other side of that is that I think I had just recently finished up or was finishing up my National board process and one of the things they ask for are um, I think its like leadership positions, and I was like Oh, this is a perfect educational leadership position is to be a mentor to a student teacher.

R: $\mathrm{mm}$ hmm, so you said that you mentor made that transition to being a real teacher more accessible, can you remember some ways that she did that for you?

I: Honestly, she took me out for margaritas when we had a bad day.

R: <laugh> Margaritas are important!

I: It was a tough...they are very important!...it was a tough school district, it was a tough school, and she just had this great rapport with the kids, like she just got them, and that was something that I sort of struggled with in that placement. I didn't struggle with it later, 
um, you know its much easier when the program is yours, but it was pretty apparent that like connecting with students was something that challenged me, and so, she did a really good job of modeling that. I don't think she always did a great job of explicitly explaining how she accomplished things...

R: $0 \mathrm{k}$

I: and so that's something that I try to do for my student teachers, but you know she was very warm, she was very friendly, we were both horn players, so we had a lot in common $\mathrm{R}: \mathrm{mm} \mathrm{hmm}$

I: and so, just that that welcoming sort of presence and the fact that she <pause $>$ she was always really positive about what I was doing with the kids even when she had feedback to give me, so those were some things that I remember really strongly about her.

R: So you mentioned some reasons why you first started to, so why do you continue to host so many ST's?

I: mmm $<$ pause $>$ sorry... < chewing $>$

R: Oh, no, please, chew

I: Um, one, is the college credist that I get, and the recert credits and the fact that when it comes time for me to recertify for National Board, I'm gonna talk a lot about mentoring ST's, um and it has been for the most part really enjoyable, but the second reason is I just really like having their help in the classroom, I like being able to delegate tasks, I like being able to have sectionals or help for students, like individuals that need um, remediation, right now we're working on a project in our class, uh, a chamber group project, and its really helpful to have another set of ears, another set of eyes, like going around to those different chamber groups and offering them coaching, rather than me just sending them away, and trusting that their rehearsal is going well

\section{Excerpt from Adam-Interview 2}

A: And I sort of threw you into that purposefully, sometimes you don't get a whole lot of time to look at a score prior, so what are some things that you're like I want to take this away from this personal experience of sight-reading this score

S: I think tempo is super important, like the relationship between the tempos.

A: and I would say this to, you probably could have taken a little bit more time for yourself to, to, to um, in rehearsal to go let's make sure we're playing the right tempo, maybe pop it into the metronome, and let the kids hear, but its also for you, right?

S: yeah <smiling > I have a hard time, like taking that time, I always forget that that's something I can do

A: Absolutely, cause you feel rushed, you want to get through things, and especially on a piece like that

A; and she especially felt rushed, like I feel she gets in front of the ensemble and wants to go a little bit

R: uh huh

A: that, and sometimes slow is fast and trying to convey that,

R: so she's going too fast?

A: well, I think she feels the need to like move through material

R: okay 
A: like if we're sightreading, its not gonna be the same sort of sightreading you're gonna have if you're in a university level where they just actually go beginning to end and then go back. These kids need to be regrouped

R: uh huh

A: restarted, you know and that type of thing, so that was part of the discussion, that we didn't necessarily put on the tape.

OC: I think is related to the topic that he was trying to get at in their final video they sent me. They were talking about the macro vs. micro in a rehearsal. He said that young teachers, especially Samantha tend to want to stop and fix every little thing as opposed to allowing the ensemble to run all the way through a piece.

R: uh, okay

A: but, absolutely, don't feel rushed, take the time to make sure, it'll help the kids out later too to understand that relationship, um <cough> when time is a little more steady and they

understand that. Other take ways from it besides time?

$S$ : um, I think breaking it down into smaller pieces in some parts, it was hard in that middle section, cause it's so like, pointalistic with the eighth notes

A: yeah, that's a tough one to sight read, especially with a young group like that, and that's what makes this piece maybe a little out of their reach is that independence is needed. If we think to like that section, what is it, 108?

S: yeah

A: You have the presentation of that melody and 8 bars later we have another group who has the same melody, that's easy, cause...

A: I would have liked to have brought in her a little bit more and have her come up with this as opposed to giving it to her

R: okay

A: on this section, um cause the way it was scored, its like, you have 8 bars of one, and then eight bars of the exact presentation again and another and I wanted her to kind of go, oh, I could have rehearsed all of that together

R: uh huh

A: but I didn't necessarily give it to her, or she kind of, I told her <laugh>

R: right

A: as opposed to letting her

R: so how do you think you could have gotten it out of her?

A: well, the whole time, when I do, I don't like doing these recordings. One, because I feel um, I'm never prepared enough with how I want that conversation to go

R: okay

A: you know what I mean?

R: right

A: we do a lot of um, <pause > in, informal sort of conversations,

R: $\mathrm{mm}$ hmm

A: where we'll hit on things like, as the day is going and come back to things 


\section{Excerpt from Bob-Interview 3}

R: $\quad$ Right. Makes sense. How about your, can you just describe your relationship with C? How would you describe that? How would you sum up your working relationship?

B: It's ... I would say it's a positive relationship but I don't have any point of reference there since he is my first student teacher. I would say I feel like, and I could be wrong again because of lack of reference, I feel like l'm doing a little bit more of the work as far as nuts and bolts go, so I guess that goes back to whatever I told you about, I just envisioned a student teacher being like me where I was just kind of ready to go. Some of us just need to get thrown to the wolves. Some of us come in and want to kick the teacher out of the room. I think he's one that needs to get thrown to the wolves. Figuring that out early on would be really beneficial.

OC: I'm not sure that a different student teacher would be less work necessarily, but it would definitely be different. With $\mathrm{C}$ he does have a lot of work because $\mathrm{C}$ didn't really want to be there in the first place.

R: $\quad$ They are all different.

B: Absolutely. Absolutely. Jimmy student taught here last fall and he was one that was ready to just say, "You don't need to be here." He's not a typical student teacher, either.

R: He's much more experienced than a lot of our student teachers.

B: $\quad$ Exactly. But, I mean, l've seen that before. You hear that from my other band director colleagues, teacher colleagues, where the student teacher is just ready to go and you start to go, "Well, I'm not needed here anymore." You know? Then you have the ones where you need to just make them fall so that you can help guide them back up. Give them the tools so that - You know, they don't know what they don't know.

R: True.

B: I think that's C. I've been trying to figure that out. I think we're to that place finally. Here we have three and a half weeks to go.

OC: He is still hopeful. He really wanted him to succeed. Maybe that's why he seemed to take it personally when he did not succeed.

R: $\quad$ Great timing.

B: But it's not like that's not enough time. You know? There's still plenty we can get done within this time frame. It's... Now, you know what you didn't know and so what's the plan going forward? That's crept into our conversations.

R: What do you think that will look like going forward? 
B: I think it's going to be him taking more of an active role in the warm-up and pre-lesson part of a class. We're doing a rehearsal, we're supposed to be getting ready for performance. We want the kids to have that awesome experience but we also need to teach concepts that are going to help that, that are transferrable to other things. So, that's where I ... When I plan my warm-ups - I've got to be honest, when I plan my warm-ups, I'm not necessarily just winging it but l've got a huge bag of tricks and so I'll walk in there going, "I want to get this done, this done, this done. This makes sense, this makes sense, and this makes sense. Here we go."

OC: Not only is he dealing with a less than stellar student teacher, but he is just trying to figure out how to be a CT, how to let a ST takeover in his classroom, how to share his teaching process with others.

R: Right.

B: When there's something that's really bugging me then I'll sit back, l'll open my score, and I'll really pre-plan a warm-up. I think he's starting to get to that point where he'll know which warm-ups really work. Which parts of the lesson are really going to be applicable.

R: $\quad$ When you two are working together or talking together, does it feel like a teacher-student kind of relationship or are you moving more towards equal?

B: I think I started out wanting it to feel equal-

R: Okay.

B: $\quad-$ too soon.

OC: I think this is key - he wanted an equal, collaborative relationship. He set his expectations so high that it took him a while to realize that Charlie was never going to meet those expectations. Other ST's might not meet those expectations either, yet not be as low as $C$.

R: Oh.

B: $\quad$ Yeah. Again, me not knowing what I didn't know as far as how he's going to be as a student teacher, and things like that. Had I known, now with hindsight 20/20 and everything, I would have just thrown him in. Said, "Hey, great, you're going to start classes right away." and I would have let him start classes and sit up there going "uhh... uhh..." and then have the conversation stem from that.

\section{Excerpt from Joanna-Interview 4}

R: okay, well, we're gonna watch a video, just like the last time we did the video interview we'll watch it twice, the first time, feel free to just hit the space bar and pause it anytime that you want to tell me about something. Maybe you notice how much guidance you give 
her, or who asks questions during the conversation. It might occur to additional ideas that might have been discussed or anything that you think, or where you might have expected Ellen to ask a question or anything like that. So just pause it and talk.

J: okay

J: so how has your week of soloing gone? How do you feel?

E: it was fun

J: are you tired?

E: I'm very tired

J: I'm tired because I wasn't up there <laugh> watching made me tired.

E: yeah, like I enjoyed it and it was really fun. I felt like I got to try a lot of stuff that I'd never really tried before, so it was really fun to see like my classroom management style would work J: well, I think she had a good time experimenting that week, and that was what she needed, that was what she meant by that, I think.

R: nice

E: and I for the most part it did really work, cause I started, you weren't there on Monday and Tuesday, but I started each class giving them a little bit of background about myself, like where I come from, I have a very musical family so I told them about that and then like my beliefs about music and what it is, so I basically talked to them, told them about how they need to respect the music that is being made all the time, so we don't talk while people are playing, when we come in the class we come in with the mindset that we're going to make music and so I've been playing the drone, that they come in and they already hear something, um and then they're supposed to start tuning.

J: so she had, it sounded like a didgeridoo, a recording, and she would play that and they would come in and she explained, I wasn't here the first day that she explained to them what it was going to be, but just kind of a competition, use this to tune, tuning is part of getting ready, and who can get ready the fastest.

OC: sounds very different from what they would do with Joanna. Clearly Joanna was open to letting Ellen try something different, though. I think that Joanna kind of looked at like, well, I wouldn't do it, but go ahead and try.

J: she did a little thing with that

E: and then they get into the mindset of making music while they were in class, which I think really worked for them, um and then I had a competition just to make it fun for them

J: cool, what was the competition?

E: um, whoever can get the fastest time of getting ready

$J$ : and that included finishing tuning?

E: yeah

J: where did you get the idea for the drone?

E: um, it's something that Erika Eckert uses all the time, so I got these drones, they're actually from Paul Erhard, he went to India to do like a bright start study, and so it's a <inaudible> drone, which is one of the string instruments, and it has the bass note, the dominant, and two octave notes, um so there's three different pitches actually in it, so you get the overtone series, which is really cool and it helps to tune the open strings a little bit better. So Erika had me use them all the time to tune, that's what I always tuned with, um so I wanted to see if that would work with middle school if they really kind of had to be aware of what it was, so I didn't really talk about what the drone was at all, I just said you're going to hear a drone and its gonna, it's playing an A so tune you're a string to it and then tune all of your other strings. 
<interrupted by students with a teacher appreciation gift for Joanna> J: I think while it's stopped, in these, you know these conversations are kind of short, we just record for you, but I was trying to get more out of her. How did it go, meaning, um $<$ pause > like, how did the pieces go, like I was looking for more of a technique, kind of, you know, how was your teaching?

R: yeah, like teaching technique

$\mathrm{J}$ : and she gave me more of a broader, sort of overall, and it's just funny what their perspective is compared to ours, and there's nothing wrong with that at all, it's just I find it kind of funny, that you know their perspective seems to be wider

$\mathrm{J}$ : and ours, mine seems to be more narrow, like I wanted to hear oh, you know 2nds are working on this and dah da da, and I'm struggling with this measure, but it was more like a broad, oh, you know, I did these overall things with them

E: I definitely heard that they were getting their instruments more in tune, I only had to make a couple of adjustments when I was going around, um so I think that worked even though I didn't really explain like they're supposed to be listening for the overtones and like they're supposed to hear the $5^{\text {th }}$ in it.

J: and it changed texture as it went through?

E: yeah

J: like it would, its almost like if the mouth was singing it, it would change its form. That's cool!

E: yeah

J: so it looked like you had some success with that, and that's just getting started, um, and now what were some other successes you thought you had this week?

E: um, I feel like, yesterday

J: yeah, I was just trying to pull it out of her a little bit more details, you know

R: yeah, yeah

$\mathrm{J}$ : and that conversation did happen, you know eventually, um, but you know with these kind of filmed conversations, you know 


\section{Appendix G}

\section{Student Teacher Interview 1 Guide}

1. Tell me about your student teaching experience so far.

2. Walk me through a typical day.

3. Can you tell me what you think are the most important aspects of your relationship with your cooperating teacher?

4. How would you describe the job duties of a cooperating teacher?

5. What do you think the important qualities of a cooperating teacher are? How about a student teacher?

\section{Student Teacher Interview 2 Guide}

1. Now that you have completed your student teaching, how has your perception of the job of a cooperating teacher changed?

2. Have you ever disagreed with your cooperating teacher's advice or way of thinking about a teaching-related problem?

3. How has you relationship with your cooperating teacher changed? 
4. Tell me about some ways in which your cooperating teacher has helped you develop as a music teacher?

5. What has been your favorite thing about this student teaching placement?

6. Tell me about a challenge that you have faced during this student teaching placement? How was your CT able to help you in this situation? 


\section{Appendix $\mathrm{H}$}

\section{Codebook}

\section{Codebook}

\begin{tabular}{|l|l|l|} 
Background \\
\hline \multirow{4}{*}{ Experience } & As a Teacher & Background teaching experience \\
\cline { 2 - 3 } & As a CT & Background experience as a CT \\
\cline { 2 - 3 } & As a ST & Personal experience as an ST \\
\hline \multirow{3}{*}{ Why host ST's } & Larger goals & $\begin{array}{l}\text { Big picture thoughts related to profession or } \\
\text { university }\end{array}$ \\
\cline { 2 - 3 } & $\begin{array}{l}\text { Immediate } \\
\text { goals }\end{array}$ & Everyday impact of having a ST in the classroom \\
\hline Preparation & External & Formal, external preparation to be a CT \\
\cline { 2 - 3 } & Internal & Personal preparation/experience \\
\hline $\begin{array}{l}\text { CT } \\
\text { Expectations }\end{array}$ & Srogram & CT expectations or plans for their program \\
\cline { 2 - 3 } & ST & CT expectations or plans for their ST \\
\hline
\end{tabular}

\begin{tabular}{|l|l|l|} 
MERID Model & Musical & Focused on content area and repertoire \\
\cline { 2 - 3 } & $\begin{array}{l}\text { Instructional and } \\
\text { Organization }\end{array}$ & Planning, approach, management \\
\cline { 2 - 3 } & $\begin{array}{l}\text { Students and } \\
\text { class }\end{array}$ & Rapport, connections, student response \\
\cline { 2 - 3 } & Miscellaneous & Extra duties, school, future \\
\hline Style and \\
Supervisory Skills & Direct & Direct advice, feedback, goal setting \\
\cline { 2 - 3 } & Indirect & $\begin{array}{l}\text { Guiding questions, elicit ST input, allow ST } \\
\text { freedom, podium time }\end{array}$ \\
\hline Input & Active & Introducing topics, directs dialogue \\
\cline { 2 - 3 } & Reactive & $\begin{array}{l}\text { Reacting to ST input (validating concerns, } \\
\text { empathy, offer suggestions) }\end{array}$ \\
\hline Phase & Questions & General questions \\
\cline { 2 - 3 } & & Specific questions \\
\cline { 3 - 3 } & & Guiding/reflectiive \\
\cline { 2 - 3 } & Probing \\
\cline { 2 - 3 } & Offering & advice \\
\cline { 3 - 3 } & & suggestions \\
\cline { 2 - 3 } & & Answer questions \\
\cline { 3 - 3 } & feedback \\
\hline
\end{tabular}




\begin{tabular}{|l|l|l|}
\hline Classroom Factors & Concert cycle & $\begin{array}{l}\text { How the concert cycle impacts, mentor } \\
\text { approach }\end{array}$ \\
\cline { 2 - 3 } & $\begin{array}{l}\text { Performance } \\
\text { pressure }\end{array}$ & $\begin{array}{l}\text { CT and ST feel stress due to upcoming } \\
\text { performance }\end{array}$ \\
\cline { 2 - 3 } & Podium time & $\begin{array}{l}\text { Amount of ST time on podium impacted } \\
\text { by CT approach/concert }\end{array}$ \\
\hline & Placement timing & Timing of or within placement \\
\hline & $\begin{array}{l}\text { Classroom } \\
\text { function }\end{array}$ & role in classroom, relationship \\
\hline
\end{tabular}

\begin{tabular}{|l|l|l|}
\hline CT/ST Factors & \multicolumn{2}{|l|}{} \\
\cline { 2 - 3 } Personality & ST & CT personality impact approach \\
\hline Teaching style & CT style & $\begin{array}{l}\text { ST personality impact } \\
\text { dialogues/relationship }\end{array}$ \\
\hline \multirow{2}{*}{$\begin{array}{l}\text { Relevant } \\
\text { Experience }\end{array}$} & Teacher & Approach ST similar to students \\
\cline { 2 - 3 } & CT & Draw on teaching experience \\
\cline { 2 - 3 } & ST & Draw on experience as a student teacher \\
\hline Relationship & Colleague & CT or ST views relationship as collegial \\
\cline { 2 - 3 } & Teacher-student & $\begin{array}{l}\text { CT or St views relationship as teacher- } \\
\text { student }\end{array}$ \\
\hline
\end{tabular}

\begin{tabular}{|l|l|l|}
\hline Student Teacher \\
\hline \multirow{4}{*}{$\begin{array}{l}\text { Expectations ST } \\
\text { Adapt }\end{array}$} & $\begin{array}{l}\text { Meets } \\
\text { expectations }\end{array}$ & ST meets expectations \\
\cline { 2 - 3 } & $\begin{array}{l}\text { Does not } \\
\text { meet }\end{array}$ & ST doesn't meet expectations \\
\hline ST response & CT adapt to ST \\
\cline { 2 - 3 } & ST adapt to CT \\
\cline { 2 - 3 } & ST adapts to students \\
\hline & $\begin{array}{l}\text { Ask } \\
\text { questions }\end{array}$ & Ask related question \\
\cline { 2 - 3 } & agreement & ST agree with CT \\
\cline { 2 - 3 } & Follow-up & ST build off of CT statement \\
\cline { 2 - 3 } & Acceptance & ST agree, reflect on practice \\
\cline { 2 - 3 } & Apply & ST apply feedback to teaching \\
\cline { 2 - 3 } & Add & ST add to conversation with idea, opinion, needs \\
\cline { 2 - 3 } & Avoidance & ST avoid responsibility or show apathy \\
\cline { 2 - 3 } & success & ST describe feeling of success \\
\cline { 2 - 3 } & reflect & ST reflect on areas for improvement \\
\hline
\end{tabular}

